PNL-7245

UC. 245

$18 H$

Subcontractor Report

\title{
Testing of an Advanced Thermochemical Conversion Reactor System
}

January 1990

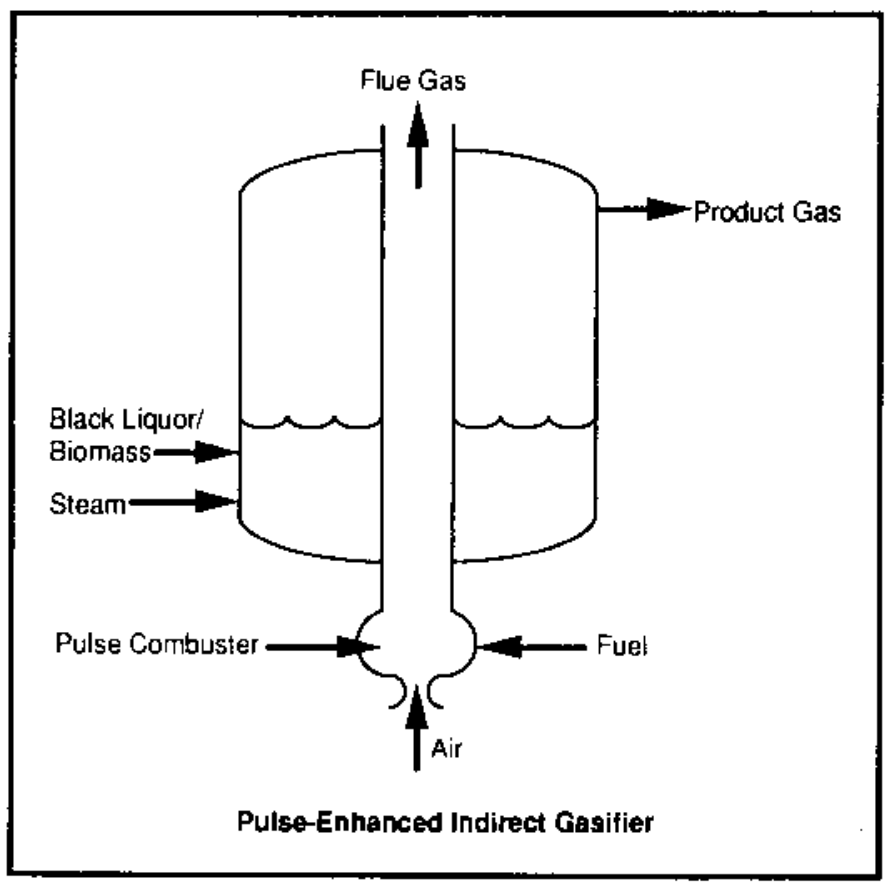

Prepared by Manufacturing and Technology Conversion International Incorporated for Pacific Northwest Laboratory under Contract DE-AC06-76RLO 1830 with the U.S. Department of Energy

Pacific Northwest Laboratory Operated for the U.S. Department of Energy by Battelle Memorial Institute

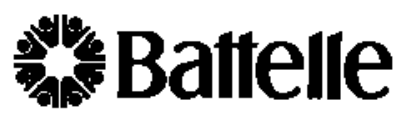




\title{
DISCLAIMER
}

This report was prepared as an account of work sponsored by an agency of the United States Government. Neither the United States Government nor any agency thereof, nor Battelle Memorial Institute, nor any of their employees, makes any warranty, expressed or tmplied, or assumes any legal Itability or responsibility for the accuracy, completeness, or usefulness of any information, apparatus, product, or process disclosed, or represents that its use would not infringe privately owned rights. Reference herein to any specific commercial product, process, or service by trade name, trademark, manufacturer, or otherwise, does not necessarily constitute or imply its endorsement, recommendation, or favoring by the United States Government of any agency thereof, or Battelle Memorial Institute. The views and opinions of authors expressed herein do not necessarily state or reflect those of the United States Government or any agency thereof.

\author{
PACIFIC NORTHWEST LABORATORY \\ operated by \\ BATTELLE MEMORIAL INSTITUTE \\ for the \\ UNITED STATES DEPARTMENT OF ENERGY \\ under Contract DE-ACO6-76RLO 1830
}

Printed in the United States of America

Available to DOE and DOE contractors from the

Office of Scientific and Technical Information, P.O. Box 62, Oak Ridge, TN 37831; prices available from (615) 576-8401. FTS 626-8401.

Available to the public from the National Technical Information Service,

U.S. Department of Commerce, 5285 Port Royal Rd., Springfield, VA 22161.

NTIS Price Codes, Microfiche A01

Printed Copy

\begin{tabular}{|c|c|c|c|}
\hline Price Code & Page Range & Price Code & Page Range \\
\hline $\mathrm{AO2}$ & $1-10$ & A15 & $326-350$ \\
\hline $\mathrm{A} 03$ & $11+50$ & A16 & $351-375$ \\
\hline$A 04$ & $51-75$ & A.17 & $376-400$ \\
\hline $\mathrm{AOS}$ & $76-100$ & A18 & $401-425$ \\
\hline$A 06$ & $101-125$ & A19 & $426-450$ \\
\hline $\mathrm{A} 07$ & $126-150$ & A20 & $451-475$ \\
\hline A08 & $151-175$ & A21 & $476-500$ \\
\hline$A 09$ & $176-200$ & $A 22$ & $501-525$ \\
\hline A10 & $201-225$ & A 23 & $526-550$ \\
\hline A11 & $226-250$ & A24 & $551-575$ \\
\hline $\mathrm{A} 12$ & $251-275$ & $A 25$ & $576-600$ \\
\hline A13 & $276-300$ & $A 99$ & $601-U_{p}$ \\
\hline A14 & $301-325$ & & \\
\hline
\end{tabular}


PNL -7245

UC -245

TESTING OF AN ADVANCED

THERMOCHEMICAL CONVERSION

REACTOR SYSTEM

Manufacturing and Technology

Conversion International Incorporated Columbia, Maryland

G. F. Schiefelbein, PNL Project Manager

January 1990

Prepared by Manufacturing and Technology

Conversion International Incorporated

for Pacific Northwest Laboratory

under Contract DE-AC06-76RLO 1830

with the U.S. Department of Energy

under Agreement $007109-\mathrm{A}-\mathrm{C}$

Pacific Northwest Laboratory

Richland, Washington 99352 


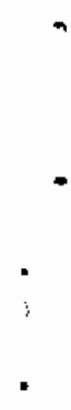




\section{ABSTRACT}

This report presents the results of work conducted by MTCI to verify and confirm experimentally the ability of the MTCI gasification process to effectively generate a high-quality, medium-Btu gas from a wider variety of feedstock and waste than that attainable in air-blown, direct gasification systems. The system's overall simplicity, due to the compact nature of the pulse combustor, and the high heat transfer rates attainable within the pulsating flow resonance tubes, provide a decided and near-term potential economic advantage for the MTCI indirect gasification system

The primary objective of this project was the design, construction, and testing of a Process Design Verification System for an indirectly heated, thermochemical fluid-bed reactor and a pulse combustor as an integrated system that can process alternative renewable sources of energy such as biomass, black liquor, municipal solid waste and waste hydrocarbons, including heavy oils into a useful product gas. The test objectives for the biomass portion of this program were to establish definitive performance data on biomass feedstocks covering a wide range of feedstock qualities and characteristics. The test objectives for the black liquor portion of this program were to verify the operation of the indirect gasifier on commercial black liquor containing 65 percent solids at several temperature levels and to characterize the bed carbon content, bed solids particle size and sulfur distribution as a function of gasification conditions.

Nine different biomass/waste feedstocks in addition to black 1 iquor were gasified during the test program. These feedstocks covered a wide range of physical and chemical characteristics and encompass the most likely categories of feed types which might reasonably be considered for fuel gas production. Each of the biomass test runs were characterized by a product gas with a high concentration of hydrogen that ranged from approximately 32 to $50 \mathrm{vol} \%$. Methane levels were relatively constant in the range of 8 to $12 \mathrm{vol} \%$, and higher hydrocarbons typically ranged from about 1 to 5 vol.\%. 
The product yields were calculated on a weight percent carbon basis and are segregated into three fractions: dry gas, char, and tar/oil. The product yields for the test runs ranged from 74 to 94 percent dry gas, 4 to 23 percent char, and 1 to 5 percent tar/oils dependent upon the feedstock. The char fraction represents unconverted carbon that is entrained or otherwise removed from the gasifier. No char recycling was performed for any of the runs. The tar/oil fraction represents heavy hydrocarbons that are condensed along with steam in the sampling train. The objective of the test matrix was to cover a wide range of temperature conditions so that in some cases less than optimal processing conditions were selected and the fractions reported do not reflect the optimum values attainable.

System testing of the indirect gasifier on black liquor feedstocks was conducted over a six-week period from late May 1988 to early July 1988. The test results provided detailed information on specific gasification rates, product yields, bed carbon levels, and operating bolndaries. The black liquor feedstock consisted of approximately 67 percent solids. The higher heating value of the solids was approximately $6500 \mathrm{Btu} / \mathrm{lb}$. The black liquor is representative of by-products from a commercial mi? 1 and was provided by the Weyerhaeuser Company from their Longview, Washington mill.

Over 100 hours of hot fluidization tests were achieved during this period. The gasifier operated on black liquor feeds for over 60 hours. A single long duration test of over 40 hours of continuous operation was also conducted. A total of seven separate test runs were attempted covering eight distinct operating temperatures and typicaliy measured approximately 64 percent hydrogen, 1 to 5 percent methane with the higher heating value of the dry gas in the range of 240 to $290 \mathrm{Btu} / \mathrm{scf}$. 


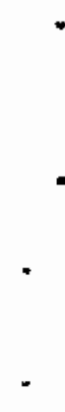




\section{ACKNOWLEDGHENT}

The total program effort for biomass gasification, black liquor recovery, and extended testing reported herein was supported by the California Energy Commission's "Energy Technologies Advancement Program," the Weyerhaeuser Company, and the Battelle Pacific Northwest Laboratories.

The authors wish to acknowledge the help and support received from the U.S. Department of Energy, Technical Project Managers Simon Friedrich and Stan Sobczynski, Tom Miles of Thomas Miles Engineering, Gary Schiefelbein of Battelle Northwest Laboratories, George Simons and Kelly Birkinshaw of the California Energy Commission, and Denny Hunter of Weyerhaeuser Paper Company. The current work is being partially supported by the California Energy Commission, ETAP Contract No. 500-86-012, and DOE/PNL Subcontract No. 007109-A-C. 


\section{TABLE OF CONTENTS}

Page

ABSTRACT ....................... i

ACKNOWLEDGMENT

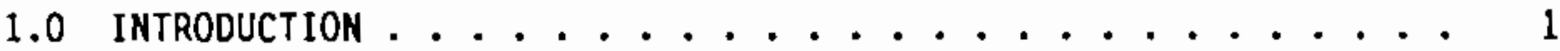

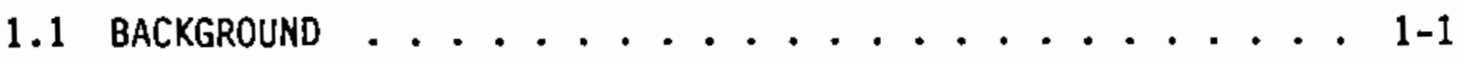

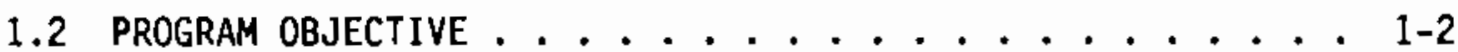

1.3 PROGRAM SUMMARY .................... 1. . .

1.4 TECHNOLOGY PROJECTIONS ................ 1-6

1.4.1 Black Liquor Recovery . . . . . . . . . 1-6

1.4.2 Biomass Energy Recovery .......... 1. . 1.6

2.0 REVIEW OF PRIOR ART IN BIOMASS THERMOCHEMICAL CONVERSION $\ldots . .2-1$

2.1 THERMOCHEMICAL CONVERSION ................ 2-1

2.2 BIOMASS FUELS ................ 2-3

2.2.1 Source and Potential Energy

Contribution of Biomass ........... 2-3

2.2.2 Advantages of Biomass Fuels ......... 2-5

2.2.3 Environmental Issues ............ 2-8

2.3 COMPARISON OF GASIFICATION SYSTEMS:

DIRECT (PARTIAL OXIDATION) VS. DIRECT ........ 2-13

2.3.1 Overview of Gasifier Technologies ....... 2-13

2.3.2 Retrofit of Boilers and Heat Engines ....... 2-23

2.3.3 Methanol Production ............ 2-25

2.3 .4 Hydrogen Production ............. 2-28

2.3.5 High-Moisture Feedstocks . . . . . . . . . 2-30

2.3.6 Low Ash Fusion Temperature Feedstocks ...... 2-31

3.0 THE MTCI GASIFICATION TECHNOLOGY . . . . . . . . . 3-1

3.1 BIOMASS GASIFICATION ................. 3-1

3.2 BLACK LIQUOR RECOVERY . . . . . . . . . . . . . 3-4 


\section{TABLE OF CONTENTS}

(CONT'O)

Page

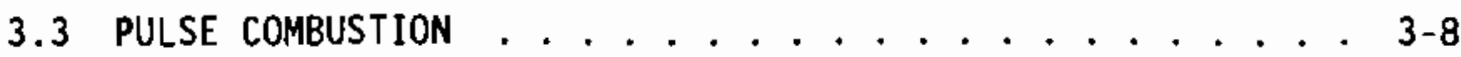

3.3.1 Background .............. 3-8

3.3.2 Types of Pulse Combustors and Their Operation . . 3-8

3.3.3 Pulse Combustion Advantages ......... 3-11

4.0 OVERALL PROGRAM OBJECTIVES AND WORK TASK DESCRIPTION . . . . . 4-1

4.1 SPECIFIC OBJECTIVES - BIOMASS ENERGY RECOVERY . . . . . 4-1

4.2 SPECIFIC OBJECTIVES - BLACK LIQUOR RECOVERY . . . . . 4-1

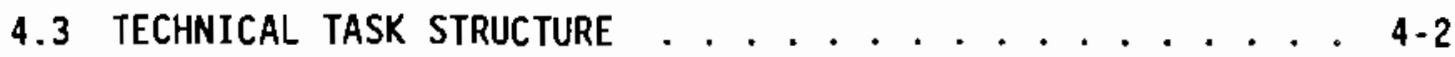

4.3.1 Establishment of Performance and Design Objectives ........... 4-2

4.3.2 Preliminary Design ........... . 4-3

4.3.3 Test Plan Development .......... . 4-3

4.3.4 Final Design .............. . 4-3

4.3.5 Facility Modification and Construction...... 4-3

4.3.6 System Shakedown Tests ............. 4-4

4.3.7 System Tests ................ 4-. 4

4.3.8 Data Reduction and Analysis ........... 4-4

4.3 .9 other ................ 4-. 4

5.0 BIOMASS GASIFICATION TEST PROGRAM ........... . 5-1

5.1 TEST SYSTEM OESCRIPTION . . . . . . . . . 5-1

5.1.1 Gasification Test Rig ............ 5-1

5.1.2 Two-Tube Gasifier .......... 5-3

5.1.3 Eight-Tube Scale-Up Gasifier.......... 5-3

5.1 .4 Biomass Feeder ............ 5- . 5-10

5.1.5 Analytical Gas Sampling Train .......... 5-11

5.1.6 Material Balance Methodology ......... 5-11

5.2 SPECIFIC TEST OBJECTIVES ............. . . 5-12

5.3 TEST RESULTS ..................... 5-12

5.3.1 Feedstocks .............. . 5-13

5.3.2 Operating History and Test Conditions ..... 5-14

5.3 .3 Compositions ............... 5-16 


\section{TABLE OF CONTENTS}

\section{(CONT'D)}

Page

5.3 .4 Product Yields............... 5-16

5.3 .5 Scale-up Issues ............ 5-21

5.4 DEVELOPMENT PLAN AND COMMERCIALIZATION ....... 5-24

5.4.1 Commercialization ............ 5-24

5.4.2 Gasifier Economics ........... . . 5-27

5.4.3 Fifty Ton Per Day Demonstration Plant . . . . 5-28

6.0 BLACK LIQUOR GASIFICATION TEST PROGRAM . . . . . . . . 6-1

6.1 BACKGROUND ..................... $6-4$

6.2 TEST OBJECTIVES ................... 6-5

6.3 TEST SYSTEM DESCRIPTION . . . . . . . . . . . . 6-6

6.3 .1 Process Description ........... 6- 6- 6

6.3 .2 Gasifier.............. . . 6-10

6.3 .3 Instrumentation .......... . 6-19

6.4 TEST RESULTS .............. . . 6-20

6.4.1 Feedstock . . . . . . . . . . . . 6-20

6.4 .2 Operating History .......... 6- 6-21

6.4 .3 Gasification Product Yields ......... . 6-23

6.4 .4 Product Solids Analysis ........... . 6-29

6.4.5 Gasification Rates ......... . . . . 6-39

6.4.6 Particle Size Evolution . . . . . . . . . . 6-40

6.4.7 Sulfur Distribution and Sulfate Reduction .... 6-42

6.4.8 Melt Agglomeration ............. 6- 6-42

6.4 .9 Sulfur Equilibrium Analysis ....... . . . 6-43

6.4.10 Recovery of Sodium Sulfide . . . . . . . . . 5-47

6.4 .11 Dissolution of Inorganics .......... . 6-49

6.4.12 Pulsating Heat Transfer. . . . . . . . . . 6-49

6.5 STATUS AND COMPARISON OF BLACK LIQUOR RECOVERY TECHNOLOGIES 6-5?

6.6 COMMERCIAL CONFIGURATION . . . . . . . . 6-57

6.7 RESEARCH AND DEVELOPMENT NEEDS . . . . . . . . . 6-66

7.0 CONCLUSIONS AND RECOMMENDATIONS ........... $7-1$

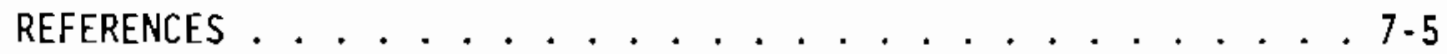




\section{LIST OF FIGURES}

Page

FIGURE 1-1 MTCI THERMOCHEMICAL REACTOR (DEVELOPMENT CHRONOLOGY) ............ $1-3$

FIGURE 2-1 BIOMASS RESOURCE AREAS IN THE UNITED STATES . . . . . 2-6

FIGURE 2-2 COMPARISON BETWEEN THE VOLATILITY OF WOOD AND COAL . . . 2-7

FIGURE 2-3 COMPARISON OF CHAR REACTIVITY . . . . . . . . 2-7

FIGURE 2-4 RENUGAS PROCESS ............... 2-14

FIGURE 2-5 PHASE I OXYGEN GASIFIER CONFIGURATION. ....... 2-17

FIGURE 2-6 SYNGAS OEMONSTRATION FACILITY PROCESS FLOW DIAGRAM . . 2-18

FIGURE 2-7 SIMPLIFIED SCHEMATIC OF BATTELLE'S BIOMASS GASIFICATION SYSTEM ............ . 2-20

FIGURE 2-8 BATTELLE'S BIOMASS GASIFICATION PRU. . . . . . . . 2-21

FIGURE 2-9 METHANOL PLANT INTEGRATION REQUIREMENTS FOR DIFFERENT GASIFICATION SYSTEMS . . . . . . . . . . 2-29

FIGURE 2-10 SENSITIVITY OF PRODUCT GAS HEATING VALUE FOR DIFFERENT GASIFICATION SYSTEMS . . . . . . . . 2-32

FIGURE 3-1 KRAFT CHEMICAL RECOVERY CYCLE ......... 3-5

FIGURE $3-2 \quad$ PRINCIPLE OF OPERATION . . . . . . . . . . . 3-7

FIGURE 3-3 INTEGRATED BLACK LIQUOR RECOVERY PLANT EMPLOYING INDIRECT GASIFIER . . . . . . . . . . . . . 3-9

FIGURE 3-4 OPERATING PHASES OF AN IDEALIZED PULSE COMBUSTOR . . . 3-12

FIGURE 5-1 PROCESS DIAGRAM FOR BIOMASS GASIFIER . . . . . . . 5-2

FIGURE 5-2 TWO-TUBE REACTOR SYSTEM (TUBES ONLY) ........ 5-4

FIGURE 5-3 TW0-TUBE GASIFIER TEST RIG . . . . . . . . . 5-5

FIGURE 5-4 REACTOR GENERAL LAYOUT . . . . . . . . . . . . 5-6

FIGURE 5-5 FIRE-TUBE BUNDLE .............. 5-7

$\begin{array}{ll}\text { FIGURE 5-6 } & \text { REACTOR TUBE LAYOUT AND STEAM } \\ & \text { DISTRIBUTION ORIFICES ................ 5-8 }\end{array}$ 


\section{UST OF FIGUAES}

(Cont'd)

Page

FIGURE $5-7$ REACTOR AND COMBUSTOR TUBE SHEETS. . . . . . . . 5-9

FIGURE $5-8$ HYDROGEN/CARBON MONOXIDE RATIO ......... 5-18

FIGURE 5-9 PRODUCT GAS HEATING VALUE AS A FUNCTION

OF FEEDSTOCK MOISTURE CONTENT .......... . 5-19

FIGURE 5-10 PRODUCT GAS HEATING AS A FUNCTION OF

GASIFIER TEMPERATURE . . . . . . . . . . 5-20

FIGURE 5-11 CHAR YIELO AS A FUNCTION OF GASIFIER TEMPERATURE . . . 5-22

FIGURE 5-12 RELATIONS BETWEEN REQUIRED BED VOLUME, SPECIFIC GASIFICATION RATE, AND BED

INVENTORY FRACTION FOR SCALE-UP GASIFIER

OPERATED AT HEAT-LIMITED THROUGHPUT RATE . . . . . . . 5-25

FIGURE 5-13 SCHEMATIC OF RECYCLE PAPER MILL WITH

PROPOSED FIELD DEMONSTRATION GASIFIER . . . . . . 5-31

FIGURE 5-14 BIOMASS GASIFIER SCHEMATIC . . . . . . . . 5-32

FIGURE 6-1 SCHEMATIC OF MTCI BLACK LIQUOR GASIFIER SYSTEM . . . . 6-2

FIGURE $6-2$ MTCI GASIFIER IN KRAFT PULPING .......... . . 6-3

FIGURE 6-3 SCHEMATIC OF MTCI BLACK LIQUOR GASIFIER SYSTEM . . . . 6-7

FIGURE $6-4$ BLACK LIQUOR INJECTOR . . . . . . . . . . . . 6-8

FIGURE 6-5 BLACK LIQUOR GASIFIER WITH CYCLONE

AND SOLIDS CATCH DRUMS ............. . 6- . .

FIGURE 6-6 TWO-TUBE REACTOR SYSTEM - FRONT VIEW . . . . . . 6-11

FIGURE 6-7 TWO-TUBE REACTOR SYSTEM - SIDE VIEW . . . . . . 6 6-12

FIGURE 6-8 TWO-TUBE REACTOR SYSTEM, REACTOR SHELL

AND STEAM INJECTION TUBES ........... . . 6-13

FIGURE 6-9 TWO-TUBE REACTOR SYSTEM - TUBE LAYOUT . . . . . . 6-14

FIgURE $6-10$ TUBE WALL TEMPERATURE PROFILES ......... 6-15

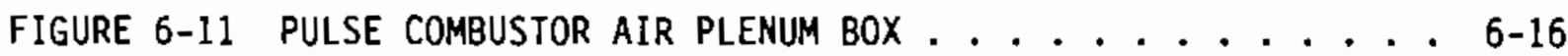




\section{LIST OF FIGURES}

(CONT'D)

Page

FIGURE 6-13 PULSE COMBUSTORS INTEGRATED HITH FIRE TUBES . . . . . 6-18

FIGURE 6-14 SCHEMATIC OF BED SOLIDS SAMPLING VALVE . . . . . . 6 6-19

FIGURE 6-15 BLACK GASIFICATION TEST, 6/10/88

(BED TEMPERATURE AT CD. $1030^{\circ} \mathrm{F}$ ) ........ . 6- 6-25

FIGURE 6-16 BLACK GASIFICATION TEST, 6/15/88

(TEMPERATURE, $\left.1110-1130^{\circ} \mathrm{F}\right) \ldots \ldots$. . . . . . 6-26

FIGURE $6-17$ BLACK GASIFICATION TEST, $6 / 22 / 88$

(TEMPERATURE, $\left.1150-1175^{\circ} \mathrm{F}\right) \ldots \ldots$. . . . . . 6-27

FIGURE 6-18 REACTOR TEMPERATURE VS. TIME FOR

LONG DURATION TEST RUN . . . . . . . . . . . . . 6.28

FIGURE 6-19 PRODUCT GAS HEATING VALUE AS A

FUNCTION OF GASIFIER TEMPERATURE . . . . . . . . . . $6-30$

FIGURE 6-20 BED SOLIDS CARBON CONTENTS VS. OPERATING TIME . . . . 6-32

FIGURE 6-21 SULFUR SPECIES IN BED SOLIDS VS. OPERATING TIME $\ldots \ldots$ 6-33

FIGURE 6-22 CARBON CONTENT OF BED SOLIDS VS. OPERATING TIME . . . 6-35

FIGURE 6-23 SULFUR SPECIES IN BED SOLIDS VS. OPERATING TIME . . . 6-36

FIGURE 6-24 INITIAL AND FINAL PARTICLE SIZE DISTRIBUTIONS

FOR LONG DURATION TEST RUN . . . . . . . . . . . 6-41

FIGURE 6-25 SEM OF AGGLOMERATED PARTICLE SHOHING

CHLORIDE-ENRICHED BINDER ZONE .......... 6- 6-44

FIGURE 6-26 SEM OF AGGLOMERATED PARTICLE SHOWING

CHLORIDE-ENRICHED BINDER ZONE ........... . . 6-45

FIGURE 6-27 THEORETICAL HEAT TRANSFER COEFFICIENTS

UNDER NON-PULSATING CONDITIONS COMPARED

TO MEASURED DATA IN PULSATING FIRE TUBES . . . . . . 6-51

FIGURE 6-2B BLACK LIQUOR GASIFIER FOR COMMERCIAL

CONFIGURATION . . . . . . . . . . . . . . . . . . . 6-60

FIGURE 6-29 CONCEPTUAL COMMERCIAL MTCI GASIFIER . . . . . . 6-62

FIGURE 6-30 BLACK LIQUOR GASIFIER PROCESS FLOW DIAGRAM . . . . . . 6-63 


\section{LIST OF TABLES}

Page

TABLE 2-1 ENVIRONMENTAL BENEFITS TO CALIFORNIA (REDUCTIONS IN TONS/YEAR) .............. . 2-8

TABLE 2-2 AIR EMISSION FACTORS FROM COMBUSTION OF BIOMASS (lb/ton) ............... 2-10

TABLE 2-3 SOME COMPOUNDS REPORTED TO BE PRESENT IN HARDWOOD SMOKE ................... 2-1l

TABLE 2-4 OVERVIEW OF EFFLUENT STREAMS AND LAND REQUIREMENTS FOR LARGE-SCALE WOOD COMBUSTION . . . . . 2-12

TABLE 2-5 SUMMARY OF RESULTS FOR RENUGAS TESTS . . . . . . . 2-15

TABLE 2-6 TYPICAL PRODUCT GAS ANALYSIS - DRY BASIS . . . . . 2-19

TABLE 2-7 PROPERTIES OF GASIFIER . . . . . . . . . . . 2-22

TABLE 2-B SUMMARY OF DRY GAS COMPOSITIONS . . . . . . . . . . . 2-24

TABLE 2-9 ADIABATIC FLAME TEMPERATURE FOR NATURAL GAS AND BIOGAS................... . 2-25

TABLE 2-10 COMPOSITION AND DEFORMATION TEMPERATURE FOR STRAW ASH ................... 2-33

TABLE 3-1 PRIMARY SULFUR REACTIONS IN INDIRECT BLACK LIQUOR GASIFIER . . . . . . . . . . . . . . 3-6

TABLE 5-1 PARTICLE SIZE DISTRIBUTION FOR BED SOLIDS . . . . . . 5-3

TABLE 5-2 ANALYSIS FOR FEEDSTOCKS TESTED IN PULSEENHANCED INDIRECT GASIFIER .............. 5-14

TABLE $5-3$ OPERATING SUMMARY AND PROCESS CONDITIONS

FOR BIOMASS TEST RUNS .............. 5-15

TABLE 5-4 SELECTED GAS COMPOSITIONS AND PRODUCT YIELD FOR BIOMASS TESTS CONDUCTED IN PULSE-ENHANCED INDIRECT GASIFIER . . . . . . . . . 5-17

TABLE 5-5 BIOMASS - PAPER MILL WASTE GASIFICATION . . . . . 5-29 TABLE 6-1 ANALYSIS OF BLACK LIQUOR FEEDSTOCK $(67 \%$ SDLIDS) . . . 6-20 


\section{LIST OF TABLES \\ (CONT'D)}

Page

TABLE 6-2 SUMMARY OF OPERATING HISTORY ........... 6-21

TABLE 6-3 REPRESENTATIVE DRY GAS YIELDS FOR BLACK

LIQUOR GASIFICATION TEST RUNS . . . . . . . . . . . . 6-24

TABLE 6-4 BED SOLIDS SAMPLES FOR TEST RUN (6/22/88) . . . . . 6-31

TABLE $6-5$ BED SOLIDS SAMPLES FOR TEST RUN $(7 / 6 / 88) \ldots \ldots . \ldots .6 .34$

TABLE 6-6 CYCLONE SOLID SAMPLES FOR LONG DURATION RUN

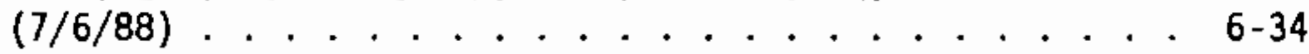

TABLE 6-7 ELEMENTAL BALANCE FOR LONG DURATION TEST RUN $(7 / 6 / 88) \ldots \ldots . . . . . . . . .66-38$

TABLE 6-8 ESTIMATEO GASIFICATION RATES .......... 6-40

TABLE 6-9 EQUILIBRIUM GAS COMPOSITION IN GASIFIER AT $1200^{\circ} \mathrm{F}$. . $\quad 6-48$

TABLE 6-10 COMPARISON OF GAS RATIOS WITH THERMODYNAMIC EQUILIBRIUM CONSTANTS AT $1200^{\circ} \mathrm{F} \ldots \ldots . . . . . .6-48$

TABLE 6-11 COMPARISON OF BLACK LIQUOR RECOVERY TECHNOLOGIES . . . 6-58

TABLE 6-12 MATERIAL BALANCE FOR I TON/H BLACK LIQUOR SOLIDS GASIFICATION PLANT . . . . . . . . . . . 6-63

TABLE 6-13 MASS AND ENERGY BALANCE SUMMARY . . . . . . 6-66 


\section{SECTION 1.0}

\section{INTRODUCTION}

A pulse-enhanced, indirectly heated fluidized bed reactor system was constructed and tested by MTCI in 1986 for the gasification of biomass under the Phase II of a DOE/SBIR Program. The results of these tests confirmed the technical feasibility of the steam gasification of biomass feedstocks using the resonance tubes of the MTCI pulse combustor technology as an in-bed heat exchanger. In fact, the system demonstrated a capability for generating a medium-Btu product gas of a quality superior to that attainable in air-blown, direct gasification systems. The system's overall simplicity, due to the compact nature of the pulse combustor, and the high heat transfer rates attainable within the pulsating flow resonance tubes, provided a decided and near-term potential economic advantage for the MTCI system when compared to alternative direct or indirect gasification systems.

\subsection{BACKGROUND}

MTCI's proprietary pulse-enhanced, indirect, steam gasification technology was first investigated under Phase I and Phase II DOE/SBIR awards (1984 - 1986). Under Phase II of this DOE/SBIR award, testing of the gasifier was 1 imited to biomass feedstocks only. In early 1987, the Weyerhaeuser Paper Company expressed an interest in testing the MTCI gasifier using black liquor feedstocks. The pulp and paper industry has an ongoing and substantial interest in developing new black liquor recovery methods since the existing technology has significant economic, safety, and environmental shortcomings.

Preliminary feasibility tests were conducted which verified the feasibility of the MTCI gasifier with black liquor feedstocks. These shortterm, proof-of-principle tests on black liquor provided additional material evidence supporting the basic feasibility of pulse-enhanced, indirect gasification for a wide range of biomass materials. The short-term, proof-ofprinciple test was conducted in April 1987. The tests were performed using a black liquor feedstock containing 50.6 percent solids. The fluidized bed contained an initial charge of fresh sodium carbonate and was operated continuously for the full planned period of four hours without any evidence of smelt formation. Black liquor was fed at an average rate of $40 \mathrm{lbs} / \mathrm{hr}$ and the reactor generated a product gas with a heating value of approximately $400 \mathrm{Btu} / \mathrm{scf}$. The feasibility test was conducted at the relatively low temperature of approximately $1030^{\circ} \mathrm{F}$. At these conditions, approximately 57 percent of the organic carbon contained within the black liquor was converted to gas species. This conversion level represented the test period average over the unsteady-state run. At the completion of the test run, the carbon inventory in the bed was approximately 5 wt.\%. Preliminary evidence suggested that a longer term run could have attained a higher steady-state carbon level. Indeed, an additional feasibility test soon afterwards resulted in a carbon inventory of approximately $12 \mathrm{wt} . \%$. Furthermore, an analysis of the data indicated that high carbon conversions could be achieved at bed carbon inventories as low as a few percent if the reactor temperature was 
increased to the range of $1100^{\circ} \mathrm{F}$ to $1200^{\circ} \mathrm{F}$. However, additional data and process characterization was necessary to more clearly define the potential of this specific technology application as an alternative or complement to the Tomlinson recovery furnace.

At this stage the feasibility of processing black liquor in the MTCI reactor was established at the same level as the previous feasibility tests for biomass. In order to further develop this technology for biomass waste gasification, including black liquor recovery, MTCI applied for and was awarded a research contract from the California Energy Commission's Energy Technologies Advancement Program (ETAP). Funds were also provided by the Department of Energy's Pacific Northwest Laboratories and the Weyerhaeuser Company for a set of complementary projects in both biomass energy and black liquor recovery.

The objectives of the present phase of development included process development and verification of the MTCI black liquor recovery technology, the testing of a broad spectrum of biomass feedstocks under varying process conditions for relatively long periods of time, and the verification of gasifier scale-up to the 100 to $200 \mathrm{lb} / \mathrm{hr}$ level. These projects were successfully completed in early 1989 and yielded extremely exciting results, confirming the commercialization potential of the MTCI gasification system. This report presents the results of that effort.

In summary, the results of the Phase I SBIR program established the analytical feasibility of an innovative pulse-combustor, indirectly heated, thermochemical fluid-bed gasifier concept. The Phase II SBIR program provided experimental verification of the technical feasibility of the concept and reduced it to practice. Phase II also provided the engineering analysis for an integrated pulse combustor, fluid-bed gasifier based on the laboratory experimental verification data. Information, with a high degree of certainty, aiso became available for the design of an integrated Process Design Verification System at the 200 to $300 \mathrm{lb} / \mathrm{hr}$ feed level and the ability to predict its performance as an operating system. Figure 1-1 depicts the development chronology for the MTCI thermochemical reactor from its inception as a Phase I SBIR project through the present.

\subsection{PROGRAM OBJECTIVE}

The overall objective of this program was to design, construct and test a Process Design Verification System for an indirectly heated, thermochemical fluid-bed reactor and a pulse combustor as an integrated system that can process alternative renewable sources of energy such as biomass, municipal solid waste and waste hydrocarbons, including heavy liquids, into useful product gas.

This program which could be considered Phase III of an overall development program therefore involved several technical activities that were structured to meet the aforementioned objectives. The major emphasis of the program involved the test and evaluation of the Process Design Verification 


\section{MTCI THERMOCHEMICAL REACTOR Development Chronology}

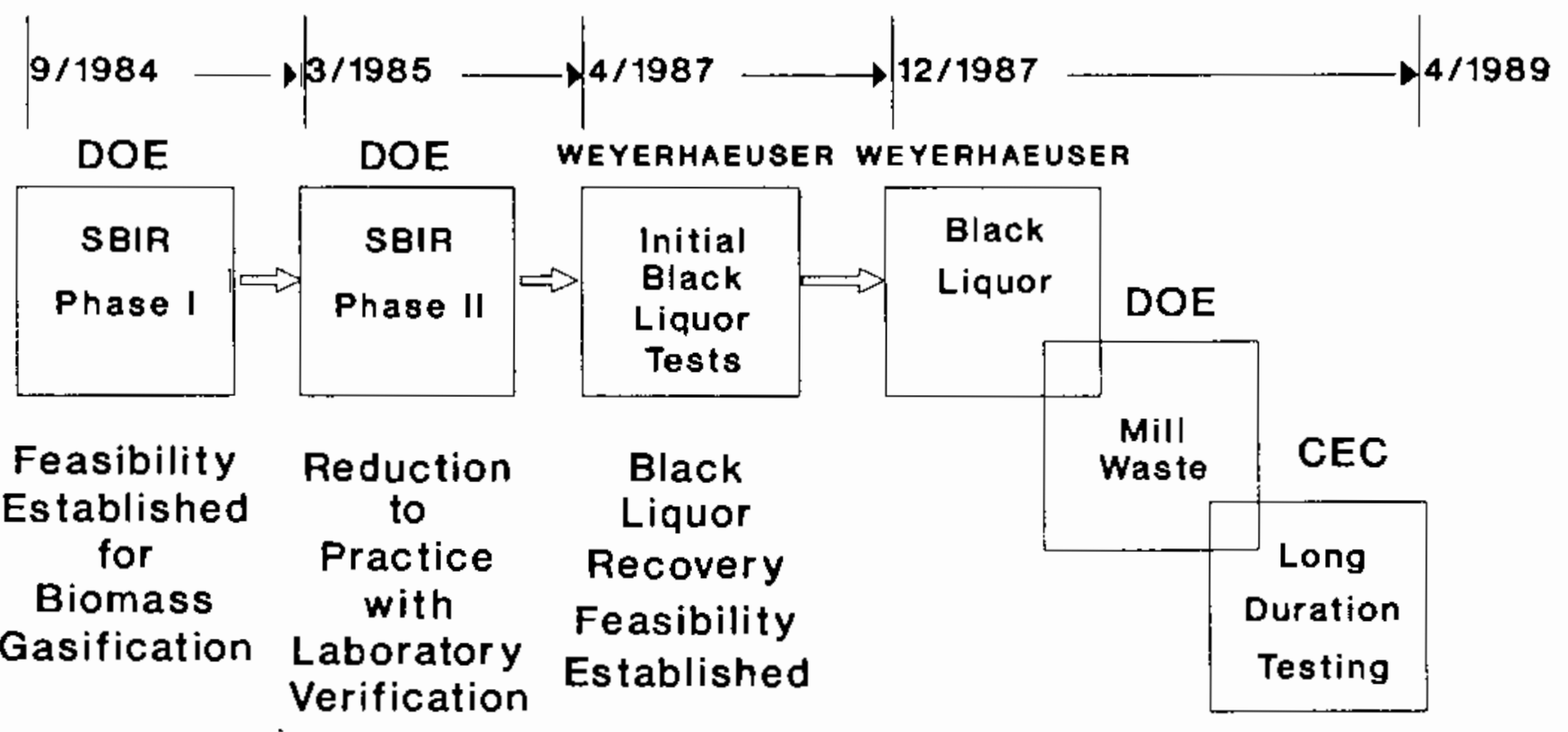

Black Liquor Recovery and

Mill Waste Energy Recovery

Characterized for

Process \& Product at PDU and Scale-Up Size 
System as an integrated unit that could utilize a portion of the product gas for the combustion process. The innovative design involved two primary components: the indirectly fired, fluid-bed reactor and the pulse combustor.

The test objectives for the biomass portion of this program were to establish definitive performance data on biomass feedstocks covering a wide range of feedstock qualities and characteristics. The ability to define the range of biomass feeds suitable for gasification in the indirect gasifier was considered essential to this program since many gasification technologies perform well on premium feedstocks, such as dried wood chips, but are unable to handle less optimum feedstocks containing high moisture, high ash contents with low melting temperature ash constituents, or those feedstocks with fluffy, low density, or irregular geometries. Other objectives of these tests were to obtain data over a range of processing conditions, including reactor temperature, throughput rate, and steam-to-biomass ratio for relatively long periods of time.

These were to verify scale-up operation to provide a data base allowing scale-up of the pulse-enhanced technology to the field demonstration stage (50 TPD). To accomplish this objective, an eight-tube scale-up gasifier was constructed and tested. The pulse combustor tube bundle was designed for a firing rate of approximately $500,000 \mathrm{Btu} / \mathrm{hr}$. This unit represents a one-third scale model of the pulse combustor module anticipated for use in a 50 TPD biomass gasifier facility. In the 50-TPD gasifier, six such modules would be employed, each module having a nominal firing rate of $1,500,000 \mathrm{Btu} / \mathrm{hr}$.

The specific test objectives for the black "uor gasification tests included the following:

- Verification of improved reactor mechanical design

- Verify operation on commercial black lio'or containing 65 percent solids

- Conduct long-duration steady-state gasificat:or : st.

- Conduct higher temperature gasification tests in the regime of $1100^{\circ} \mathrm{F}$ to $1200^{\circ} \mathrm{F}$

- Monitor bed carbon level as a function of gasification conditions

- Monitor bed solids particle size evolution

- Evaluate distribution of sulfur species

The work scope provided for the development of a technology data base which could permit the design and operation of these systems at a commercial level of approximately $2000 \mathrm{lbs} / \mathrm{hr}$ of feedstock. A description of the work scope is provided in Section 4.0 . 


\subsection{PROGRAM SUMARY}

Two separate pulse-enhanced gasifier systems were constructed under this program. The first unit consisted of a $20 \mathrm{~cm}$ fluid-bed reactor shel1 enclosing 2 pulse combustor resonance tubes. This unit was employed to define essential gasification process data. The second gasifier consisted of a $46 \mathrm{~cm}$ reactor shell containing 8 pulse combustor resonance tubes. The 1 arger unit was sized for a throughput capacity of $200 \mathrm{lb} / \mathrm{hr}$ and was intended to provide scale-up design criteria for integration of large, multi-tube heat exchange bundles. Both of these reactors shared essentially similar basic designs.

The major components of the gasifier test beds were the integrated pulse combustor(s) and thermochemical reactor, a lock hopper and metering screw for feeding biomass materials, and a steam boiler for providing fluidization and reaction steam. The downstream equipment included a hot cyclone, quench scrubber and incinerator for controlling emissions and combusting the product gas.

For the black liquor tests the biomass feeder was replaced with a steam jacketed agitated vessel for reducing the viscosity of the black liquor slurry so that it could be easily pumped through the reactor injector. The cooled and scrubbed (for $\mathrm{SO}_{2}$ ) gases were then vented through a roof-mounted induced draft fan.

System testing of the indirectly heated, pulse-enhanced gasifier on biomass feedstocks was performed over a four-month period from october 1988 through January 1989 . The test results provided detailed information on system performance, including gas compositions, char and tar/oil yields, and bed carbon inventories.

The initial testing of pistachio shells and wood chips aroused considerable interest among the test observers that included the project managers and other invited guests. The spectrum of feedstocks was expanded dramatically to include difficult materials such as rice hulls and finally recycle paper mill sludge with and without plasticizers. The gasifier, in all tests, produced a high-quality, medium Btu gas with higher heating values ranging from $329 \mathrm{Btu} / \mathrm{scf}$ to $435 \mathrm{Btu} / \mathrm{scf}$.

System testing of the indirect gasifier on black liquor feedstocks was conducted over a six-week period from late May 1988 to early July 1988 . The test results provided detailed information on specific gasification rates, product yields, bed carbon levels, and operating boundaries. Over 100 hours of hot fluidization tests were achieved during this period. The gasifier operated on black liquor feeds for over 60 hours. A single long duration test of over 40 hours of continuous operation was also conducted. A total of seven separate test runs covering eight distinct operating temperatures were conducted. The temperatures were successfully maintained over the full planned test period.

These tests provided the data required for an evaluation of the longer term stability of the fluidized bed. The quantity of inorganic material fed to the reactor was sufficient to completely replace the initial bed charge material. In this sense, any anomalous behavior which might occur with 
respect to particle size evolution, defluidization tendencies, or other problems should have been evident. However, no such phenomena were found to occur over the test period. A sufficiently reliable data base with which to prepare preliminary estimates of performance in a larger scale integrated system was obtained.

The heating value of the product gas varied from about $240 \mathrm{Btu} / \mathrm{scf}$ to $300 \mathrm{Btu} / \mathrm{scf}$ and decreased with increasing temperature.

Note that the earlier feasibility test, higher heating values in the range of $400 \mathrm{Btu} / \mathrm{scf}$ were attained at operating temperatures in the range of $1030^{\circ} \mathrm{F}$.

\subsection{TECHNOLOGY PROJECTIONS}

\subsubsection{BLACK LIQUOR RECOVERY}

Over the next decade, the total investment in refurbishing, expanding, or adding new black liquor recovery capacity in the United States is projected to be of the order of four billion dollars. If new advanced technologies are not rapidly developed, then mill expansions will be satisfied by outdated black liquor recovery technologies that are noted for poor operational safety records, high environmental emissions, and low thermal efficiency. In addition, the existing technology is not well-suited to incremental capacjty expansion through the use of modular plant additions. For this reason, a significant social and economic motivation exists for developing new black liquor recovery routes that can overcome the limitations of the current technology.

The technology employs an indirect gasification process (proprietary to HTCI) which is highly flexible, offers a broad spectrum of potential end-use applications, including Kraft black liquor and sulfite liquor mills, and can be economically constructed in modular sizes. More importantly, the total investment cost for demonstrating the indirect gasification process at an industrially meaningful scale is anticipated to be lower than for competing systems. Although alternative recovery routes, such as molten salt gasification, appear to be technically quite promising, their high cost of demonstration may ultimately constrain their rate of commercial introduction. In contrast, the MTCI technology offers a rapid and perhaps more economically realistic development path. This will ensure accelerated commercial penetration of new technologies and prevent the fulfillment of near-term expansion needs by the implementation of older, less desirable technologies.

\subsubsection{Biomass Emergy Recovery}

The implementation of an extensive biomass energy recovery industry appears to be thwarted by several major technical, economic, and environmental issues, none of which appear to MTCI to be limitations with respect to the commercialization of the technology for specific market entry scenarios. MTCl, for example, has demonstrated in this program the value of its advanced thermochemical reactor system for the gasification and energy recovery from many different feedstocks such as wood, pistachio shells, recycle paper pulp 
sludge, waste by-products, black liquor, etc. The market entry of a new technology is generally motivated by a market need. The more immediate the need, the earlier the technology will reach commercialization. MTCI has therefore focused upon the pulp and paper industry as the near-term commercial market for its gasification process. Here the issues normally associated with the biomass gasification of mill wastes and black liquor are not an impediment because the need or incentive exists, is well understood, fairly extensive, and the early market penetration for a problem-solving technology almost assured.

The MTCI strategy for early commercialization at this stage of development perceives that the need in a well-established industry such as the pulp and paper industry where the near-term commercial application of the gasifier can demonstrate its capability for biomass processing utilizing a waste sludge that is presently being disposed of in landfills. The recovery of energy from this waste and the avoidance of solid disposal costs provides an inherent commercialization motivation to the industry. The ability of the MTCI process to eliminate this kind of an economic problem with the proposed technology is a strong economic incentive rather than an economic barrier. The MTCI system also permits them to optimize investment opportunities by offering a modular system which can begin to generate income in fairly short order and provide small businesss opportunities in both the pulp and paper industry and in an emerging biomass energy industry.

In summary, the barriers to the commercialization of the proposed technology do not seem applicable to the market segment chosen because of the industry incentive and need. The pulp and paper industry is sufficiently large and well-organized so that a considerable market segment is available for the early introduction of the proposed beneficial biomass gasification technology. Although it would appear that the technology is focused upon a single industry, that industry can provide the experience of use that would be vital to the establishment of a generic biomass energy industry which can apply the technology and the experience for other applications. 


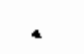

,

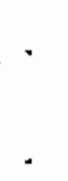




\title{
SECTION 2.0
}

\author{
REVIEU OF PRIOR ART IN BIOMASS \\ THERHOCHEMICAL CONVERSION
}

Energy that can be produced by the conversion of biomass material represents a significant but under-utilized resource of a renewable fuel in the United States. Biomass sources of energy currently supply 2.8 quads $\left(10^{15} \mathrm{Btu}\right)$ per year, which amounts to only 3.7 percent of the annual U.S. energy consumption. Studies to assess the ultimate potential of biomass as an energy resource have concluded that by the year 2000 , biomass energy could provide from 5 to 15 percent ( 6 to 16.6 quads/year) of the U.S. energy needs. Thus, biomass is now and will remain for the foreseeable future, the nation's single most important renewable energy resource (U.S. D0E, 1983). The pulp, paper and paperboard industries have already made significant strides in bark and wood residue utilization in the last 5 years, increasing the consumption by over 50 percent to 370 trillion Btu in their fuel mix, thereby reducing their dependence upon gas and oil.

Biomass can be converted to gaseous, liquid, and solid fuels. These products can be used by residential, commercial, and industrial consumers for heat, power, and fuel, and by utilities for electricity production. Biomass can be converted to energy in a number of ways, including thermochemical, biochemical, and photobiological means.

\subsection{THERMOCHEMICAL CONVERSION}

Thermochemical conversion is considered to be one of the more attractive methods for producing useful, easy-to-use fuel from biomass. It generally produces gaseous or liquid fuels that can be utilized in a broad range of end-use applications. The rate of fuel yield by thermochemical conversion is higher if compared to other biomass conversion techniques and the conversion of biomass to fuel by thermochemical conversion is thermally more efficient. Thermochemical conversion offers, in addition, a higher degree of flexibility in controlling the quality of fuel produced. As such, fuel heating value and composition (including the level of contamination) produced from biomass can be controlled to satisfy the requirement of a specific end-use application. Fuel quality can further be modified by the use of steam reforming as well as thermal cracking to expand the spectrum of end-use applications. Thermochemical conversion is relatively easy to scale to a large-scale plant and thus offers a more viable approach to the commercial use of biomass as a source of fuel. Finally, thermochemical conversion is a more mature technology offering an early return on development costs.

Thermochemical conversion processes include direct combustion and direct liquefaction to produce steam, electricity, process heat, and synthetic oils. With process upgrading such as hydrogenation, lighter distillates, gasoline, and petrochemicals can also be produced. 
The discussion in this section, however, is limited to biomass gasification concepts that utilize steam or other reactants such as hydrogen, or by partial oxidation with air or oxygen to produce low or medium Btu fuel gas or synthesis gases for end products such as methanol, Fischer-Tropsch hydrocarbon liquids, and ammonia.

The biomass gasification processes which are presently either in use or under investigation can be divided into two categories: (1) those for which the endothermic heat of reaction is provided by partially combusting the biomass within the gasification reactor, called "partial oxidation processes"; and (2) those for which heat from an external source is transferred to the biomass via a heat exchanger immersed in the gasification reactor or via hot circulating solids, termed "indirectly heated processes." In the indirectly heated processes, the biomass is usually gasified by reaction with steam and the external heat is obtained by combustion of residual char from the gasifier and/or part of the product fuel gas. The partial oxidation/autothermal processes are advantageous in that reactor design is relatively simple and the in-situ heat transfer between endothermic and exothermic reactions proceeds at an effective rate provided the process utilizes a properly maintained conductive medium such as provided by an efficient fluid-bed reactor. Since the process is one of oxidation and requires an oxidizer such as air or oxygen in addition to steam for the reaction, the product gas contains significant amounts of diluent nitrogen and/or combustion products. In "oxygen-blown" systems, the atmospheric nitrogen content is reduced but the cost is increased significantly. The potential end-use economics for the product gas are therefore limited.

The indirectly heated gasification processes do not contain combustion products or atmospheric nitrogen and therefore are not as constrained with respect to potential end uses. Production of medium Btu gas (350 to $550 \mathrm{Btu} / \mathrm{ft}^{3}$ ) is a major asset of the indirect heating process. Medium Btu gases have significant advantages with regard to heating value, flame temperature, retrofit, transportation, and fuels upgrading. By definition, medium Btu gas has about double the energy per unit volume of low Btu gas. The higher heating value makes medium Btu gas a more versatile fuel. The higher flame temperatures allow for more market penetration regarding retrofit applications since flame temperature is a primary concern. Transportation is enhanced since medium Btu gas has a wider range of marketability and is not restricted to near-site consumption as is the case with low Btu gas. Furthermore, gas upgrading is possible for methanol and liquids synthesis and synthetic natural gas (SNG) production. The product gas contains little or no nitrogen. Some indirectly heated gasifier systems, such as MTCI's, can tailor product gas production to favor syngas (synthetic gas consisting of mostly hydrogen and carbon monoxide) for special applications such as fuel cells, etc., or to produce higher medium Btu gases $\left(500+B t u / \mathrm{ft}^{3}\right)$ by a change in operating temperature.

The disadvantages of indirectly heated systems employing immersed heat exchangers are primarily a function of the ineffective heat transfer rates between the thermal source and the fluid bed. This results in additional surface area requirements for heat transfer, complex designs, higher capital costs, and lower product gas throughput. 


\subsection{BIONASS FUELS}

Biomass is an organic material which is derived from plants or animals. It is renewable and may be considered a solar-energy-based resource since the energy content of most biomass materials is the result of the conversion of $\mathrm{CO}_{2}$ and water via photosynthesis in the presence of sunlight. The primary sources of biomass are wood scrap from sawmill and logging operations and residues from agricultural, forestry, and livestock operations. Future biomass resources will include woody and herbaceous crops as well as aquatic crops that will be cultivated and harvested specifically for use as fuel.

\subsubsection{Source and Potential Energy Contribution of Biomass}

Biomass material consists of sawill wastes, waste from animals in confinement, agriculture residues and wastes, herbaceous plants including forage crops, trees grown with short-rotation intensive culture techniques, and aquatic plants. Sawmill wastes consist of the wood and bark fragments generated when logs are processed into various timber products such as lumber and plywood. Much of the sawmill waste is used as fuel for process heat and as raw material for wood pulp (to make paper products) and particle board. Logging residues, however, represent a potentially large, untapped source of biomass for energy production. These residues consist of the branches, foliage, trunk pieces, and stumps not removed in commercial logging operations. They usually remain in the forest and decay. Where forests are to be replanted, however, these residues must be cleared away and are usually burned on site. Wood feedstock is also available from surplus forest growth, natural mortality, and nonmerchantable timber in commercial forests. According to one government-sponsored study (U.S. DOE, 1983), more than 500 million dry tons of wood per year could be available for energy production by the year 2000 . This would amount to approximately 10 quads of gross energy annually.

Biomass wastes from pulp and paper mills represent another significant energy resource. Sludge waste accounts for approximately 5 percent by weight of the total pulp processing capacity in these mills. Sludge wastes are currently discharged in dilute form to waterways and sludge ponds, or dewatered and landfilled at significant operating costs. Increasingly, stringent regulations limiting the discharge of these wastes are anticipated to provide substantial economic incentives for reducing the volume of these wastes through thermochemical conversion processes which simultaneously yield fuel gas that can be utilized within the mill.

Wastes from animals in confinement totals approximately 5 million dry tons annually and accounts for more than 50 percent of total livestock waste generated each year. The primary sources of animal waste are cattle feedlots and dairy, hog, and poultry farms. It is estimated that by the year 2000, as much as 0.3 quad of gross energy could be derived from these wastes annualiy.

Agricultural residues are the leaves, stalks, roots, and other plant material left in the field after a crop harvest. The most important residues are corn stalks, wheat straw, and soybean field waste, which comprise more than 85 percent of the residues generated each year. Most residues are returned to the soil to supply nutrients, maintain soil structure, and prevent soil erosion. Some are also used for livestock feed, particularly those from 
corn and sorghum crops. However, about 20 percent of the annual yield of more than 400 million dry tons of crop residues could be used for the production of energy without adversely affecting soil quality or livestock feed supplies. It is estimated that by the year 2000 , as much as 1 quad of gross energy could be derived from these residues annually.

Agricultural wastes are by-products of the crop processing industry. About 50 to 70 percent of these by-products are sold as animal feed or for use in the production of chemicals, leaving the remainder potentially available for energy production. Orchard prunings and cotton gin wastes make up more than 50 percent of these potential feedstocks. Other agricultural wastes that could be used to produce energy include sugar cane bagasse, rice hulls, tomato pumice, potato peel and pulp, walnut and pistachio shells, and citrus rag and pee 1. It is estimated that 1.3 quads of gross energy could be supplied annually from agricultural residues and wastes by the year 2000 .

Herbaceous plants include forage crops such as Bermuda grass and tall fescue, other tall grasses such as sugar cane and napier grass, hydrocarbonbearing plants such as milkweed and euphorbia, and oilseed crops such as soybeans and sunflowers. When grown specifically as energy feedstocks, these nonwoody 1 and plants represent another potential biomass resource. Herbaceous plants have a capacity to produce high yields of biomass and can grow on arid or marginal land. Species selection, application of fertilizers, and identification of optimal harvesting times could improve yields even more.

Trees grown by short-rotation intensive culture techniques are another potential source of energy feedstock. Rotation (the number of growing seasons until harvest) is determined by the purpose for which the trees will be used. Trees for lumber and plywood, for example, need to be tall and straight with good fiber quality. This requires relatively long rotations ranging from 15 to 65 years or more. However, trees can be grown in rotations of 3 to 8 years if total biomass yield is the primary consideration - as is the case when trees are grown solely for use as energy feedstock. It is estimated that cultivation of herbaceous plants and short-rotation trees could supply as much as 5 quads of gross energy annually by the year 2000 .

Aquatic plants such as microalgae, kelp, reeds, and water hyacinth have the potential for very high yields. Some aquatic plants are capable of producing 50 or more dry tons per acre-year, a yield which surpasses that of most terrestrial plants. Aquatic plants can be grown in a number of locations including oceans, marshlands, artificial ponds, or wastewater. Since research on aquatic biomass is still in the early stage of development, the overall energy potential of this resource cannot yet be estimated.

The geographic distribution of biomass resources in the United States depends on a number of factors such as land and water availability, soil type, and climate. Wood resources, for example, are abundant in the Northeast, the Southeast, the Great Lakes states, and the Northwest, as well as in Alaska and Hawail. These wood-producing areas and other regions of the nation, however, have the potential to produce other feedstocks as well. Short-rotation trees could be cultivated on marginal and abandoned cropland. This includes underutilized pastureland and rangeland in the Midwest and the Plains States. 
Near-shore aquatic plant production could take place along the Atlantic, Pacific, and Gulf Coasts; emergent and floating aquatic plants could be grown in the marshlands of the Lake and Delta States and of the Southeast. Aquatic plants that tolerate saline or brackish water could be grown in shallow seasonal lakes and in water from subsurface groundwater reservoirs in the Southwest.

Herbaceous plant production could take place in several areas of the country. Arid-land herbaceous plants could be grown in the Southwest, and semitropical grasses could be cultivated in Hawaii. Other herbaceous species, as well as grains and sugar crops, could be grown in the Midwest and the Plains States. Biomass resources can potentially be grown in nearly every region of the country, as illustrated in Figure 2-1.

\subsubsection{Advantages of Biomass Fuels}

Biomass also has significant technical, commercial, and environmental advantages when compared with other solid fuels such as coal. These advantages relate to the fuel's high volatility, char reactivity, and to its low sulfur and ash content. Biomass fuels also offer other less quantifiable factors such as public acceptance and economies of waste utilization for energy production. A brief discussion of technical advantages of biomass relative to coal are as follows:

i. Volatility: Typical coals contain 45 percent or less volatiles by weight while wood for example contains about 80 percent volatiles. Therefore, devolatilization and subsequent reaction can occur at lower temperatures. Figure 2-2 compares weight loss upon devolatilization for hardwood and coal. The devolatilization temperatures for wood are significantly below that of coal.

ii. Char Reactivity: The weight loss versus reaction time for several kinds of biomass compare favorably to those of peat and coal. Biomass is nearly an order of magnitude more reactive than peat or coal as shown in Figure 2-3.

iii. Sulfur Content: Because biomass materials are obtained from biologically active sources, sulfur content is generally limited to that necessary for organic functioning molecules (disulfide linkages and other biologically necessary organosulfur complexes). This sulfur content is typically two parts per thousand by weight or less. For catalytic systems this is a strong attribute since sulfur poisoning of catalysts is greatly retarded. However, even for non-catalytic systems, gas clean-up costs are greatly reduced and the environment is less heavily taxed.

iv. Ash Content: Because ash has no heating value and some environmental restrictions, ash must be collected and disposed of. Most biomass feedstocks, including wood, average less than 3 percent ash whereas coal may contain as much as 9 to 10 percent. Capital costs for ash collection equipment as well as operating costs for ash removal obviously benefit from the low ash content. 


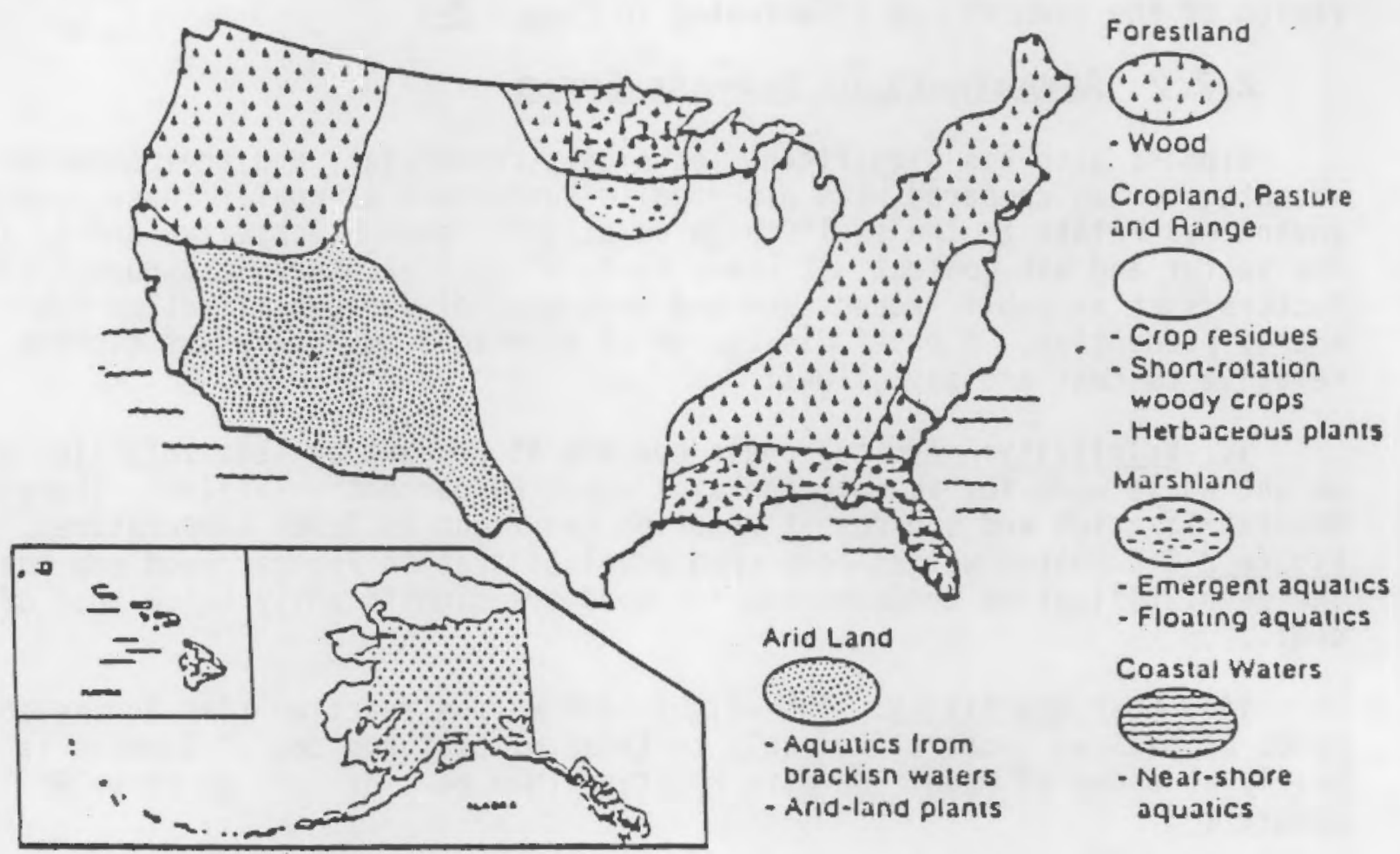

FIGURE 2-1: BIOMASS RESOURCE AREAS IN THE UNITED STATES (U.S. Department of Energy, 1983) 


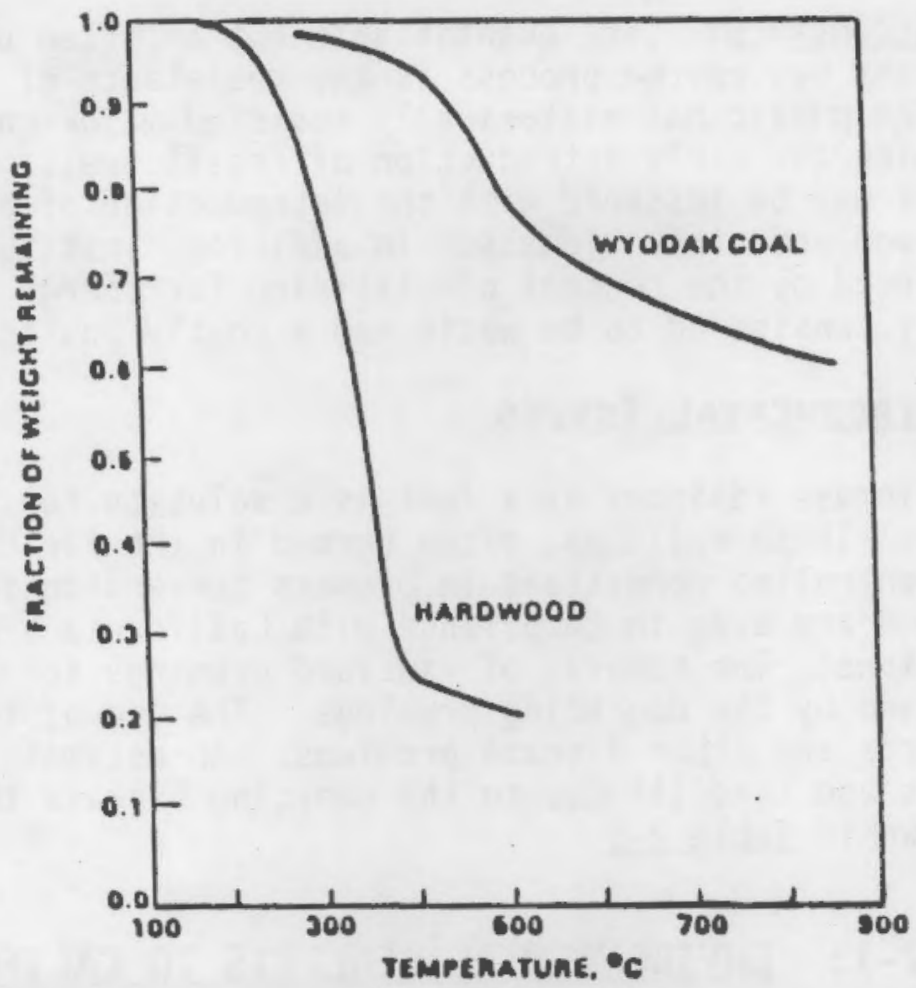

FIGURE 2-2: COMPARISON BETWEEN THE VOLATILITY OF WOOD AND COAL

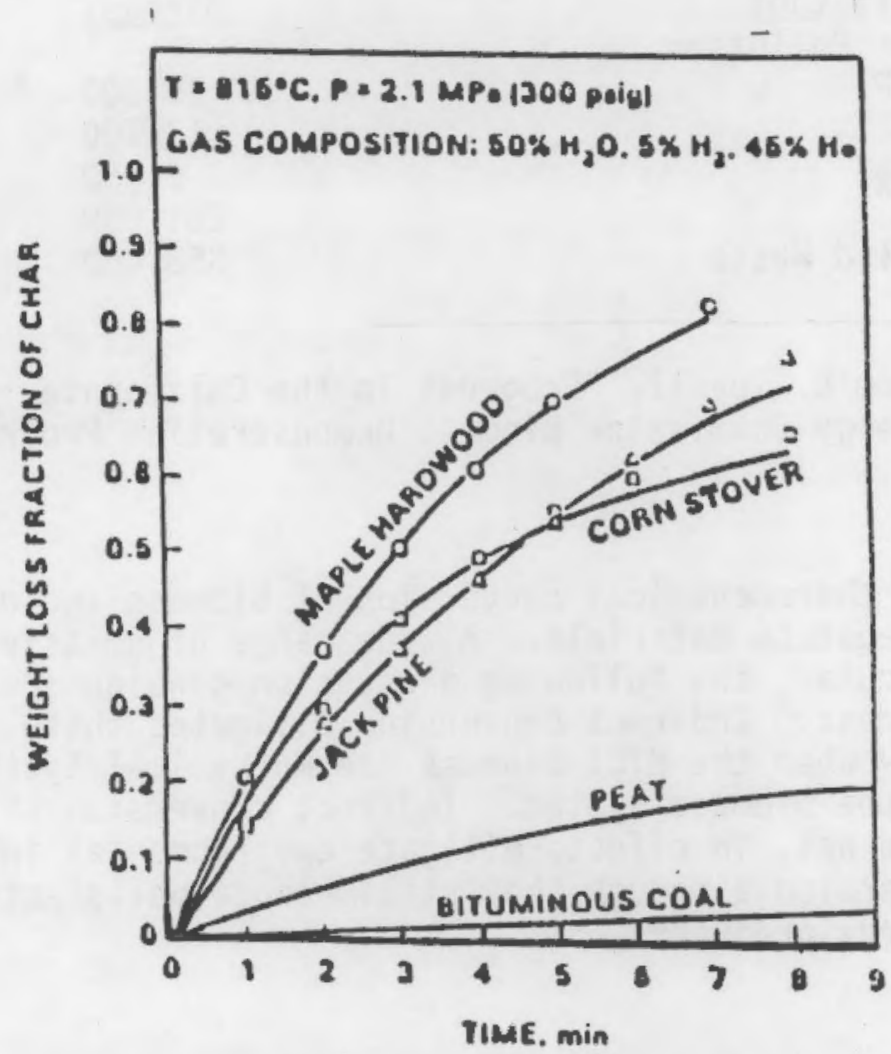

FIGURE 2-3: COMPARISON OF CHAR REACTIVITY (M.J. Antal, July 1978) 
v. Social Acceptance: Less quantifiable but an often underestimated economic cost in any new energy process is the resistance of the public toward new processes. The public has historically resisted major changes in energy feedstocks including the early introduction of fossil fuels, coal, and nuclear power. Such fears may be lessened with the introduction of a more familiar energy source - wood and other biomass. In addition, institutional acceptance is further reinforced by the concept of utilizing for energy production that which is popularly considered to be waste and a costly public nuisance.

\subsubsection{EnVIROMmEntal ISSUES}

The use of biomass residues as a fuel is a solution for its own waste disposal problems. These residues, often burned in the fields can now be processed under controlled conditions in biomass conversion facilities that generate energy and are even in compliance with California's stringent air pollution regulations. The removal of vineyard prunings for fuel minimizes plant disease caused by the degrading prunings. The use of forest residues reduces fire hazards and other disease problems. An estimate of the reductions in emissions and landfill due to the emerging biomass technology in California is shown in Table 2-1.

\section{TABLE 2-1: ENVIRONMENTAL BENEFITS TO CALIFORNIA (REDUCTIONS IN TONS/YEAR)}

\author{
Pollutant \\ Air Pollution \\ TSP \\ RHC \\ $\mathrm{NO}_{\mathrm{X}}$ \\ $\mathrm{CO}$
}

Solid Waste

\author{
Biomass \\ 15,500 \\ 17,700 \\ 6,450 \\ 201,000 \\ 358,400
}

From R. Tuve11, "Progress In the California Energy Commission Biomass Demonstration Program."

The effects of thermochemical conversion of biomass includes a variety of technologies and feedstock materials. A wide range of emissions is therefore expected. In particular, the following discussion considers direct conversion or pyrolysis of biomass. Indirect conversion mitigates these affluents considerably especially when the MTCI Biomass Thermochemical System proposed here is integrated into the biomass system. Indirect conversion utilizing conventional burners do not, in effect, mitigate environmental intrusion from biomass energy conversion although they still reduce pollutants when compared to conventional energy producers. 
Some air emission factors from the combustion of biomass is provided in Table 2-2. It is interesting to note that the $\mathrm{NO}_{\mathrm{X}}$ value for wood in boilers are greater by a factor of 10 than open type burning. This is primarily due to the higher temperature, excess air requirements for operating this boiler efficientiy, but not necessarily in a benign manner.

The effluents in wood smoke which are associated with the thermal processing of almost any cellulosic material is described first. Some compounds reported in wood smoke are given in Table 2-3. Smoke is commonly emitted during direct biomass conversion, but little information on the characteristics of this smoke is available. However, wood smoke (especially hardwood smoke) has been studied in some detail in the laboratory (King, 1975; Einhor et a1., 1978; Doerr et al., 1966; Jahnsen, 1961). Smoke from other biomass materials may not be too different from that of wood, but this fact will need to be confirmed. Two types of studies were encountered, those that focus on hydrocarbons in wood smoke and those that examine carbon monoxide and smoke. Health effects are implicated in each.

Wood smoke is a complex mixture of solid particles, condensed liquid particulates, and volatiles and is produced most abundantly by combustion of moist wood in a restricted flow of air (Jahnsen, 1961). The volume of airborne condensate increases rapidly and linearly with increasing levels of moisture. The 22 hydrocarbon compounds identified in the condensate were acids, alcohols, carbonyls, and phenols. Formic and acetic acids constituted 57 percent, ethanol 10.3 percent, and 2,6-dimethoxy pyrogallol 4.2 percent. The remaining fraction contained furfural, anisole, the three cresols, veratiole, xylenols, hydroquinone, thymol, vanillin, guaiacol, pyrocatechol, pyrogallol and phloroglucinol. In order of decreasing concentration, the carbonyls identified were acetone, acetaldehyde, formaldehyde, furfural, and several diacetyls. Table 2-3 1ists some compounds reported to be present in smoke by a different researcher. The stack gas condensate from a Douglas-fir veneer wood dryer was investigated to characterize the organic emissions and to evaluate their toxicity (Fraser and Swan, 1972). The condensate was about one-third acids (resin acids and fatty acids) and two-thirds neutrals, which were poorly characterized but reported as mainly composed of lipids with more than 15 carbon atoms. Samples from a smoking stack contained more resin acids than those from a clean stack, suggesting that a smoking-stack gas contains more condensate hydrocarbons, whereas a clean-stack gas may contain more volatile hydrocarbons.

Wastewater effluents from the wood-products industry are useful for examining possible effluents from the preconversion portion of biomass conversion technologies. For example, wet storage of logs produces floating solids in the holding stream, in addition to tannins and other wood extractables. Log washing and debarking results in suspended solids and biological oxygen demand (BOD). In addition, water or steam in contact with wood or wood products leads to an aqueous discharge high in BOD and phenols (Thomson, 1976). Inasmuch as wastewater effluents from the wood products industry are treatable using conventional water treatment methods, it is expected that wastewater from thermochemical processing of biomass will also be treatable. An overview of effluent streams for large-scale wood combustion is provided in Table 2-4. 


\section{TABLE 2-2: AIR EMISSION FACTORS FROM COMBUSTION COMBUSTION OF BIOMASS (LB/TON)}

SOURCE

Wood/Bark in Boilers, $50 \%$

Wood in Residential

Fireplaces

Sma1] Wood Stoves,

Oak and Pine

Waste Open Burning,

Agricultural and

Wood Refuse

Unspecified

Corn

Rice (dry)

Rice (wet)

Sorghum

Surgarcane

Oats

Wheat

Forest Residues, Unspecified

Bagasse Burning

Bagasse Boilers
PARTICULATES

CARBON HYDRO- SULFUR NITROGEN

$30^{\mathrm{a}}$

$20^{b}$

$3.4-20.0$
OXIDE

10

2-60

$2-70$

1.5

120

5

1

$\begin{array}{rcc}21 & 117 & 23 \\ 14 & 108 & 16 \\ 9 & 83 & 10 \\ 29 & 161 & 21 \\ 18 & 77 & 9 \\ 7 & 71 & 10 \\ 21-44 & 136 & 18-33 \\ 13-22 & 108-128 & 11-17\end{array}$

17

140

24
22

16

aBark only, $50 \mathrm{lb} /$ ton.

${ }^{b}$ Contains as much as $70 \%$ condensate.

Source: Compiled from data in U.S. Environmental Protection Agency, 1973. Compilation of Air Pollutant Emission Sectors, AP-42. $2 \mathrm{~d}$ ed. (and supplements), Research Triangle Park, N.C. 


\section{TABLE 2-3: SOME COMPOUNDS REPORTED TO BE PRESENT IN HARDWDOD SMOKE}

ACIDS

Formic

Acetic

Propionic

Butyric

Tricarballylic?

Ketoglutaric?

ALCOHOLS
Methanol
Ethanol

\section{CARBONYLS}

Formaldehyde

Acetaldehyde

Acetone

Diacetyl

Furfural

Methyl furfural

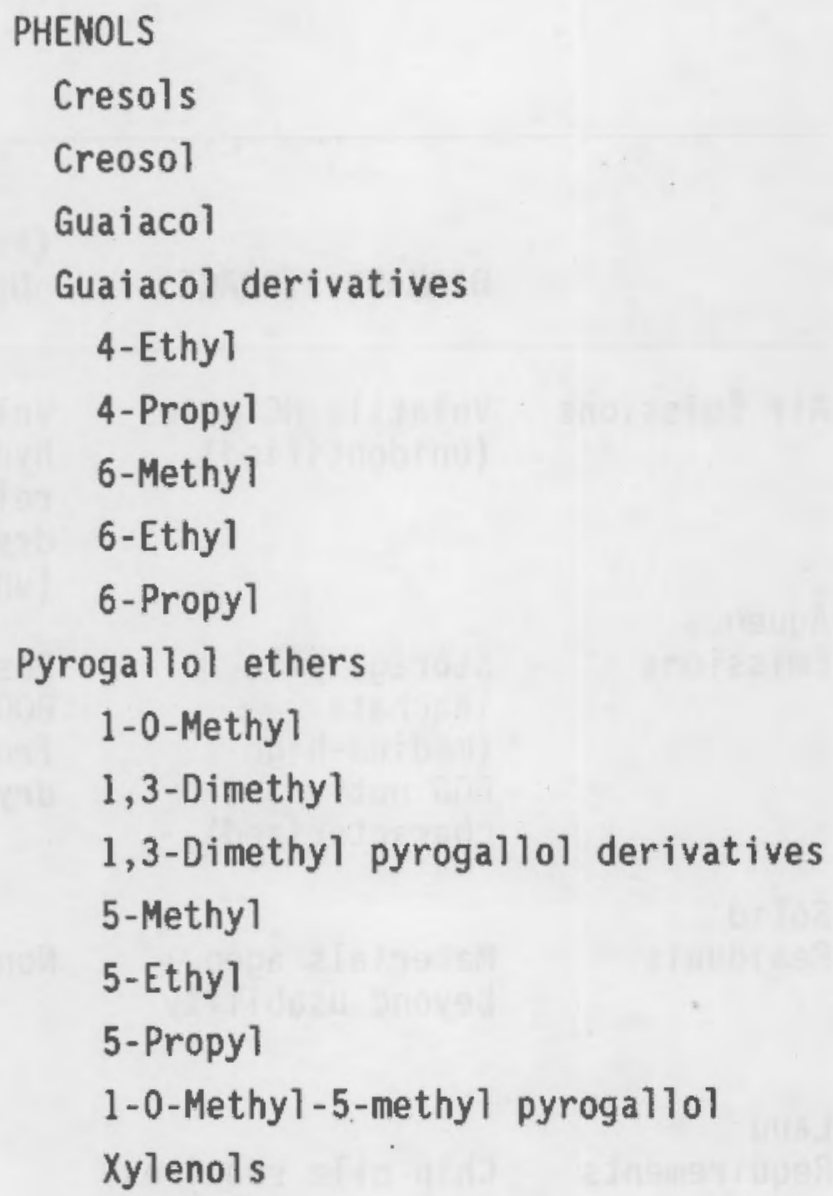

PHENOLS

Cresols

Creosol

Guaiacol

Guaiacol derivatives

4-Ethyl

4-Propy1

6-Methy1

6-Ethyl

6-Propyl

Pyrogallol ethers

1-0-Methy 1

1,3-Dimethy1

1,3-Dimethyl pyrogallol derivatives

5-Methy1

5-Ethyl

5-Propyl

1-0-Methy1-5-methyl pyrogal101

Xylenols
HYDROCARBONS
3,4-Benzpyrene
1,2,5,6-Dibenzanthracene
20-Methylchol anthrene

AMMONIA

CARBON DIOXIDE

RESINS

WATER

WAXES

Source: Jahnsen, V.J., 1961. The Chemical Composition of Hardwood Smoke, Ph.D. thesis, Purdue University, Lafayette, Ind. 


\section{TABLE 2-4: OVERVIEW OF EFFLUENT STREAMS AND LAND REQUIREMENTS FOR LARGE-SCALE WOOD COMBUSTION}

\begin{tabular}{|c|c|c|c|}
\hline & BIOMASS STORAGE & $\begin{array}{c}\text { HANDLING } \\
\text { (Pretreatment } \\
\text { Drying, etc.) }\end{array}$ & $\begin{array}{c}\text { COMBUSTIONa } \\
\text { (1b/Btu } \times 10^{6} \text { Output) }\end{array}$ \\
\hline Air Emissions & $\begin{array}{l}\text { Volatile HC gases } \\
\text { (unidentified) }\end{array}$ & $\begin{array}{l}\text { Volatile } \\
\text { hydrocarbons } \\
\text { released during } \\
\text { drying } \\
\text { (unidentified) }\end{array}$ & $\begin{array}{l}\mathrm{NO}_{\mathrm{X}}, 0.7 ; \mathrm{SO}_{2}, 0 ; \\
\text { particulates, } 0.1 ; \mathrm{b} \\
\text { particulates, } 8-10 ; \mathrm{c} \\
\text { NC, } 0.25 ; \mathrm{CO}, 0.25 \\
\text { None }\end{array}$ \\
\hline $\begin{array}{l}\text { Aqueous } \\
\text { Emissions }\end{array}$ & $\begin{array}{l}\text { Storage pile } \\
\text { leachate } \\
\text { (medium-high } \\
\text { BOD not } \\
\text { characterized) }\end{array}$ & $\begin{array}{l}\text { Possible high } \\
\text { BOD condensate } \\
\text { from chip } \\
\text { drying }\end{array}$ & None \\
\hline $\begin{array}{l}\text { Solid } \\
\text { Residuals }\end{array}$ & $\begin{array}{l}\text { Materials aged } \\
\text { beyond usability }\end{array}$ & None & $\begin{array}{l}\text { Bottom ash about } \\
1.39 \mathrm{lb} / \mathrm{Btu} \times 10^{6} \\
\text { input }\end{array}$ \\
\hline $\begin{array}{l}\text { Land } \\
\text { Requirements }\end{array}$ & $\begin{array}{l}\text { Chip pile requires } \\
\text { about three times } \\
\text { as much space as } \\
\text { equivalent coal pile }\end{array}$ & & $\begin{array}{l}\text { Less than } 0.001 \\
\text { acre/Btu } \times 10^{9} / \text { year } \\
\text { output }\end{array}$ \\
\hline
\end{tabular}

\footnotetext{
aFrom Gikis, B.J. et al., 1978. Preliminary Environmental Assessment of Energy Conversion Processes for Agricultural and Forest Product Residues, EPA 600/7-78-047, NTIS PB-281 189, Municipal Environmental Research Laboratory, Cincinnati, Ohio.

bith controls.

cWithout controls.
} 
In summary, it is expected that the environmental, health and safety effects of utilizing indirectly heated gasification of biomass will mitigate effluents from directly fired systems or open pyrolysis.

\subsection{COMPARISON OF GASIFICATION SYSTEMS: DIRECT (PARTIAL OXIDATION) VS. INDIRECT}

In the following subsections, an overview is given of state-of-the-art direct and indirect gasification technologies. The operating characteristics, performance, and technical status for each of these systems are described.

Since each of these systems has unique operating properties, it is important to assess their suitability for different end-use applications. In the following section, biogas generation for several end uses, including retrofit of boilers and heat engines, methanol production, and hydrogen production, are discussed. The gasifiers are also compared with regard to their ability to handle varying feedstock properties including moisture content, ash fusion temperature, and chlorine content.

\subsubsection{OVERVIEM OF GASIFIER. TECHNOLOGIES}

\section{A. Directly Heated Gasifiers}

State-of-the-art directly heated gasification processes are represented by the Institute of Gas Technology (IGT) RENUGAS process and the Solar Energy Research Institute (SERI) stratified down-draft gasifier. The IGT gasifier consists of an air- or oxygen-blown fluidized bed which is capable of operating under pressure. The SERI gasifier is a moving bed reactor which may be air- or oxygen-blown and is also capable of pressurized operation.

The IGT development gasifier (Babu et al., 1985) consists of a $29.2 \mathrm{~cm}$ ID $\times 7 \mathrm{~m}$ high reactor. The fluidized bed consists of $40 \times 70$ mesh alumina beads. The bed is fluidized by steam and air or oxygen. Separate distributors are provided for each fluid. A schematic of the gasifier is shown in Figure 2-4.

The gasifier has been tested on maple wood chips at pressures of 300 psia and temperatures from $1400^{\circ} \mathrm{F}$ to $1800^{\circ} \mathrm{F}$. The gasifier was tested at throughputs up to $1000 \mathrm{lb} / \mathrm{hr}$ or approximately $1350 \mathrm{lb} / \mathrm{ft}^{2} / \mathrm{hr}$. The gasifier consumes approximately 0.2 to 0.34 pound of oxygen per pound of biomass over the operating temperature range. Gas yields for the IGT reactor for varying conditions on wood chips are summarized in Table 2-5. The gas composition is seen to have high levels of unconverted methane. Carbon conversion to gas ranged from approximately 82 to 95 percent over the test conditions. Liquid yields ranged from approximately 1 to 5 percent over the test conditions.

The developers note the following primary advantages for the IGT gasifier:

- Capable of handling a wide range of feedstock types.

- Excellent heat transfer between endothermic and exothermic reactions.

- High throughput and simple design. 


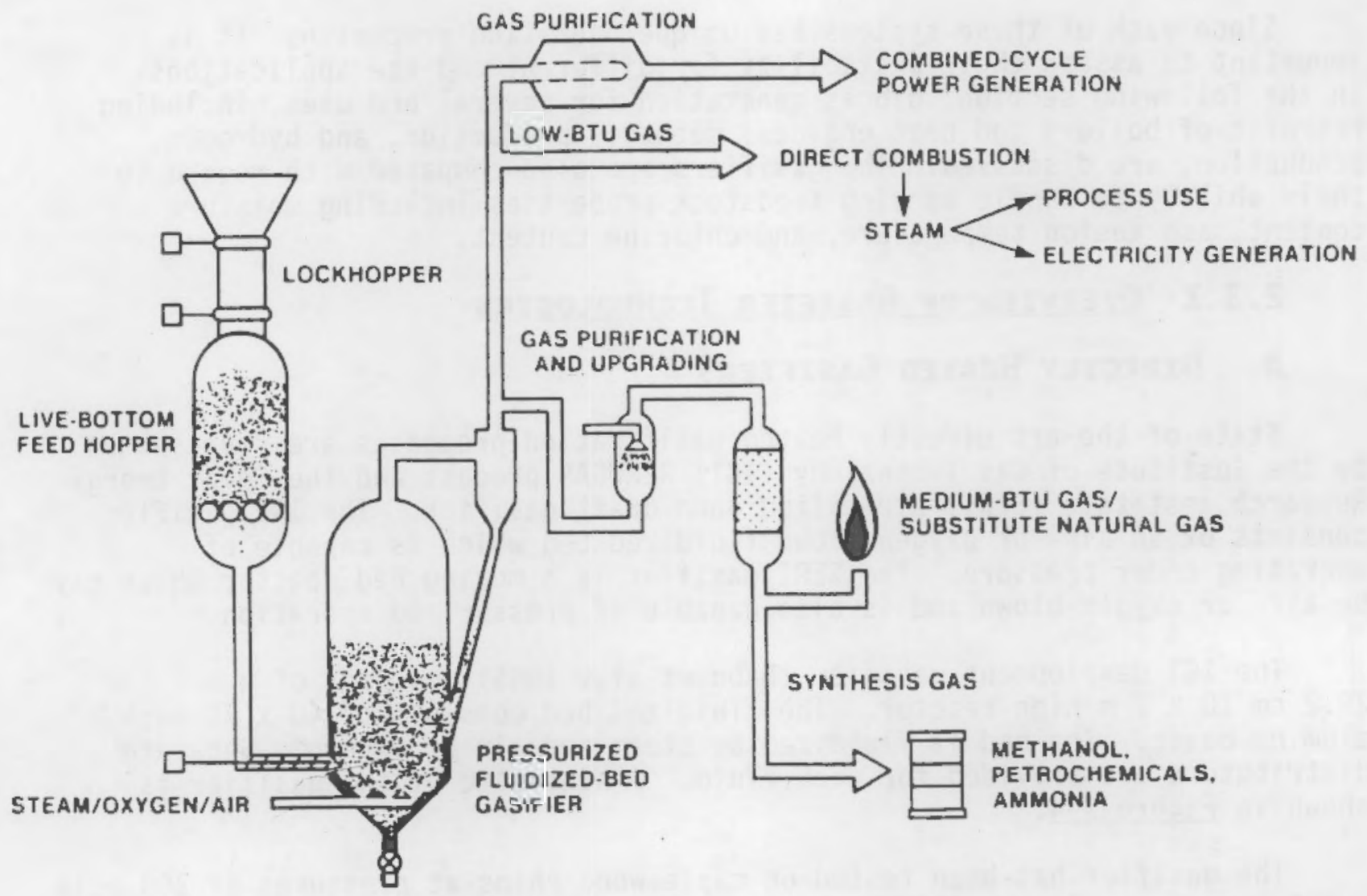

FIGURE 2-4: RENUGAS PROCESS

(S.P. Babu, M. Onishak, and W.G. Bair, June 1985) 


\section{TABLE 2-5: SUMMARY OF RESULTS FOR RENUGAS TESTS}

\begin{tabular}{|c|c|c|c|c|}
\hline TEST NUMBER & $G T-A^{*}$ & GT-2 & GT-4 & GT-5 \\
\hline $\begin{array}{l}\text { Pressure, } \mathrm{M} \mathrm{Pa} \\
\text { Temperature, }{ }^{\circ} \mathrm{K} \\
\text { Feed Rate (wet) } \mathrm{kg} / \mathrm{m} \\
\text { Moisture, wt.\% } \\
\text { Steam, } \mathrm{kg} / \mathrm{kg} \text { Feed (wet) } \\
\text { Oxygen, } \mathrm{kg} / \mathrm{kg} \text { Feed (wet) } \\
\text { Nitrogen, } \mathrm{kg} / \mathrm{kg} \text { Feed (wet) } \\
\text { Product Gas Flow Rate, m }{ }^{3} \text { (st)/h } \\
\text { Product Gas Composition, mol.\% }\end{array}$ & $\begin{array}{r}2.17 \\
1091 \\
341.2 \\
10.07 \\
0.77 \\
0.22 \\
0.51 \\
896\end{array}$ & $\begin{array}{r}2.232 \\
1172 \\
313.2 \\
9.50 \\
0.71 \\
0.25 \\
0.45 \\
769\end{array}$ & $\begin{array}{r}2.128 \\
1256 \\
331.9 \\
9.70 \\
0.60 \\
0.34 \\
0.51 \\
884\end{array}$ & $\begin{array}{r}2.128 \\
1028 \\
328.5 \\
10.47 \\
0.77 \\
0.17 \\
0.42 \\
783\end{array}$ \\
\hline $\begin{array}{l}\mathrm{H}_{2} \\
\mathrm{CO} \\
\mathrm{CO}_{2} \\
\mathrm{CH}_{4} \\
\mathrm{C}_{2} \mathrm{H}_{4} \\
\mathrm{C}_{2} \mathrm{H}_{6} \\
\mathrm{C}_{3} \mathrm{H}_{8} \\
\mathrm{C}_{6} \mathrm{H}_{6} \\
\mathrm{~N}_{2} \\
\mathrm{H}_{2} \mathrm{O} \\
\mathrm{A}^{2}\end{array}$ & $\begin{array}{r}9.54 \\
6.03 \\
14.88 \\
6.71 \\
0.12 \\
0.34 \\
0.00 \\
0.14 \\
16.57 \\
42.41 \\
3.26\end{array}$ & $\begin{array}{r}11.82 \\
6.38 \\
17.15 \\
7.39 \\
0.00 \\
0.03 \\
0.00 \\
0.29 \\
15.42 \\
41.52 \\
0.00\end{array}$ & $\begin{array}{r}13.58 \\
9.92 \\
15.49 \\
5.29 \\
0.00 \\
0.00 \\
0.00 \\
0.00 \\
16.23 \\
34.96 \\
4.53\end{array}$ & $\begin{array}{r}9.62 \\
4.07 \\
15.92 \\
6.20 \\
0.10 \\
0.84 \\
0.02 \\
0.21 \\
14.93 \\
48.09 \\
0.00\end{array}$ \\
\hline $\begin{array}{l}\text { Molecular Weight } \\
\text { Gas Yield } \mathrm{m}^{3} \text { (st)/kg Feed (wet) } \\
\text { Dry, Inert Free Product Gas } \\
\text { (Composition, mol.\%) }\end{array}$ & $\begin{array}{l}23.30 \\
2.633\end{array}$ & $\begin{array}{l}22.78 \\
2.455\end{array}$ & $\begin{array}{l}23.36 \\
2.663\end{array}$ & $\begin{array}{l}22.62 \\
2.385\end{array}$ \\
\hline $\begin{array}{l}\mathrm{H}_{2} \\
\mathrm{CO} \\
\mathrm{CO}_{2} \\
\mathrm{CH}_{4} \\
\mathrm{C}_{2} \mathrm{H}_{4} \\
\mathrm{C}_{2} \mathrm{H}_{6} \\
\mathrm{C}_{3} \mathrm{H}_{8} \\
\mathrm{C}_{6} \mathrm{H}_{6}\end{array}$ & $\begin{array}{r}25.26 \\
15.97 \\
39.41 \\
17.77 \\
0.32 \\
0.90 \\
0.00 \\
0.37\end{array}$ & $\begin{array}{r}27.45 \\
14.82 \\
39.83 \\
17.16 \\
0.00 \\
0.07 \\
0.00 \\
0.67\end{array}$ & $\begin{array}{r}30.67 \\
22.40 \\
34.98 \\
11.95 \\
0.00 \\
0.00 \\
0.00 \\
0.00\end{array}$ & $\begin{array}{r}26.01 \\
11.01 \\
43.05 \\
16.77 \\
0.27 \\
2.27 \\
0.05 \\
0.57\end{array}$ \\
\hline $\begin{array}{l}\text { Gross Calorific Value, } M J / \mathrm{m}^{3} \text { (st) } \\
\text { Dry Inert Free Gas Yield, } \\
\mathrm{m}^{3} \text { (st)/kg Feed (wt) } \\
\text { Superficial Gas Velocity, m/sec } \\
\text { Cold Gas Thermal Efficiency, \% } \\
\text { Overall Material Balance, } \% \\
\text { Overall Energy Balance, } \%\end{array}$ & $\begin{array}{r}0.991 \\
0.654 \\
74.25 \\
100.0 \\
98.9\end{array}$ & $\begin{array}{r}1.057 \\
0.588 \\
76.15 \\
100.0 \\
98.3\end{array}$ & $\begin{array}{r}1.179 \\
0.759 \\
73.85 \\
100.0 \\
91.8\end{array}$ & $\begin{array}{r}0.882 \\
0.549 \\
68.80 \\
100.0 \\
95.1\end{array}$ \\
\hline
\end{tabular}

* Average of 3 tests GT-1, GT-6 and GT-8 conducted at about $1091^{\circ} \mathrm{K}$. 
The developers indicate that many of the advantages of the IGT gasifier result from basic properties of fluidized beds. These advantages have been exploited in several other fluidized bed gasifiers such as those being developed by MTCI and Energy Products of Idaho, Advanced Energy Applications, Studsvik, Creusot-Loire, and Omni.

The SERI gasifier consists of a down-draft moving bed reactor (Reed et al., 1988). Biomass and air or oxygen are fed to the reactor from the top. Synthesis gases are generated and withdrawn from the bottom. The gasifier has several distinct zones including a flaming pyrolysis zone, a char gasification zone, and a dead char zone. Ash and char is discharged from a bottom grate. A schematic of the SERI Phase I gasifier is shown in Figure 2-5.

The Phase I design encountered several problems during operation including a build-up in pressure drop through the bed and excessively high temperatures in the upper flaming pyrolysis zone. In order to overcome these problems, multiple oxygen injection nozzles were provided and a bed stirring rod assembly was added. The build-up of pressure drop due to bed compression and accumulation of char ash fines has been noted as a primary drawback for moving bed designs.

The bench-scale test reactor operated at SERI was designed with a 6 -inch ID. Tests were conducted with wood chips and pellets. The gasifier was operated at typical throughput rates of approximately $30 \mathrm{lb} / \mathrm{hr}\left(150 \mathrm{lb} / \mathrm{ft}^{2} /\right.$ hr). Pressurized (150 psia) and atmospheric tests were run using both air and oxygen. Typical oxygen requirements were 0.25 (1b/1b biomass) for oxygen gasification of wood chips at high stirring rates. Bench-scale tests indicated that the unit produced very low tar/0il yields (less than $1 \%$ ). In addition to bench-scale work, a larger scale version of the SERI reactor (1 t ph) was constructed and tested by Syn-Gas Inc., which indirectly acquired the technology rights through the DOE's government technology transfer program. A schematic of the Syn-Gas, Inc. demonstration facility is shown in Figure 2-6. Demonstration tests were conducted from November 1985 to May 1986.

For these tests, carbon conversions typically ranged from 87 to 91 percent. Char typically represented 6 to 9 percent of the biomass heating value, while tar/oil accounted for up to 6 percent of the biomass heating value. These tar levels are considerably greater than that observed for the bench-scale reactor.

A primary disadvantage of the moving bed gasifier is its inability to handle a wide range of feedstock geometries. Irregular, fluffy, or straw-type material tends to impede flow through the rector, create high pressure drops, and promote channeling. Therefore, these feeds must be pelletized or otherwise prepared in order to render them suitable for the gasifier. This type of feed preparation can add considerable cost to the biomass fuel. 


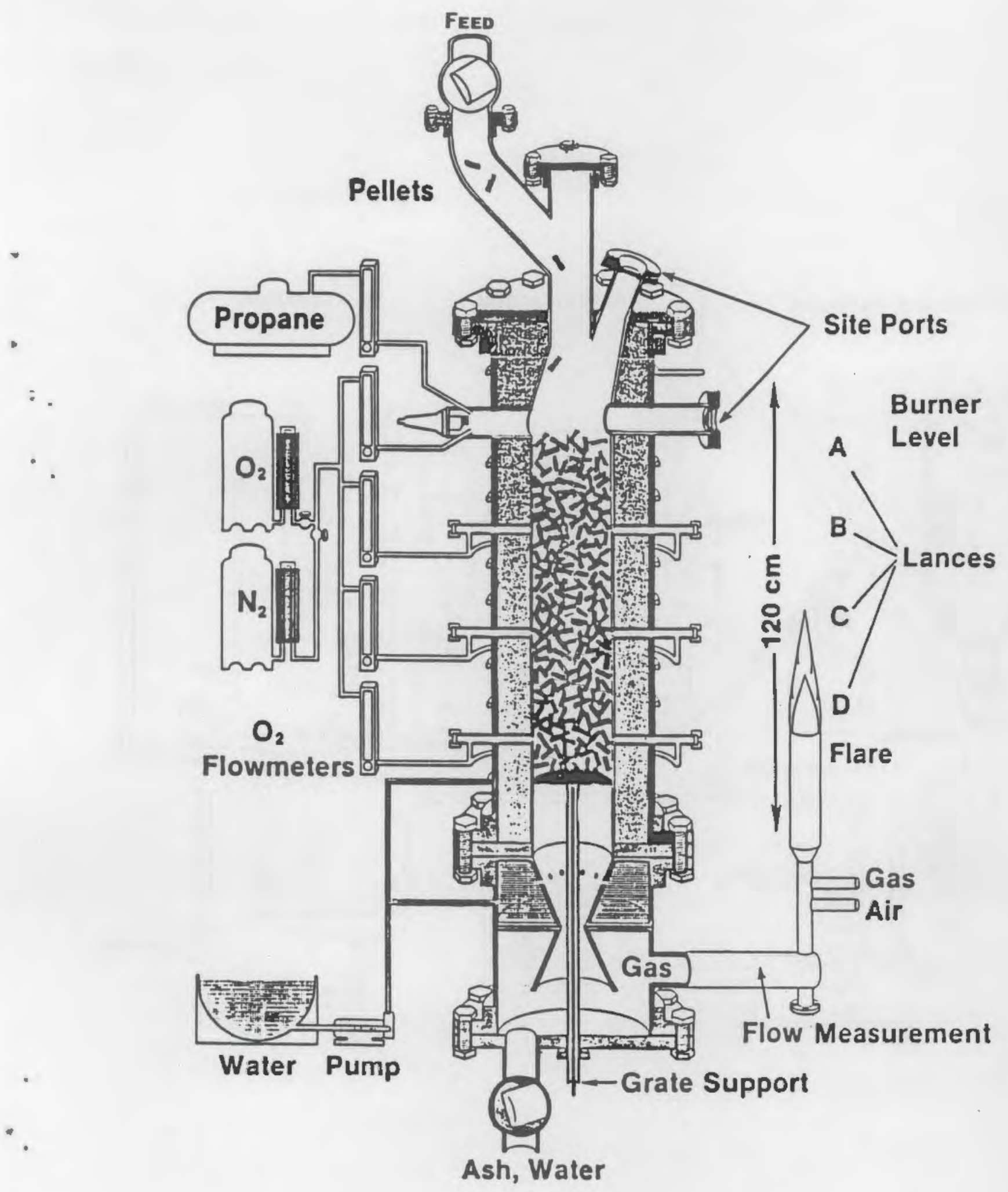

FIGURE 2-5: PHASE I OXYGEN GASIFIER CONFIGURATION (T.B. Reed, B. Levie, and M.A. Grabowski, June 1988) 


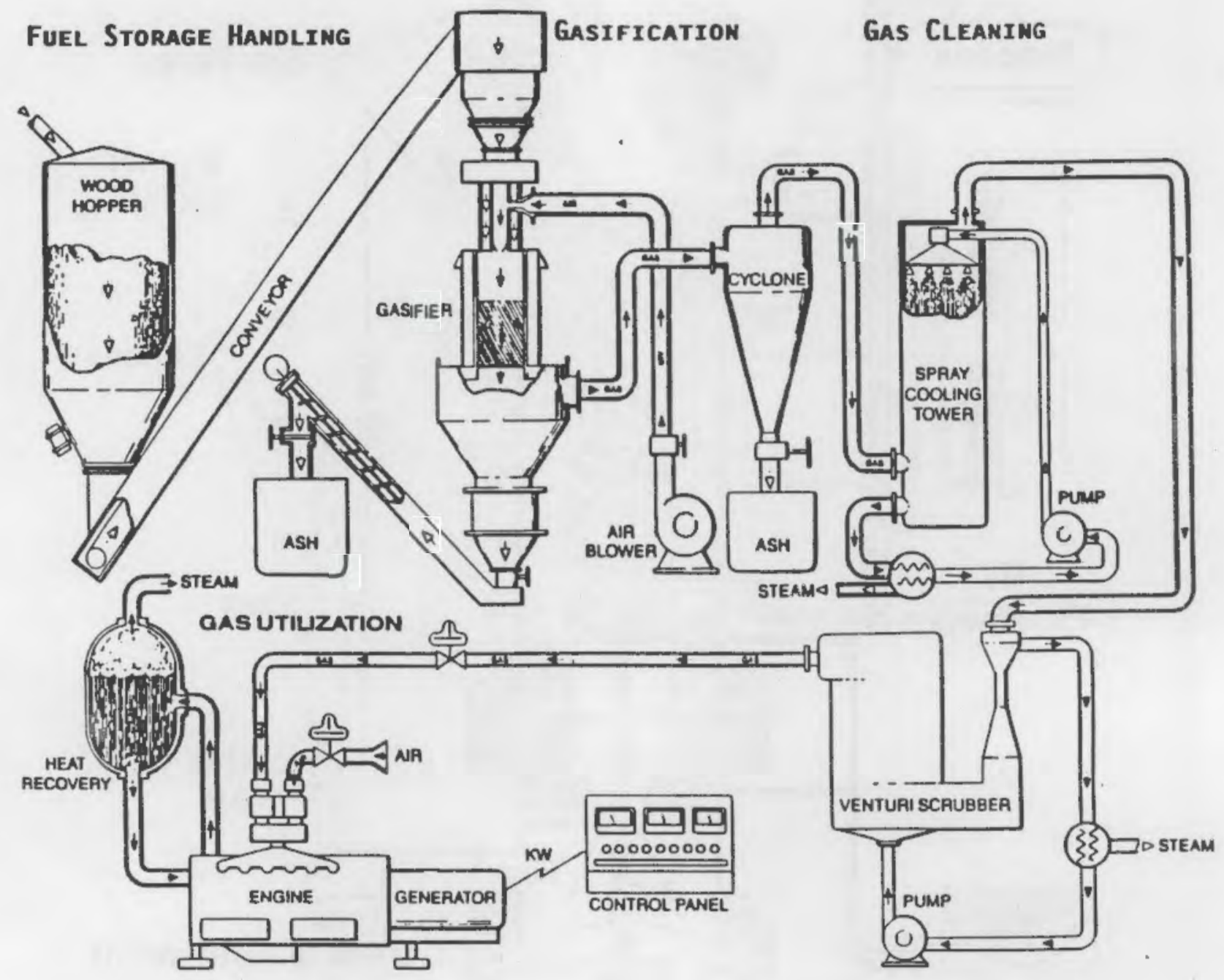

FIGURE 2-6: SYNGAS DEMONSTRATION FACILITY PROCESS FLOW DIAGRAM

(T.B. Reed, B. Levie, and M.A. Grabowski, June 1988) 


\section{B. Indirectly Heated Gasifiers}

Indirectly heated gasifiers are represented by MTCI's pulse-enhanced steam gasifier and the Battelle Columbus circulating solids gasifier. These systems differ from direct gasifiers primarily in their ability to generate medium-Btu gas without using expensive oxygen. Since the MTCI gasifier will be treated in detail in later sections, only the Battelle gasifier will be discussed here.

The Battelle process employs an entrained gasifier which is supplied heat by recirculating a stream of sand between a separate combustion vessel and the gasifier. Char remaining after gasification of biomass provides the fuel for the combustor. In the commercial concept, the combustor will operate in an entrained mode; however, the development gasification system tested by Battelle utilized a fluidized bed combustor. Figure 2-7 shows a schematic of the circulating bed gasifier concept.

The development unit operated by Battelle (Feldmann et al., 1988) consisted of a 10-inch ID gasifier and a 40-inch ID fluidized bed combustor. A schematic of the development unit is shown in Figure 2-8. Sand enters the combustor through a 10-inch line connected to the disengager. Sand enters the gasifier through an L-valve located 24 inches above the distribution. Solids circulation rate is controlled by varying the flow of gas in the L-valve.

The gasifier was operated over temperatures from $1300^{\circ} \mathrm{F}$ to $1850^{\circ} \mathrm{F}$. Carbon conversion in the gasifier ranged from approximately 45 to 85 percent over the conditions tested. Dry feed rates (dry basis) of up to 1900 pounds were obtained in the gasifier. The tar yields were typically in the range of 1 to 2 percent.

A typical product gas analysis from the gasifier is shown in Table 2-6. The gas product contains high concentrations of methane and carbon monoxide. The hydrogen content is relatively low.

\section{TABLE 2-6: IYPICAL PRODUCT GAS ANALYSIS - DRY BASIS}

\begin{tabular}{lcc} 
& $\begin{array}{c}\text { DRY GAS COMPONENT } \\
\text { ( } \mathrm{N}_{2} \text { Free) }(\% \text { Volume) }\end{array}$ & $\begin{array}{c}\text { CONTRIBUTING TO } \\
\text { HEATING VALUE }\end{array}$ \\
\cline { 2 - 3 } $\mathrm{H}_{2}$ & 17.5 & 56.9 \\
$\mathrm{CO}$ & 50.4 & 161.9 \\
$\mathrm{CO}_{2}$ & 9.4 & -- \\
$\mathrm{CH}_{4}$ & 15.5 & 156.9 \\
$\mathrm{C}_{2} \mathrm{H}_{4}$ & 6.1 & 97.8 \\
$\mathrm{C}_{2} \mathrm{H}_{6}$ & 1.1 & 19.5
\end{tabular}

Calculated Heating Value by ASTM Method D3588 $=493 \mathrm{Btu} / \mathrm{SCF}$ 


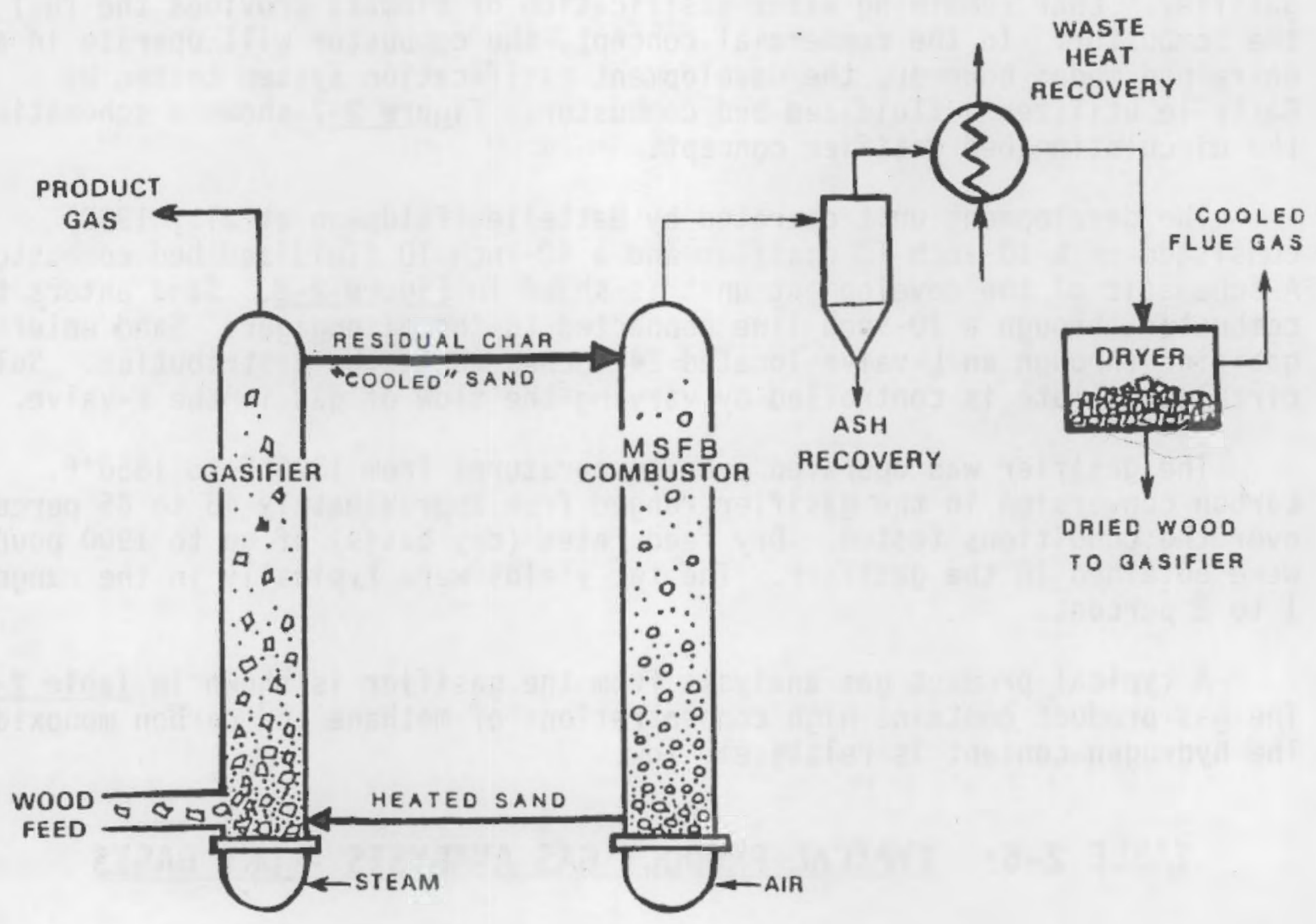

FIGURE 2-7: SIMPLIFIED SCHEMATIC OF BATTELLE'S BIOMASS GASIFICATION SYSTEM

(H.F. Feldmann, M.A. Paisley, H.R. Appelbaum, D.R. Taylor, May 1988) 


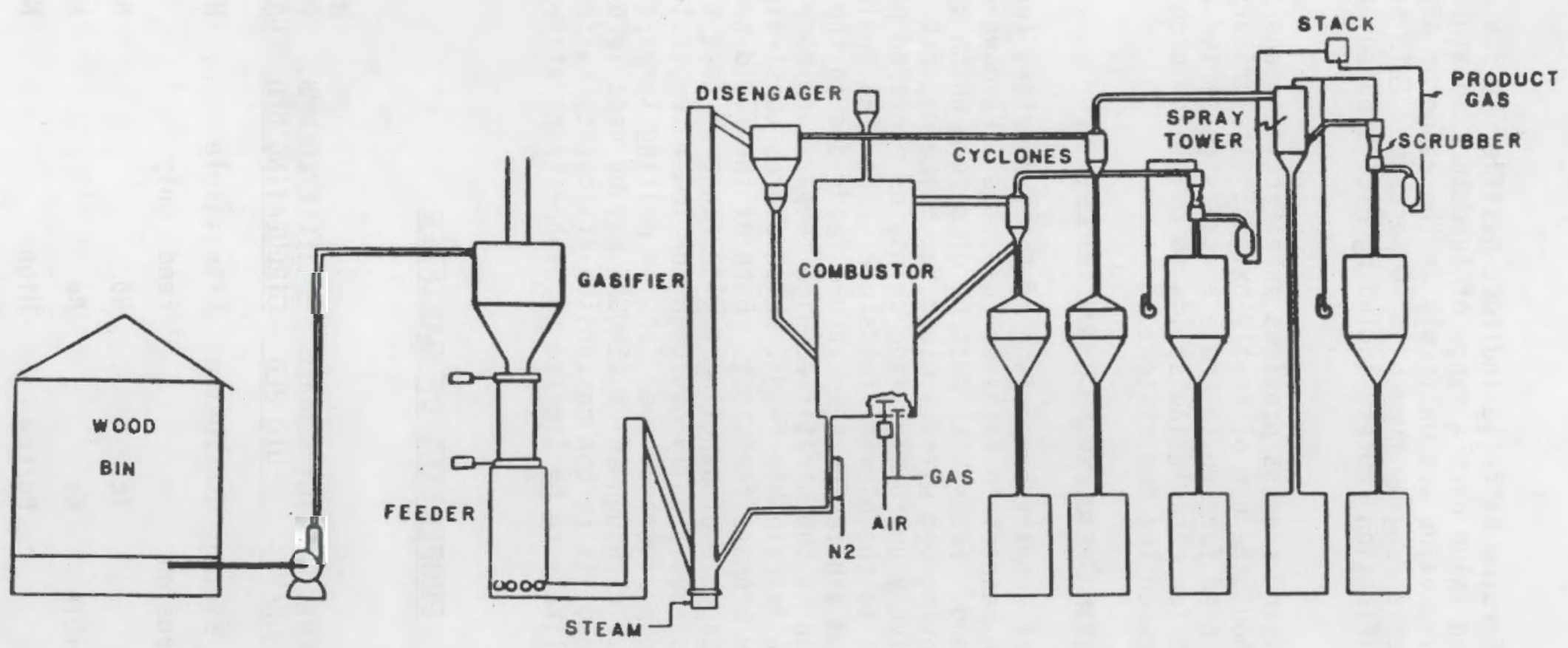

FIGURE 2-8: BATTELLE'S BIOMASS GASIFICATION PRU

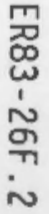

(H.F. Feldmann, M.A. Paisley, H.R. Appelbaum, D.R. Taylor, May 1988) 
A significant advantage for the Battelle indirect gasifier is its ability to maintain product gas heating value over a range of feedstock moisture levels. The product gas heating value was uniformly in the range of 450 to $500 \mathrm{Btu} / \mathrm{scf}$ for moisture contents ranging from 5 to 40 percent. This property is common to the indirect gasification routes, including MTCI's pulse-enhanced steam gasifier.

The Battelle circulating sand process provides an effective means for generating medium-Btu gas without the use of costly oxygen. Its primary disadvantages result from the need for two separate reactors (gasifier and combustor) and the requirement for circulating solids to maintain integrated operation and heat balance between the two systems.

\section{Summary of Gasifier Operatimg Characteristics}

Table 2-7 provides a brief summary comparison of the properties for each of the gasifier systems. With respect to feedstock use, the SERI down-draft gasifier is the most constrained. Feedstocks must be of a form which are easily conveyed through the moving bed without plugging, bridging, etc. This limits the feedstock to relatively uniformly sized chips, or prepared pellets. This may add considerable cost to the biomass feedstock. The SERI gasifier is also limited to relatively high ash fusion temperature feeds due to the potential for bed agglomeration in the stratified high temperature zones. The Battelle process is limited to entrainable feeds, which places constraints on the size and/or density of the biomass feedstock. Both of the fluid-bed processes (IGT and MTCI) are capable of handling a wide range of feed types and sizes. However, MTCI's is specifically designed for lower temperature operation and has demonstrated performance even for low melting temperature organics such as black liquor. Although IGT's RENUGAS may be capable of operating at lower temperatures, its carbon conversion efficiency suffers greatly. Thus, operation is likely to be limited to higher temperatures where ash fusion limitations exist.

\section{TABLE 2-7: PROPERTIES OF GASIFIER}

\begin{tabular}{|c|c|c|c|c|}
\hline & $\begin{array}{c}\text { SERI } \\
\text { DOHNDRAFT }\end{array}$ & $\begin{array}{l}\text { IGT RENUGAS } \\
\text { FLUID BED } \\
\end{array}$ & $\begin{array}{l}\text { BATTELLE/COLUMB. } \\
\text { CIRCULATING BED }\end{array}$ & $\begin{array}{l}\text { MTCI } \\
\text { PULSE } \\
\text { GASIFIER } \\
\end{array}$ \\
\hline Feedstock Limitations & $\begin{array}{l}\text { Type/Sizing } \\
\text { Ash Fusion }\end{array}$ & Ash Fusion & $\begin{array}{l}\text { Entrainable } \\
\text { Feeds Only }\end{array}$ & None \\
\hline Oxygen Required & Yes & Yes & No & No \\
\hline Mechanical Stirring & Possible & No & No & No \\
\hline Solids Recirculation & No & No/Low & High & No/Low \\
\hline Moisture Sensitivity & Modest & Modest & Low & Low \\
\hline
\end{tabular}


By definition, the oxygen-blown gasifiers require a source of pure oxygen. For a typical oxygen consumption of 0.3 pound per pound of biomass, with oxygen priced at 40 to 60 dollars per ton, this represents a loss of approximately $\$ 15 /$ ton of biomass gasified. This cost may in fact exceed the cost of the biomass feedstock in some cases. In contrast, the indirect gasifiers do not require a source of oxygen, and thus offer an opportunity for a significant savings.

The SERI down-draft gasifier requires mechanical stirring for good performance. This is anticipated to result in a tangible reduction in system reliability and an increase in system maintenance. Similarly, the Battelle gasifier requires a high level of solids recirculation which is anticipated to increase system wear and maintenance.

Finally, both oxygen-blown systems exhibit a sensitivity to feedstock moisture level, though not as significant as air-blown gasifiers. Conversely, the MTCI pulse-enhanced gasifier and the Battelle process are relatively insensitive to feedstock moisture.

Table 2-8 summarizes the dry gas composition from each reactor under typical operating conditions using woody biomass. As seen in Table 2-8, the MTCI gasifier yields a significantly higher hydrogen concentration compared to the other systems. The MTCI gasifier also exhibits low tar/oil yields, and relatively low methane and higher hydrocarbon yields. The importance of these attributes will be discussed in the following sections in the context of potential end uses for the biomass gasification systems.

\subsubsection{Retrofit of Borlers and Heat Emgines}

Fuel gas (biogas) generated from a biomass gasifier may be utilized for the production of steam in a gas-fired boiler or in reciprocating engines or gas turbines for the production of electricity. A primary concern in these applications involves the impact of the producer gas thermochemical properties on the performance of these devices.

The heat release rate within a boiler depends on the radiant properties of the furnace gases. The radiant intensity of combustion gases within the furnace depends most pronouncedly on the adiabatic flame temperature. As the average combustion gas temperature increases within the furnace, the heat flux to the cold plane surfaces within the boiler also increases. This allows a higher firing rate and thus achievement of higher steaming rates for a given boiler design.

Therefore, if a boiler is designed for natural gas, substitution of biogas with a lower adiabatic flame temperature will reduce the achievable firing rate within the boiler at a commensurate thermal efficiency. Of course, boiler derating as a result of differing thermochemical properties of biogas compared to natural gas is highly undesirable since it negatively impacts operating economics. 


\section{TABLE 2-8: SUMMARY OF DRY GAS COMPOSITIONS}

\begin{tabular}{|c|c|c|c|c|}
\hline & IGT "RENUGAS" 1 & $\begin{array}{c}\text { SERI } \\
\text { DOWNDRAFT }^{2}\end{array}$ & $\begin{array}{l}\text { BATTELLE } \\
\text { CIRCULATION } \\
\end{array}$ & MTCI INDIRECT $^{4}$ \\
\hline GASIFIER TYPE & FLUID BED & $\begin{array}{l}\text { STRATIFIED } \\
\text { DOWNDRAFT }\end{array}$ & $\begin{array}{l}\text { ENTRAINED/ } \\
\text { MSFB COMBUSTDR }\end{array}$ & FLUID BED \\
\hline $\begin{array}{l}\text { Maximum Tested } \\
\text { Throughput (1b/hr) }\end{array}$ & 1000 & 2000 & $\begin{array}{l}2000 \text { Gasifier } \\
70 \text { MSFB } \\
\text { Combustor }\end{array}$ & 200 \\
\hline Oxygen & Yes & Yes & No & No \\
\hline
\end{tabular}

Typical Dry Gas

Composition

\begin{tabular}{lrrrr}
$\mathrm{H}_{2}$ & 27.45 & 22.38 & 17.50 & 48.11 \\
$\mathrm{CO}$ & 14.82 & 43.23 & 50.40 & 22.91 \\
$\mathrm{CO}_{2}$ & 39.83 & 25.92 & 9.40 & 20.18 \\
$\mathrm{CH}_{4}$ & 17.16 & 6.02 & 15.50 & 8.32 \\
$\mathrm{C}_{2}{ }^{+}$ & 0.74 & 2.45 & 7.20 & 0.48 \\
\cline { 2 - 2 } & 100.00 & 100.00 & 100.00 & 100.00 \\
\hline $1-2 \%$ & $2-4 \%$ & $1-2 \%$ & $1-2 \%$
\end{tabular}

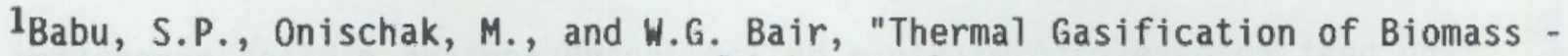
The IGT Renugas Process," 16th world Gas Conference, Munich, F.R.G., June $24-27,1985$.

${ }^{2}$ Reed, T.B., B. Levie, and M.A. Grabowski, "Fundamentals, Development, and Scale-up of the Air-Oxygen Stratified Down-draft Gasificer," prepared by SERI for PNL, DOE Contract No. DE-AC06-76RL01830, June 1988.

${ }^{3}$ Feldmann, H.F., M.A. Paisley, H.R. Appelbaum, D.R. Taylor, "Conversion of Forest Residues to Methane-Rich Gas in a High-Throughput Gasifier, " prepared by Battelle Columbus Division for PNL, DOE Contract No. DE-AC06-76RL01830, May 1988.

4MTCI, "Advance Thermochemical Reactor," California Energy Commission Contract No. 500-800-012, 1988. 
Table 2-9 compares the adiabatic $f 1$ ame temperature for natural gas (approximated as pure methane) and two different biogases. The first biogas represents a low-Btu product from an air-blow gasifier, while the second biogas represents a medium-Btu product from MTCI's indirect gasifier. Fifteen percent excess air is assumed for each case.

\section{TABLE 2-9: ADIABATIC FLAME TEMPERATURE FOR NATURAL GAS AND BIOGAS}

\begin{tabular}{lc} 
FUEL & ADIABATIC TEMPERATURE $\left({ }^{\circ} \mathrm{F}\right)$ \\
\cline { 2 - 2 } Natural Gas & 3280 \\
Air-Blown Biogas (Low Btu) & 2750 \\
Indirect Biogas (Medium Btu) & 3310
\end{tabular}

As seen in Table 2-9, the air-blown biogas results in an adiabatic flame temperature which is approximately $500^{\circ} \mathrm{F}$ lower than that of natural gas. In contrast, the medium-Btu indirect biogas exhibits a flame temperature which is almost identical to that of natural gas.

From these results, it is evident that indirect gasifiers produce a medium-Btu gas which is easily substituted for natural gas by virtue of its similar thermochemical properties. Furthermore, the volumetric energy density of indirect biogas is three times that of air-blown biogas and more closely resembles natural gas. Therefore, the extent of burner modifications necessary to accommodate these fuels will be significantly less than for low-Btu biogases.

\subsubsection{Methanol Production}

Gasification of biomass provides a viable option for utilizing renewable resources to produce premium liquid products, such as methanol, which can be used to replace gasoline in internal combustion engines. In a recent report prepared by the Hawai i Natural Energy Institute (HNEI) and the Florida Solar Energy Center (FSEC), it was concluded that in areas where biomass is plentiful, biomass gasification offers the most economical route for hydrogen and methanol production from renewable resources. The report estimates that biomass could easily replace all of the annual consumption of gasoline used in Hawaii (325 million gallons per year).

The currently favored method for producing methanol in the United States involves catalytic steam reforming of light hydrocarbons. The synthesis gas from the steam reforming operation, containing primarily hydrogen and carbon monoxide, is then reacted in a high pressure catalytic vessel to form methanol. For light hydrocarbons rich in hydrogen, e.g., methane, carbon dioxide may be recycled to the reformer to increase the ratio of carbon monoxide to hydrogen. Additional quantities of hydrogen may have to be 
removed from the synthesis gas to achieve the proper stoichiometry for methanol production. The methanol reaction stoichiometry is shown below:

$$
\mathrm{CO}+2 \mathrm{H}_{2} \longrightarrow \mathrm{CH}_{3} \mathrm{OH}
$$

Unlike natural gas or petroleum-derived hydrocarbons, biomass contains a high concentration of bound oxygen, typically accounting for approximately 44 wt.\% of the biomass material. Due to differences in the elemental composition of biomass compared to light hydrocarbons, synthesis gas products from biomass contain significantly lower ratios of hydrogen to carbon oxides. Because of this fact, the method of processing biomass-derived synthesis gas must be substantially modified.

As previously discussed, there exists two primary routes for biomass gasification: direct and indirect. The direct route involves partial oxidation of the biomass by introduction of air or oxygen into the gasifier. However, since air-blow gasifiers generate a synthesis gas that is diluted by nitrogen, and therefore, are unsuitable for methanol production, it will not be considered here. 0xygen-blown direct gasifiers require an air separation plant to generate pure oxygen. This oxygen, when combined with biomass, produces a synthesis gas rich in carbon oxides.

The second route involves indirect steam gasification. This process requires no oxygen plant, since biomass is reacted with steam only to produce a hydrogen-rich synthesis gas. Indirect heat for the reaction must be supplied by combustion of a portion of the synthesis gas or by combustion of a purge fuel stream. below:

The general stoichiometries for the two gasification routes are shown

Indirect (Steam-blown):

$$
\begin{aligned}
\mathrm{C}_{1} \mathrm{H}_{1.5} 0.75+7 / 12 \mathrm{H}_{2} \mathrm{O} & \longrightarrow 2 / 3 \mathrm{CO}+4 / 3 \mathrm{H}_{2}+1 / 3 \mathrm{CO}_{2} \\
\longrightarrow & 2 / 3 \mathrm{CH}_{3} \mathrm{OH}+1 / 3 \mathrm{CO}_{2}
\end{aligned}
$$

Direct (0xygen-blown):

$$
\begin{aligned}
\mathrm{C}_{1} \mathrm{H}_{1.5} 0_{.75}+0.25 \mathrm{O}_{2}+3 / 9 \mathrm{H}_{2} \mathrm{O} \longrightarrow 3 / 8 \mathrm{CO}+6 / 8 \mathrm{H}_{2}+5 / 8 \mathrm{CO}_{2} \\
\longrightarrow 3 / 8 \mathrm{CH}_{3} \mathrm{OH}+5 / 8 \mathrm{CO}_{2}
\end{aligned}
$$

As seen above, both of the gasifiers produce carbon oxides in excess of that required for methanol production. Therefore, in each case, carbon dioxide must be removed from the gas stream at some point during processing. However, by inspection of the relative stoichiometries, it can be seen that the direct (oxygen-blown) route requires removal of approximately 100 percent more carbon dioxide than the indirect route. For each unit of carbon in the biomass feed, $5 / 8$ unit of carbon dioxide must be removed for the direct 
gasifier. Only $1 / 3$ unit of carbon dioxide must be removed from the indirect steam gasification route. Carbon dioxide removal systems are both capital and energy intensive. Therefore, a significant cost advantage exists for the indirect steam gasification route compared to the direct oxygen-blown route.

The ratio of hydrogen to carbon monoxide at the exit of a gasifier is primarily dictated by thermodynamic considerations. For some types of oxygenblown direct gasifiers (e.g., the SERI and Battelle units), this ratio must be adjusted to increase the hydrogen content of the synthesis gas. This is commonly achieved using a shift reaction as shown below:

$$
\mathrm{CO}+\mathrm{H}_{2} \mathrm{O} \longrightarrow \mathrm{H}_{2}+\mathrm{CO}_{2}
$$

The shift reaction conditions must be controlled to yield a 2:1 ratio of hydrogen to carbon monoxide. The balance of carbon dioxide is then removed in a subsequent step.

However, for the indirect gasifier, the partial pressure of steam at the outlet of the gasifier is high. This promotes an in-situ shift reaction that results in much higher hydrogen concentrations than achieved for oxygen-blown systems. In fact, the ratio of hydrogen to carbon monoxide is almost precisely that required for methanol production (2:1). For instance, the ratios at the exit of MTCI's indirect gasifier for several different feedstocks tested are shown below:

\begin{tabular}{ll} 
FEEDSTOCK & $\frac{\mathrm{H}_{2} / \mathrm{CO}}{}$ \\
\hline Pistachio Shells & 2.01 \\
Wood Chips & 2.10 \\
Rice Hulls & 2.17
\end{tabular}

It is evident that by modest control of the indirect gasifier process conditions (e.g., temperature and steam-to-biomass ratio), the desired synthesis gas ratios can be achieved without the need for a separate shift conversion step. This provides a significant economic advantage for indirect gasifiers compared to oxygen-blown direct gasifiers.

Finally, all of the state-of-the-art gasifiers generate significant quantities of methane and higher hydrocarbon components. These hydrocarbons typically represent 20 to 40 percent of the biomass heating value. Since these hydrocarbons do not contribute to the methanol conversion reaction, they must be removed from the synthesis gas at some point.

Due to the significant energy content of this unconverted hydrocarbon stream, some means must be devised for their efficient use with the plant. However, by definition, the heat requirements for the direct gasifier are satisfied by partial combustion of the biomass feedstock. Thus, there exists no convenient avenue for exploiting this energy value. In contrast, the indirect gasifier requires an energy source to provide the endothermic heat of reaction. In fact, the residual heat of the unconverted hydrocarbon stream closely matches the indirect gasifier heat duty. 
Based on these considerations, it is evident that indirect gasification offers significant operating advantages compared to direct gasifiers. The indirect gasifier integrates with the methanol plant in a similar manner to that of a conventional steam reformer plant, which is not surprising since the catalytic steam reformer is an indirectly heated process. Furthermore, the indirect gasifier requires no air separation plant and no shift reactor unit. Fiqure 2-9 compares the unit operations and flows for the indirect and direct gasifiers in a methanol plant application. As seen from Figure 2-10, the indirect gasifier allows significant simplifications in the overall plant configuration.

\subsubsection{Hydrogen Production.}

The production of high-purity hydrogen from biomass offers an attractive means of upgrading renewable resources to a high-valued end product. Hydrogen production can be considered for its merchant value, heating value, or electric generation potential in advanced fuel cells.

A biomass-to-hydrogen plant will consist of several process units including a gasifier, a shift reactor, and a purification step. When hydrogen is the desired product, the shift reactor is designed to react steam and carbon monoxide to produce hydrogen and $\mathrm{CO}_{2}$ to the greatest extent possible. In order to accomplish high conversions, the thermodynamics of the reaction dictate that low reactor outlet temperatures be monitored. Typically, a hightemperature shift is followed by cooling and a second low-temperature shift step.

However, since the shift reaction is exothermic, excessive temperature rises can occur when the carbon monoxide level is too high at the reactor inlet. High temperatures can destroy the activity of the shift reactorcatalyst. In these cases, the shift reaction must be further separated with additional intercoupling.

Inspection of gas yields from direct gasifiers shows that these streams contain high levels of carbon monoxide. In contrast, indirect gasifiers produce lower ratios of carbon monoxide due to the higher steam partial pressures and lower temperatures of operation for the gasifier. Thus, while the shift reaction for direct synthesis gas will require special consideration due to high heat releases, such problems do not exist for indirect synthesis gas.

Finally, when high-purity hydrogen is desired, Pressure Swing Absorption (PSA) purification is commonly employed. In this purification process, hydrogen-rich gases enter a packed bed that absorbs impurities, such as methane and carbon dioxide, under pressurized conditions. A high-purity hydrogen stream is generated. When the pressure in the absorber vessels is released, the impurities are desorbed into a purge stream. Typically, 20 percent of the hydrogen contained in the synthesis gas is removed in the purge stream. 


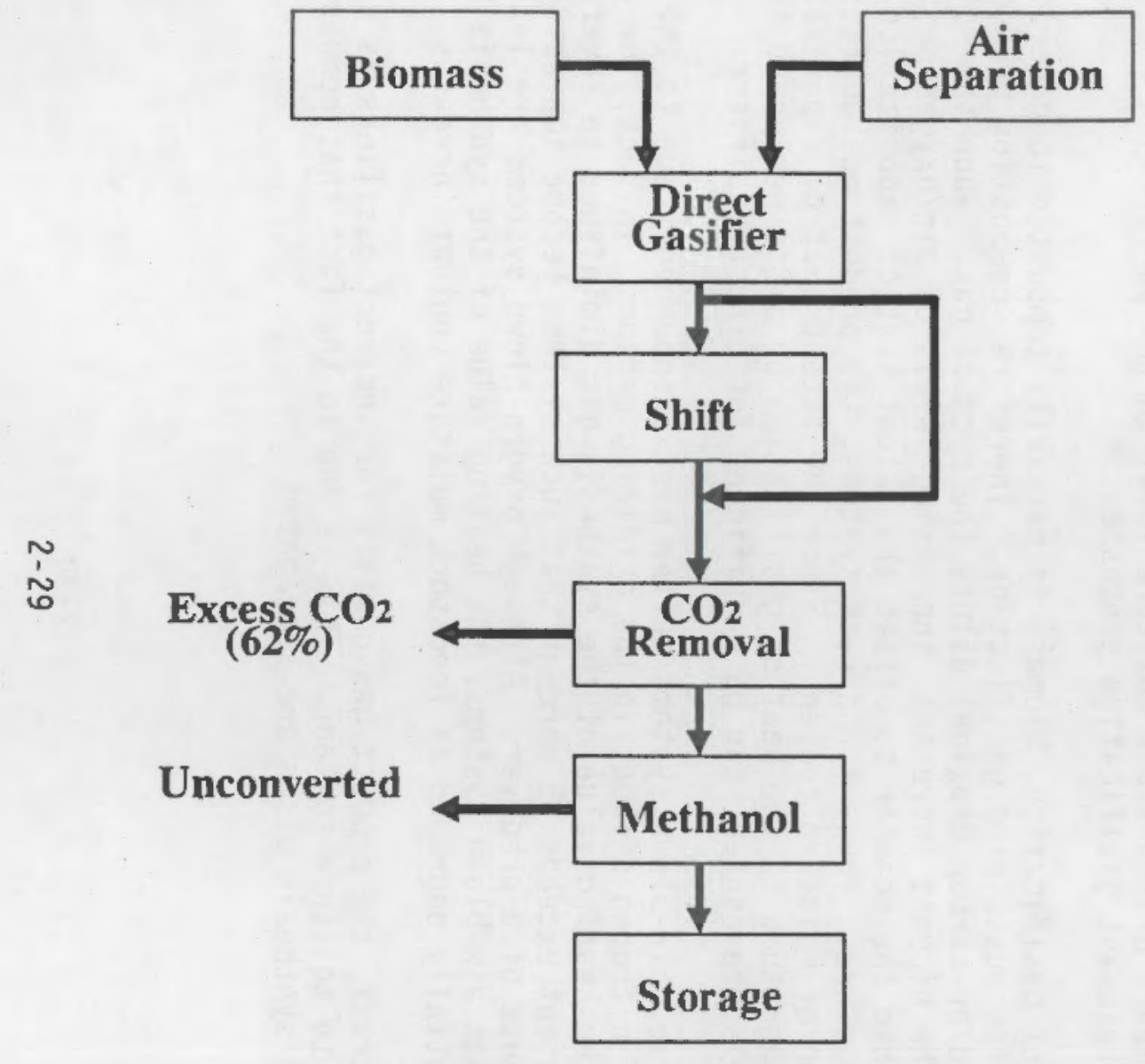

Direct Gasification

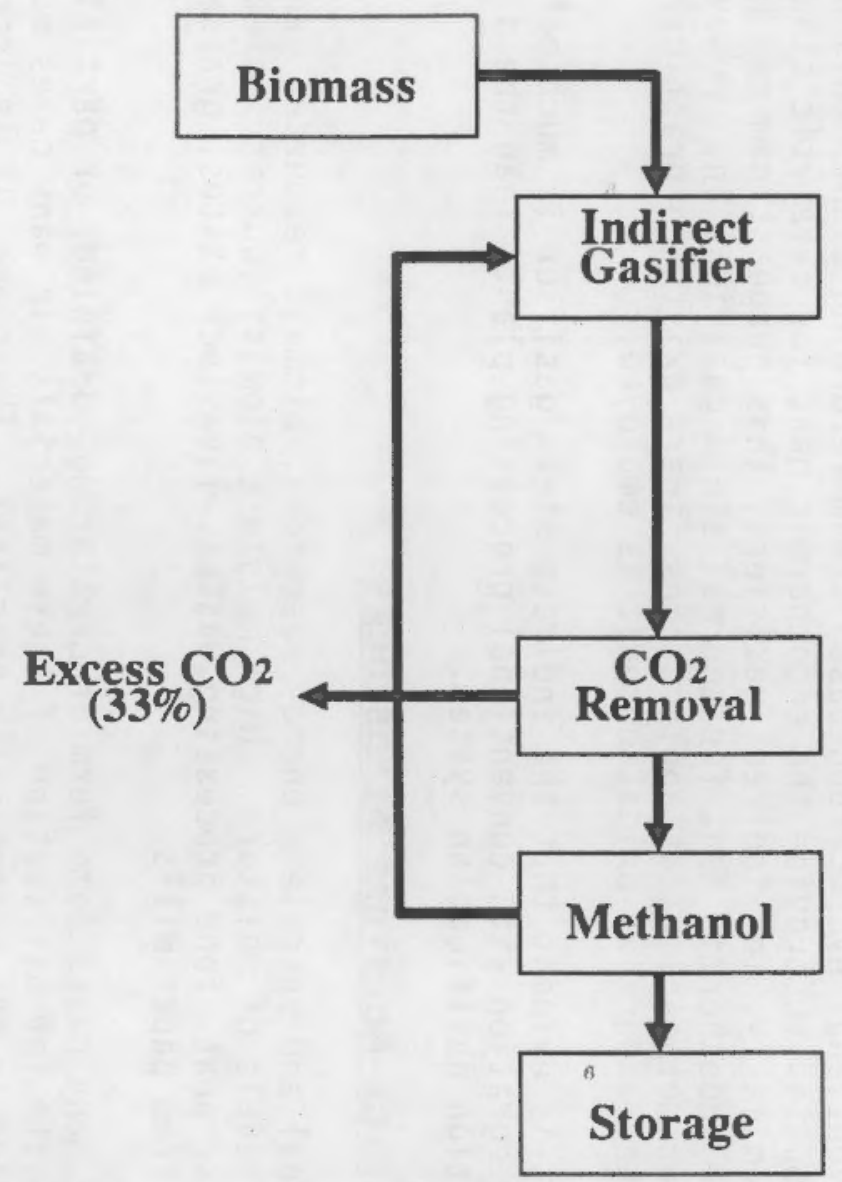

Indirect Gasification 
As previously discussed, all gasifiers generate unconverted hydrocarbons. These hydrocarbons can account for 20 to 40 percent of the biomass heating value. Therefore, these hydrocarbons, combined with unrecovered hydrogen, represent a significant energy stream.

In a conventional hydrocarbon-based steam-reforming plant, this purge stream is combusted to provide the endothermic heat for catalytic steam reforming. Similarly, for indirect gasifiers, this purge stream can be used to provide the endothermic heat for thermal steam gasification. However, as discussed under methanol plant applications, there exists no practical use for this stream when a partial oxidation unit is employed.

Again, it is evident that the indirect steam gasifier is much better suited for integration with conventional processing plants than the direct partial oxidation gasification system.

\subsubsection{High-Morsture Feedstocks}

Unlike coal and petroleum energy resources, biomass resources generally contain high levels of moisture. High moisture biomass sources include aquatic plants, peat, food processing wastes, livestock wastes, grasses, and sludge waste from paper mills.

While in many cases some form of dewatering, draining, or partial drying is a prerequisite for utilization of these materials, in many cases more extensive drying is not economically practical. Therefore, it is important to assess the impact of feedstock moisture level on the performance and gas quality for relevant gasification processes.

In direct gasification, biomass is partially combusted to generate the heat needed for sustaining gasification. Therefore, combustion products (nitrogen and/or carbon dioxide) dilute the product gas. When the moisture content of the biomass increases, increasing levels of air/oxygen must be introduced into the reactor to offset the latent heat of vaporization of the contained moisture. Thus, for direct systems, the product gas quality varies as a function of moisture content. Since the latent heat of vaporization is similar in magnitude to the heat of gasification on a Btu per pound basis, the impact of moisture content can be significant for direct gasifiers.

of course, air-blown systems suffer most pronouncedly due to the inclusion of nitrogen diluent in the oxidizing medium. In fact, for air-blown gasifiers, the heating value of the synthesis gas diminishes so severely when moisture content exceeds 25 percent that such systems become impractical without the use of a predryer. Although oxygen-blown systems are less sensitive than air-blown systems, the heating value of the synthesis gas is also substantially degraded as feedstock moisture content increases.

In contrast, the product gas quality for indirect gasifiers is virtually insensitive to moisture content. This is due to the fact that combustion products and synthesis gases are segregated. 
Figure 2-10 compares the effect of feedstock moisture content on the heating value of synthesis gases generated from various gasifiers. As seen in Figure 2-10, the heating value for the indirect steam gasifier is constant over a wide range, while the heating value diminishes rapidly for alternative systems.

When considering the integration of a gasifier with a heat engine or boiler, it is important to assess the need for controlling the fuel gas properties within certain tolerances. When these tolerances are exceeded, plant performance and control is compromised. Therefore, since biomass moisture levels can vary considerably, even for similar classes of feeds, it is highly desirable to employ a gasifier that exhibits a low sensitivity to feedstock moisture variations.

Although the thermal efficiency for all gasifier systems diminishes with increasing feedstock moisture content, thermal efficiency may not be critical when waste volume reduction is the essential priority. Such is the case, for instance, with paper mill sludge waste where disposal costs exceed the thermal value of the waste. Paper mili sludge can be efficiently dewatered to 50 percent moisture using a screw press. For indirect gasifiers, this feed can be gasified directly without the need for an expensive predrying system. These predryers represent not only a capital expense, but also an environmental problem due to odor emissions. These waste products cannot be practically handled by oxygen-blown direct gasifiers without predrying.

Based on the above discussion, it is evident that the indirect gasification route offers increased flexibility in processing a broad range of high-moisture feedstocks. This unique property is anticipated to open markets not available to direct gasification.

\subsubsection{LOW Ash Fuston Temperature Feedstocks}

A number of biomass feedstocks contain high ash levels that are characterized by low ash melting temperatures. These feedstocks have posed particular problems in combustion systems due to the formation of molten ash which reduces char combustion efficiency and hampers the operation of grates and ash removal equipment. Examples of these types of feedstocks include rice hulls, oat straw, and barley straw.

The ash compositions and initial deformation temperatures for various straw ashes are shown in Table 2-10. The concentration of $\mathrm{K}_{2} \mathrm{O}$ and $\mathrm{CaO}$ is seen to have a significant impact on the ash melting point. Higher levels of these components tend to depress the ash melting temperature as shown for oat and barley straw compared to wheat straw.

Due to the critical nature of these feedstocks, the selection of gasification systems which can accommodate these materials must be carefully assessed. Ideally, the gasifier should provide uniform and controlled temperatures which are consistently maintained below the ash fusion point. 


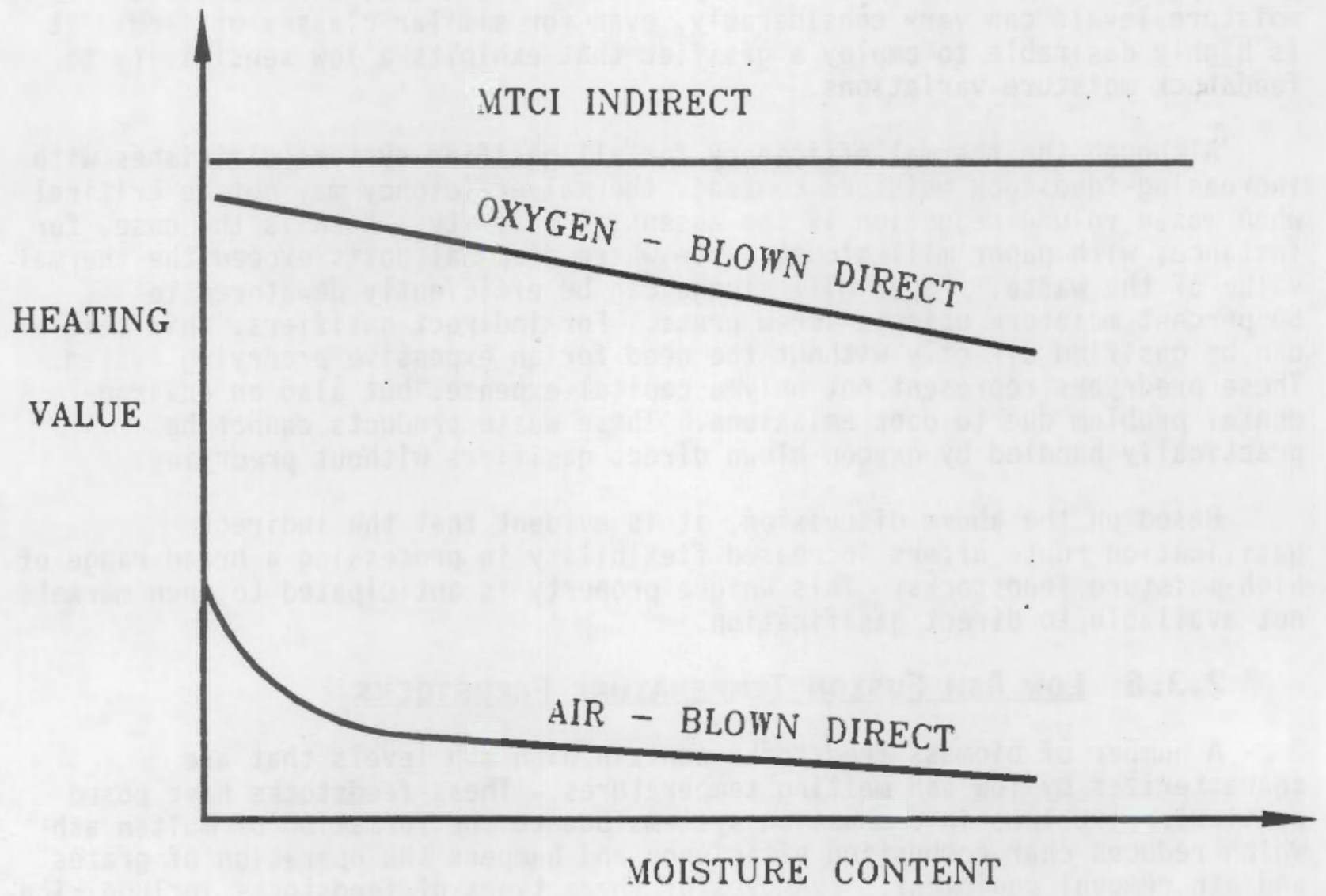

FIGURE 2-10: SENSITIVITY OF PRODUCT GAS HEATING VALUE FOR DIFFERENT GASIFICATION SYSTEMS 


\section{TABLE 2-10: COMPOSITION AND DEFORMATION TEMPERATURE FOR STRAW ASH}

•

$\mathrm{K}_{2} \mathrm{O}$
$\mathrm{CaO}$
$\mathrm{P}_{2} \mathrm{O}_{5}$

$\mathrm{Mg} 0$

$\mathrm{Al}_{2} \mathrm{O}_{3}$

$\mathrm{Fe}_{2} \mathrm{O}_{3}$

$\mathrm{SO}_{3}$

$\mathrm{Na}_{2} \mathrm{O}$

Initial Deformation

Temperature, ${ }^{\circ} \mathrm{C}$
WHEAT

78.2

6.6

5.0

3.3

3.6

2.0

1.5

1.4

0.3

$900-1050$
RYE

61.7

19.2

7.4

3.7

2.8

2.1

1.5

1.3

0.3

800-850
BARLEY

44.7

37.1

9.3

3.8

2.5

0.4

0.5

1.4

0.3

$750-850$
OAT

37.3

40.3

12.3

4.1

3.0

0.8

0.5

1.4

0.3

$730-800$

In MTCI's indirectly heated, fluidized-bed gasifier, temperatures within the fluid bed are easily controlled. Fluidized beds are known, of course, for extremely uniform temperature distributions. In contrast, oxygen-blown systems, such as SERI's stratified down-draft gasifier, produce zones of nonuniform temperature. In certain regions of the bed, high temperatures are achieved which are apt to melt the ash constituents contained in these feeds. Resulting agglomeration poses significant problems for the conveyance of material through these moving bed systems.

For alternative indirectly heated gasifiers, such as Battelle's circulating sand system, char is combusted in an external reactor at temperatures which exceed that of the gasifier. This also increases the likelihood of ash melting, and imposes constraints on the range of feedstocks that can be successfully handled.

MTCI's gasifier has demonstrated performance on low ash fusion feedstocks such as rice hulls and black liquor. Black liquor presents a particularly challenging feedstock since it contains high concentrations of sodium salts which form low-temperature eutectic mixtures. These materials were successfully gasified without any problems associated with ash melting or bed agglomeration. 
Based on these considerations, it is anticipated that the indirectly heated gasifier of the type being developed by MTCI will have wide application to a range of biomass materials, including those with low ash melting temperatures. 


\section{SECTION 3.0}

\section{THE MTCI GASIFICATION TECHNOLOGY}

MTCI's gasification technology represents a significant departure from existing indirectly heated gasification technologies as well as those that employ partial oxidation to supply heat to the reacting system. In MTCI's process, the heat of reaction for the steam-carbon reaction is provided indirectly by using pulse combustor resonance tubes as a heat transfer surface. This heat transfer technique provides very high heat transfer rates about five times higher than conventional fire-tube systems. As an indirect gasification process, it does not require an oxygen plant or use air in the reactor vessel and the $\mathrm{CO}_{2}$ produced in the gasifier per mole of hydrogen is reduced, thus requiring less clean-up equipment. In addition, the dilution of the product gas with nitrogen is completely avoided.

In the following section the merits of the MTCI gasification technology are discussed within a comparative framework that includes a summary of the detailed discussion provided in Section 2.0. A discussion of the commercial Kraft Black Liquor Recovery process is also provided herein.

\subsection{BIOMASS GASIFICATION}

A review of the present technology base for biomass thermochemical conversion processes with respect to research development and commercialization included an assessment of the present technology, and the identification and an analysis of constraints inherent in the presently available system designs.

In the area of pyrolysis and directly heated gasification processes, an overview of the technologies being developed, both at the laboratory scale and in PDU operations was detailed in Section 2.0. Emphasis was placed on assembling information that was of common interest to indirectly heated gasification processes (such as solids handling, fluidization experience, reaction kinetics) as well as identification and assessment of limitations of the directly heated processes with respect to product gas quality and the spectrum of end-use applications. The indirectly fired biomass gasification technology was also discussed in Section 2.0 to facilitate a detailed evaluation of the process options presently being investigated. In the course of this assessment of indirectly heated gasification systems, the areas given special attention are those that imposed limitations on the process throughput; namely, heat transfer rates, heat release rates, carbon/steam conversion efficiencies, and overall system thermal efficiency.

In partial oxidation gasifiers, combustion products and diluents are co-mingled with the gasification products. This results in a low-Btu gas that has a volumetric energy density which is one-tenth to one-seventh that of natural gas. For this reason, the potential end-use applications for the product gases are limited. While the use of oxygen in direct autothermal gasifiers can overcome some of the technical limitations of air-blown systems, 
the cost of oxygen can account for a significant fraction of the total fuel gas production cost. This is particularly true for small dispersed gasifiers where transportation costs for merchant oxygen supply are high and the capital costs for an on-site generator are justified.

When biomass-to-methanol conversion employing a conventional synthesis gas route is considered, additional cost penalties are associated with the use of an oxygen-blow gasifier. Since biomass is oxygen-rich, carbon dioxide must be selectively removed from the product gas stream prior to entering the methanol conversion loop. Inspection of the basic stoichiometry for partial oxidation routes reveals that oxygen-blown systems require removal of approximately 100 percent more carbon dioxide than the indirect steam gasification routes. This imposes significant capital and operating cost penalties for direct gasification.

Finally, state-of-the-art gasifiers produce a synthesis gas containing methane and higher hydrocarbon fractions which account for 20 to 40 percent of the initial biomass feedstock heating value. When methanol or high purity hydrogen is the desired end product, these hydrocarbons must be purged from the product stream (e.g., PSA purification). By considering the energy flows for the integrated gasification plant, it is immediately evident that oxygenblown systems do not offer an easy means for efficiently utilizing the energy values of the residual hydrocarbon stream. This is because the gasifier, by definition, satisfies its thermal requirements by partially combusting the feedstock. In contrast, the residual energy value of these hydrocarbons closely matches the heat requirements for the indirect heat exchange gasifier. In fact, the heat integration for the indirect gasifier closely resembles that of the steam-reforming route most commonly practiced by industry for the production of methanol or hydrogen from hydrocarbon feedstocks. For example, product gas heating values of approximately 120 to $150 \mathrm{Btu} / \mathrm{scf}$ are typical of air-blown autothermal gasifiers, whereas indirectly heated systems are capable of producing medium-Btu gas in the range of 350 to $500 \mathrm{Btu} / \mathrm{scf}$. The improved quality of product gas from indirectly heated systems is particularly important when gas transportation to remote end users or upgrading to premium liquid fuels are considered. It also has an impact upon the cost of burner or other ancillary systems that are necessary for retrofit applications (i.e., substitution of biogas for natural gas). Furthermore, gas clean-up and downstream gas handling equipment costs are lower for product streams generated from indirect gasification processes compared to autothermal systems.

In contrast to autothermal gasification routes, the indirectly heated gasification processes do not contain combustion products or atmospheric nitrogen and are not as constrained with respect to potential end uses. Product gas quality from indirect systems is highly insensitive to feedstock moisture content and this provides a flexibility for the utilization of a broad range of high-moisture feedstocks for which pre-drying is impractical or uneconomical. For instance, paper mill sludge waste, mechanically dewatered to 50 wt.\% moisture in a screw press, can be fed directly to the indirect gasifier without significant deterioration of product gas heating value. of course, for all gasification systems, the net thermal efficiency decreases with increasing biomass moisture content. However, for inexpensive feedstocks, or when the reduction in waste volume is a primary factor, reduced thermal efficiency may not be a significant limitation. 
Thus, indirectly heated gasifiers appear to offer many advantages for the thermochemical conversion of biomass to fuel gas, synthesis gas, or premium products. However, the practical issues of transferring large amounts of heat to the gasifier in order to satisfy the endothermic heat of reaction must be addressed. Several different indirectly heated systems have been proposed for achieving this task and were discussed in some detail in Section 2.0.

The Battelle-Columbus process is an example of an indirectly heated system in which hot solid (sand) is circulated between a biomass steam gasifier and a char combustor. The solid is heated by the combustion of residual biomass char, and the sensible heat of the solid is released in the gasifier to support the endothermic heat of reaction. While this system accomplishes the task of effective heat transfer to the gasifier, two separate vessels are required along with critical equipment necessary for handling hot solids during recirculation. This is anticipated to reduce the costeffectiveness and reliability of the system and is likely to increase equipment wear, maintenance, and operating cost. Also, the somewhat higher temperatures achieved in the char combustor may limit the ability to handle material with low-ash fusion points.

In a second approach, developed by the University of Missouri-Rolla (V.J. Flanigan et al., March 1983) in-bed fire tubes are employed to supply the endothermic reaction heat load. Conventional fire tubes are typically found to be heat transfer limited to the extent that inside convective heat transfer coefficients of only 8 to $10 \mathrm{Btu} / \mathrm{hr} / \mathrm{ft}^{2} /{ }^{\circ} \mathrm{F}$ can be achieved within the range of economical pressure drop constraints. This requires a large number of high alloy tubes to be immersed within the bed in order to provide sufficient surface area for heat transfer. This results in a fluidized bed that is packed with tube bundles. Furthermore, this results in increased material and fabrication costs. The heat transfer limitations of the conventional fire-tube arrangement are particularly unfortunate since fluid bedside heat transfer coefficients are typically quite high (30 to $60 \mathrm{Btu} / \mathrm{hr} / \mathrm{ft}^{2} /{ }^{\circ} \mathrm{F}$ ). Therefore, means for improving heat transfer rates are needed.

In the MTCI reactor technology, a multiple resonance tube pulse combustor is employed to achieve these goals. Using the resonance tubes as a fire-tube bundle substantially alleviates heat transfer limitations on the flue gas side. This is due to the presence of a vigorous oscillating flow field contained within the resonance tubes. The oscillatory flow field, which causes periodic flow reversal, induces a significant level of turbulence in the boundary layer on the inner walls of the fire tubes. This in turn gives rise to effective heat transfer coefficients $\left(40\right.$ to $\left.508 \mathrm{tu} / \mathrm{hr} / \mathrm{ft}^{2} /{ }^{\circ} \mathrm{F}\right)$, which are about five times higher than that for conventional fire tubes. Thus, the characteristics of the pulse-enhanced, indirectly heated gasifier overcomes many of the limitations of state-of-the-art, indirectly heated gasifier systems. 


\subsection{BLACK LIOUOR RECOVERY}

More than 50 percent of the pulp produced in the United States is made by the Kraft process in more than $100 \mathrm{mills}$. A simple schematic of a typical Kraft mill is presented in Figure 3-1. In this process, wood chips and "white liquor," a solution of sodium sulfide and sodium hydroxide, are fed to Kraft digester, where elevated temperature and pressure causes the lignin to separate from the cellulosic fibers in the wood. The fibers are washed, refined, and fed to the paper machine. The residual liquor, known as "black liquor," is concentrated from a solids content of below 15 percent to about 62 to 65 percent in multiple effect evaporators, and is combusted in a Tomlinson recovery boiler. The combustion takes place in two stages. In the lower section, the black liquor is burned substoichiometrically, producing a "smelt" containing the sodium and sulfur in reduced form. The combustion is completed in the upper volume of the boiler by adding air, producing a significant quantity of steam for use elsewhere in the plant. Common recovery boilers produce 600 to 900 psi steam, but more modern boilers can produce steam up to $1500 \mathrm{psi}$. The smelt is recovered from the bottom of the boiler where it falls into water and dissolves to become "green liquor." This material is causticized with lime to become the "white liquor" that is fed back to the digester. Thus, the recovery boiler extracts useful energy and chemicals from the black liquor stream. This fundamental process has been used by the industry since the 1920 s and has emerged as the dominant technology in the production of Kraft paper. Many investigations into alternatives to the Tominson furnace have been undertaken, but none have been successful.

The hydration of smelt is an extremely exothermic process and, as a consequence, the lower region of the boiler represents a relatively high hazard potential. Rupture of a boiler tube can produce catastrophic failure of the boiler and even explosion; about three recovery boilers are damaged or destroyed each year throughout the industry by such failure. Coupled with the fact that there is an increasing tendency in the industry to select larger boilers and higher pressures, the risk of disrupting production becomes relatively high and very costly. As a result, Tomlinson boilers tend to be operated conservatively in terms of energy efficiency to reduce this risk.

Because the char bed of a conventional recovery boiler operates at high temperature, volatilization of sodium occurs at a high rate. The sodium condenses in cooler regions of the furnace where it captures $\mathrm{SO}_{2}$ emitted during the combustion process. A large fraction of these particulates are recovered in an electrostatic precipitator (ESP) where it is recycled to the process. However, significant levels of $\mathrm{SO}_{2}$ and submicron fume particles also escape to the atmosphere. In addition, fume generation causes severe fouling problems in recovery boiler convective regions. It has been noted that over 50 percent of North American recovery boilers are capacity-limited due to fire-side deposits. 


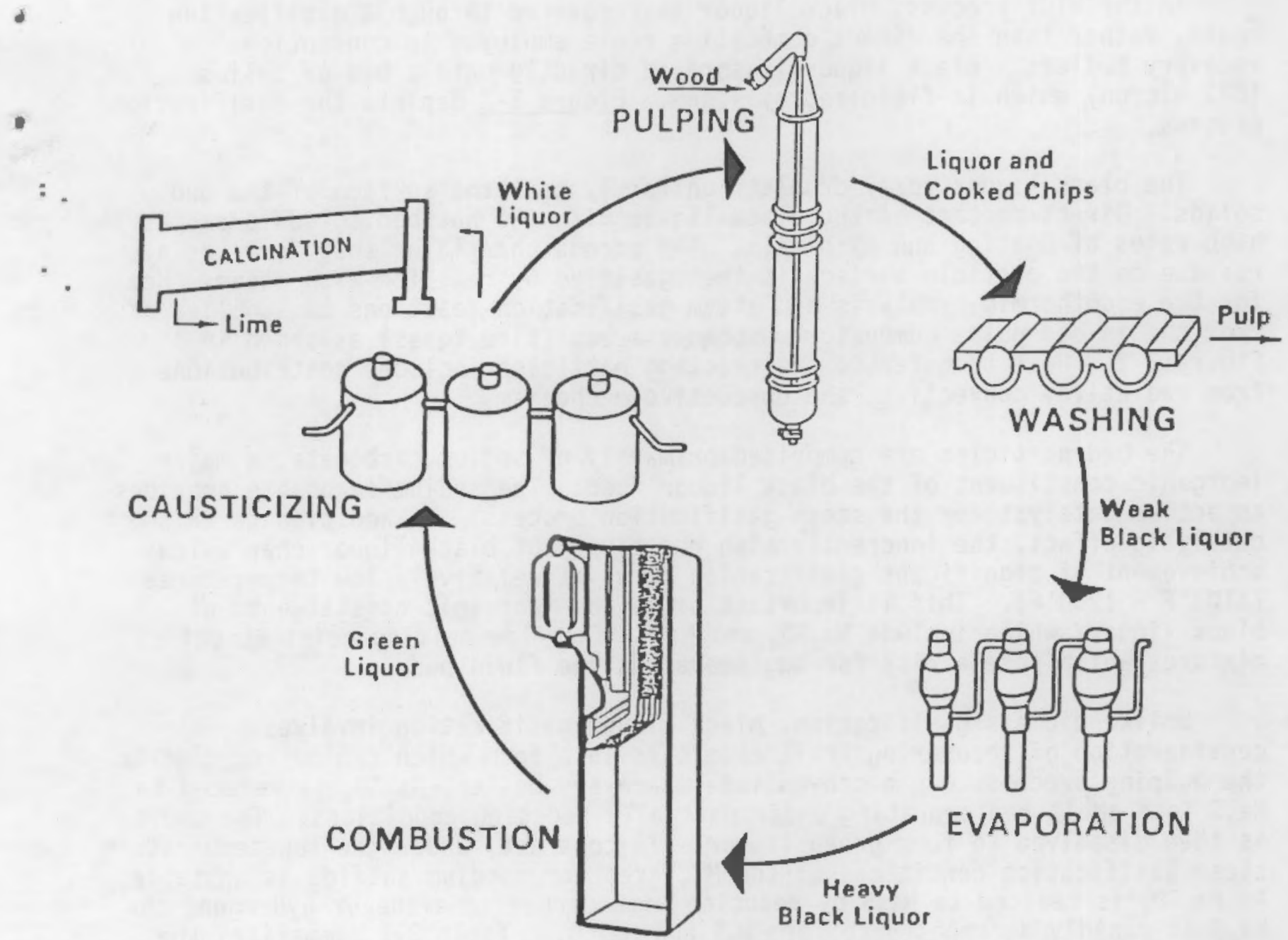

FIGURE 3-1: KRAFT CHEMICAL RECOVERY CYCLE 
Finally, conventional recovery boilers can only be economically constructed in large sizes due to their complexity. Therefore, expansion of plant capacity in small increments is very difficult. For the above reasons, the paper industry has actively searched for alternatives to the conventional black liquor recovery route. One objective of this program was to characterize the performance of the MTCI indirect gasifier for application to black 1iquor recovery.

In the MTCI process, black liquor is recovered through a gasification route, rather than the direct combustion route employed in conventional recovery boilers. Black liquor is sprayed directly onto a bed of solids (600 micron) which is fluidized by steam. Figure 3-2 depicts the gasification process.

The black liquor spray droplets uniformly coat the surface of the bed solids. Direct contact of the black liquor with the hot bed solids promotes high rates of heating and pyrolysis. The porous char layer that forms as a residue on the particle surface is then gasified by reaction with steam. Heat for the endothermic pyrolysis and steam-gasification reactions is supplied from the in-bed pulse combustor resonance tubes (fire tubes) as shown in Figure 3-2. Heat transfer to the reacting particles includes contributions from radiative, convective, and conductive mechanisms.

The bed particles are comprised primarily of sodium carbonate, a major inorganic constituent of the black liquor feed. The sodium carbonate provides an active catalyst for the steam-gasification process. In addition to this catalytic effect, the inherently high reactivity of black liquor char allows achievement of significant gasification rates at relatively low temperatures $\left(1100^{\circ} \mathrm{F}-1200^{\circ} \mathrm{F}\right)$. This is important since the inorganic constituents of black liquor, which include $\mathrm{Na}_{2} \mathrm{SO}_{4}$ and $\mathrm{NaCl}$, form low melting point eutectic mixtures which pose a risk for agglomerating the fluid bed.

Unlike biomass gasification, black liquor gasification involves consideration of recovering Kraft chemicals in a form which can be recycled to the pulping process. In a conventional recovery boiler, $\mathrm{Na}_{2} \mathrm{SO}_{4}$ is reduced to $\mathrm{Na}_{2} \mathrm{~S}$ in a smelt bed operating under partially reducing conditions. The smelt is then dissolved to form green 1iquor. In contrast, under the low-temperature steam gasification conditions of the MTCI reactor, sodium sulfide is unstable. As $\mathrm{Na}_{2} \mathrm{SO}_{4}$ is reduced to $\mathrm{Na}_{2} \mathrm{~S}$ by reaction with carbon monoxide or hydrogen, the $\mathrm{Na}_{2} \mathrm{~S}$ is rapidly decomposed to form $\mathrm{H}_{2} \mathrm{~S}$ and $\mathrm{Na}_{2} \mathrm{CO}_{3}$. Table 3-1 summarizes the major sulfur reactions occurring in the MTCI gasification process.

\section{TABLE 3-1: PRIMARY SULFUR REACTIONS IN INDIRECT BLACK LIOUOR GASIFIER}

1. Lignin $\longrightarrow$ Organic Sulfides $+\mathrm{H}_{2} \mathrm{~S}$

2. Organic Sulfides $+\mathrm{H}_{2} \mathrm{O} \longrightarrow \mathrm{CO}, \mathrm{CO}_{2}, \mathrm{H}_{2}+\mathrm{H}_{2} \mathrm{~S}$

3. $\mathrm{Na}_{2} \mathrm{~S}+\mathrm{H}_{2} \mathrm{O}+\mathrm{CO}_{2} \longrightarrow \mathrm{Na}_{2} \mathrm{CO}_{3}+\mathrm{H}_{2} \mathrm{~S}$

4. $\mathrm{Na}_{2} \mathrm{SO}_{4}+4 \mathrm{CO} \longrightarrow \mathrm{Na}_{2} \mathrm{~S}+4 \mathrm{CO}_{2}$

5. $\mathrm{H}_{2} \mathrm{O}+\mathrm{CO} \longrightarrow \mathrm{CO}_{2}+\mathrm{H}_{2}$ 


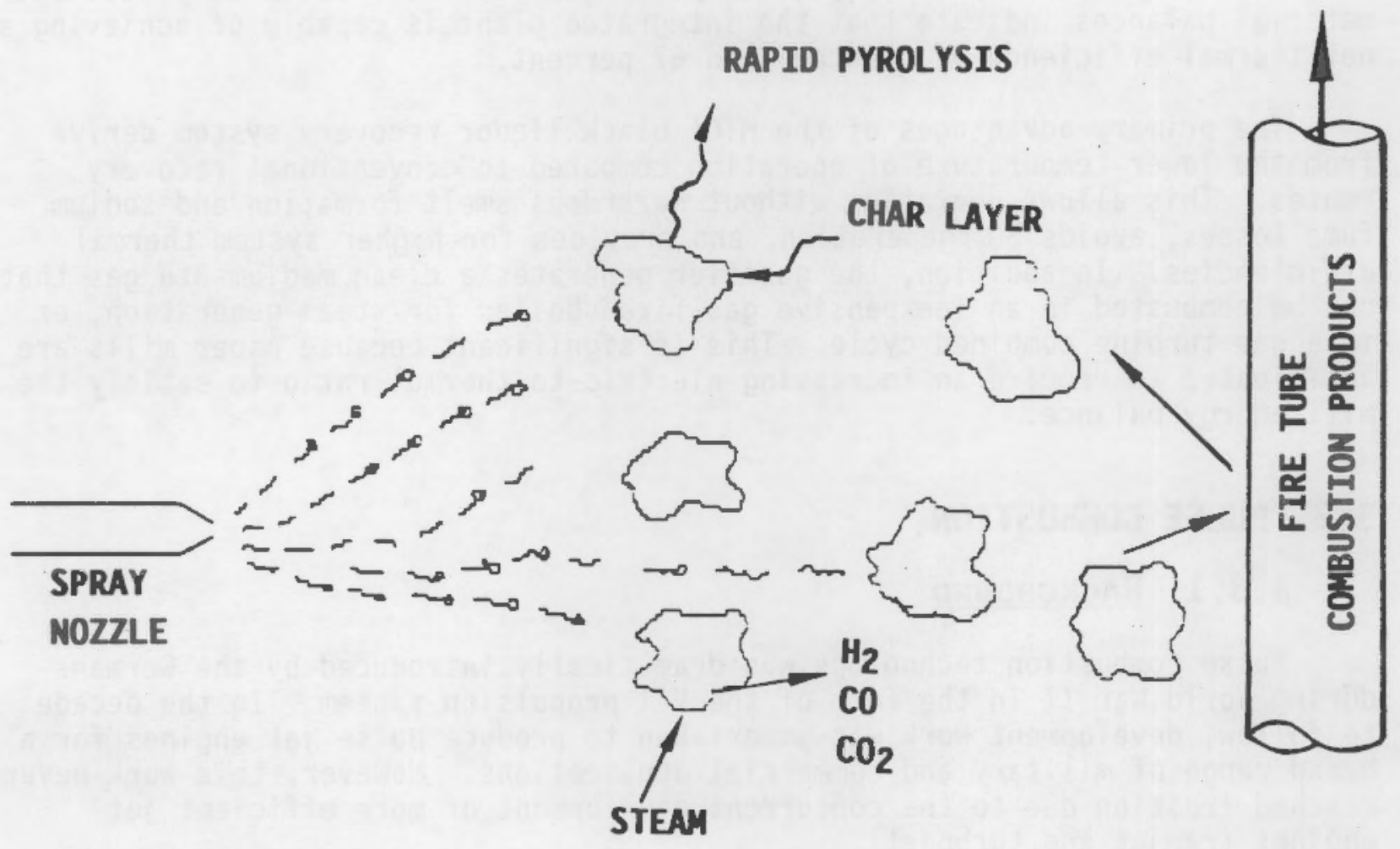

FIGURE 3-2: PRINCIPLE OF OPERATION 
A conceptual configuration for an integrated recovery process based on the indirect steam gasifier is shown in Figure 3-3. Black liquor is introduced into the gasifier and reacted with steam to generate a producer gas. The producer gas is cooled in a heat recovery steam generator (HRSG) before entering a scrubber. Dry sodium carbonate solids are discharged from the gasifier and dissolved to form an alkaline solution. This solution is then employed to scrub the producer gas of hydrogen sulfide and regenerate the green liquor. The scrubbed fuel gas is then combusted in a gas-fired boiler to generate steam for process use and power generation. Preliminary heat and material balances indicate that the integrated plant is capable of achieving a net thermal efficiency of greater than 67 percent.

The primary advantages of the MTCI black liquor recovery system derive from the lower temperature of operation compared to conventional recovery routes. This allows operation without hazardous smelt formation and sodium fume losses, avoids $\mathrm{SO}_{2}$ generation, and provides for higher system thermal efficiencies. In addition, the gasifier generates a clean medium-Btu gas that can be combusted in an inexpensive gas-fired boiler for steam generation, or in a gas turbine combined cycle. This is significant because paper mills are anticipated to require an increasing electric-to-thermal ratio to satisfy the mill energy balance.

\subsection{PULSE COMBUSTION}

\subsubsection{BACKGROUND}

Pulse combustion technology was dramatically introduced by the Germans during World War II in the form of the V-l propulsion system. In the decade to follow, development work was undertaken to produce pulse jet engines for a broad range of military and commercial applications. However, this work never reached fruition due to the concurrent development of more efficient jet engines (ramjet and turbojet).

During the $1950 \mathrm{~s}, 1960 \mathrm{~s}$, and 1970s, numerous programs were conducted in the U.S. and other countries aimed at developing a variety of systems employing pulse combustion. These products included portable heaters, fog generators, hot water heaters, forced-air furnaces, and dryers. Several pulse combustion products are now being commercially offered.

\subsubsection{Types of PULSE COMBUStORs and Their OPERATION}

Pulse combustors can be divided into two general classes: those in which the pulsations occur "naturally" due to combustion-induced oscillations and those that require an external device, such as a spark plug or a rotating valve to maintain pulse combustion. Since the majority of the practical combustors developed to date belong to the first class, the remainder of this section will focus on these combustors, which can be referred to as "selfinduced" or resonating pulse combustors. 


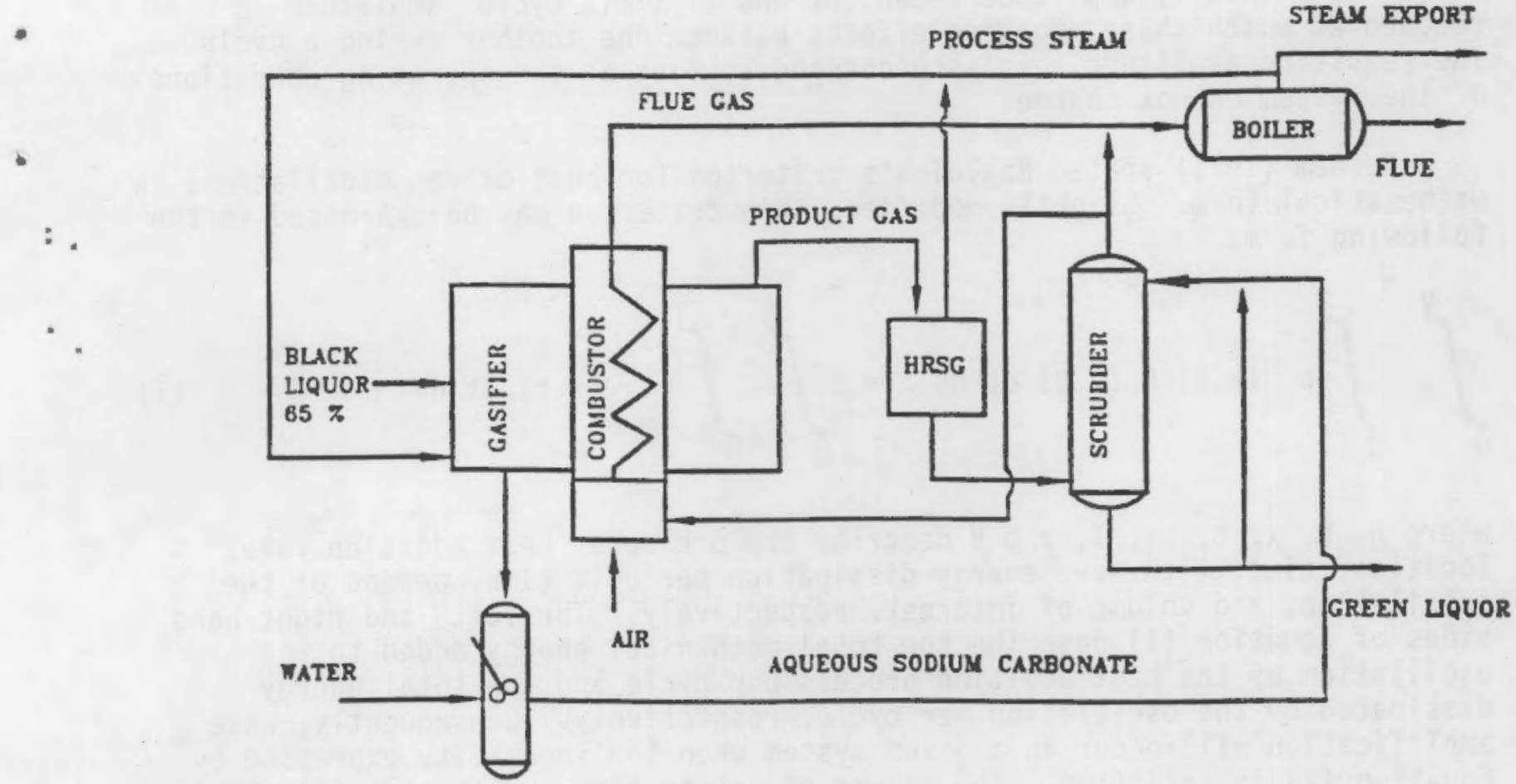

FIGURE 3-3: INTEGRATED BLACK LIQUOR RECOVERY PLANT EMPLOYING INDIRECT GASIFIER 
Investigations of pulse combustors indicate that the combustion process is the source of the energy needed for maintaining the pressure oscillations. To attain pulse combustor operation, it is required that during the initial phase of the pulsations, the energy provided by the combustion process per cycle be larger than the energy lost per cycle due to viscous dissipation, heat transfer, acoustic radiation, and so on. In general, as the amplitude of the oscillation grows, the various energy addition and dissipation processes become non-linearly amplitude dependent and a "limit cycle" amplitude is reached at which these opposing effects balance one another during a cycle. The resulting amplitude remains unchanged as long as the operating conditions of the system do not change.

Putnam (1971) stated Rayleigh's criterion for heat-driven oscillations in mathematical form. Slightly modified, this criterion may be expressed in the following form:

$$
\int_{0}^{y} \int_{0}^{J} p(x, t) Q(x, t) d t d V>=\int_{0}^{y} \int_{0}^{T} L_{i}(x, t) d t d V
$$

where $p, q, x, t, L_{i}, T$, and $V$ describe the pressure, heat addition rate, location, time, $i-t h$ wave energy dissipation per unit time, period of the oscillation, and volume of interest, respectively. The left- and right-hand sides of Equation (1) describe the total mechanical energy added to the oscillation by the heat addition process per cycle and the total energy dissipated by the oscillation per cycle, respectively. Consequently, wave amplification will occur in a given system when the inequality expressed by Equation (1) is satisfied. The volume of integration in Equation (1) should include all sections of the system where relevant processes which affect the growth and/or decay rates of the oscillation occur and the summation on the right-hand side should include all wave energy dissipation modes.

Pulse combustors can be divided into three general types that can be distinguished by their configuration and characteristics of oscillation; that is, the Helmholtz-, Schmidt-, and Rijke-type combustors. Among these, the quarter-wave combustors of the Helmholtz and Schmidt type have received the most attention. The Rijke type is a half-wave unit.

The quarter-wave combustor can be considered to consist of three primary components: the inlet valve, the combustion chamber, and the tailpipe or exhaust pipe, sometimes referred to as a resonance tube. The inlet section may consist of mechanical flapper valves that open or close when the combustor pressure is lower or higher than the ambient pressure upstream of the valve. However, in some quarter-wave type combustors, the inlet section consists of an aerodynamic valve which offers a high resistance to backward flow and a low resistance to forward flow. These aerodynamic valves are like fluidic diodes, and perform much the same as the flapper valves but contain no moving parts. 
The operating cycle of an aerovalved quarter-waver pulse combustion system consists of four steps (Figure 3-4). In the first step, the ignition and combustion of the fuel occurs (Figure 3-4[1]). Generally, the fuel ignition is spontaneously triggered by the hot gases from the previous cycle. The combustion of the fuel increases the pressure in the chamber, forcing the burning mixture to move outward (second step) in both directions towards the entrance and exit of the combustion chamber (Figure 3-4[2]). The gases continue to expand and move outward through the resonance tube and the inertia of the gas column ultimately causes the pressure to drop in the combustion chamber. Back flow through the inlet tube is prohibited by the mechanical valve or impeded by the aerodynamic valve. Eventually the pressure falls below atmospheric pressure from the expansion of the products of combustion through the resonance tube. The third step involves the purge and recharge of the combustion chamber (Figure 3-4[3]). The purging and recharging of the combustion chamber occurs by the in-flow of fresh air, due to the negative pressure created within the combustion chamber. The fourth and final step involves the recharge and compression of the new batch of fuel/air mixture (Figure 3-4[4]). The compression of the charge occurs because of the momentum of the back flow through the resonance tube and the forward flow through the air valve where upon the gases meet within the combustion chamber. The momentum effects of the flow cause both the pressure and temperature in the combustion chamber to increase. Finally, spontaneous ignition of the fuel/air mixture occurs, leading to a repeat of the operating cycle.

With respect to the velocity and pressure fluctuations, the combustion chamber behaves as a pressure antinode and a velocity node. In contrast, the end of the tailpipe behaves as a pressure node and a velocity antinode. It is precisely this behavior (i.e., large pressure fluctuations in the combustion chamber translated into large velocity fluctuations in the tailpipe) that allows the tailpipe to be employed as an extremely effective means for heat transfer.

For instance, for a combustor peak pressure fluctuation of $\pm 34.5 \mathrm{kPa}$ ( $\pm 5 \mathrm{psi}$ ), the quarter-wave model predicts a peak velocity fluctuation of $\pm 180 \mathrm{~m} / \mathrm{s}$ ( $\pm 600 \mathrm{ft} / \mathrm{sec}$ ) near the tailpipe exit. This velocity fluctuation occurs at a frequency characteristic of the combustor (typically 30 to 300 cycles per second). These large velocity fluctuations continually scrub the convective heat transfer boundary layer that exists at the inside surface of the resonance tube, thereby significantly enhancing the rate of heat transfer therein.

\subsubsection{Pulse Combustion Advantages}

The use of pulse combustion offers significant advantages for applications to indirectly heated systems. These advantages include the following:

- High volumetric heat release

- Compact size

- Enhanced heat transfer coefficients

- More uniform heat flux distribution

- Pressure boost and self-aspiration 


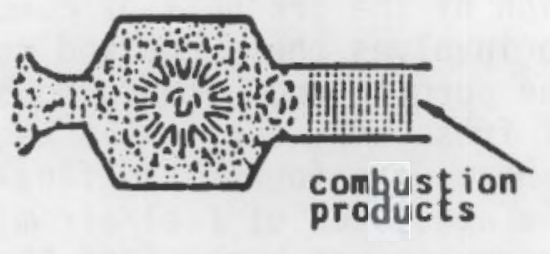

1. Ignition and Combustion

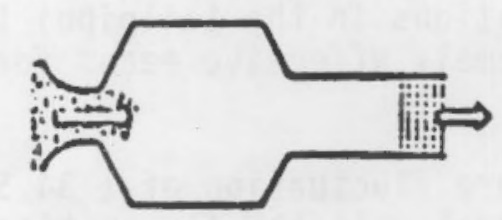

3. Purge and Recharge

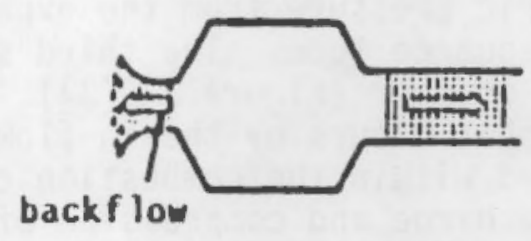

2. Expansion

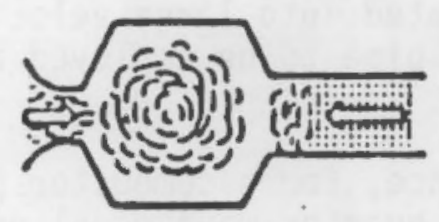

4. Recharge and Compress 
These attributes allow indirect heating to be implemented in a significantly more cost-effective manner than for steady flow conventional combustion systems. In the following section, a description of these advantages is given in more detail.

\section{A. Heat Transfer Coefficients}

Heat transfer coefficients in pulsating flow can exceed those for steady flow systems by a factor of five, within the limits of practical pressure drop constraints. Due to this enhancement effect, pulse combustors have received attention in applications where heat-transfer efficiency is critical, such as in condensing-mode, forced-air furnaces. MTCI is exploiting the properties of pulsating flow to develop an indirectly heated waste gasifier that offers significant economic advantages compared to conventional heat exchange systems or fire tubes.

Modifications of convective heat transfer coefficients in pulsating flow can be explained in terms of the nonlinear relation between heat transfer and stream velocity. The velocity of gas under oscillating flow conditions is given by:

$$
V=V_{m}(1+B(\cos (w t))
$$

Where $B=w A / V_{m}$ is the dimensionless pulsation velocity, $V_{m}$ is the steady-flow velocity component, $W$ is the oscillation frequency, and $A$ is the pulsation amplitude.

Using the quasi-steady state theory (Hanby, 1969), the heat transfer coefficient at any instant can be calculated from the instantaneous velocity through the following relation for turbulent flow:

$$
h D / k=a(\mathrm{CP} \mu / k)^{0.4}(\mathrm{VD} / \nu)^{0.8}
$$

Thus, by integrating over a pulsation cycle, the ratio of the mean pulsating heat transfer coefficient to that under steady-flow conditions is given by:

$$
h / h_{s}=1 /(2 \pi) \int_{0}^{2 \pi}(|1+B \cos (w t)|)^{0.8} d(w t)
$$

This relation is shown to yield approximately linearly increasing enhancement ratios for values of $B$ greater than 1.0 .

\section{B. Heat flux Distributron}

In conventional combustor and fire-tube arrangements, essentially all of the heat is released by burning the fuel in the combustor. The heat is stored in the form of sensible heat in the flue gas which achieves peak temperature at the inlet to the fire tubes. This leads to a high temperature at the inlet region and requires the use of a high-temperature material in a transition section. As heat is transferred from the flue gas to the reactor, its temperature is monotonically reduced along the length of the tube from inlet 
to exit. In the case of a conventional fire tube, most of the heat transfer on the flue gas side of the tube is convective. In pulse combustion, not all of the fuel burns in the combustion chamber and combustion persists down the resonance tubes (fire tubes) for a significant length in an environment of an oscillating flow field.

Thus, for the same heat transfer duty, the inlet flue gas temperature to the resonance tubes is lower than in the case of conventional systems.

However, the continued heat release from fuel burning in the tubes maintains a higher bulk flue gas temperature than in the conventional case where the heat loss from the flue gas is supplied by loss in sensible heat and thus a rapid drop in flue gas temperature. In addition to the higher radiant heat transfer component along the resonance tube, an enhanced convective heat transfer component is also achieved due to the oscillatory flow field of the gases. This results from an increase in both the average (or mean flow) velocity caused by the pressure boost that is induced in the combustion chamber and the superimposed oscillatory velocity component which further increases the rootmean-square flue gas film velocity within the tube. We should note that in a Helmholtz pulse combustor, the oscillatory flow velocity monotonically increases from the resonance tube inlet to the exit. This means that the convective heat transfer coefficient actually increases towards the end of the tube where the temperature-driving forces are at a minimum. Thus, high heat transfer rates are distributed more uniformly down the tube length.

\section{Pressure Boost and Self-Aspiration}

Finally, pulse combustors are self-aspirating devices with an ability to automatically compensate for the appropriate combustion stoichiometry. Unlike conventional fire tubes that represent a flow resistance and thus require the consumption of parasitic power in the form of a forced or induced draft fan, the pulse combustor generates a pressure boost (pulse combustors have been employed as thrust jets). Therefore, the use of pulse combustors may reduce the need for blowers and combustion controls and thus further reduce capital cost. This is particularly significant for small-scale gasifiers where simplicity in ancillary systems and controls is a prerequisite for a costeffective system. 


\section{SECTION 4.0 \\ OVERALL PROGRAM OBJECTIVES \\ AND WORK TASK DESCRIPTION}

The primary objective of this project was the design, construction, and testing of a Process Design Verification System for an indirectly heated, thermochemical fluid-bed reactor and a pulse combustor as an integrated system that can process alternative renewable sources of energy such as biomass, black liquor, municipal solid waste and waste hydrocarbons, including heavy oils into a useful product gas. The technology provides an advanced system for gasification, pyrolysis, and steam-reforming applications.

The innovative design involves two primary components: the indirectly heated fluid-bed reactor and the pulse combustor. The program work scope was intended to provide a technology data base, through gasification of both biomass and black liquor, that will permit the design and operation of these systems at a commercial level of approximately $2,000 \mathrm{lbs} / \mathrm{hr}$ of feedstock.

\subsection{SPECIFIC OBJECTIVES - BIOMASS ENERGY RECOVERY}

The test objectives for the biomass portion of this program were to establish definitive performance data on biomass feedstocks covering a wide range of feedstock qualities and characteristics. The ability to define the range of biomass feeds suitable for gasification in the indirect gasifier was considered essential to this program since many gasification technologies perform well on premium feedstocks, such as dried wood chips, but are unable to handle less optimum feedstocks containing high moisture, high ash contents with low melting temperature ash constituents, or those feedstocks with fluffy, low density, or irregular geometries. Other objectives of these tests were to obtain data over a range of processing conditions, including reactor temperature, throughput rate, and steam-to-biomass ratio for relatively long periods of time.

\subsection{SPECIFIC OBJECTIVES - BLACK LIQUOR RECOVERY}

The specific test objectives for the black liquor gasification tests included the following:

- Verification of improved reactor mechanical design

- Verify operation on commercial black liquor containing 65 percent solids

- Conduct long-duration steady-state gasification tests 
- Conduct higher temperature gasification tests in the regime of $1100^{\circ} \mathrm{F}$ to $1200^{\circ} \mathrm{F}$

- Monitor bed carbon level as a function of gasification conditions

- Monitor bed solids particle size evolution

- Evaluate distribution of sulfur species

\subsection{TECHNICAL TASK STRUCTURE}

The specific technical tasks executed to achieve these objectives are summarized here. Although the work statements for each of the complementary projects funded by the CEC, the Weyerhaeuser Company and the DOE have a different structure, the technical tasks were consistent in the work to be accomplished and are therefore described below as an integrated program encompassing each.

\subsubsection{Establishment of Performance AND DESIGH OBJeCtIVES}

System performance parameters were established based on analys is of the data and design activities compiled in Phase I and II of the SBIR effort. Based on these performance parameters, design requirements were developed for all system components and plant hardware. These included provisions for process controls, instrumentation, and data acquisition.

Performance and design objectives were specified for each type of fuel to be tested and included but were not limited to:

- Air/fuel ratios;

- Fuel feed rates;

- Steam injection rates;

- Energy production rate (in millions of Btu per hour) to be achieved at a specific air/fuel ratio, fuel feed rate and steam injection rate;

- Product gas production rate and energy content (Btu per standard cubic foot);

- Based on previous data, the concentration ( $\left.p p m_{v}\right)$ and distribution of low to high molecular weight hydrocarbons in the product gas;

- Product gas particulate matter concentration and size distribution; and

- Char or ash production rates. 


\subsubsection{Preliminary Design}

A set of preliminary designs for the thermochemical reactor and other support subsystems were developed. The preliminary design included mass and energy balances for the system. In addition, chemical kinetic calculations, subsystem performance sensitivity analysis, environmental impact analysis, safety analysis, and critical materials analysis were made for the overall system and each of the following subsystems:

- System instrumentation and control,

- Fuel feed system,

- Air and steam injection systems,

- Pulse combustor,

- Thermochemical reactor,

- Ash or char handling system, and

- Air pollution (particulate matter) control system.

\subsubsection{Test Plan Development}

A test plan for system testing and evaluation was developed and approved. The plan described the overall objectives of each major phase of testing, and, for each of the subsystems identified in the preliminary design, included performance testing over the full operational range of the system. The plan included a description of each initial fuel to be tested, each test performed, a protocol for conducting the test, equipment necessary, and data to be obtained. As the matrix of biomass fuels processed were increased, the same procedure was followed without modifications to the test plan.

\subsubsection{Final Design}

A set of working final designs including materials selection for the thermochemical reactor and other support subsystems were developed. The final designs of the system included the following:

- Blueprints or detailed drawings of the overall system,

- Individual blueprints and materials specifications for each of the major subsystems, and

- Estimated bills of materials for all major subsystems.

Detailed design specifications for equipment fabrication procurement and for assembly drawings as well as start-up and normal and emergency shut-down procedures were developed.

\subsubsection{Facility Modification and COnstruction}

All facility equipment was fabricated, procured and/or modified in accordance with the final design. All components, equipment, utilities, controls, and instrumentation were installed and assembled. A final component by component operability test was performed to assure safe and proper installation and operation prior to initiating hot test operations. 


\subsubsection{SYSTEM SHAKEdown TESTS}

System shakedown tests were conducted to verify performance and proper operation of significant gasifier subsystems including instrumentation, pulse combustor, fluid bed reactor, feeding system and emission control system. A more detailed breakdown of these activities is as follows:

- Instrument calibration including thermocouples, DP cells, flow meters, gas chromatograph and gas analyzers, pressure transducers and data acquisition system;

- Pulse combustor subsystem testing including ignition tests' combustor tuning tests and final combustor performance characterization;

- Emission control system checkout including flare incinerator, flue gas scrubber, scrubber effluent analyzer, and scrubber quench tank control loop;

- Fluid-bed reactor testing including hot and cold reactor leak test, reactor fluidization tests with both sand and sodium carbonate and checking the cyclone particle capture efficiency;

- Testing the reactor feed subsystems including the boiler and steam trim heaters, rotary lockhopper biomass feeder system and a black liquor feeding system.

These tests were performed in both cold and hot modes to assure proper operation of the facility as a system. The shakedown tests included component off-design operation to assure satisfactory performance of the safety and control equipment. A final system test was performed to assure that all subsystems and controls were operating within the required range of performance.

\subsubsection{SYSTEMS TESTS}

A series of experimental gasifier system characterization tests were conducted to define an envelope of feasible operating conditions for the gasification system. During these tests, gasifier performance was monitored over a range of key operating variables. Significant operating variables were examined and evaluated including gasifier feed rate, steam-to-feed rate, bed temperature and pulse combustor tube temperature. Tests were conducted with both black liquor, paper mill waste sludges and several biomass feedstocks which included wood chips, rice hulls, pistachio shells, orchard prunings and bagasse.

\subsubsection{Data Reduction and Analysis}

Analysis of the data from the short-term tests was used to identify ideal operating conditions for long-term, steady-state gasification experimental tests. 
Data logs for each test were kept and the original data set for each test and each operation (facility shakedown, cold checkout, test series, etc.) were maintained and controlled. Data reduction and analysis were performed on a continuous basis during the test series and compared with the predicted values. Data anomalies were also analyzed and reported.

\subsubsection{OTHER}

In addition, many management, reporting and administration tasks were undertaken. Each of these differed for the specific complementary project for each participating funding entity and are therefore not discussed here. 



\section{SECTION 5.0 \\ BIOMASS GASIFICATION TEST PROGRAM}

Two separate pulse-enhanced gasifier systems were constructed under this program. The first unit consisted of a $20 \mathrm{~cm}$ fluid-bed reactor shell enclosing 2 pulse combustor resonance tubes. This unit was employed to define essential gasification process data. The second gasifier consisted of a $46 \mathrm{~cm}$ reactor shel1 containing 8 pulse combustor resonance tubes. The larger unit was sized for a throughput capacity of $200 \mathrm{lb} / \mathrm{hr}$ and was intended to provide scale-up design criteria for integration of large, multi-tube heat exchange bundles. Both of these reactors shared essentially similar basic designs.

\subsection{TEST SYSTEM DESCRIPTION}

\subsubsection{Gasification TESt RIg}

The main components of the gasifier test rigs are shown in Figure 5-1. For biomass tests, a slide gate lock hopper and metering screw feeder $(X-1)$ were employed. Biomass material was fed directly into the fluidized bed. The feeder, which was modified for this work, was originally designed by Tom Miles, consultant to the current project, and used in conjunction with Solar Energy Research Institute's (SERI) down-draft gasifier.

Steam for fluidizing the gasifier was generated in boiler $\mathrm{H}-1$. Steam was introduced into the bed through a series of sparge tubes uniformly spaced around the lower circumference of the gasifier. Steam flow rates were measured using a metering orifice. The fluid bed solids consisted of a commercial MW 15-40 grade calcium carbonate with an average initial particle size of 750 microns. The particle size distribution for the bed solids is shown in Table 5-1. The bed was maintained at a height of approximately five feet.

Gasification products from R-1 entered a hot cyclone V-2 for disengaging entrained solids. Solids retained in $V-2$ were discharged to a receiving catch-drum $V-3$. The cyclone dipleg was furnished with a set of gate valves and a Y-branch to allow instantaneous sampling of cyclone solids.

The product gases were then directed to an incinerator $\mathrm{H}-2$. A natural gas burner was continuously fired, and temperatures of greater than $1600^{\circ} \mathrm{F}$ at a residence time of at least two seconds were maintained for complete combustion of the product gases.

The combustion products then entered a scrubber through which an alkaline scrubbing media was circulated. The $\mathrm{pH}$ of the scrubbing media was regularly monitored to ensure high scrubbing efficiency for $\mathrm{SO}_{2}$. The cooled and scrubbed gases were then vented through a roof-mounted induced draft fan. 


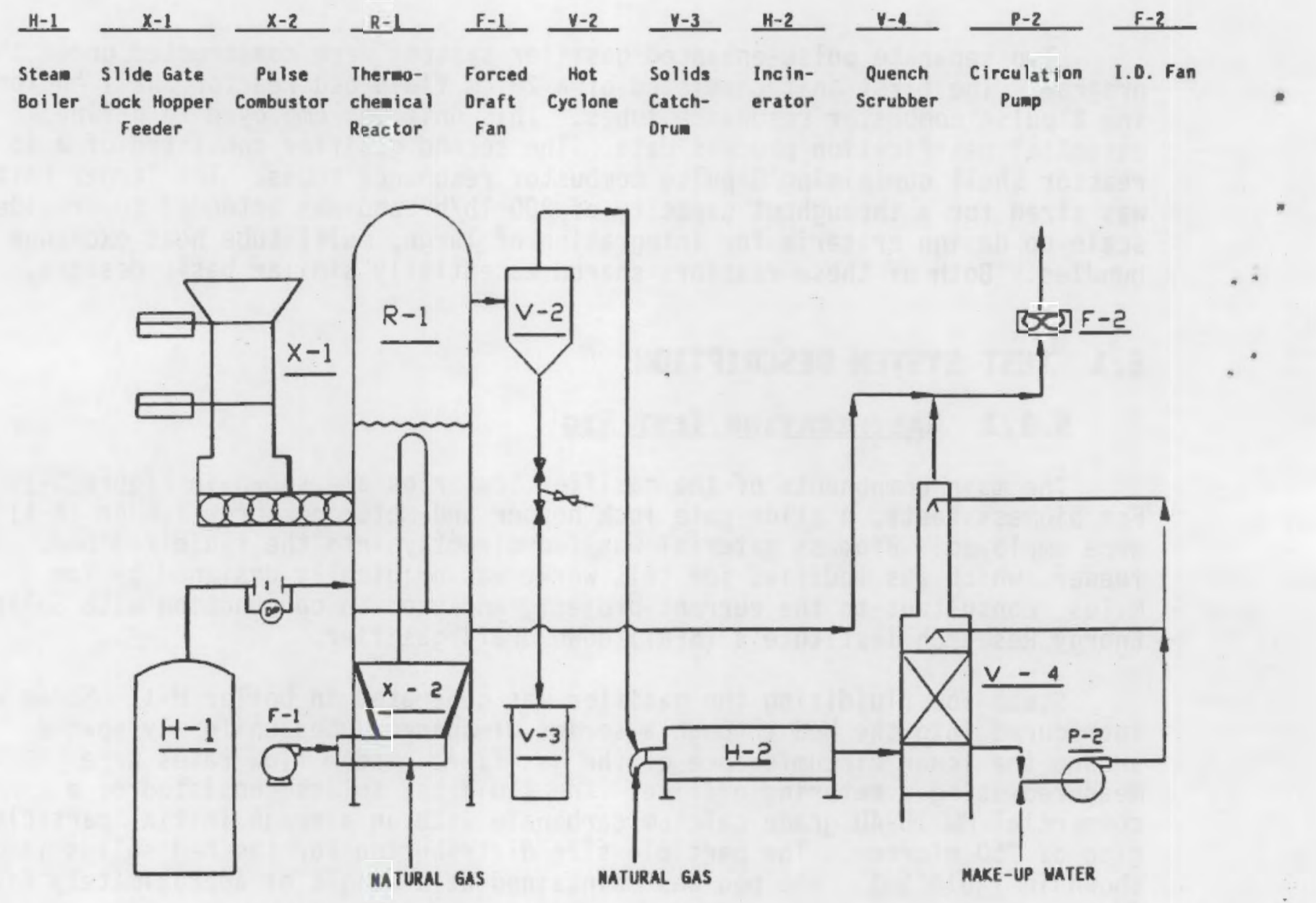

FIGURE 5-1: PROCESS DIAGRAM FOR BIOMASS GASIFIER 


\title{
TABLE 5-1: PARTICLE SIZE DISTRIBUTION FOR BED SOLIDS
}

\begin{tabular}{cc}
$\begin{array}{l}\text { U.S. SIZE } \\
\text { MESH NO. }\end{array}$ & $\begin{array}{c}\text { DIAMETER } \\
\text { MICRON }\end{array}$ \\
\cline { 2 - 2 } 14 & 1400 \\
20 & 850 \\
30 & 600 \\
40 & 425 \\
50 & 300 \\
70 & 212 \\
-70 & 212 \\
\end{tabular}

\author{
\% 4 T. \\ RETAINEO \\ 0.13 \\ 72.30 \\ 21.30 \\ 5.50 \\ 0.44 \\ 0.05 \\ 0.24
}

\subsubsection{Two-Tube GASIFIER}

In the initial configuration for the two-tube reactor, a separate baremetal pulse combustor was furnished for each resonance tube. This configuration, which was employed for the black liquor gasification tests, is shown in Figure 5-2.

Although the reactor performed well for the duration of the black liquor gasification tests, several modifications were made to further improve its performance for the biomass gasification tests. These modifications included increasing the internal resonance tube pipe diameter from $3 / 4$ inch to 1 inch. This modification was made to allow higher firing rates to be achieved in each tube and thus allow higher biomass throughput rates. The increased tube diameter allowed firing rates of 100,000 Btu per tube compared to only 60,000 Btu per tube for the 3/4-inch pipe.

Second, the two bare metal pulse combustors were replaced with a single refractory-1ined chamber that was bolted to the base of the gasifier and communicated with each of the two resonance tubes. This modification was made to increase the life of the combustor and to test a configuration more closely resembling that which is anticipated for use in a commercial prototype which will employ multiple resonance tubes $(20$ - 30) emanating from a single combustor. The two-tube gasifier shell was approximately $20 \mathrm{~cm}$ ( $8^{\prime \prime}$ ) in diameter. The shell contained a biomass injection port located approximately mid-height in the fluid bed. In addition, a screw discharge valve was furnished on the shell to allow regular sampling of the carbon content within the fluid bed. A photograph of the installed two-tube gasifier test rig is shown in Figure 5-3.

\subsubsection{EIght-Tube SCALe-Up Gasifier}

An eight-tube scale-up gasifier was constructed and tested to verify the mechanical and process scale-up of the indirectly heated, pulse-enhanced gasifier concept. The gasifier design is depicted in Figure 5-4 through Figure 5-7. 


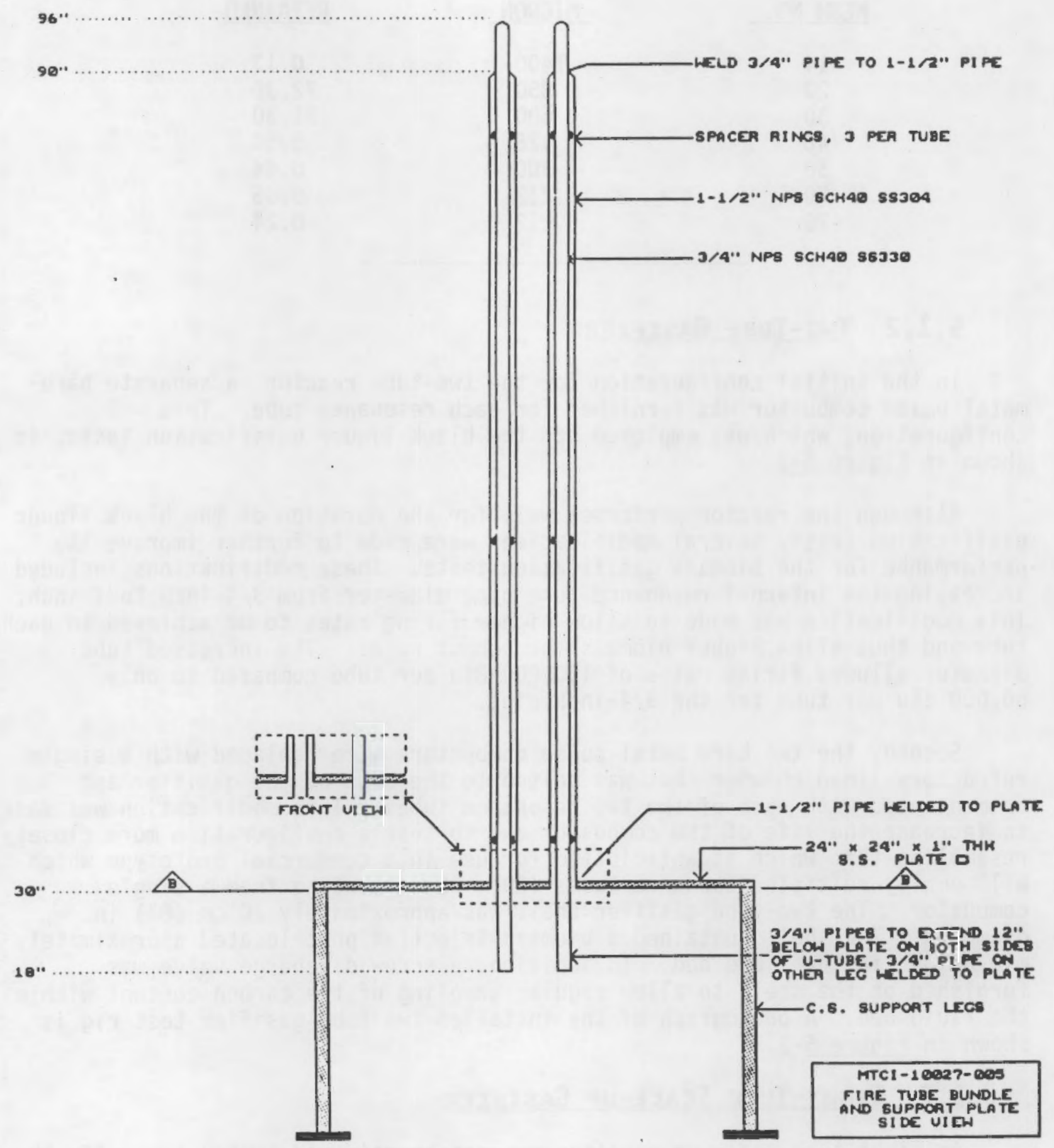

FIGURE 5-2: TWO-TUBE REACTOR SYSTEM (TUBES ONLY) 


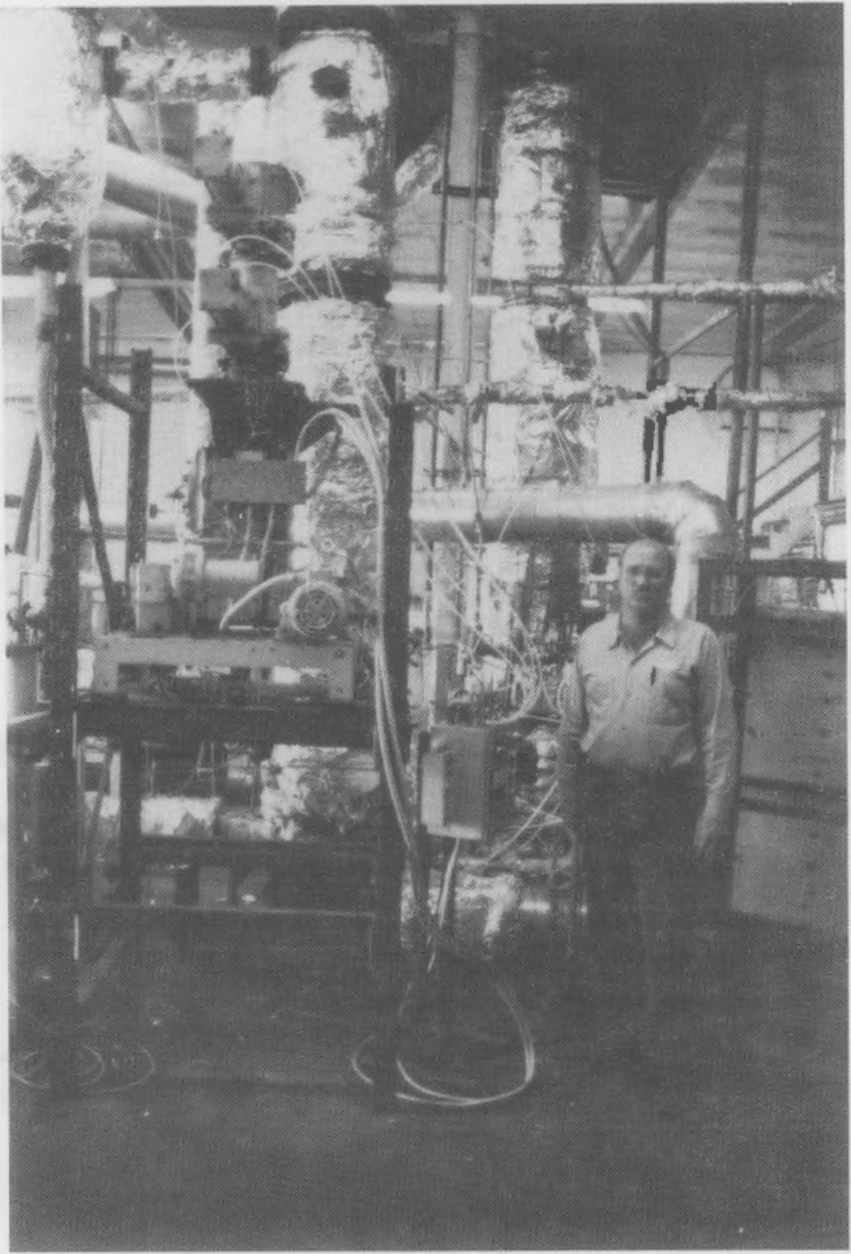

FIGURE 5-3: TWO-TUBE GASIFIER TEST RIG 


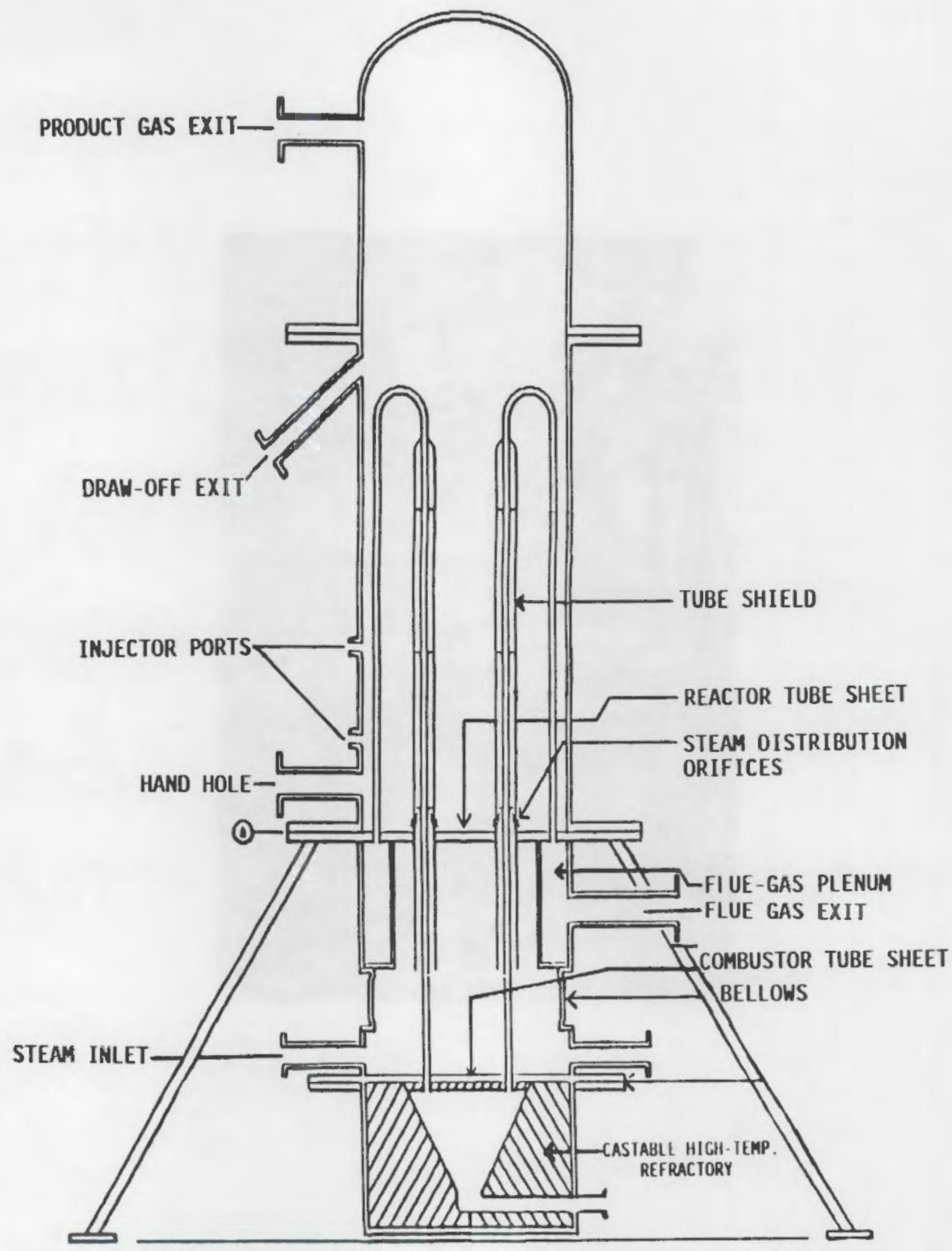

FIGURE 5-4: REACTOR GENERAL LAYOUT 


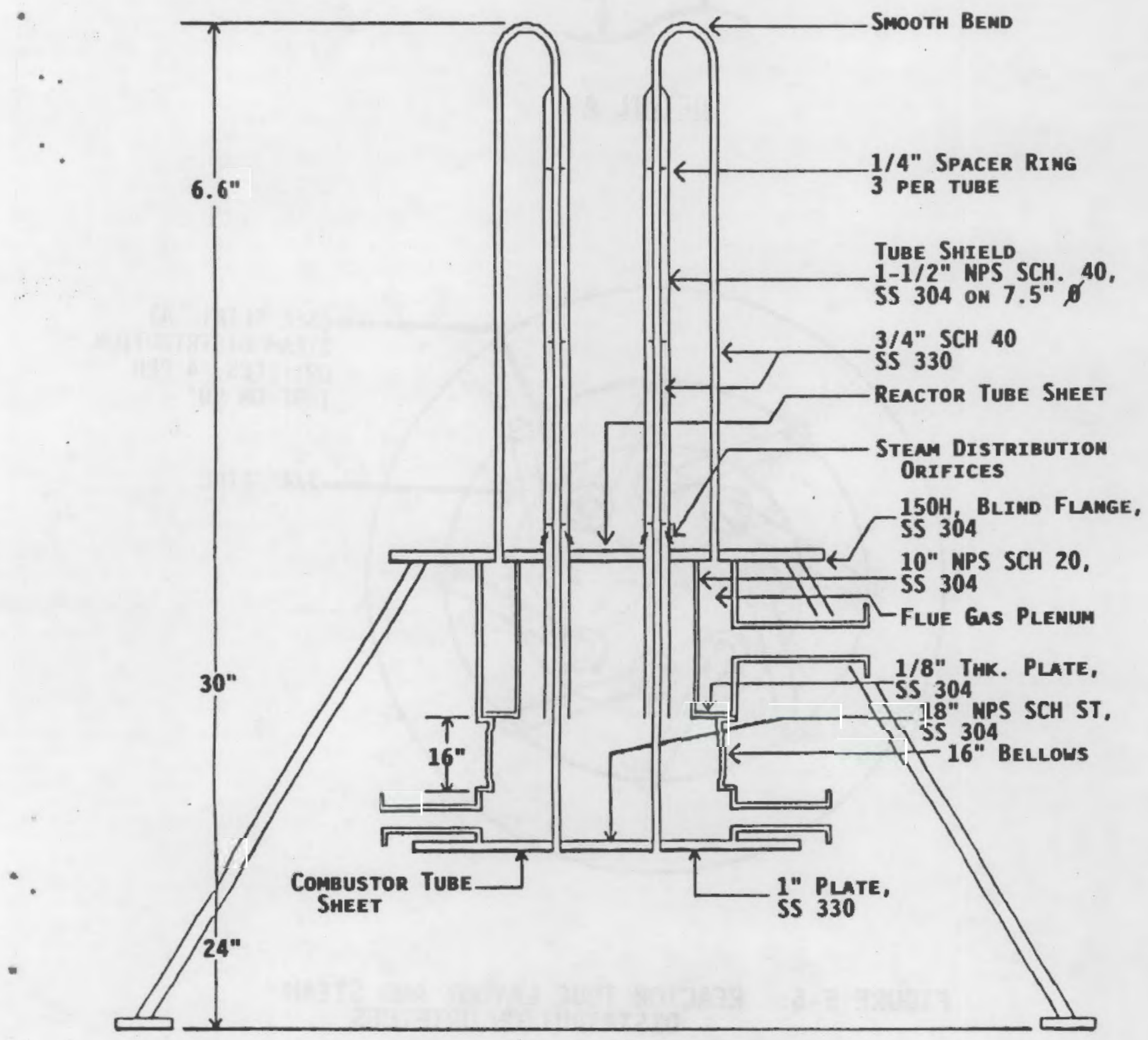

FIGURE 5-5: FIRE-TUBE BUNDLE 


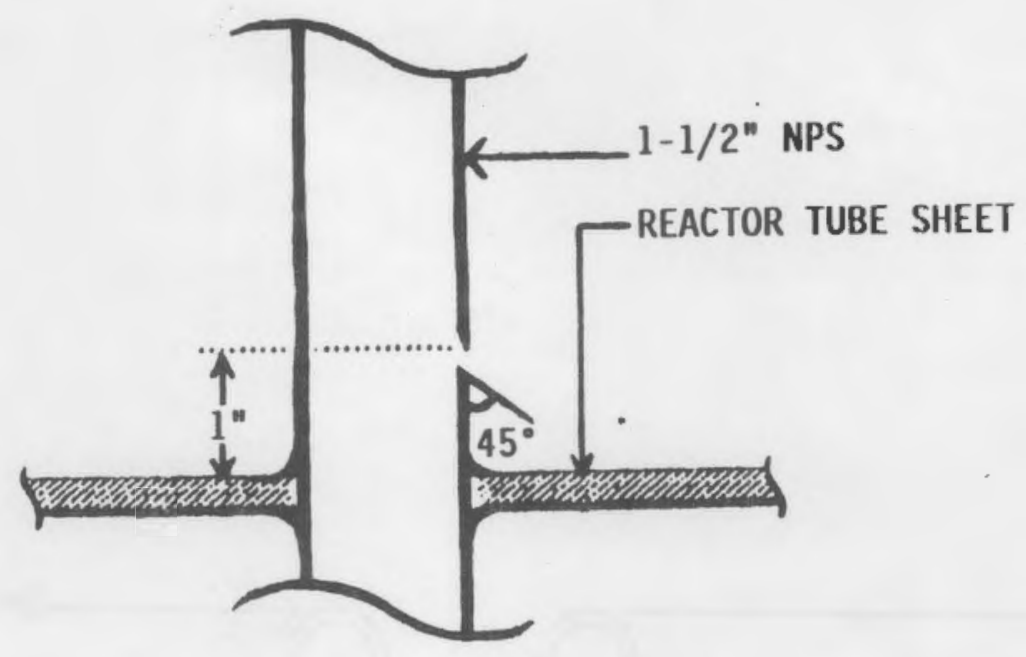

\section{DETAIL A}

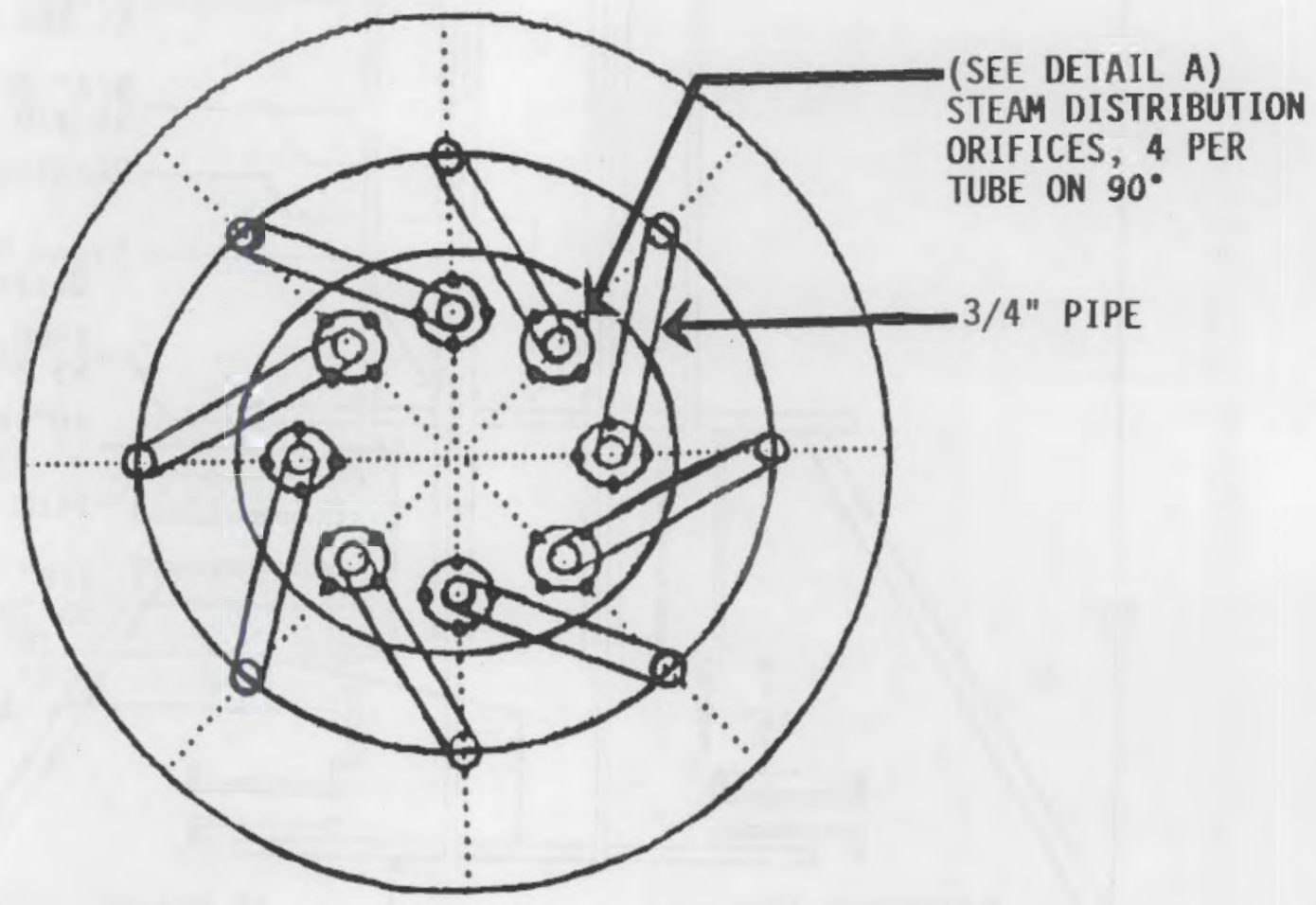

FIGURE 5-6: REACTOR TUBE LAYOUT AND STEAM DISTRIBUTIDN ORIFICES 


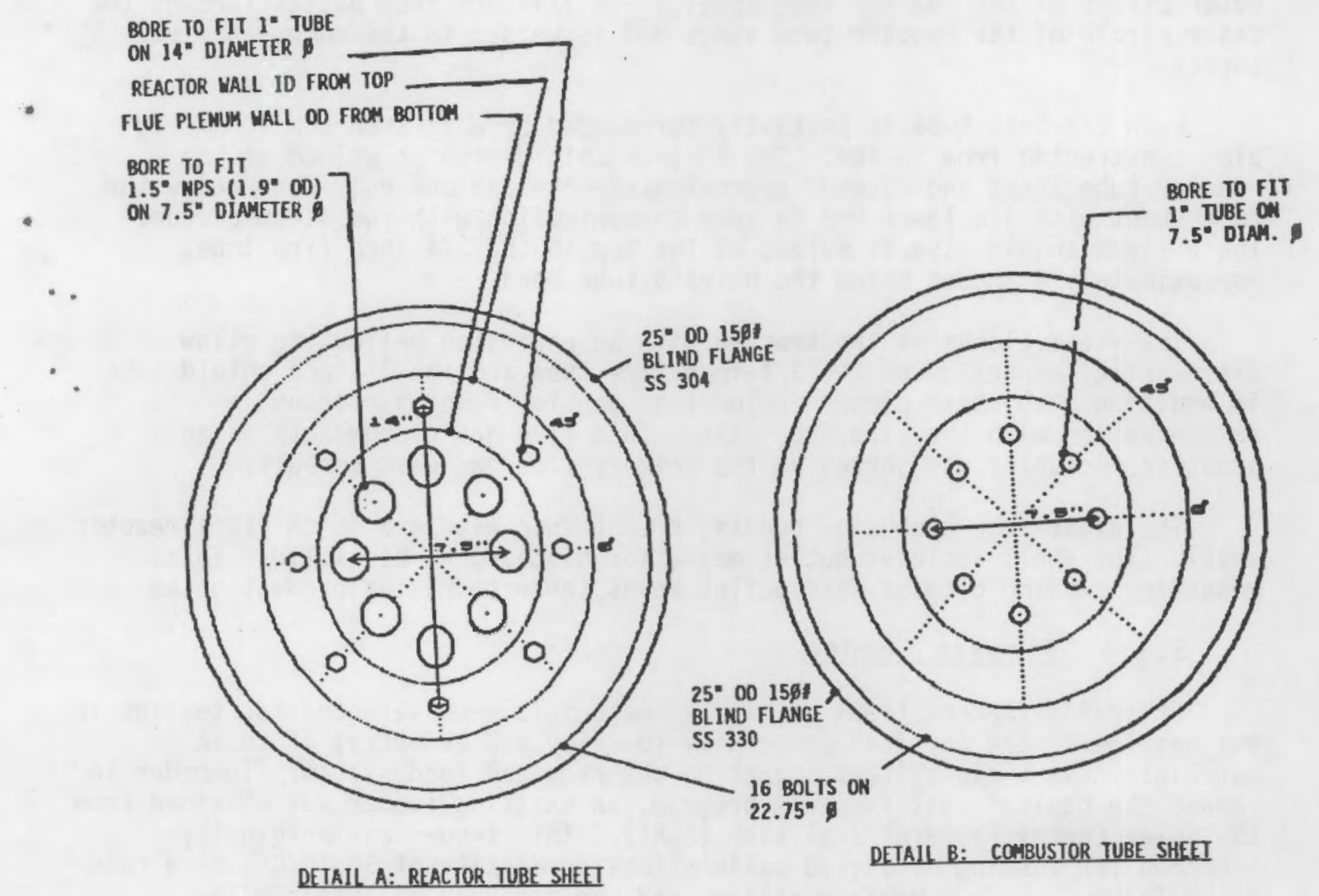

FIGURE 5-7: REACTOR AND COMBUSTOR TUBE SHEETS 
The eight-tube gasifier consisted of a multiple resonance tube bundle communicating with a single refractory-lined pulse combustor. The fire-tube bundle was constructed from eight $3 / 4$-inch sch 40 pipes consisting of SS 330 high alloy material. The $3 / 4$-inch tubes were bent in a smooth radius to form a hairpin-type heat exchange surface. One end of the tubes were welded to the outer circle of the reactor tube sheet. The $3 / 4$-inch tube passes through the inner circle of the reactor tube sheet and is welded to the combustor tube sheet.

Each 3/4-inch tube is partially surrounded by a 1 -inch sch 40 shield pipe constructed from SS 304 . The 1 -inch shield pipe is welded at the reactor tube sheet and extends approximately one and one-half feet below the tube sheet with its lower end in open communication with the steam plenum. The 1 -inch shield pipe is welded at the top to the $3 / 4$-inch fire tube, approximately 4 inches below the hairpin tube bend.

The steam plenum is constructed with an expansion bellows to allow differential expansion of the 3/4-inch fire tube and the 1 -inch shield tube. * In addition, the steam plenum includes an annular flue gas plenum in communication with the fire-tube exit. This flue gas plenum acts as an acoustic decoupler and serves as the primary flue gas exit conduit.

The eight-tube combustor bundle is contained within a $46 \mathrm{~cm}$ (18") reactor shel1. The shell includes outlet means for discharging bed solids, inlet means for feeding biomass, and outlet means for withdrawing product gases.

\subsubsection{Biomass Feeder}

Several different types of biomass materials were selected for testing in the gasifier. The physical properties (density and geometry) of these materials have a significant impact on the required feed system. In order to reduce the capital cost for this program, an existing feeder was obtained from the Solar Energy Research Institute (SERI). This feeder was originally intended for feeding densified pellets (having density of $30 \mathrm{lb} / \mathrm{CF}$ ) at a rate of $40 \mathrm{lb} / \mathrm{hr}$ to a down-draft gasifier, and was designed by Thomas Miles Consulting Engineers. Since the feeder for this project was required to supply $100-200 \mathrm{lb} / \mathrm{hr}$ of lower density material $(8-29 \mathrm{lb} / \mathrm{CF})$ to the gasifier, several modifications were required. In the following sections, a description of the original design is made and the required modifications are highlighted.

The original feeder is comprised of a dual pneumatic gate lock hopper assembly. The purpose of the lock hopper is to pressurize the system and prevent escape of any gases from the gasifier. The lock hopper assembly is located directly above the metering bin. The capacity of the metering bin is approximately $1.4 \mathrm{CF}$. The bin has two dielectric sensors which indicate whether the bin is full or empty. When the level in the bin drops below the lower level sensor, a relay will energize to open the lower gate valve and close the upper valve. The material then flows from the lock hopper into the bin. The relay will remain energized until the bin has been filled to the upper level sensor. At this point, the relay will be de-energized and it closes the lower gate and opens the upper gate so that the lock hopper can be refilled. The metering bin contains three $141 / 2$-inch long metering screws 
with 2 5/8-inch outer diameter and $13 / 4$-inch pitch. The screws are powered by a $1 / 3$ HP electric motor. The metering screws convey the material to a $331 / 2$-inch long injector screw with the same outer diameter and pitch as the metering screws. The injector screw is powered by a 1/4 HP electric motor.

The maximum speed of rotation of the metering screws was designed for $1.75 \mathrm{RPM}$. In order to gear up the feeder for higher feed rates, the $40 \mathrm{~T}$ sprocket originally connected to the metering screw gear box was moved to the reducer and a $10 \mathrm{~T}$ sprocket was placed on the gear box drive shaft. This alteration increased the speed of the metering screws to approximately 19 RPM.

The SERI unit's automatic control relay logic was not functional and buildup of tars in the metering bin also appeared to impede sensor performance. For this reason, operation of the pneumatic slide gates was performed manually for al1 runs. To avoid excessive heating of the injector barrel, a water-cooled sleeve was installed. As a result of these modifications, the feed system proved adequate for the operation of the gasifier.

\subsubsection{Amalytical Gas Sampling Train}

The performance of the gasifier was continuously monitored using a gas chromatographic sampling train which provided detailed information on the product yields for various biomass test runs. Gas samples were withdrawn upstream of the cyclone to minimize the potential for air leakage. The gas was filtered of particulates before being introduced to an indirect cooler/condenser. The sample line was insulated to minimize premature condensation of tars and oils.

The condensate was collected in a primary knock-out pot and then further cooled in an ice bath. The ice bath was followed by a secondary knock-out pot upstream of the vacuum pump. The vacuum pump provided a continuous sample gas stream to the gas chromatograph. A continuous sample gas flow rate was maintained to ensure that the gas sample was representative of the instantaneous gasifier conditions, i.e., sufficiently high purge volume rates, and to ensure that a sufficient draw rate was maintained to allow representative breakthrough of tars and oils.

The tars and oils were collected at regular intervals and sent to an outside laboratory to determine carbon content. The dry gas stream was analyzed by an in-house gas chromatograph. Two separate gas chromatograph systems were available: a Carle unit and a Microsensor (Fremont, CA) unit. Both units were tested to establish the consistency of the gas analyses; however, the bulk of the analyses were performed using the Microsensor unit because of its rapid turnaround time.

\subsubsection{Material Balance Methodology}

An overall material balance was calculated for each of the test runs. The overall material balances provided data on the gas, char, and tar/oil yields. Each of these yields was calculated during this program on the basis of weight percent carbon contained in each fraction.

(3) Carle is a registered trademark of the Hach Company, Loveland, Co. 
The total carbon input for a given run was established based on the mass of feedstock fed to the gasifier and the ultimate analys is of the feed material over the total operating period. At the conclusion of the test run, the total material collected as overflow, cyclone catch, or scrubber bottoms was weighed and analyzed for carbon. The ratio of carbon in these fractions to the total input carbon was defined as the char yield.

In addition, a representative sample of condensate was analyzed for weight percent carbon. Utilizing the information on the dry gas composition and the steam-to-biomass ratio at the gasifier inlet, an estimate of the theoretical ratio of carbon to steam at the gasifier exit was calculated. This ratio, in conjunction with the condensate analysis, was used to calculate the tar/oil yield.

In the following section, test results on the indirectly heated, pulseenhanced gasifier are presented for a wide range of biomass feedstocks.

\subsection{SPECIFIC TEST OBJECTIVES}

The specific test objectives for the biomass portion of this program was to establish definitive performance data on biomass feedstocks covering a wide range of feedstock qualities and characteristics. The ability to define the range of biomass feeds suitable for gasification in the indirect gasifier was considered essential to this program since many gasification technologies perform well on premium feedstocks, such as dried wood chips, but are unable to handle less optimum feedstocks containing high moisture, high ash contents with low melting temperature ash constituents, or those feedstocks with fluffy, low density, or irregular geometries.

It was also the specific objective of these tests to obtain data over a range of processing conditions, including reactor temperature, throughput rate, and steam-to-biomass ratio.

Finally, it was the specific objective of this test program to verify scale-up operation to provide a data base allowing scale-up of the pulseenhanced technology to the field demonstration stage (50 TPD). To accomplish this objective, an eight-tube scale-up gasifier was constructed and tested. The pulse combustor tube bundle was designed for a firing rate of approximately 500,000 Btu/hr. This unit represents a one-third scale model of the pulse combustor module anticipated for use in a 50-TPD biomass gasifier facility. Note that in the 50-TPO gasifier, six such modules would be employed, each module having a nominal firing rate of $1,500,000 \mathrm{Btu} / \mathrm{hr}$.

\subsection{TEST RESULTS}

System testing of the indirectly heated, pulse-enhanced gasifier on biomass feedstocks was performed over a four-month period from October 1988 through January 1989. The test results provided detailed information on system performance, including gas compositions, char and tar/oil yields, and bed carbon inventories. 
In the following sections the test results for biomass gasification will be presented. The discussion will include a description of feedstocks tested, operating history, gas compositions, product yields, and scale-up operation and considerations.

\subsubsection{FeedstOCKS}

Nine different biomass/waste feedstocks were gasified during the test program. These feedstocks covered a wide range of physical and chemical characteristics and encompass the most likely categories of feed types which might reasonably be considered for fuel gas production. The feedstocks tested included:

- Wood chips
- Wood shavings
Orchard prunings
Urban wood waste
- Pistachio shells
- Rice hulls
- Paper mill sludge
- Baper mill sludge with plastics
Basse

The wood shavings were obtained from Lutaz Patterns, located in Santa Fe Springs, California. The wood chips and orchard prunings were supplied through Thomas Miles Consulting Engineers, feed consultant for the project. The orchard prunings were shredded and sized prior to feeding. The pistachio shells were obtained from Keenan Farms, Inc., located in Fresno, California. The urban wood waste (playground mix) was purchased from Artesia Sawdust Products in Gardenia, California. The rice hulls were obtained through Kelly Birkinshaw, Technical Project Officer for the California Energy Commission. The paper mill sludge wastes were obtained directly from a recycle paper mill production line operated by Gaylord Container Corporation in Antioch, California and the bagasse was shipped directly from Hawaian Commercial and Sugar, located in Maui, Hawaii.

The ultimate analysis (MAF wt.\% basis) and the "as received" moisture and ash content for several of these feedstocks are shown in Table 5-2. As seen in the table, the feedstock moisture contents range from approximately 8 to 50 percent. The ash contents range from 0.18 to 20.48 percent, and the sulfur contents range from 0.04 to 0.9 percent.

The paper mill sludge waste is representative of materials discharged from virgin pulp mills and recycle mills located throughout the United States. These sludges typically contain 70 percent moisture as delivered from a belt press. Many mills are currently installing screw presses to reduce the moisture content to 50 percent. The mill sludge waste tested in this program also contained 50 percent moisture and, thus, is similar in characteristics to wastes processed using mechanical screw presses or other similar devices. This material, therefore, offered an opportunity to access the performance of the gasifier on high moisture, organic-containing industrial waste products that are most cost-effectively processed without the benefit of predrying. 
Note that many other gasifiers, such as the air-blown autothermal type, are incapable of maintaining reasonable performance levels utilizing feedstock containing such high moisture contents.

\section{TABLE 5-2: ANALYSIS FOR FEEDSTOCKS TESTED IN PULSE-ENHANCED INDIRECT GASIFIER}

\begin{tabular}{|c|c|c|c|c|c|}
\hline & $\begin{array}{l}\text { PISTACHIO } \\
\text { SHELLS } \\
\end{array}$ & WOOD CHIPS & RICE HULLS & $\begin{array}{l}\text { PAPER MILL } \\
\text { SLUDGE } \\
\end{array}$ & $\begin{array}{l}\text { ORCHARD } \\
\text { PRUNINGS }\end{array}$ \\
\hline & \multicolumn{5}{|c|}{ (Ultimate Analysis, MAF wt.\%) } \\
\hline $\begin{array}{l}\text { Carbon } \\
\text { Hydrogen } \\
\text { Oxygen } \\
\text { Sulfur } \\
\text { Nitrogen }\end{array}$ & $\begin{array}{r}49.51 \\
6.18 \\
43.96 \\
0.11 \\
0.24 \\
\end{array}$ & $\begin{array}{r}49.33 \\
6.74 \\
43.67 \\
0.16 \\
0.10 \\
\end{array}$ & $\begin{array}{r}49.09 \\
6.17 \\
44.19 \\
0.04 \\
0.51 \\
\end{array}$ & $\begin{array}{r}50.00 \\
6.55 \\
42.76 \\
0.31 \\
0.38 \\
\end{array}$ & $\begin{array}{r}51.65 \\
6.26 \\
41.05 \\
0.30 \\
0.74 \\
\end{array}$ \\
\hline TOTAL & 100.00 & 100.00 & 100.00 & 100.00 & 100.00 \\
\hline $\begin{array}{l}\text { Heating value } \\
\text { MAF (Btu/lb) }\end{array}$ & 8349 & 8358 & 8371 & 8836 & 8621 \\
\hline $\begin{array}{l}\text { Ash (as-rec'd wt.\%) } \\
\text { Moisture (as-rec'd } \\
\text { wt.\%) }\end{array}$ & $\begin{array}{l}0.41 \\
8.74\end{array}$ & $\begin{array}{r}0.18 \\
20.46\end{array}$ & $\begin{array}{r}20.48 \\
8.67\end{array}$ & $\begin{array}{r}2.80 \\
49.50\end{array}$ & $\begin{array}{r}1.76 \\
23.99\end{array}$ \\
\hline
\end{tabular}

The orchard prunings, rice hulls, pistachio shells, and bagasses were selected as feed materials representing agricultural waste by-products that are generated in large quantities in agricultural regions and which generally command a relatively low feedstock price. This is due to either their high ash content, low bulk density, and/or difficulty in handling, transporting, or processing the feedstock materials. In addition, the rice hulls were selected due to the low melting temperature of the high ash constituents which have presented particular difficulties in processing these materials in alternative systems.

Finally, the wood chips were selected as representative of premium biomass fuels which might be cultivated for large-scale biomass-to-energy conversion plants sometime in the future when a significant increase in the price differential between petroleum fuels and biomass fuels is anticipated to occur.

\subsubsection{Operating History amd Test Conditions}

System testing on the indirect gasifier was conducted over a period from October 18, 1988 through January 13, 1989. During this period, seven test runs were conducted over a range of processing conditions. In some cases, 
different feedstocks were sequentially fed during a single test run. For instance, on January 13, urban wood wastes were fed followed by a blend of bagasse and orchard prunings. The results of these multiple-feed tests are presented as a cumulative average for the entire run. The test runs covered the following range of process conditions:

$$
\begin{array}{ll}
\text { Feed rate }(1 \mathrm{~b} / \mathrm{hr}): & 17.6-35.5 \\
\text { Steam-to-Feed Ratio: } & 0.73-2.07 \\
\text { Reactor Temperature ( } \left.{ }^{\circ} \mathrm{F}\right): & 1172-1327
\end{array}
$$

Table 5-3 summarizes the operating summary and process conditions for each test run. Each of these test runs represented successful operation of the gasifier concluding with a planned shutdown of the unit. In only one instance was a scheduled test run aborted due to mechanical difficulties. During this aborted test run, a fatigue failure occurred at the hairpin bend of the resonance tube. This failure was attributed to insufficient postannealing of the tube bend. A thermocouple weld-pad located at the 180-degree bend may also have contributed to the failure mode. The tube bend was replaced by two 90-degree weld elbows and no further problems were encountered during the remainder of the test program.

\begin{tabular}{|c|c|c|c|c|c|}
\hline FEEDSTOCK & $\frac{\text { TEMPERATURE }}{\left(^{\circ} \mathrm{F}\right)}$ & $\begin{array}{l}\text { AVERAGE } \\
\text { FEED RATE } \\
(1 \mathrm{~b} / \mathrm{hr})\end{array}$ & $\begin{array}{l}\text { STEAM } \\
\text { RATE } \\
(1 \mathrm{lb} / \mathrm{hr})\end{array}$ & $\begin{array}{l}\text { STEAM TO } \\
\text { BIOMASS } \\
(1 \mathrm{~b} / 1 \mathrm{~b})\end{array}$ & $\begin{array}{l}\text { TOTAL } \\
\text { FEED } \\
\text { (1b) }\end{array}$ \\
\hline Pistachio Shells & 1317 & 35.5 & 26.0 & 0.73 & 337.5 \\
\hline Pistachio Shells & 1216 & 30.8 & 31.5 & 1.02 & 115.5 \\
\hline Sludge Waste & 1250 & 17.6 & 36.5 & 2.07 & 119.0 \\
\hline Wood Chips & 1286 & 22.9 & 31.4 & 1.37 & 206.0 \\
\hline Rice Hulls & 1327 & 30.8 & 26.0 & 0.84 & 185.5 \\
\hline Sludge Waste $w / P l a s t i c s$ & 1290 & 30.0 & 26.0 & 0.87 & 22.5 \\
\hline $\begin{array}{l}\text { Urban Wood, Orchard } \\
\text { Prunings, and } \\
\text { Bagasse (1) }\end{array}$ & $\begin{array}{l}1172- \\
1203\end{array}$ & 23.1 & 22.0 & 0.95 & 139.0 \\
\hline
\end{tabular}

\section{TABLE 5-3: OPERATING SUMMARY AND PROCESS CONDITIONS FOR BIOMASS TEST RUNS}

(1) Cumulative results for all feeds. 


\subsubsection{COMpositions}

The dry gas compositions for the various test runs are summarized in Table 5-4. Note that each of these runs are characterized by a high concentration of hydrogen that ranged from approximately 32 to 50 vol.\%. Methane levels were relatively constant in the range of 8 to 12 vol.\%, and higher hydrocarbons typically ranged from about 1 to 5 vol.\%.

The hydrogen yields for the indirect gasifier are approximately twice that which can be achieved in direct gasification reactors. The high hydrogen yield has important implications for the production of premium methanol fuels from biomass feedstocks. The optimum ratio for hydrogen to carbon monoxide for methanol production is 2.0. As seen in Table 5-4, this ratio is closely achieved in the indirect gasifier. Figure 5-8 shows the hydrogen-to-carbon monoxide ratios for each test run.

In all of the test runs, a high-quality, medium-Btu gas was obtained. The higher heating values of the product gas ranged from $329 \mathrm{Btu} / \mathrm{scf}$ to $435 \mathrm{Btu} / \mathrm{scf}$. In contrast to the direct gasifier, this medium-Btu gas was achieved without the consumption of expensive oxygen.

An important characteristic of the indirect gasifier is the insensitivity of product gas yield to moisture content. While the gas quality deteriorates as moisture content increases in the direct gasification route, moisture content has no significant impact in the indirectly heated gasifier. Fiqure 5-9 clearly shows the insensitivity of gas heating value to feedstock moisture content.

Heating value does show a dependence on gasifier temperature, however. As shown in Fiqure 5-10, the gas heating value diminishes with increasing temperature. This trend, which was also observed for black liquor gasification, is a result of diminishing higher hydrocarbon levels at higher temperatures.

\subsubsection{Product YIELdS}

The product yields for the test runs are also presented in Table 5-4. The product yields are calculated on a weight percent carbon basis and are segregated into three fractions: dry gas, char, and tar/oil. The char fraction represents unconverted carbon that is entrained or otherwise removed from the gasifier. No char recycling was performed for any of the runs. The tar/oil fraction represents heavy hydrocarbons that are condensed along with steam in the sampling train. Note that the char and tar/oil yields measured in these test runs do not necessarily reflect optimum conversion values which can be achieved within the gasifier. For instance, increasing gasifier temperature can significantly enhance carbon conversion. However, since it was the objective of the test matrix to cover a wide range of temperature conditions, in some cases less than optimal processing conditions were selected. 
TABLE 5-4: SELECTED GAS COMPOSITIONS AND PRODUCT YIELDS FOR BIOMASS TESTS CDNDUCTED IN PULSE-ENHANCED INDIRECT GASIFIER

\begin{tabular}{|c|c|c|c|c|c|c|c|c|}
\hline $\begin{array}{c}\text { COMPOSITION } \\
(\text { VOL.X) } \\
\end{array}$ & $\begin{array}{l}\text { PISTACHIO } \\
\text { SHELLS } \\
\end{array}$ & $\begin{array}{l}\text { PISTACHIO } \\
\text { SHELLS } \\
\end{array}$ & $\begin{array}{c}\text { SECONDARY } \\
\text { FIBER } \\
\text { HASTE } \\
\end{array}$ & $\begin{array}{l}\text { MOOD } \\
\text { CHIPS }\end{array}$ & $\begin{array}{l}\text { RICE } \\
\text { HULLS } \\
\end{array}$ & $\begin{array}{l}\text { RECYCLED } \\
\text { WASTE PAPER } \\
\text { H/PLASTIC } \\
\end{array}$ & $\begin{array}{c}\text { URBAN } \\
\text { WOOD WASTE }\end{array}$ & $\begin{array}{c}\text { ORCHARD } \\
\text { PRUNINGS AND } \\
\text { BAGASSE BLEND } \\
\end{array}$ \\
\hline $\mathrm{H}_{2}$ & 37.86 & 35.04 & 38.86 & 48.11 & 42.83 & 50.50 & 35.16 & 32.15 \\
\hline $\mathrm{CO}$ & 18.84 & 23.43 & 23.34 & 22.91 & 19.67 & 19.26 & 15.17 & 18.22 \\
\hline $\mathrm{CO}_{2}$ & 28.73 & 25.20 & 23.27 & 20.18 & 24.40 & 20.10 & 30.04 & 31.61 \\
\hline $\mathrm{CH}_{4}$ & 10.65 & 11.31 & 8.31 & 8.32 & 11.56 & 8.42 & 12.03 & 10.69 \\
\hline Ethylene & 2.12 & 2.86 & 3.44 & 0.05 & - & - & 2.76 & 2.00 \\
\hline Ethane & 0.28 & - & - & - & - & - & 0.99 & 1.05 \\
\hline Propylene & 0.95 & 1.31 & 2.19 & 0.04 & - & - & 3.59 & 3.46 \\
\hline Propane & 0.18 & 0.12 & 0.42 & 0.03 & 0.48 & 0.57 & 0.20 & 0.13 \\
\hline I-Butane & - & - & 0.27 & - & 0.29 & 0.32 & 0.06 & 0.53 \\
\hline N-8utane & 0.36 & 0.72 & 0.07 & 0.06 & 0.40 & 0.46 & - & 0.09 \\
\hline I-Pentane & 0.03 & 0.01 & 0.01 & 0.30 & 0.37 & 0.37 & - & 0.07 \\
\hline TOTAL & 100.00 & 100.00 & 100.00 & 100.00 & 100.00 & 100.00 & 100.00 & 100.00 \\
\hline HHV (Btu/scf) & 370 & 406 & 412 & 329 & 367 & 364 & 435 & 427 \\
\hline Temperature $\left({ }^{\circ} F\right)$ & 1317 & 1216 & 1250 & 1286 & 1327 & 1327 & 1203 & 1172 \\
\hline \multicolumn{9}{|l|}{ YIELD ( $\%$ CARBON) } \\
\hline Dry Gas & 94.1 & 92.1 & 86.8 & 93.0 & N/A & N/A & $74.5^{(1)}$ & $74.5^{(1)}$ \\
\hline Char & 4.6 & 5.8 & 8.5 & 4.0 & 18.10 & N/A & $23.1^{(1)}$ & $23.1^{(1)}$ \\
\hline Tar/0il & 1.3 & 2.1 & 4.7 & 3.0 & $N / A$ & N/A & $2.4^{(1)}$ & $2.4^{(1)}$ \\
\hline
\end{tabular}

(1) Cumulative results for urban wood waste and orchard prunings/bagasse blend. 
$\mathrm{H}_{2} / \mathrm{CO}$ RATIO

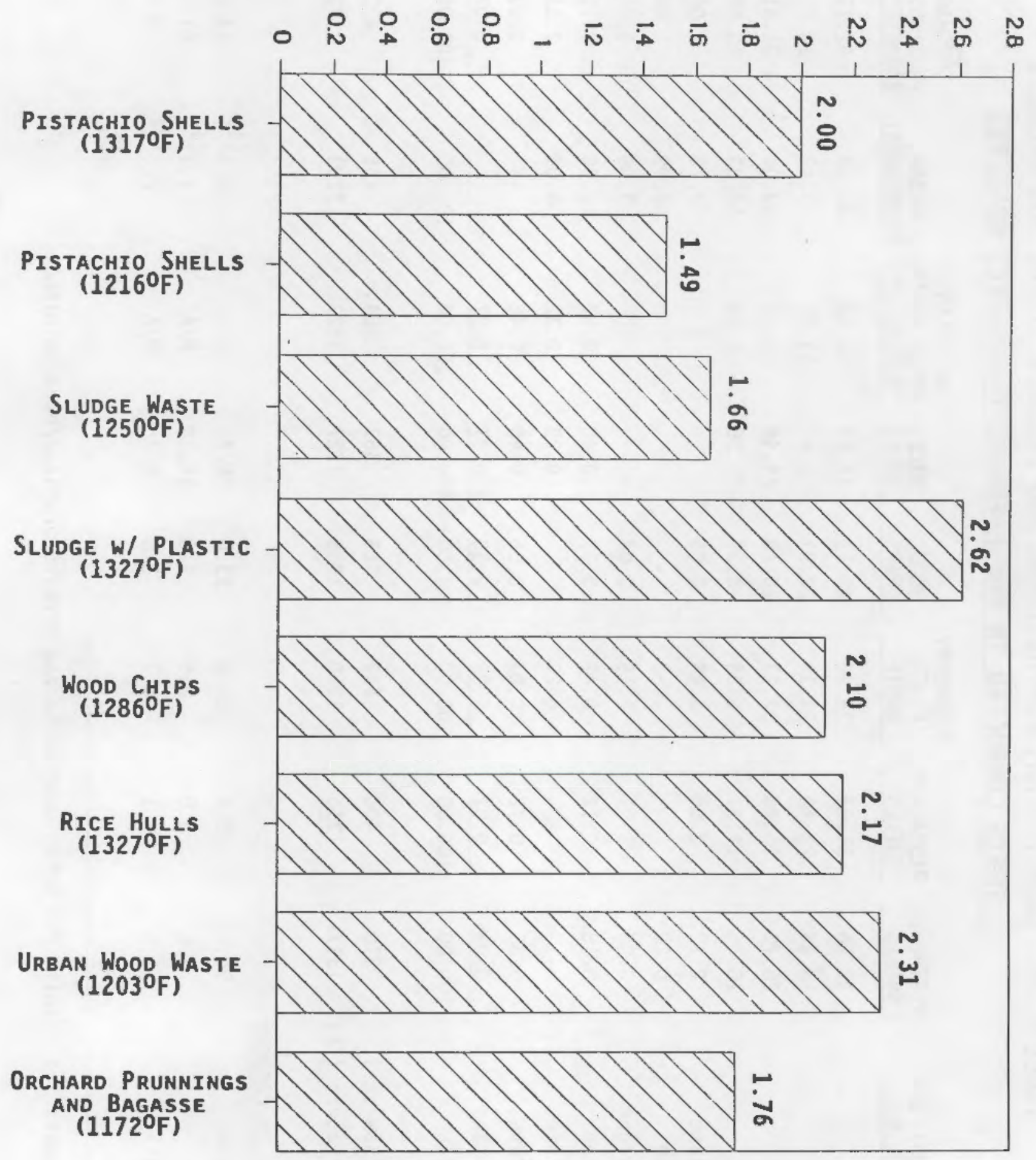

FIGURE 5-8: HYDROGEN/CARBON MONOXIDE RATIO 


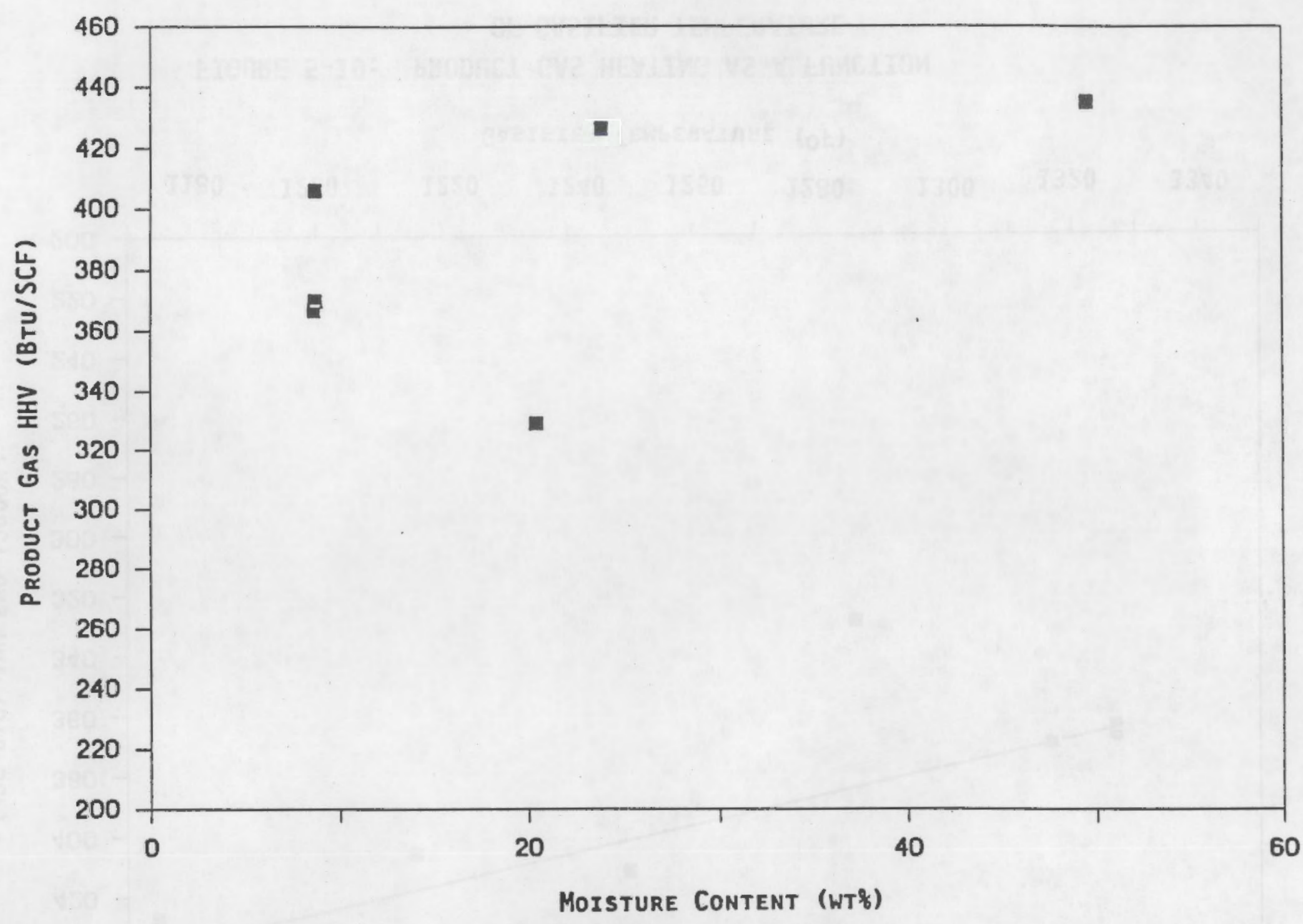

FIGURE 5-9: PRODUCT GAS HEATING VALUE AS A FUNCTION OF FEEDSTOCK MOISTURE CONTENT 


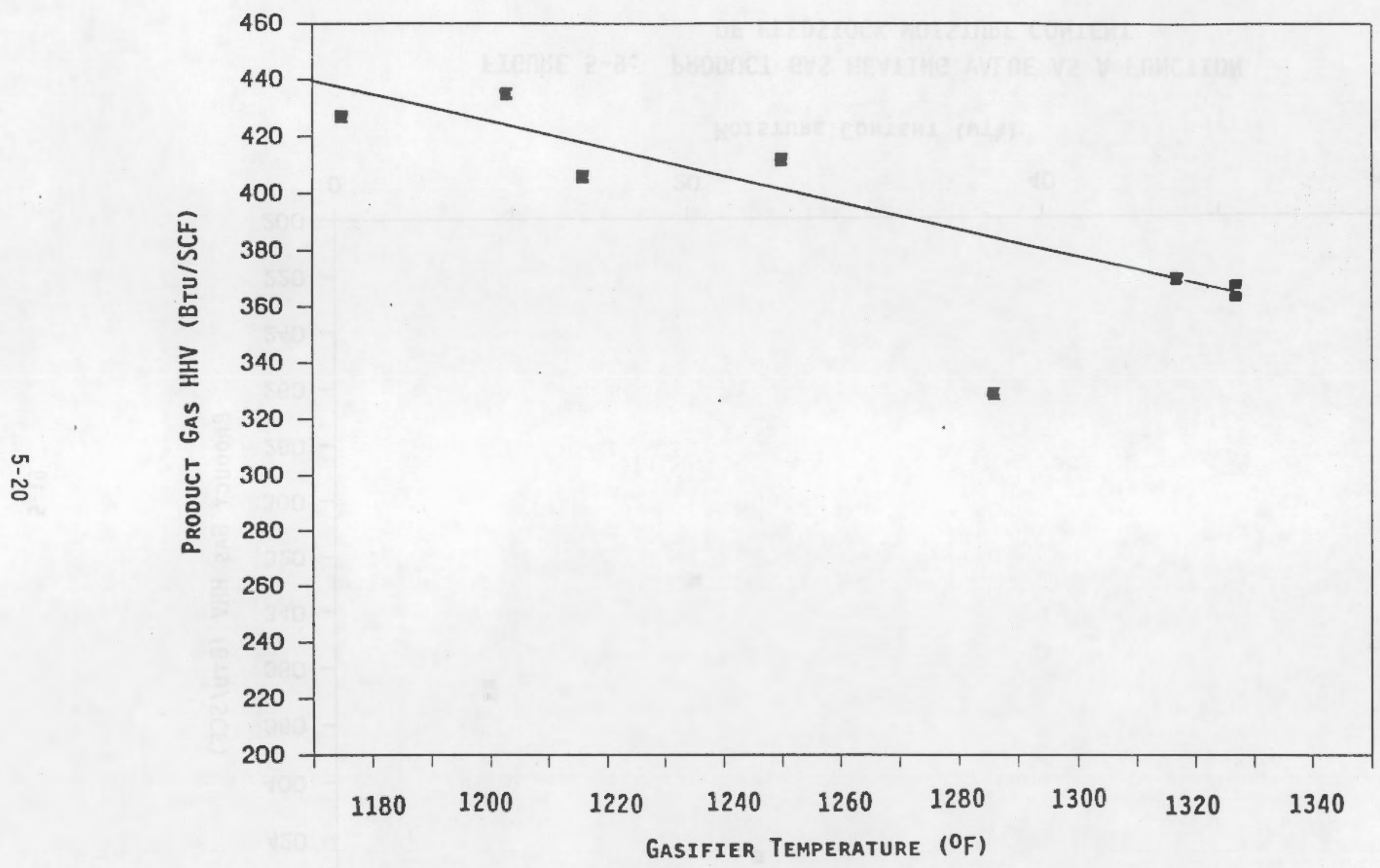

FIGURE 5-10: PRODUCT GAS HEATING AS A FUNCTION

OF GASIFIER TEMPERATURE 
As seen in Table 5-4, dry gas product yields ranged from 74.5 to 94.1 wt.\%. Char yields typically ranged from 4 to 8 wt.\%. However, particularly high char yields were obtained for tests runs on rice hulls (18.1 wt.\%) and urban wood wastes/orchard prunings and bagasse blend (23 wt.\%). The tar/oil yields were generally in the range of 1 to 3 wt.\%. The secondary fiber waste generated the highest tar/oil yield at 4.7 wt.\%.

The char yield appears to be related to a combination of the gasifier temperature and the density, particle size, and geometry of the feed material. Lightweight, fibrous or small particulate material that is easily entrainable generally leads to high char yields. Recycling of entrained char to increase residence time within the gasifier is anticipated to significantly enhance conversion of these feedstocks. In contrast, feedstocks with a high dry bulk density or large feed size (wood chips) generally result in low char yields.

Figure 5-11 shows the char yield as a function of gasifier temperature. The dotted lines tie the char yields for products exhibiting similar bulk densities on a dry material basis. The bulk density for these materials are noted next to the dotted line. From this plot, it is evident that both gasifier temperature and material density influence the char yields. It is also anticipated that the particle size and geometry will greatly influence the product yield pattern. Feedstocks with a high surface-to-mass ratio (e.g., bagasse, shredded wood waste) are expected to be more easily entrained and thus increase char yield.

\subsubsection{SCALE-UP ISSUES}

An objective of this program was to develop design criteria for scale-up of the thermochemical reactor to the $200 \mathrm{lb} / \mathrm{hr}$ level. This will allow future scale-up to the $2 \mathrm{tph}$ range with reasonable confidence. In order to verify the scale-up design criteria, an eight-tube gasifier incorporated similar design principles used in the two-tube gasifier.

Scale-up of the thermochemical reactor involves consideration of two primary issues: chemical reaction kinetics and heat transfer. The rate of chemical reaction (gasification) at a given set of process conditions determines the required bed volume. This can be expressed in the following approximation:

$$
V_{B}=M_{f} /\left(\varsigma_{B} X_{B} R_{g}\right)
$$

Where $V_{B}$ is the bed volume, $M_{f}$ is the feedstock carbon feed rate, $\varsigma_{B}$ is the bed density, $X_{B}$ is the fraction of carbon in the bed, and $R_{g}$ is the specific carbon gasification rate expressed as mass of carbon gasified per hour per mass of carbon inventory in the bed.

It is evident that increasing the specific gasification rate, for instance by increasing reactor temperature, will reduce the required reactor volume for a given mass feed rate. It should be mentioned that the design value for the carbon inventory $\left(X_{B}\right)$ must be selected in a certain range. If $X_{B}$ is too large, then excessive attrition and elutriation of unreacted carbon 


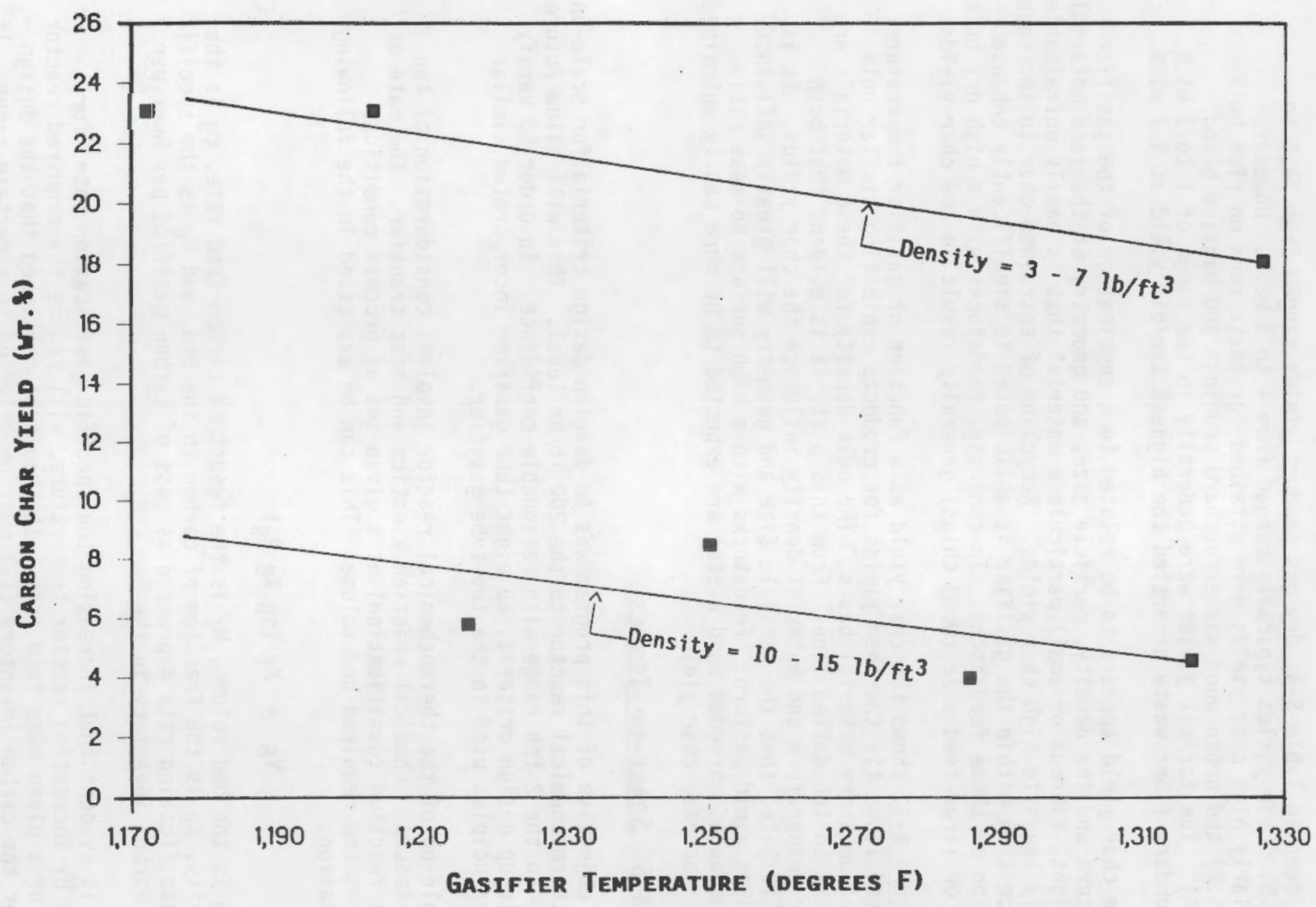

FIGURE 5-11: CHAR YIELD AS A FUNCTION OF GASIFIER TEMPERATURE 
will result. Of course, selection of very small design values for $X_{B}$ are likely to be uneconomical due to the larger size required for the reactor of a given throughput.

The heat transfer rate to the bed is a function of several factors, including tube surface area, convective heat transfer coefficients, and combustor firing rate. The net heat transferred to the bed must, of course, satisfy the reaction heat demand at the design throughput rate.

Based on measurements of heat transfer rates and firing rate limitations in the two-tube pulse combustor system, specific design criteria were developed for the scale-up unit. A primary consideration involved developing empirical correlations for the maximum firing rate of the combustor/fire tube configuration as function of tube diameter, length, and number. The maximum firing rate per tube was found to correlate approximately as follows:

$$
F_{m}=1.075 \times 10^{6} d^{2} / L
$$

Where $F_{m}$ is the maximum firing rate per tube in $B t u / h r, d$ is the inside tube diameter in inches, and $L$ is the tube length in feet.

The specific heat input requirement for the gasifier is approximately $1200 \mathrm{Btu} / 1 \mathrm{~b}$ of biomass. Assuming that the ratio between heat absorbed in the gasifier to fuel fired in the combustor is 50 percent, the combustor design will scale according to the following relation:

$$
\begin{aligned}
& M_{f}=0.5 F_{m} N_{T} / 1200 \\
& =0.54 \times 10^{6} N_{T} d^{2} / L / 1200
\end{aligned}
$$

Where $\mathrm{N}_{\mathrm{T}}$ is the tube number.

Tests were performed on the eight-tube combustor to verify the above scaling criteria. The eight-tube combustor is constructed from 3/4-inch SCH 40 pipe. The total tube length is approximately 12 feet. From equation (2), the predicted maximum firing rate per tube is $60,738 \mathrm{Btu} / \mathrm{hr}$. The eighttube combustor was found to be capable of firing approximately $460,000 \mathrm{Btu} / \mathrm{hr}$ on natural gas. This translates to $57,500 \mathrm{Btu} / \mathrm{hr}$ per tube which is quite close to the empirical prediction. Thus, combustor scaling criteria was verified.

It has been shown that the reactor design must meet two primary constraints: a chemical reaction constraint and a heat transfer constraint. It is evident that for an improperly scaled system, either heat transfer or chemical reaction limitations may predominate. For a properly scaled system, equations (2) and (3) will be in balance at the desired design temperature and bed carbon inventory level. Thus, by combination of equation (2) and (3).

$$
V_{B}=0.54 \times 10^{6} N_{T} d^{2} / L / 1200 /\left(\varsigma_{B} X_{B} R_{g}\right)
$$


Figure 5-12 shows the relation between the required bed volume $V_{B}$, the specific gasification rate $R_{g}$, and the bed carbon inventory level $X_{B}$ for the heat transfer system which was incorporated in the eight-tube reactor.

The specific gasification rate depends on several factors including feedstock type, and most noticeably, gasifier temperature. Extensive measurements of specific gasification rates under steam reaction conditions have been made by IGT (Development of Biomass Gasification to Produce Substitute Fuels, 1981). At $1500^{\circ} \mathrm{F}$ and $10 \mathrm{psig}$, the first-order (specific) gasification rate constant for maple hardwood in a mixture of 50 percent steam, 5 percent $\mathrm{H}_{2}$, and 45 percent He was found to be $7.14 \mathrm{hr}^{-1}$. Using an Arhenius activation energy of $80,000 \mathrm{Btu} / \mathrm{lb}$ mole, which is typical of steam gasification conditions, the rate constant can be extrapolated to the temperature regime of the MTCI gasifier $\left(1350^{\circ} \mathrm{F}\right)$. This results in an order of magnitude estimate for $\mathrm{R}_{\mathrm{g}}$ in the range of 1.0 to $2.0 \mathrm{hr}^{-1}$.

Returning to Figure 5-13, the dotted line shows the design bed volume for the scale-up reactor. The shaded region shows the anticipated range for the specific gasification rate. Therefore, the scale-up gasifier operated at the maximum heat- 1 imited throughput rate is predicted to reach an equilibrium bed inventory fraction in the range of $15-20 \mathrm{wt} . \%$.

On October 26, 1988, the eight-tube gasifier was operated on pistachio shells. The objective of the test was to verify operation of the gasifier and pulse combustion system at the scale-up size. The initial feed rate was set at approximately $200 \mathrm{lb} / \mathrm{hr}$; however, the reactor temperature began to drop at the maximum combustor firing rate of $460,000 \mathrm{Btu} / \mathrm{hr}$. The feed rate was then adjusted downward until a stable gasifier temperature could be maintained. This occurred at a feed rate of $132 \mathrm{lb} / \mathrm{hr}$. The lower maximum feed rate has been attributed to a combination of high heat losses and low steam preheat temperatures used for these tests.

Despite achieving only approximately two-thirds of the theoretical feed rate, the reactor performed well. It is anticipated that a feed rate close to the design prediction can be achieved for the commercial design operating with much lower specific heat losses and higher steam preheat temperatures through flue gas heat recovery. Thus, it is felt that design scale-up criteria have been verified.

\subsection{DEVELOPMENT PLAN AND COMMERCIALIZATION}

\subsubsection{COMMERCIALIZATION}

The implementation of an extensive biomass energy recovery industry appears to be thwarted by several major technical, economic, and environmental issues, none of which appear to MTCI to be limitations with respect to the commercialization of the technology for specific market entry scenarios. MTCI, for example, has demonstrated in this program the value of its advanced thermochemical reactor system for the gasification and energy recovery from many different feedstocks such as wood, pistachio shells, recycle paper pulp sludge, waste by-products, black liquor, etc. The market entry of a new 


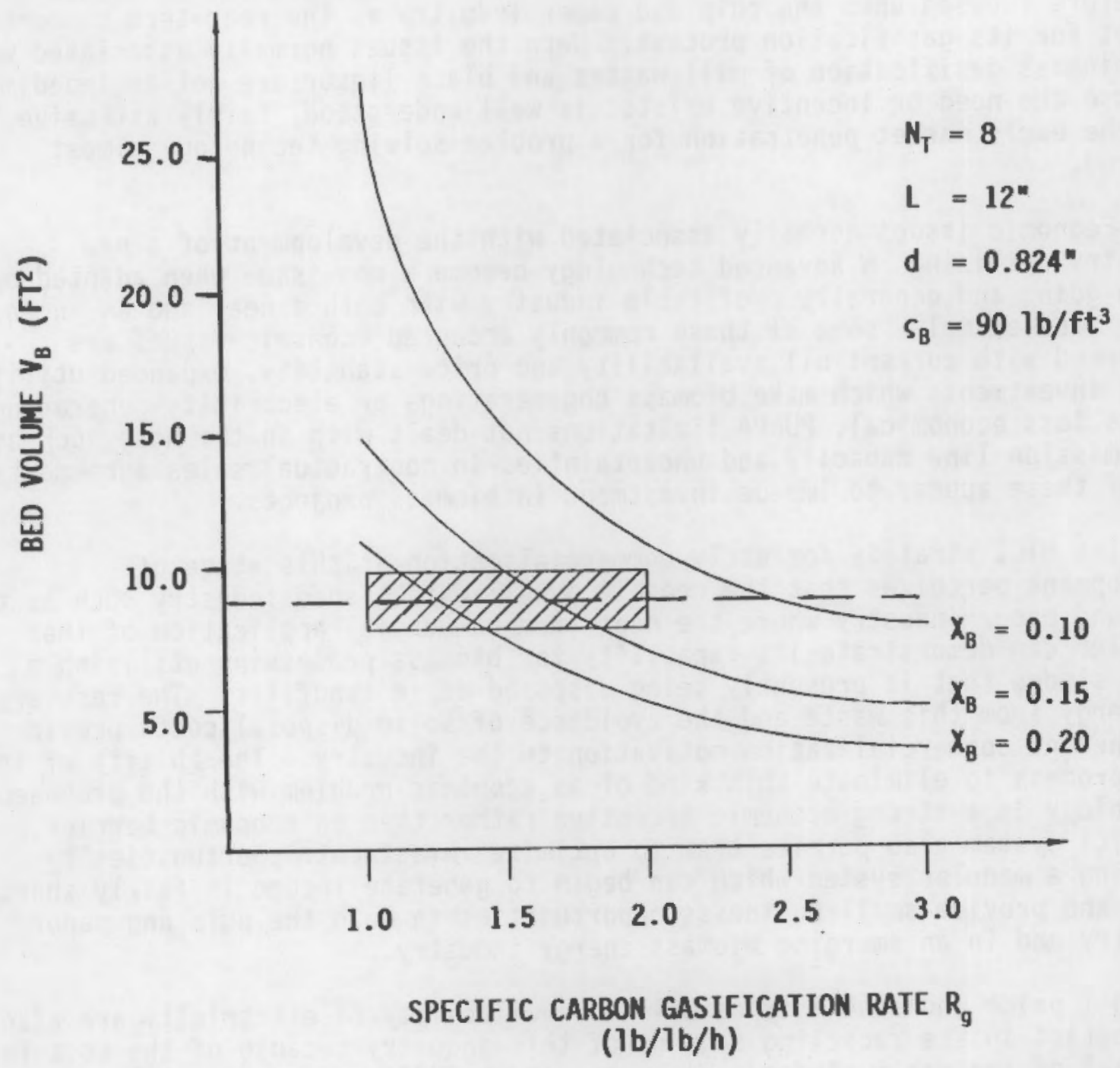

FIGURE 5-12: RELATIONS BETWEEN REQUIRED BED VOLUME, SPECIFIC GASIFICATION RATE, AND BED INVENTORY FRACTION FOR SCALE-UP GASIFIER OPERATED AT HEAT-LIMITED THROUGHPUT RATE 
technology is generally motivated by a market need. The more immediate the need, the earlier the technology will reach commercialization. MTCI has therefore focused upon the pulp and paper industry as the near-term commercial market for its gasification process. Here the issues normally associated with the biomass gasification of mill wastes and black liquor are not an impediment because the need or incentive exists, is well understood, fairly extensive, and the early market penetration for a problem-solving technology almost assured.

Economic issues normally associated with the development of a new industry utilizing an advanced technology become a non-issue when adapted by an on-going and generally profitable industry with both a need and an incentive. For example, some of these commonly accepted economic issues are concerned with current oil availability and price stability, expanded utility plant investments which make biomass cogenerating-or electricity-generating plants less economical, PURPA limitations not dealt with in the Act, such as transmission line capacity and uncertainties in contractual sales agreements. All of these appear to impede investment in biomass projects.

The MTCI strategy for early commercialization at this stage of development perceives that the need in a well-established industry such as the pulp and paper industry where the near-term commercial application of the gasifier can demonstrate its capability for biomass processing utilizing a waste sludge that is presently being disposed of in landfills. The recovery of energy from this waste and the avoidance of solid disposal costs provides an inherent commercialization motivation to the industry. The ability of the MTCI process to eliminate this kind of an economic probiem with the proposed technology is a strong economic incentive rather than an economic barrier. The MTCI system also permits them to optimize investment opportunities by offering a modular system which can begin to generate income in fairly short order and provide small businesss opportunities in both the pulp and paper industry and in an emerging biomass energy industry.

0il price and stability as well as availability of electricity are also unimportant in the recycling segment of this industry because of the cost for disposal of the waste sludge. With respect to PURPA and contractual sales issues, these are not applicable to the proposed industrial segment and reluctance on the part of investors, in this case the industry, is perhaps based more upon technical performance to meet the intended purpose of the technology rather than on the perceived barriers.

The acknowledged environmental issues associated with biomass gasification appear to be two-fold. The first is related to the characterization and classification of the waste streams (gaseous, liquid, and solid) and the second to the permitting, air emission offset legislation, and waste disposal regulations.

In the MTCI process which is an indirect thermochemical process, air emissions will be substantially reduced because the heat for the gasification reaction is generated in a gas-fired (either natural or process) combustor. The flue gas therefore will be relatively free of particulates, sulfur dioxides, and $\mathrm{NO}_{\mathrm{x}}$. As described earlier, the pulse combustion process is an inherently low $\mathrm{NO}_{x}$ producer. In the reactor the sulfur, if the biomass 
contains any, is generated primarily as $\mathrm{H}_{2} \mathrm{~S}$ which, for black liquor, can be recovered for recycling in the pulping process, particulates are captured as solid waste in the product gas clean-up equipment, and because the reaction proceeds at low temperatures as a steam-carbon reaction without the need for air or oxygen, $\mathrm{NO}_{x}$ emissions from the reactor are eliminated.

In summary, the issues which appear to impede commercialization of the proposed technology are not applicable to the market segment chosen because of the industry incentive and need. The pulp and paper industry is sufficiently large and well-organized so that a considerable market segment is available for the early introduction of the proposed beneficial biomass gasification technology. Although it would appear that the technology is focused upon a single industry, that industry can provide the experience of use that would be vital to the establishment of a generic biomass energy industry which can apply the technology and the experience for other applications.

Near-term applications for the indirect gasifier are anticipated to focus on incremental capacity additions. The gasifier system can be constructed in modular units with capacities in the range of two to ten tons per hour and units will be largely shop fabricated to allow reasonable economies at the smaller scale. The units will also likely be skid-mounted, truck or rail transportable, and will require a minimum level of field erection.

Pulp and paper mills produce large quantities of sludge continuously, which are mostly landfilled now. These wastes contain volatile inorganic materials as well as chlorinated compounds. There is some effort in burning or incinerating these sludges that have the potential of releasing pollutants into the air. MTCI's approach avoids direct oxidation and thus the hightemperature exposure of the inorganic constituents. By low-temperature gasification, only clean gas is sent to the combustors to release the energy and the inorganic constituents (ash) are discharged without decomposition from the gasifier. Since the gasifier uses limestone as the bed material, the sulfur and chlorine species in the gases $\left(\mathrm{H}_{2} \mathrm{~S}\right.$ and $\left.\mathrm{HC}_{1}\right)$ are retained in the bed and withdrawn as solids along with the ash.

\subsubsection{GASIFIER ECONOMICS}

As discussed earlier, a preliminary market survey was made of the recycle pulp mill industry within California. This market survey was based on identification of recycle pulp mills listed in the Lockwood-Post Directory (1988) followed by direct contact with the mill operators. The survey uncovered a significant market with over 25 recycle mills located within California.

During the processing of recycle pulp, a by-product waste stream is generated. In some cases, unclarified waste streams are discharged directly to the sewer system. However, regulations will limit the discharge of such waste products in the future. Therefore, many mills are clarifying the waste to form a sludge. This sludge is dewatered to approximately 50 to 70 percent moisture. 
Based on our market survey, the typical quantity of waste from these mills ranges from 500 to $4,000 \mathrm{lb} / \mathrm{hr}(0.25-2 \mathrm{ton} / \mathrm{hr})$. The mills are currently disposing of the waste product in landfills at a typical disposal cost of $\$ 40$ per ton.

We have held discussions with Gaylord Container Corporation which operates a recycle mill in Antioch, California. The mill generates 2 ton/hr of secondary (short) fiber waste and incurs an annual expense of over $\$ 500,000$ for waste disposal. Gaylord has expressed great interest in siting a demonstration plant based on MTCI's indirect gasification process. This plant would not only serve to assist in the commercialization of the MTCI technology, but also provide a tangible revenue stream to Gaylord from disposal offset costs and from credits of gas produced which would reduce their current natural gas fuel requirements. Due to the high moisture content and other properties of their waste stream, direct combustion autothermal gasification is unfeasible. MTCI's technology appears to be the only viable process for handling these wastes.

Preliminary economics for the Gaylord mill have been developed as shown in Table 5-5. It is estimated that a simple gasifier plant can be constructed for $\$ 250$ per pound per hour of gasifier capacity. This amounts to $\$ 1,000,000$ total plant investment to meet Gaylord's 2 ton/hr processing needs.

The various costs of operating the gasifier are tabulated along with the annual savings from fuel and disposal costs credits. Note that the gasifier product gas is anticipated to supplement natural gas firing in the duct burner of Gaylord's existing combined cycle power generation unit.

As seen in the Table 5-5 tabulation, the annual net savings are $\$ 433,260$ per year representing a simple payback of only about 2.5 years. The return on investment based on a present value calculation is about 40 percent. It is clearly evident that the economic incentive for such a plant is very high.

In the commercial configuration, MTCI will construct and operate a 2 tph pulse-enhanced, indirect steam gasifier which will process sludge waste into a clean fuel gas. The fuel gas will then be sent to a gas turbine generator set where it will be fired in duct burners. By gasifying the sludge waste, significant disposal costs will be avoided while simultaneously reducing natural gas consumption for the duct burners.

\subsubsection{Fifty Ton Per Day Demonstration Plant}

Gaylord Container Corporation operates both a Kraft pulp mill and a recycle paper mill at their Antioch facility. As a by-product of the mill operation, a dilute short fiber waste product is generated. This material, which contains cellulose fibers, plastics, and various inorganic constituents, is clarified to form a sludge which is dewatered in a belt press to obtain a solid waste material of approximately 70 percent moisture content. Currently, this material is deposited in a pile where additional gravity dewatering and sun drying further decreases the moisture content. This material is then trucked to a landfill site for disposal at a considerable cost to Gaylord. 


\section{TABLE 5-5: BIONASS - PAPER MILL WASTE GASIFICATION}

Run

Total plant investment cost (\$) $-1,000,000$

Plant life $(y r)-10$

Annual taxes and insur. (\% capital) - 3

Annual maintenance ( $\%$ capital) - 2

Plant capacity (ton/h) - 2

Plant capacity factor $(\%)-80$

Biomass ash content (\%) - 5

Biomass heating value (Btu/lb) - 4,000

Plant fuel-to-steam thermal efficiency (\%) - 60

Plant water consumption ( $\mathrm{g} /$ ton) -120

Plant electric consumption ( $\mathrm{kW} /$ ton) - 20

Biomass (waste) disposal cost (\$/ton) - 30

Plant steam value (\$/MMBtu) - 2.5

Water cost $(\$ / 1000 \mathrm{~g})-2$

Electricity cost $(\$ / \mathrm{kWh})-0.075$

Number of operators per shift - 0.5

Shifts per day - 3

Net salary per operator - 80,000

Annual Water Cost (\$)

Annual Electric Cost (\$)

Annual Operator Cost (\$)

Annual Steam Savings (\$)

Net Disposal Savings (\$)

Net Annual Savings (\$)

Capital Cost ( $\$ 1 \mathrm{~b} / \mathrm{hr}$ )

Simple Payback (yr)

Return on Investment (\%)
$3,363.84$

$21,024.00$

$120,000.00$

$168,192.00$

$399,456.00$

$423,260.20$

250.00

2.362613

40.95933 
As an alternative to disposal, the MTCI gasification process can be employed to generate a medium-Btu fuel gas. Figure 5-13 shows how the gasifier would be integrated into the existing mill process. A schematic of the gasifier unit is shown in Figure 5-14 using Gaylord's recycling process as a baseline.

Sludge from Gaylord's belt press will be further dewatered in a screw press (or by other means) to 50 percent moisture. The waste product will then be loaded by bucket elevation to a live storage bin ( $V-1)$. From there, the material will be metered to the gasifier injection screw $(X-1)$.

The waste material will be steam gasified in MTCI's proprietary pulseenhanced gasifier (R-1). The product gases enter a cyclone $(V-2)$ and are then quenched and scrubbed in $V-3$. The gases are cooled in condenser $E-2$ and condensate is removed in knock-out vessel $V-4$. The clean gases will then be utilized in Gaylord's existing duct burners.

The 2 tph gasifier will be of a rectangular construction with approximate dimensions of $4 \mathrm{ft}$. wide $\times 6 \mathrm{ft}$. length $\times 20 \mathrm{ft}$. height. The gasifier will include six pulse combustors in a $3 \times 2$ paired (coupled) arrangement. The pulse combustors will each be rated at approximately $1.6 \mathrm{MMBtu} / \mathrm{hr}$. Each combustor will include approximately 20 in-bed resonance tubes mounted horizontally from the side. Residual heat from the flue gases is recovered in waste heat steam boiler (E-1). A portion of the steam generated in E-1 is used to fluidize the bed and the balance is export steam which is sent elswhere in the plant.

The Gaylord Container Corporation has agreed to participate in the further development and field tests of the MTCI gasifier units for both mill sludge waste energy recovery and black liquor recovery. 


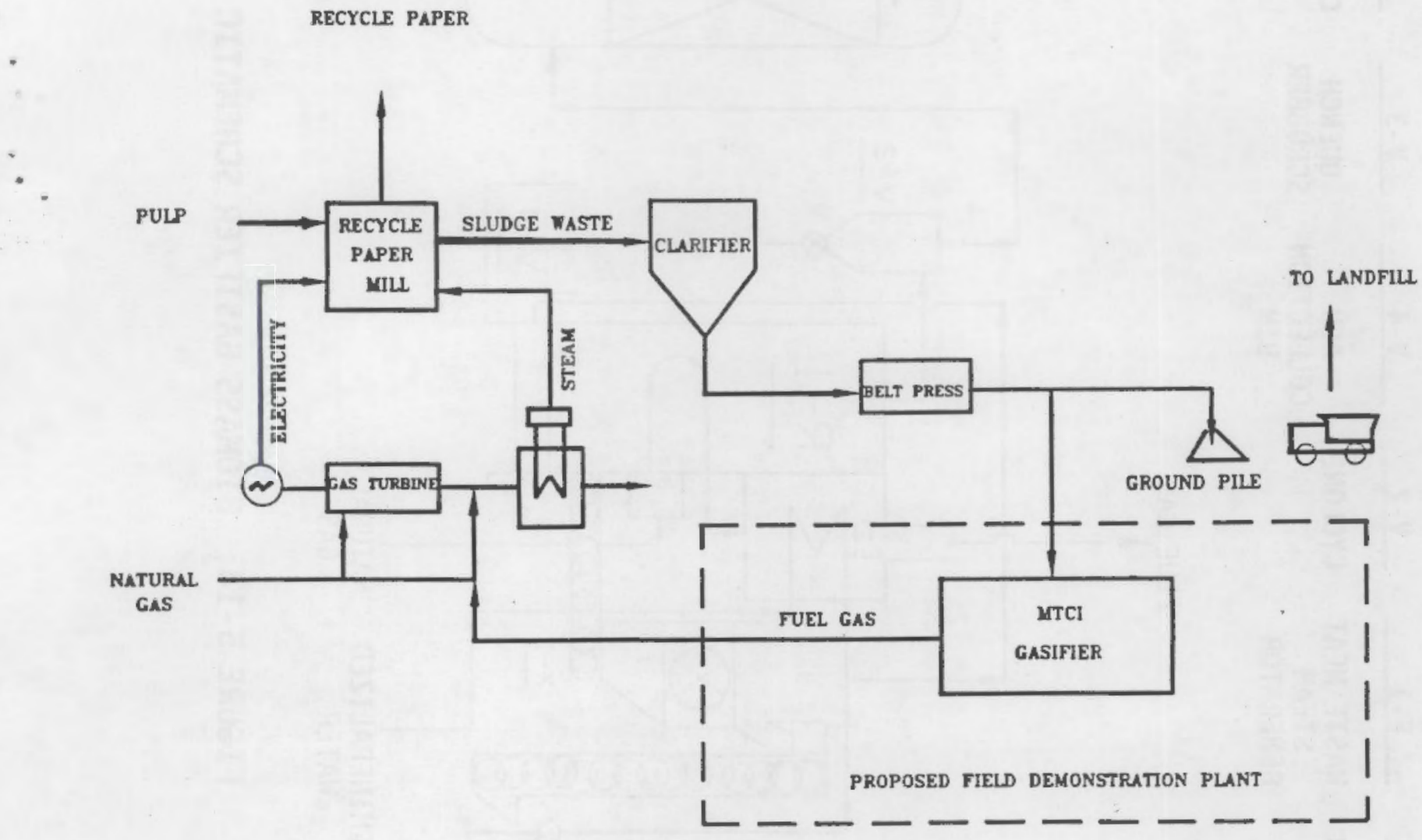

FIGURE 5-13: SCHEMATIC OF RECYCLE PAPER MILL WITH PROPOSED FIELD DEMONSTRATION GASIFIER 

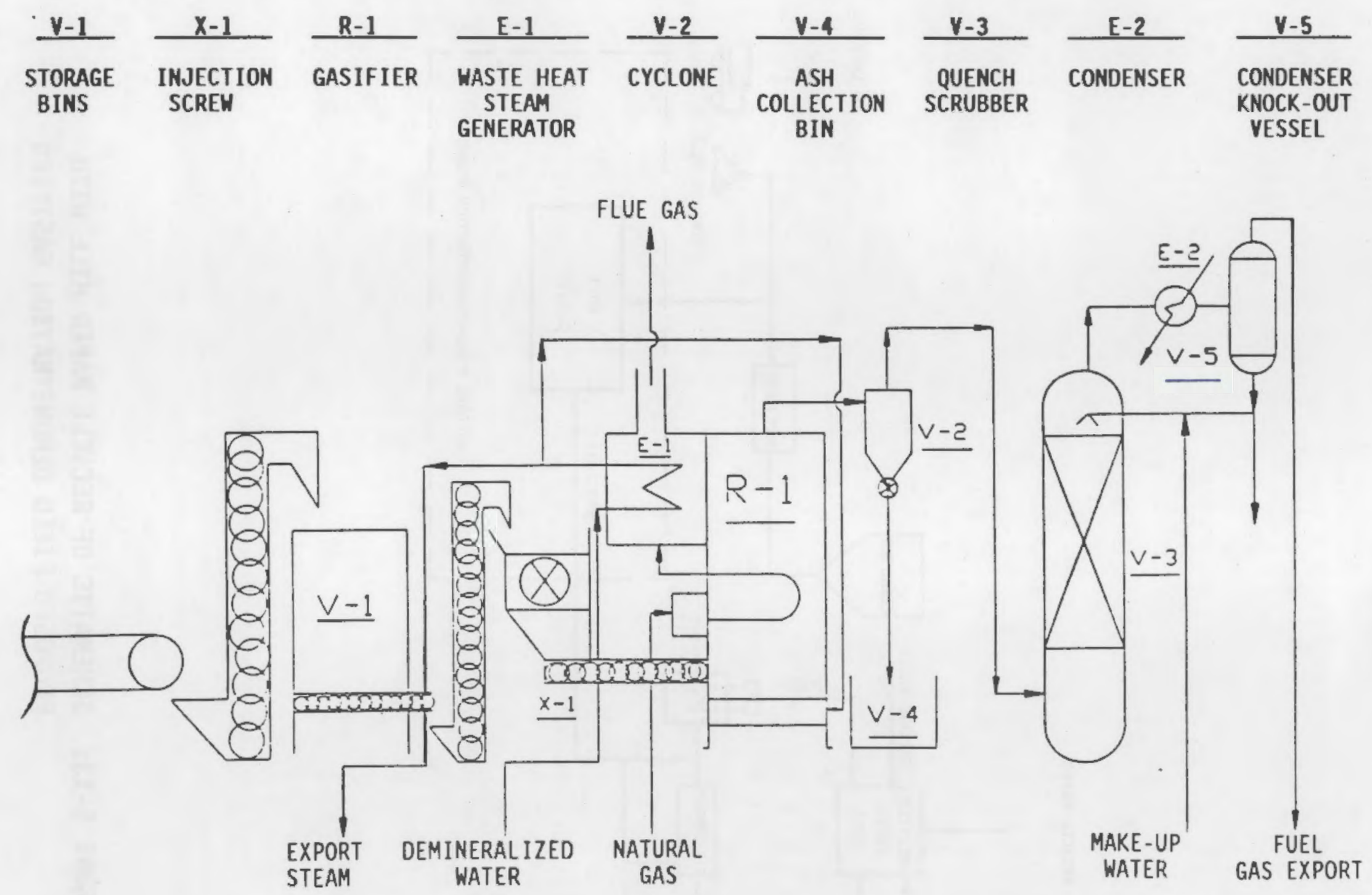

FIGURE 5-14: BIOMASS GASIFIER SCHEMATIC 


\section{SECTION 6.0 \\ BLACK LIQUOR GASIFICATION TEST PROGRAM}

The current technology for recovery of black liquor by-products relies on a combustion-related process employing a Tomlinson furnace. As an integral component of the Kraft pulping process, the Tomlinson furnace serves to recover the chemical and energy values contained in the Kraft black liquor for efficient utilization and re-use within the mill circuit. Although the Tomlinson furnace has been widely employed in the Kraft industry for several decades, it possesses some significant deficiencies, including: (1) safety hazards resulting from blackout and smelt-water explosions, (2) relatively low thermal efficiency, (3) fouling and corrosion, and (4) undesirable environmental emissions. Furthermore, Tomlinson recovery furnaces represent a significant fraction of the total capital expenditure for a modern mill. Due to the complexities of this apparatus, Tomlinson furnaces are typically constructed in large sizes in order to take advantage of the inherent economies of scale. Unfortunately, when mill capacity expansions are contemplated, there exists little opportunity for incremental plant capacity expansion through incremental capital investment. In addition, due to the dependence of modern mills on large Tomlinson furnaces if the recovery unit goes down, total plant operations are significantly curtailed.

For these reasons, the pulp and paper industry has actively searched for alternatives to the Tomlinson recovery technology. Among the more frequently explored concepts involves the gasification of black liquor. Gasifiers, which can be economically constructed in modular units, would provide management with increased flexibility in planning mill capacity expansions and may afford a delay of intensive capital investment.

In the following section, the development and testing of the MTCI reactor for black liquor gasification is described.

The MTCI Black Liquor Gasifier system is shown in Fiqure 6-1. It consists of an indirectly heated fluidized bed gasifier. The heat for the gasification is supplied by a pulse combustor which provides very high heat transfer rates through the fire tubes to the fluid bed. The product gas is scrubbed with green liquor to remove $\mathrm{H}_{2} \mathrm{~S}$, forming $\mathrm{Na}_{2} \mathrm{~S}$. The inorganic sodium material is removed as dry sodium carbonate powder from the fluid bed. No smelt is formed in the system since the temperature of operation is below $1300^{\circ} \mathrm{F}$ (typically 1100 to $1200^{\circ} \mathrm{F}$ ). The $\mathrm{Na}_{2} \mathrm{CO}_{3}$ is dissolved with water to make green liquor, which absorbs the hydrogen sulfide from the product gas. A detailed description of the system is given later.

Figure 6-2 schematically shows how the MTCI gasifier process fits into the Kraft pulping plant. The MTCI gasifier and dissolving tank replace the Tomlinson recovery furnace and smelt tank. Fuel gas from the MTCI gasifier is combusted to generate steam in an inexpensive boiler designed for clean fuels. This boiler, which is commonly available in most mills for start-up, replaces the steam-generating convective boiler of the Tomlinson recovery unit. In 


\begin{tabular}{|c|c|c|c|c|c|c|c|c|c|}
\hline E-1 & $R-1$ & $y-1$ & $v-2$ & $x-1$ & $E-1$ & $y-3$ & $E-3$ & $v-4$ & $x-2$ \\
\hline $\begin{array}{l}\text { MASTE } \\
\text { HEAT } \\
\text { STEAM } \\
\text { GENERATOR }\end{array}$ & GASIFIER & CYCLOANE & $\begin{array}{l}\text { DISSOLUTION } \\
\text { TANK }\end{array}$ & $\begin{array}{l}\text { RECYCLE } \\
\text { EJECTOR }\end{array}$ & $\begin{array}{l}\text { PROCESS GAS } \\
\text { STEAM BOILER }\end{array}$ & SCRUBBER & CONDENSER & $\begin{array}{c}\text { CONOENSER } \\
\text { KNOCK-OUT } \\
\text { VESSEL }\end{array}$ & FLARE \\
\hline
\end{tabular}

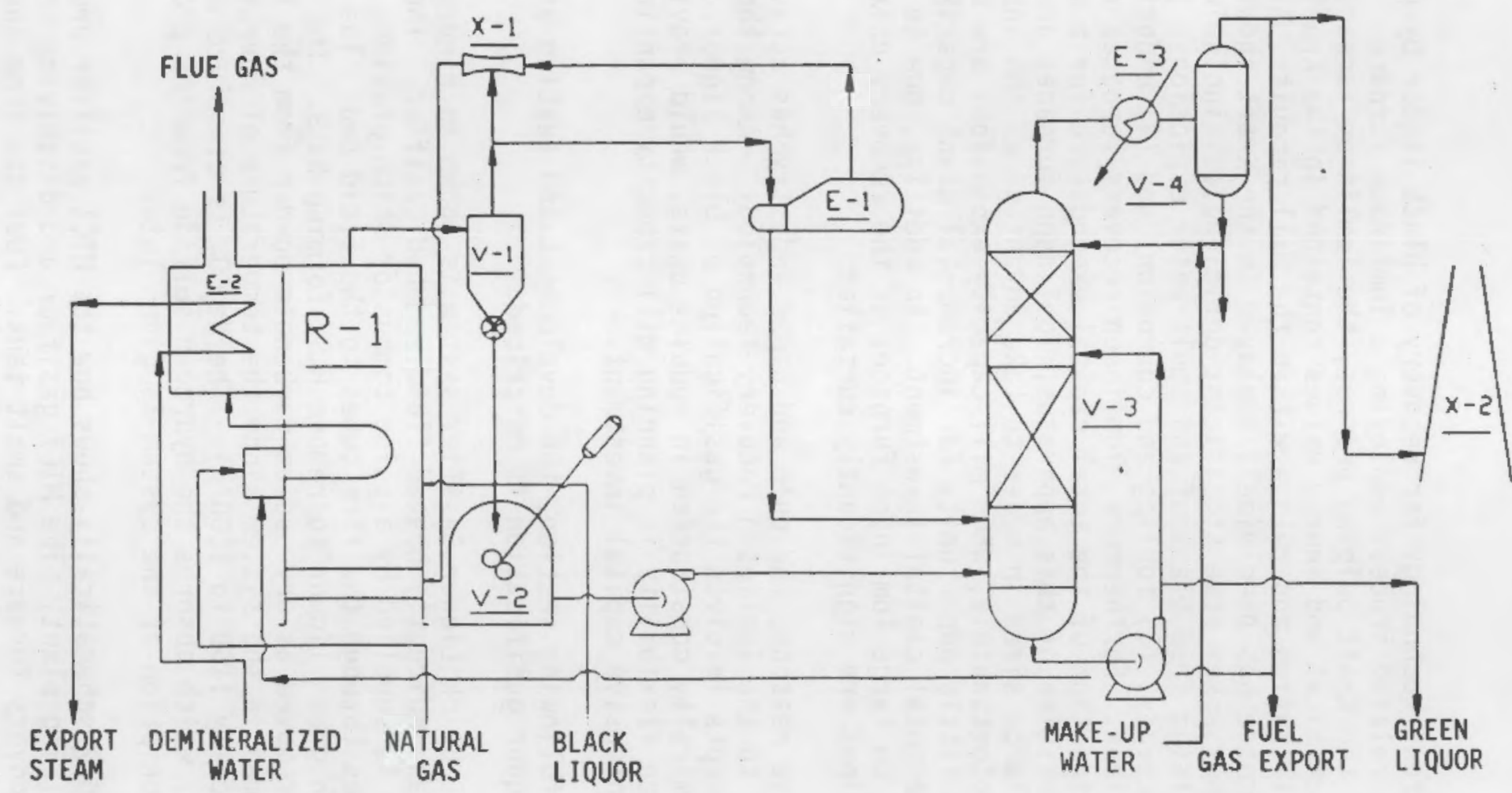

FIGURE 6-1: SCHEMATIC OF MTCI BLACK LIQUOR GASIFIER SYSTEM 


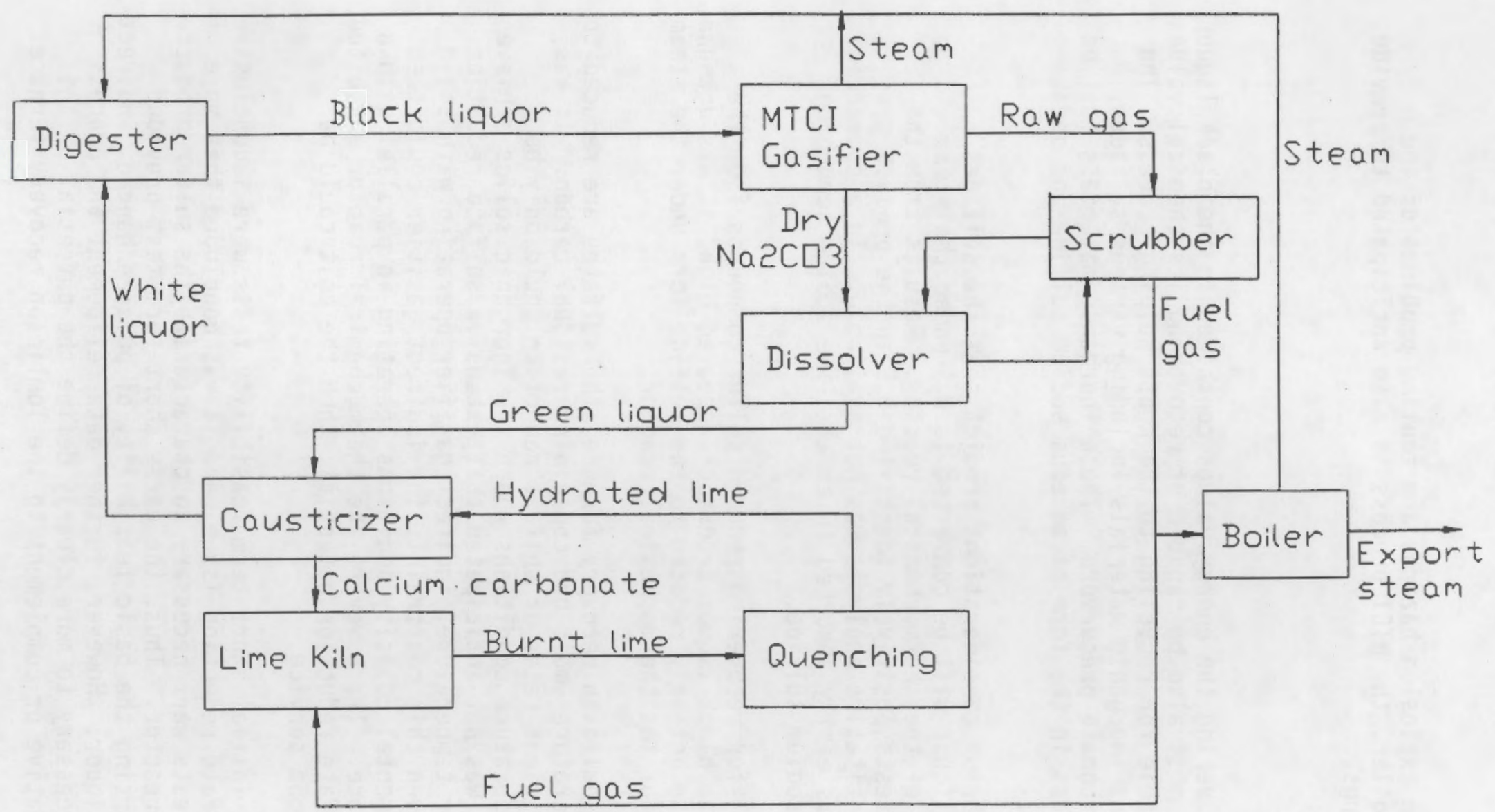

FIGURE 6-2: MTCI GASIFIER IN KRAFT PULPING 
addition to avoiding the explosion hazards and fouling problems of the conventional recovery boiler, the MTCI process is also anticipated to provide a significant cost savings.

\subsection{BACKGROUND}

In addition to recovering the energy values contained in the black liquor feedstock, the gasifier must also be capable of recovering its chemical values in a form which is suitable for recycling to the Kraft pulping process. The raw black liquor contains inorganic materials including various sulfides, sulfates, and sodium carbonate precursors. These inorganic materials must be recovered from the process in the form of aqueous sodium sulfide and sodium carbonate (green liquor).

Theoretical equilibrium considerations predict that the sulfides contained in the black liquor will be converted to $\mathrm{H}_{2} \mathrm{~S}$ under the steam gasification conditions of the thermochemical reactor. Results from the short-term feasibility tests positively identified $\mathrm{H}_{2} \mathrm{~S}$ in the product gas; however, a detailed quantitative analysis was not available. In a commercial configuration, the $\mathrm{H}_{2} \mathrm{~S}$ is easily absorbed in an alkaline sodium scrubbing solution to regenerate sodium sulfide.

While the potential for recovering reduced sulfur compounds from the sulfides contained in the black liquor feedstock appeared high, it was unknown whether sulfates could be actively reduced to the sulfide form under the steam gasification conditions of the thermochemical reactor.

In a conventional Tomlinson recovery furnace, the sulfates are reduced to sulfides in a high-temperature smelt bed containing residual carbon. It was commonly held that sufficient rates of sulfate reduction could only be attained under high-temperature conditions where the inorganic solids achieve a melt state. Thus, it was not anticipated that extensive sulfate reduction would occur in the lower temperature, indirect gasifier operating with solid inorganic material. Given this constraint, the indirect gasifier could then be considered for incremental capacity additions operating in parallel with a Toml inson recovery furnace. If, however, the thermochemical reactor exhibited a minimum degree of sulfate reduction potential, then the unit could be considered for stand-alone service.

The results of the initial short-term feasibility tests were inconclusive with respect to the sulfate reduction issue, and it was concluded that more comprehensive process tests were necessary to characterize the sulfur product distributions from the reactor. Thus, the early short-term test provided material evidence supporting the basic feasibility of pulse-enhanced, indirect gasification of black liquor. However, further data refinement and process characterization was necessary to more clearly define the potential of this technology as an alternative or complement to the Tomlinson recovery furnace.

As an element of the overall program under this contract, additional tests were planned to resolve the technical issues cited above and to more completely characterize the indirect gasifier on black liquor feedstocks. 
Weyerhaeuser provided the funding and participated in defining the necessary test objectives which are discussed in the following section.

\subsection{TEST OBJECTIVES}

The specific test objectives for the black liquor gasification tests included the following:

- Verification of improved reactor mechanical design

- Verify operation on commercial black liquor containing 65 percent solids

- Conduct long-duration steady-state gasification tests

- Conduct higher temperature gasification tests in the regime of $1100^{\circ} \mathrm{F}$ to $1200^{\circ} \mathrm{F}$

- Monitor bed carbon level as a function of gasification conditions

- Monitor bed solids particle size evolution

- Evaluate distribution of sulfur species

The initial black liquor feasibility tests were conducted in a smallscale reactor consisting of 12 pulse resonance tubes formed in a fixed tube sheet. Due to thermal expansion of the resonance tubes within the fluid bed, excessive thermal stresses were imposed on the tubes resulting in separation of tube couplings. Furthermore, the resonance tubes were unshielded, thus limiting the achievable operating temperature range due to the concern of bed solids softening during contact with the high-temperature bare metal tube surface.

In order to resolve these limitations, an improved mechanical design was prepared. In this design, the resonance tubes were formed in a U-tube arrangement to alleviate problems with thermal expansion. A radiation shield was added to the lower portion of the tube to reduce the tube-wall temperature in contact with bed solids. The pulse combustor was affixed to the tube of bundle through a bellows. This was to avoid expansion-induced leaks through plenum gaskets as experienced in the prior design. Finally, a modified steam distribution scheme was employed. A more detailed description of the reactor mechanical features is given in a later section.

In the prior tests, a black liquor feedstock containing 50.6 percent solids was employed. The 50.6 percent liquor is highly fluid at room temperature and thus can be easily pumped without preheating in an agitated vessel. However, many modern mills concentrate the black liquor to 65 percent to improve plant thermal efficiency. Therefore, an objective of these tests was to employ 65 percent solids-containing black liquor to verify that no unexpected feeding or injection problems would arise using these feedstocks. 
As previously discussed, the initial black liquor gasification feasibility test was conducted over a short duration and did not allow attainment of a full steady-state condition. Therefore, an important objective of the tests to be conducted under this program was to operate over a sufficient period to ensure attainment of a steady-state condition.

The initial black liquor gasification tests were conducted at $1030^{\circ} \mathrm{F}$, where gasification rates are relatively low. Therefore, one objective of the present work was to operate at higher temperatures where more economical gasification rates, and thus reactor throughputs, could be attained.

Another important objective of the tests under this program was to characterize the bed carbon content as a function of gasification conditions. The bed carbon content is useful for several purposes including: (1) overall material balance, (2) identification of steady-state condition, and

(3) calculation of a specific gasification rate at steady-state that relates the quantity of carbon gasified to the bed carbon inventory.

It was also the objective of these tests to characterize the bed solids particle sizes before and after an extended test run. This is a significant analysis since it is important to demonstrate that the bed particle size distributions do not drastically alter through a run thereby causing fluidization problems. Particle size evolution may result from agglomeration, accumulation of feed material on particle surfaces, or excessive attrition. In this regard, the evolving particle size distribution may provide significant information insight into the physical processes occurring within the bed.

Finally, it was the objective of these tests to characterize the sulfur distribution in product solids and gases. This is particularly important since the sulfur distribution may have significant bearing on the integration requirements of the gasifier.

\subsection{TEST SYSTEM DESCRIPTION}

\subsubsection{Process Description}

A schematic of the black liquor test system is shown in Fiqure 6-3. Steam is generated in boiler $\mathrm{H}-1$. The boiler is manufactured by Thermo Steam Boiler, Inc., and is rated at $300 \mathrm{lb} / \mathrm{hr}$. Steam from $\mathrm{H}-1$ is utilized to fluidize the gasifier and to heat the black liquor prior to injection into the gasifier. The black liquor feed tank $(V-1)$ is comprised of a steam-jacketed agitated vessel. Steam is metered to $V-l$ at a rate sufficient to maintain the biack liquor at a temperature of approximately $180^{\circ} \mathrm{F}$. At this temperature, the viscosity of the 67 percent solids containing black liquor is low enough to be easily pumped through the reactor injector.

The fluidization steam flow rate is measured using an orifice plate with a differential pressure meter. The steam flow rate was generally maintained in the range of $40 \mathrm{lbs} / \mathrm{hr}$ to provide a nominal superficial bed velocity of $1.5 \mathrm{ft} / \mathrm{sec}$. Prior to entering the gasifier, the steam is superheated to 


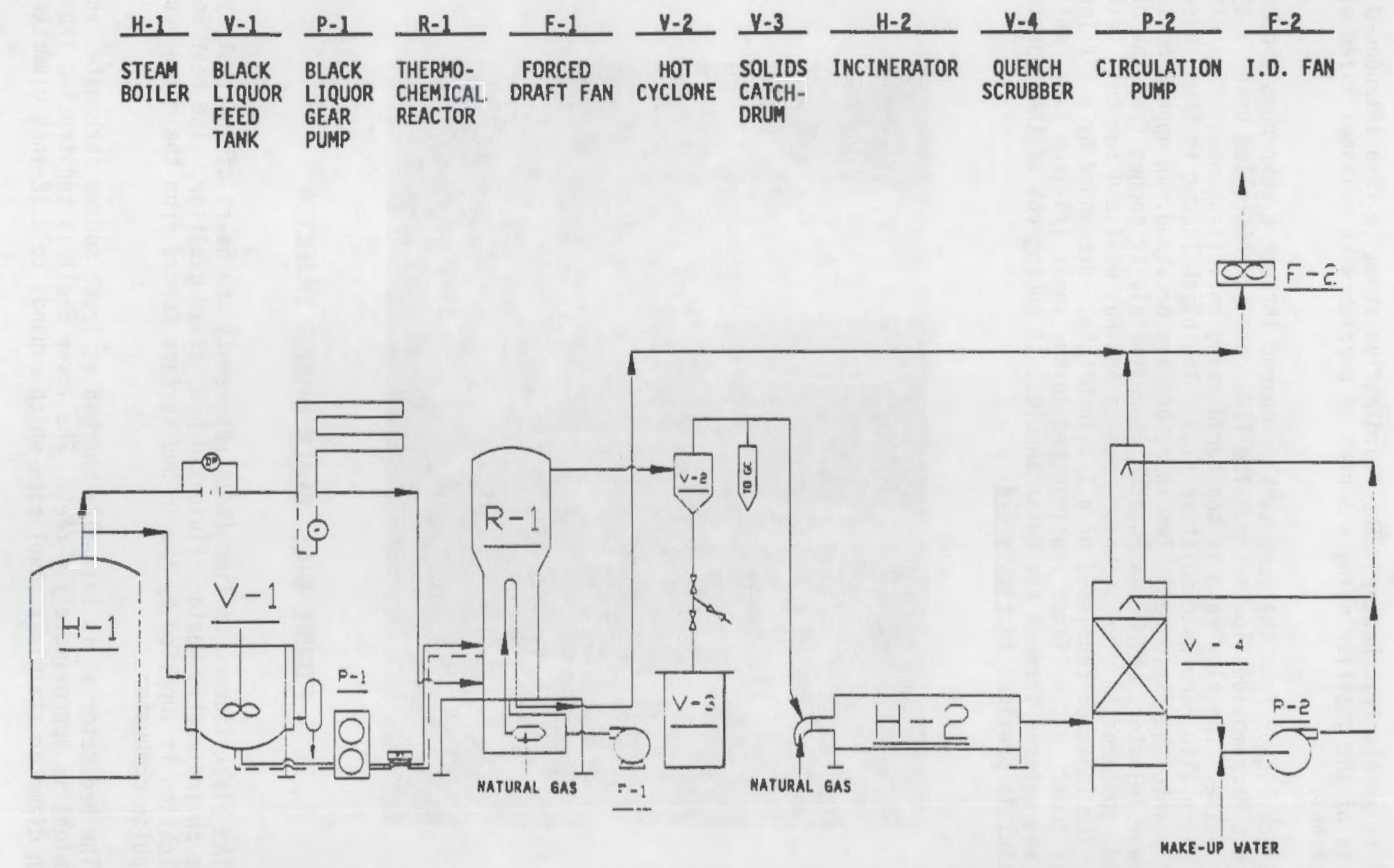

$\stackrel{9}{2}$

FIGURE 6-3: SCHEMATIC OF BLACK LIQUOR GASIFIER TEST SYSTEM 
$1000^{\circ} \mathrm{F}$ in an electric heater. The fluidization steam is then introduced into the base of the gasifier using a series of nozzles with orifices sized at $3 / 32$ inches.

Black liquor from the feed tank is pumped through a gear pump and metered through a Micromotion flow meter. The flow rate is controlled using a bypass return valve. The flow rate is monitored using an instantaneous flow rate meter which also records cumulative flow. The black liquor is then injected directly into the fluid bed. Two injectors are provided, an upper and lower. The lower injector, which was located approximately 12 inches from the base of the bed, appeared to give superior results and was utilized for most test runs. The injector consisted of a $1 / 4$-inch tube, surrounded by a $1 / 2$-inch annular tube. Black liquor was injected in the inner $1 / 4$-inch tube, while steam was metered through the outer annulus. A photograph of the injector apparatus is provided in Figure 6-4.

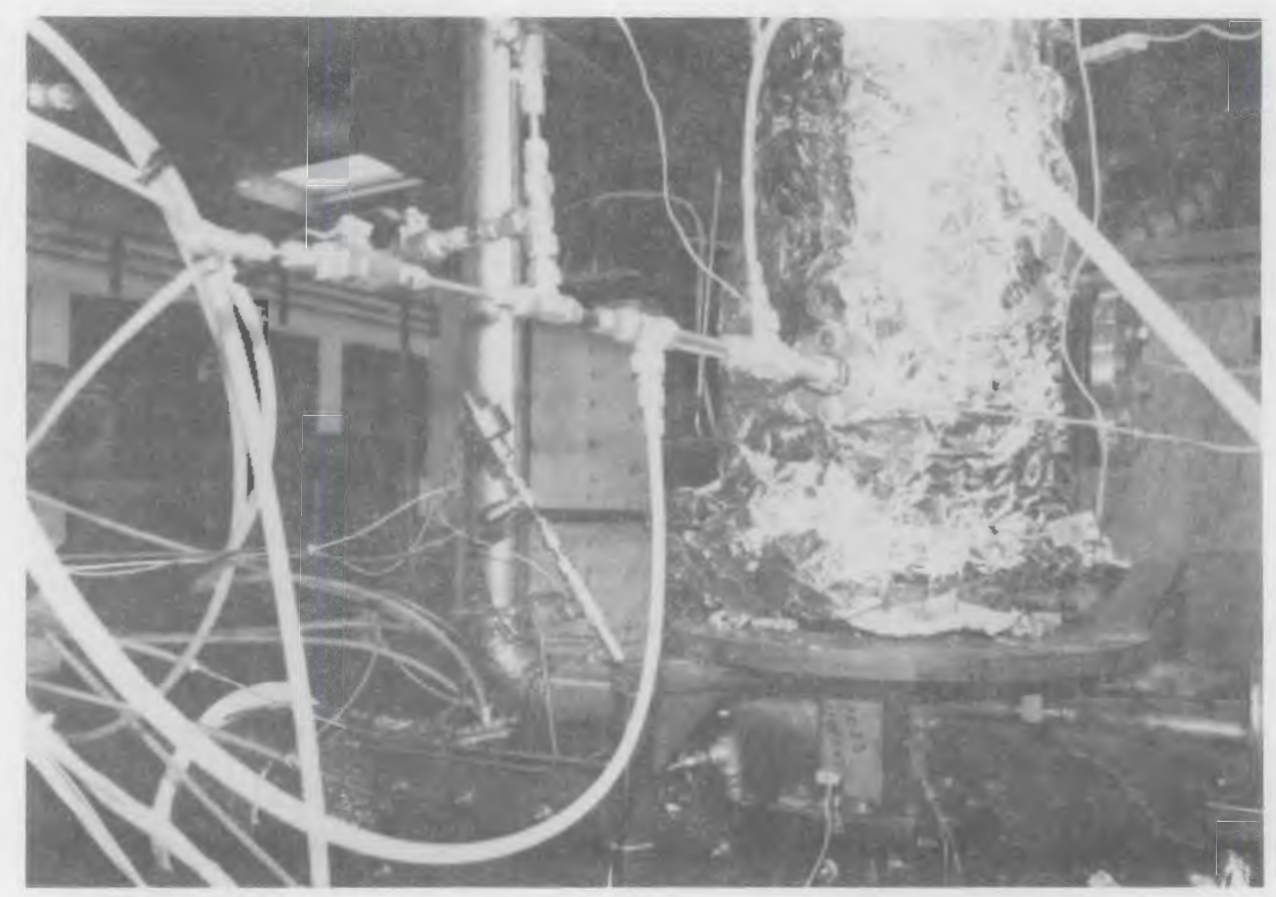

FIGURE 6-4: BLACK LIQUOR INJECTOR

The black liquor gasifier (R-1) represents the heart of the test system. R-1 is an indirectly heated, fluidized-bed, steam gasifier. The heat for gasification is supplied by the in-bed surface formed from the resonance tubes of a pulse combustor.

The bed material is initially charged as fresh sodium carbonate, and the bed height is approximately 5 feet. The lower shell is constructed from an 8-inch diameter stainless steel pipe which expands to a 12-inch diameter 
freeboard section to allow improved disentrainment. A more detailed description of the reactor is given in the next section.

The product gases from R-1 then enter a hot cyclone (V-2) to capture entrained fine bed material. The fine bed material is collected through a dipleg into a solids catch drum. The dipleg was outfitted with a "Y" connection to allow instantaneous sampling of cyclone fines. The gasifier, cyclone, and catch drums are shown in Figure 6-5. The product gases leaving V-2 then enter an incinerator $(\mathrm{H}-2)$ which is maintained at a minimum temperature of $1600^{\circ} \mathrm{F}$. A natural gas support flame is provided continuously.

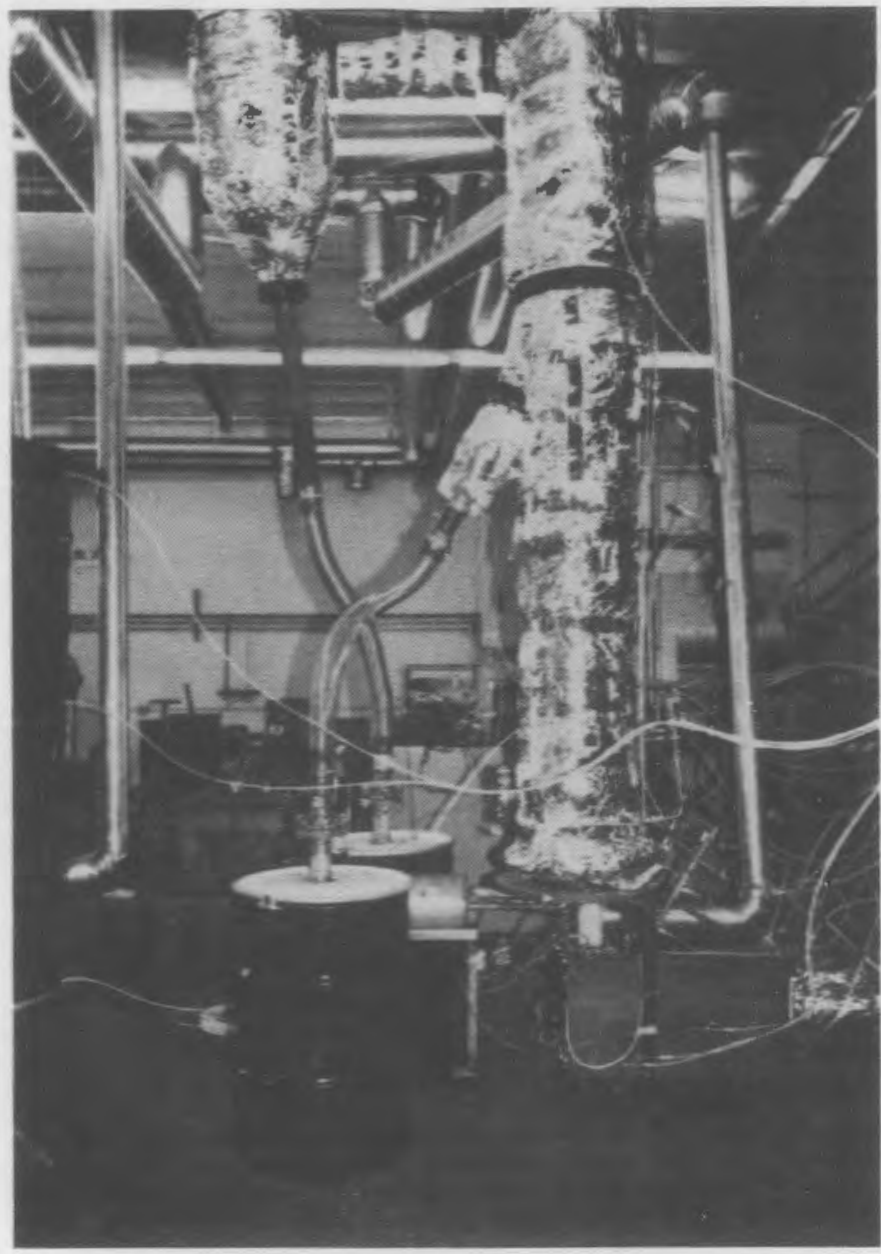

FIGURE 6-5: BLACK LIOUOR GASIFIER UITH CYCLONE AND SOLIDS CATCH DRUMS 
The incinerated gases are then directed to a packed tower, quench scrubber $(V-4)$. An alkaline scrubbing media is pumped to the top of the tower to scrub out sulfur oxides and residual particulates. The cleaned gases are mixed with the flue gases from $R-1$ before entering the roof-mounted induced draft fan.

\subsubsection{GASIFIER}

A front and side view of the gasifier is shown in Figures 6-6 and 6-7. The reactor shell and tube layout are shown in Figures $6-8$ and $\underline{6-9}$.

The gasifier consists of a two-tube fire-tube bundle which is immersed within the fluid-bed portion of the gasifier. Fuel is burned inside the pulse combustor and the flue gases are conveyed inside the fire tubes. The fire tubes are fashioned in a $U$-tube arrangement and can be easily disassembled from the gasifier.

A fundamental feature of the fire-tube design is the use of radiation shields in their lower portion. This reduces tube-wall surface temperatures as necessary to avoid melting of black liquor salts. Figure 6-10 depicts the tube-wall temperature profile for a shielded tube versus a bare tube. It is evident that the temperature of the bare tube wall near the inlet is unacceptably high for black liquor gasification. In contrast, the shielded tube wall is maintained below the critical salt melting points without a significant sacrifice in thermal efficiency.

The pulse combustors are contained inside an air plenum box. Air is supplied to the plenum box using a forced draft fan. A photograph of the reactor and plenum box is shown in Figure 6-11.

The pulse combustors are aerodynamically fashioned to support naturally oscillating combustion. The pulse combustors consist of an aerodynamic valve, a combustion chamber and a resonance tube. Due to the pulsations which occur in the combustion chamber, velocity fluctuations occur in the resonance tubes which significantly enhance heat transfer rates therein. A photograph of the pulse combustors during the initial test firing is shown in Figure 6-12.

Figure 6-13 is a photograph of the pulse combustors and resonance tubes without the gasifier shell and plenum box. Although separate combustors were employed for each resonance tube, larger scale units will be fabricated with pulse combustors supplying multiple resonance tubes.

In order to withdraw bed solids during the course of a test run, a screwtype valve was added to the reactor shell. A schematic of the solid sampling valve is shown in Figure 6-14. When a solid sample is required, the screw valve is opened and solids are drained into a nitrogen purged catch-pot. The catch-pot is purged to cool the solids before discharge into the open air, and to carry out any combustible gases. 


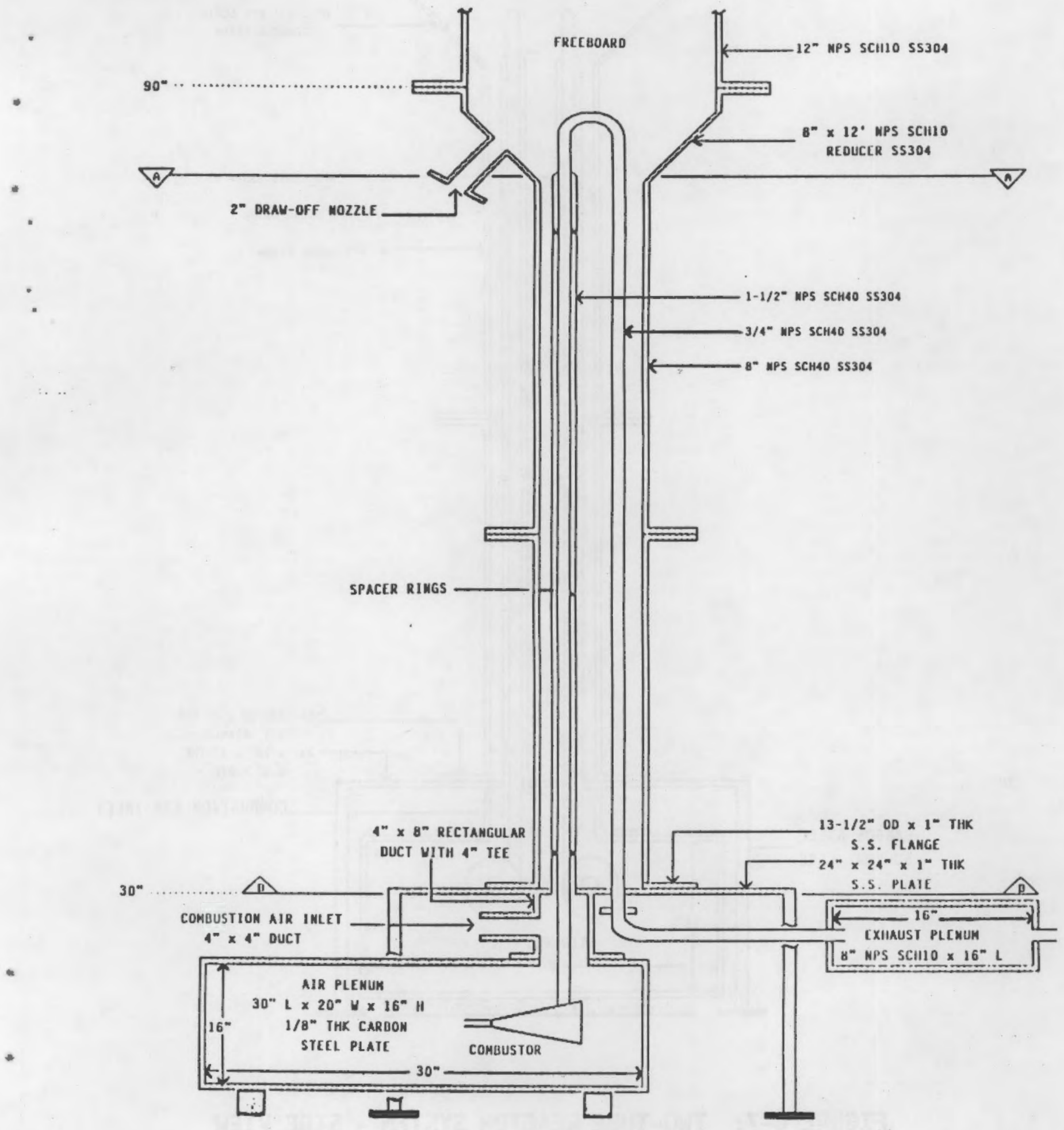

FIGURE 6-6: TWO-TUBE REACTOR SYSTEM - FRONT VIEW 


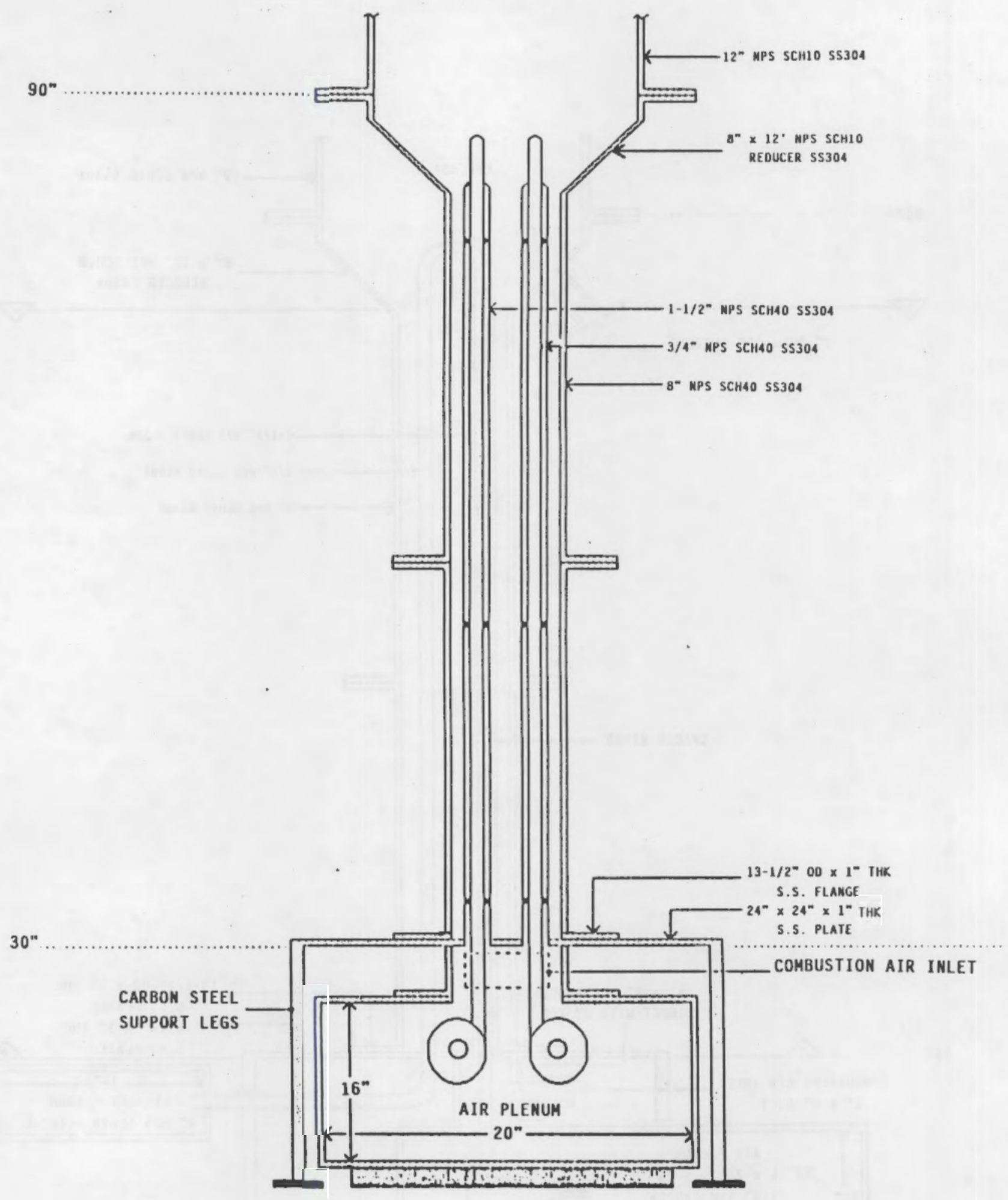

FIGURE 6-7: TWO-TUBE REACTOR SYSTEM - SIDE VIEW 


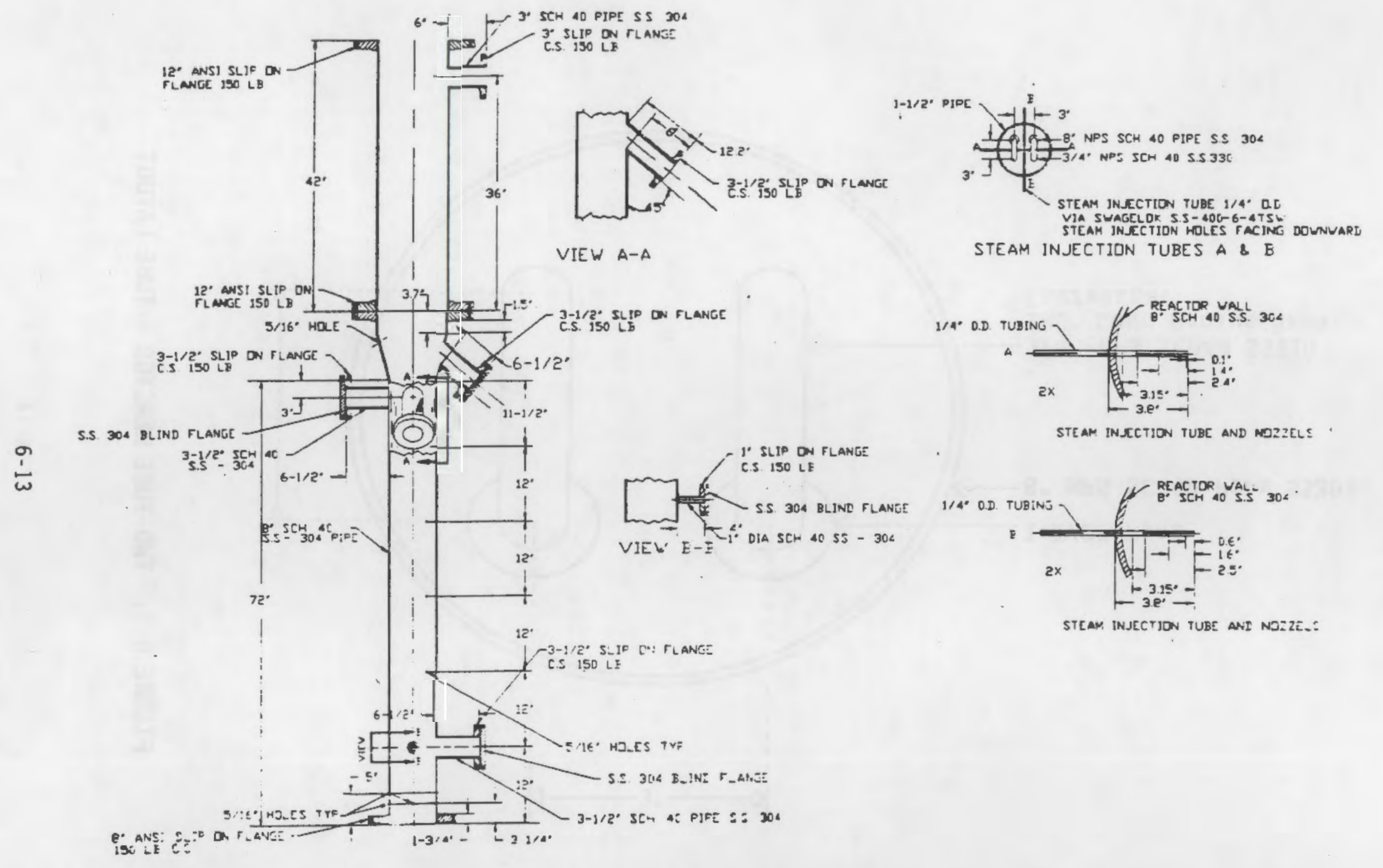

\section{FIGURE 6-8: TWO-TUBE REACTOR SYSTEM, REACTOR SHELL AND STEAM INJECTION TUBES}




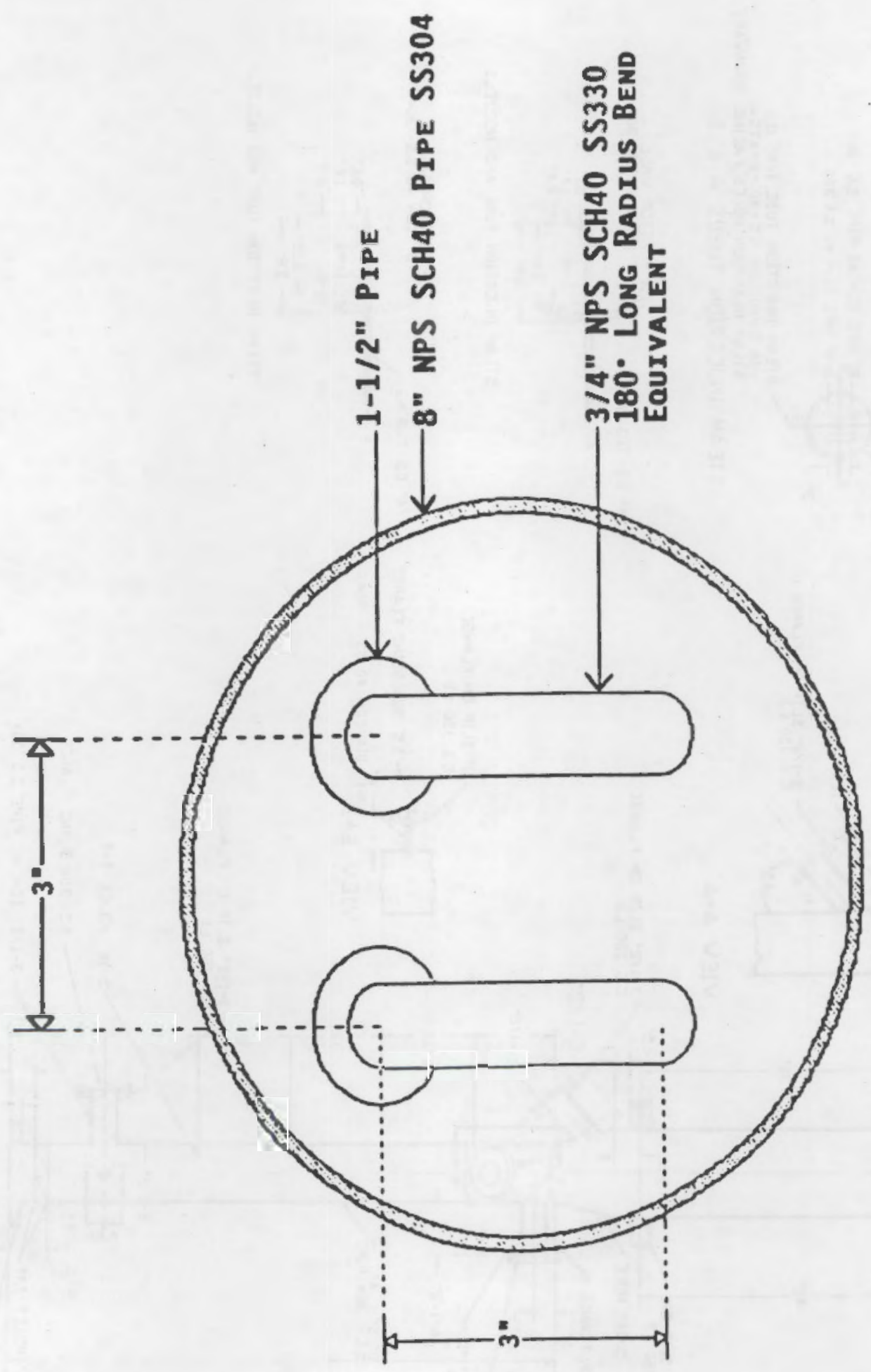

FIGURE 6-9: TWO-TUBE REACTOR - TUBE LAYOUT 


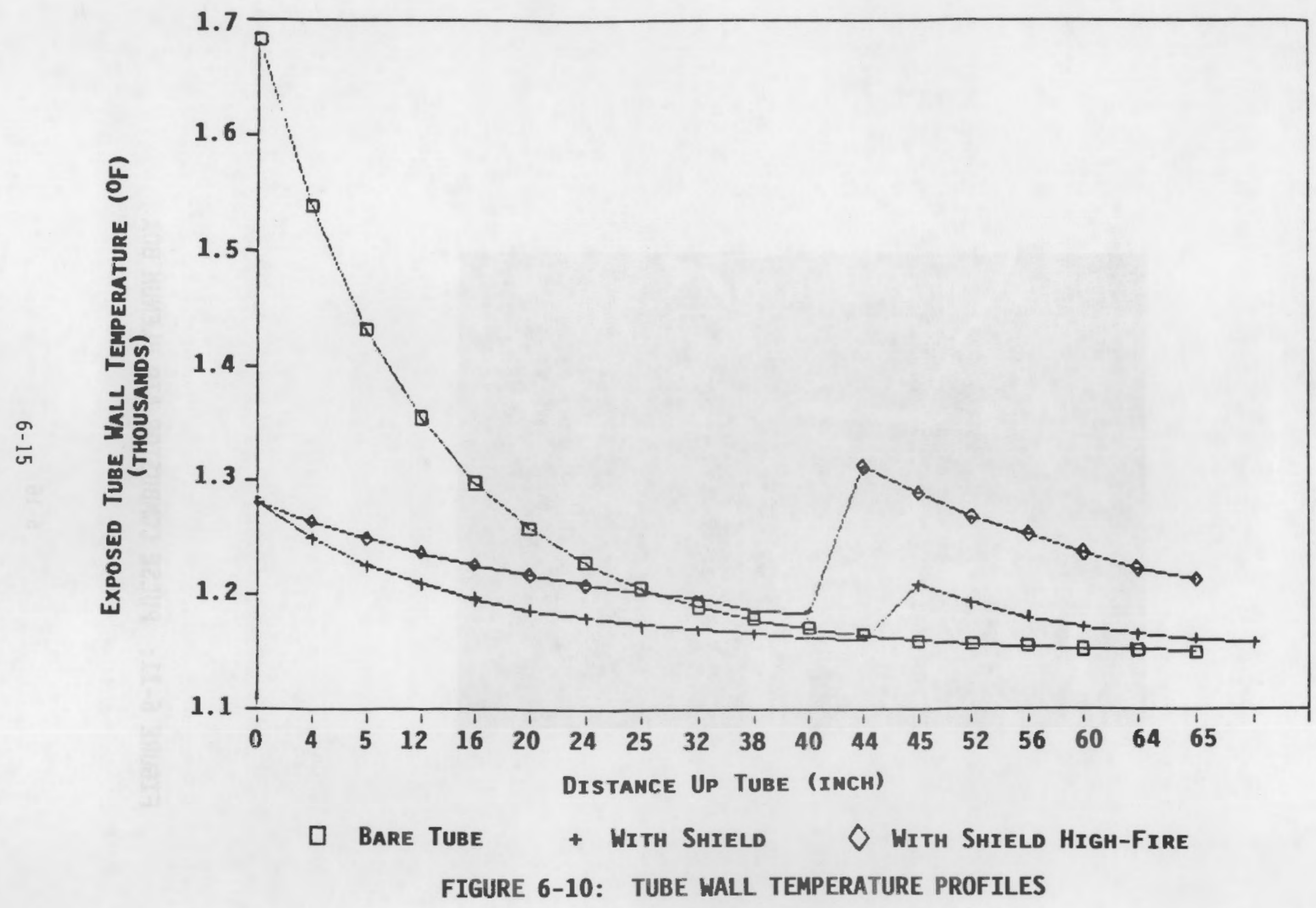




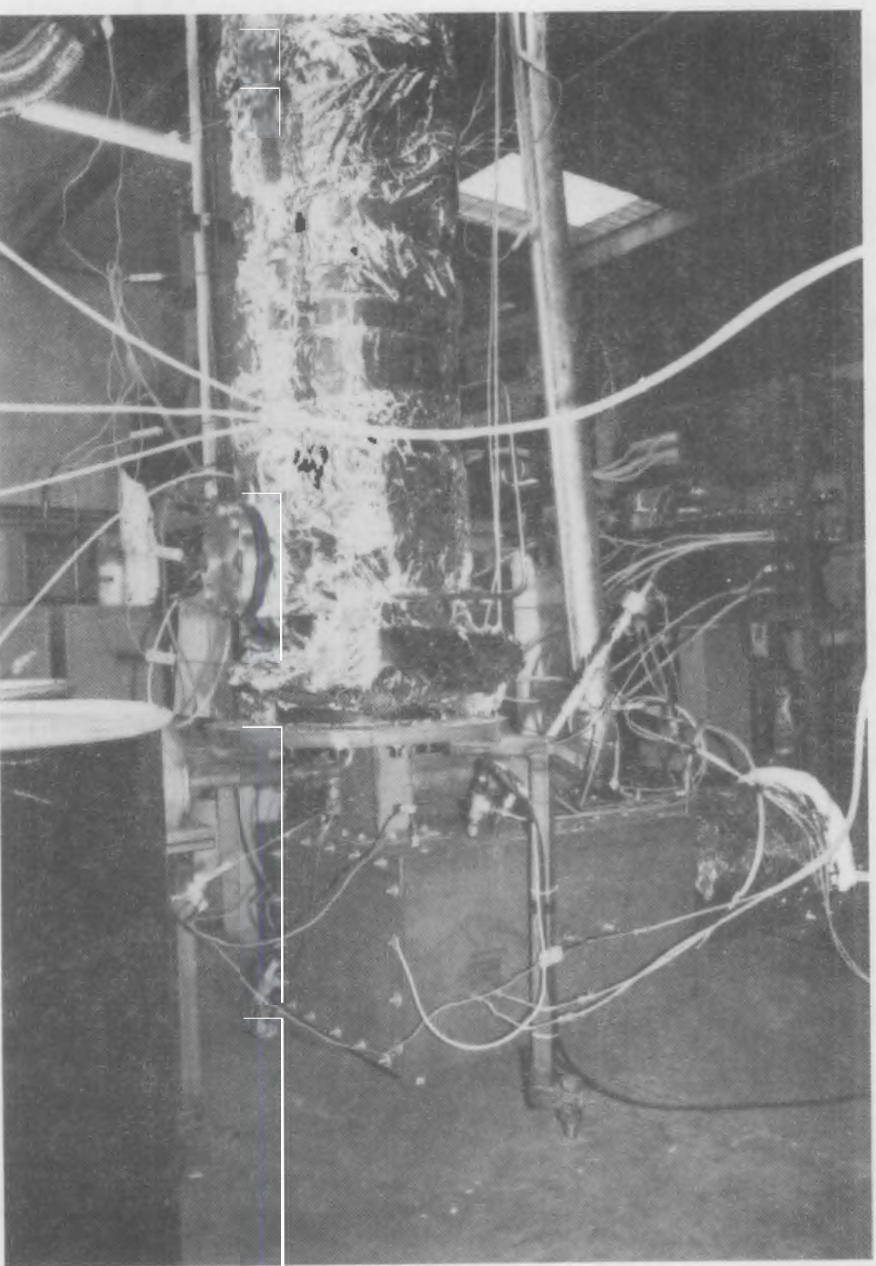

FIGURE 6-11: PULSE COMBUSTOR AIR PLENUM BOX 


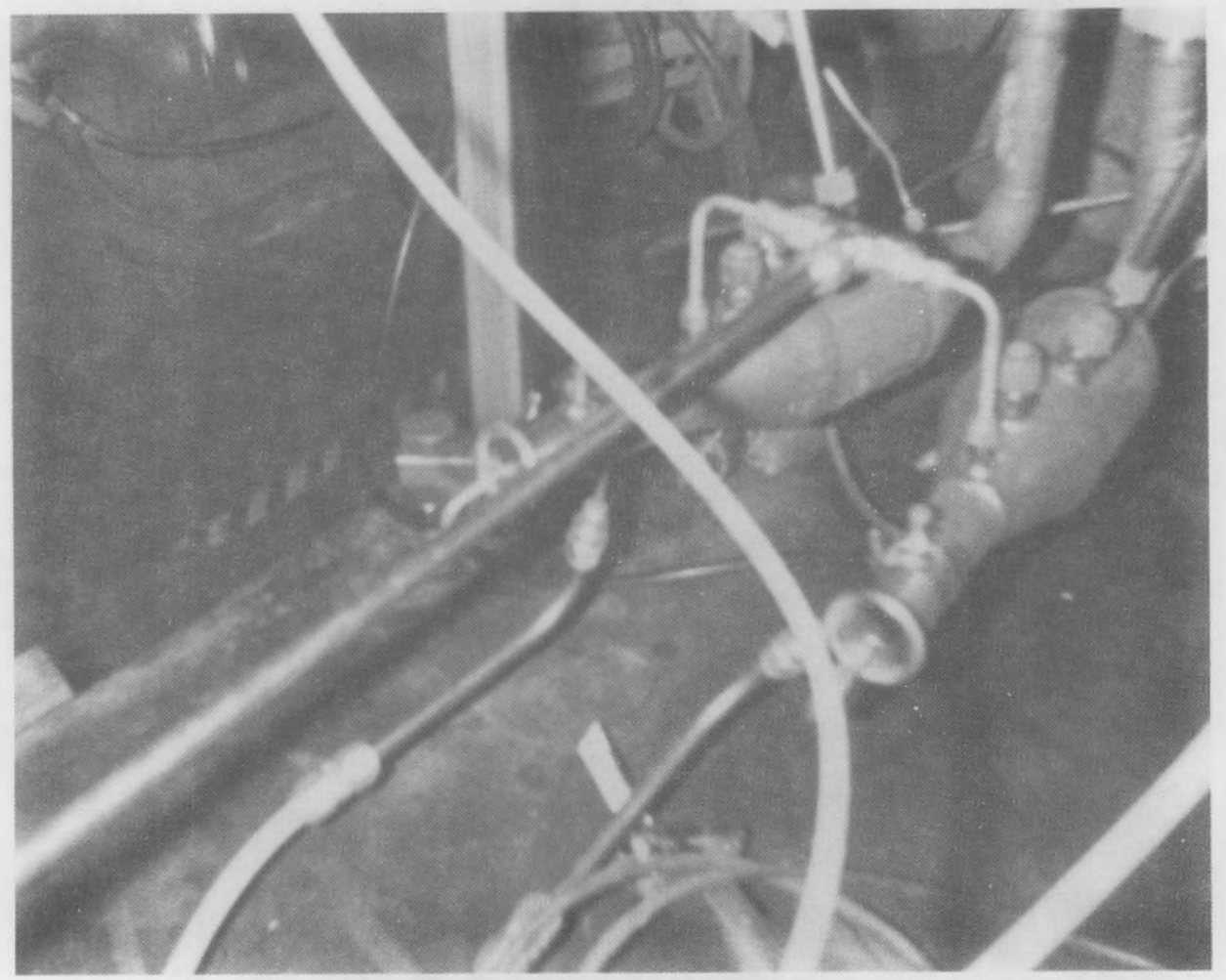

FIGURE 6-12: PULSE COMBUSTORS DURING INITIAL TEST FIRING 


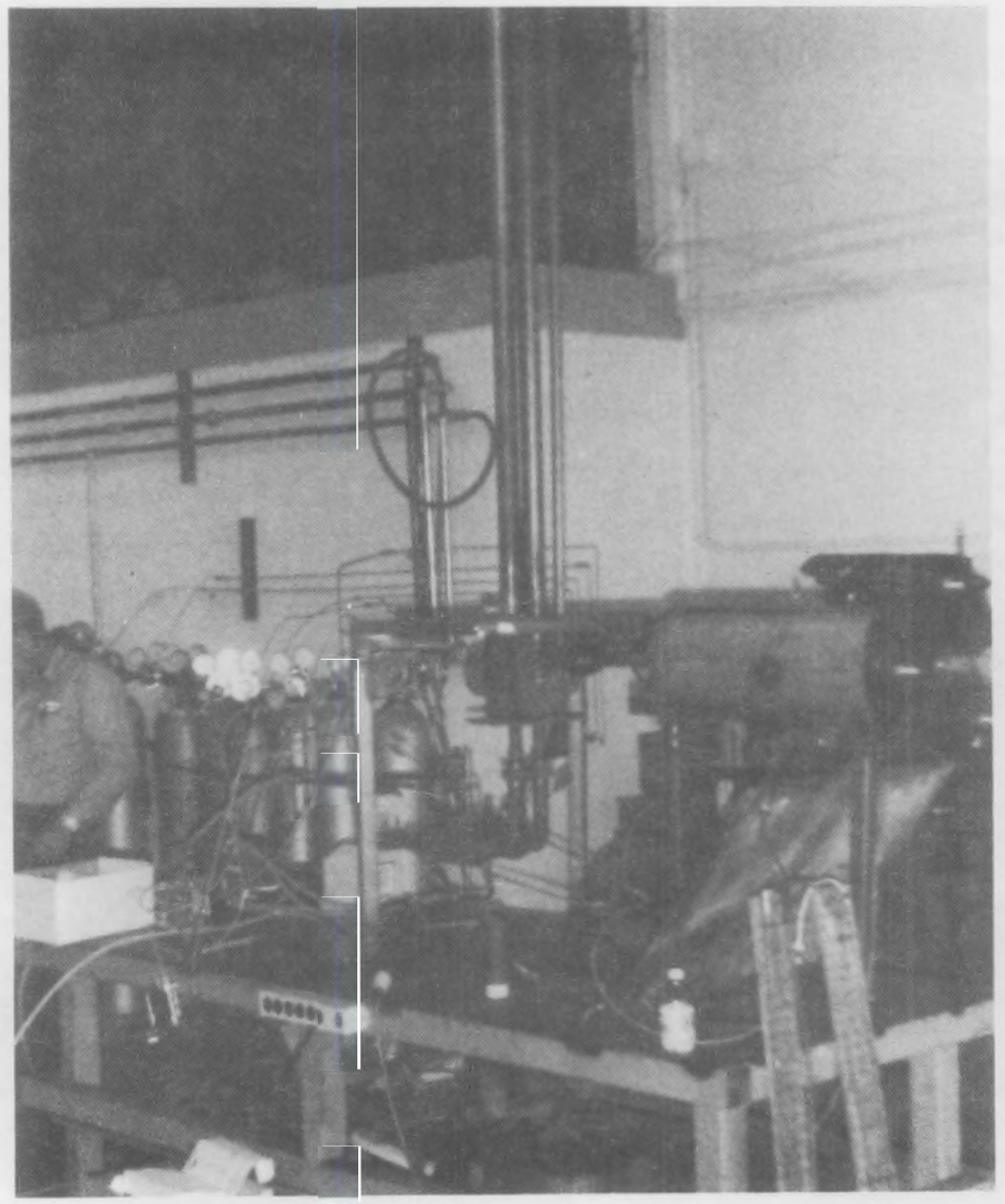

FIGURE 6-13: PULSE COMBUSTORS INTEGRATED WITH FIRE TUBES 


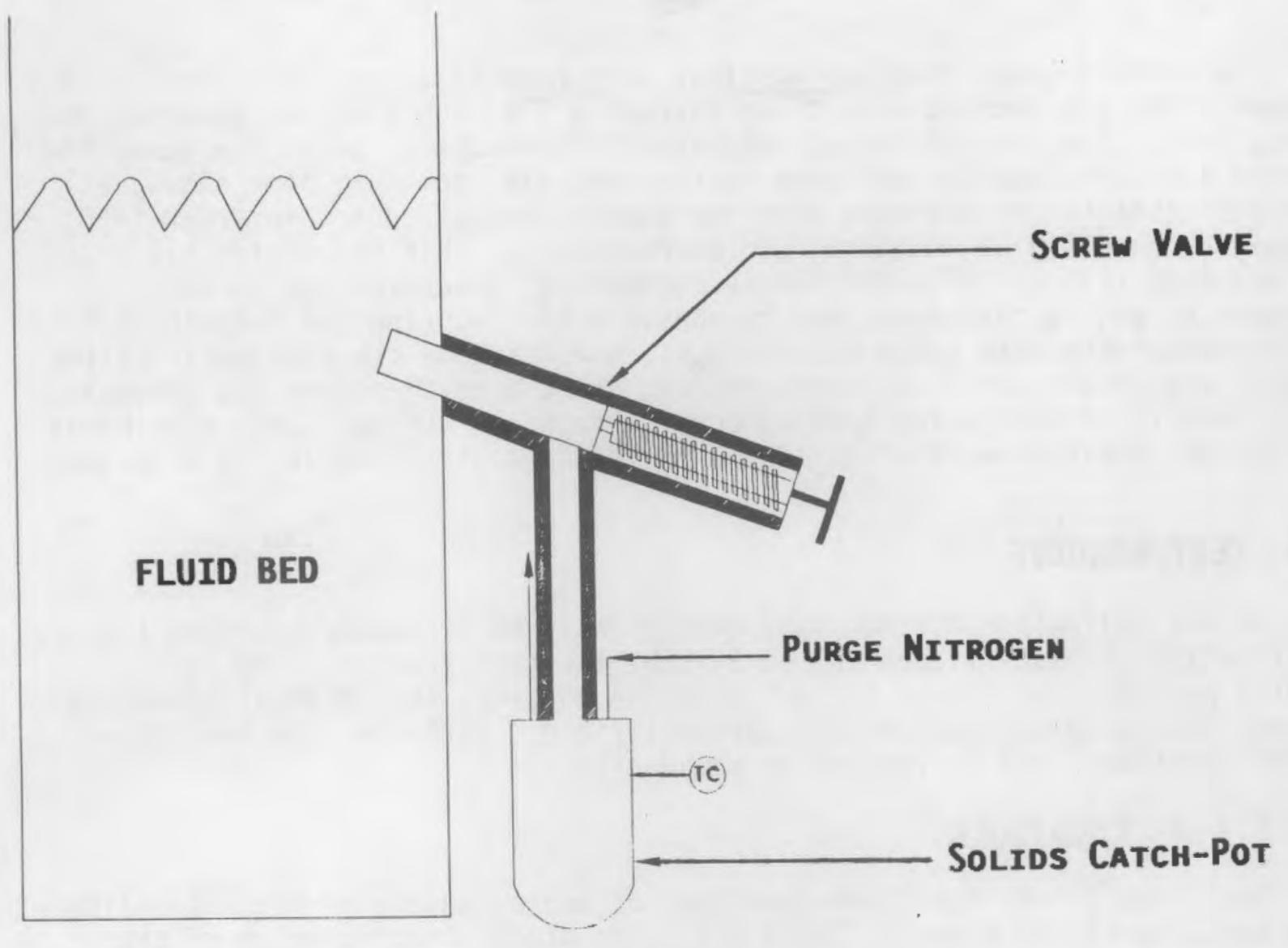

\section{FIGURE 6-14: SCHEMATIC OF BED SOLIDS SAMPLING VALVE}

\subsubsection{INSTRUMENTATION}

The gasification system was fully instrumented in accordance with the data collection requirements for characterizing gas yield distributions, bed carbon level, and critical tube wall and bed temperature profiles.

The gasifier bed was furnished with six separate thermocouples. This allowed determination of temperature profiles within the bed which provided direct evidence of fluidization quality. Each resonance tube was also fitted with three pad-mounted tube wall thermocouples. The tube wall thermocouples were mounted at the base of the radiant tube, at the entrance to the bare tube region, and at the end of the bare tube. The first two locations mentioned above are most critical, since these are the points of highest wall temperature.

In addition, thermocouples were provided to monitor temperatures in the combustors, air plenum, steam preheat exit, and flue gas exit. Selected thermocouples were integrated with a data acquisition system for continuous monitoring and data storage. The data acquisition system consisted of a DAS-8 analog to digital converter (XBX Sales, Orange, CA) and 16-channel multiplexer which was coupled to a mini-computer. 
The product gases from the gasifier were coupled at the exit from the hot cyclone. The gas samples were drawn through a $1 / 4$-inch 1 ine and quenched in an ice bath. The condensate was separated in a knock-out pot. The gases then entered a vacuum pump for delivery to the analysis room. In some cases, a sintered metal filter was used near the sample draw-off point in order to reduce the quantity of entrained sodium carbonate. This was tested since it was believed that the alkaline sample condensate, generated due to the presence of sodium carbonate, was responsible for reducing the breakthrough of sulfur-containing acid gases such as $\mathrm{H}_{2} \mathrm{~S}$. However, the sintered metal filter plugged easily and the gases were analyzed using a multi-column gas chromatograph capable of speciating hydrocarbons through $\mathrm{C}_{\mathbf{4}}$. In addition, continuous $\mathrm{NO}_{x}$ and $\mathrm{SO}_{x}$ monitors were utilized to monitor concentrations in the flue gas.

\title{
6.4 TEST RESULTS
}

In the following section, test results will be presented covering the gasification of black liquor in the 8 -inch, two-tube reactor. The test results provide significant insight into the physical and chemical mechanisms controlling the gasification rate, product yields, particle size evaluation, sulfur reactions, and agglomeration boundaries.

\subsubsection{FEEDSTOCK}

The black liquor feedstock consisted of approximately 67 percent solids with the composition shown in Table 6-1. The higher heating value of the solids was approximately $6500 \mathrm{Btu} / \mathrm{lb}$. The black liquor is representative of by-products from a commercial mill and was provided by the Weyerhaeuser Company from their Longview, Washington mill.

\author{
TABLE 6-1: \\ ANALYSIS OF BLACK LIQUOR FEEDSTOCK \\ (67\% SOLIDS)
}

COMPOSITION

Carbon

Hydrogen

oxygen

Nitrogen

Total Sulfur

Sodium

Potassium

Chloride

Sulfate

Sulfide
WT.\% (DRY BASIS)

37.7

3.7

31.6

1.0

4.3

18.7

1.1

0.5

1.1

1.3 


\subsubsection{OPERATIMG HISTORY}

System testing of the indirect gasifier on black liquor feedstocks was conducted over a six-week period from late May 1988 to early July 1988 . The test results provided detailed information on specific gasification rates, product yields, bed carbon levels, and operating boundaries.

Over 100 hours of hot fluidization tests were achieved during this period. The gasifier operated on black liquor feeds for over 60 hours. A single long duration test of over 40 hours of continuous operation was also conducted. A total of seven separate test runs were attempted covering eight distinct operating temperatures. Two of the tests resulted in forced shutdowns due to problems with the black liquor injector. One test prematurely shutdown due to agglomeration of the bed solids. In each of the cases where forced shutdowns were experienced, the operating problems were clearly identified, and means for resolving these problems were developed. In no case did the operating problems suggest fundamental limitation of the gasification system, but only the need for proper operating protocol. The temperatures were successfully maintained over the full planned test period. Table 6-2 provides a summary of the gasifier operating history.

\section{TABLE 6-2:}

SUMMARY OF OPERATING HISTORY

\begin{tabular}{|c|c|c|c|c|}
\hline TEST DATE & $\begin{array}{l}\text { TEMPERATURE } \\
\text { (' } \mathrm{F})\end{array}$ & $\begin{array}{l}\text { BLACK LIQUOR } \\
\text { FEED PERIOD (hr) }\end{array}$ & $\begin{array}{l}\text { TOTAL } \\
\text { BLACK LIQUOR } \\
\text { FEED (1bs) }\end{array}$ & COMMENTS \\
\hline $5 / 26 / 88$ & 1160 & 2.5 & 54 & $\begin{array}{l}\text { Problems with feed } \\
\text { pump and injector. }\end{array}$ \\
\hline $6 / 2 / 88$ & 970 & 1.0 & 15 & $\begin{array}{l}\text { Injector plugged } \\
\text { remedial action } \\
\text { resulted in en- } \\
\text { trainment of bed. }\end{array}$ \\
\hline $6 / 10 / 88$ & 1030 & 7.0 & 144 & Successful test. \\
\hline $6 / 15 / 88$ & 1120 & 6.0 & 78 & Successful test. \\
\hline $6 / 22 / 88$ & $1150-1160$ & 5.0 & 61 & Successful test. \\
\hline $6 / 28 / 88$ & $1200-1250$ & 0 & 0 & $\begin{array}{l}\text { Melt agglomeration } \\
\text { of bed temperature } \\
\text { too high. Carbon } \\
\text { completely gasi- } \\
\text { fied from solids. }\end{array}$ \\
\hline $7 / 6 / 88$ & $1090-1120$ & 42.0 & 347 & $\begin{array}{l}\text { Successful long } \\
\text { duration test. } \\
\text { Lost one com- } \\
\text { bustor near end } \\
\text { due to scaling. }\end{array}$ \\
\hline
\end{tabular}


On May 26, 1988, a black liquor test run was conducted for 2.5 hours, after which problems developed in the feed pump and injector system. For this test, the feed pump consisted of a progressive cavity Moyno pump. Since the black liquor feedstock contained approximately 67 percent solids, the feed was heated in a steam-jacketed, agitated vessel to reduce liquor viscosity to a range which facilitated pumping and injection. The black liquor was maintained at approximately $180^{\circ} \mathrm{F}$ in the liquor storage vessel.

However, the feed line to the injector was improperly insulated and did not include steam tracing. This resulted in excessive heat loss from the black liquor feed stream. Due to this effect, the liquor viscosity increased to a point where pumping became difficult. Low flow rates through the injector eventually resulted in carbonization and plugging at the injector tip which required shutdown of the gasifier.

A second test was conducted on June 2, 1988. For these tests, the feed line was steam traced. In addition, a protocol was developed to ensure that the injector tip was properly purged prior to admitting black liquor. This was done since back flow of solids from the bed into the injector tip also appeared to contribute to the plugging problems encountered in the prior run. With these modifications, black liquor was injected for one hour before feed problems were again experienced. These problems were found to be associated with the Moyno pumps. Inspection of the pumps revealed severe wear of the pump stator. The Moyno pump was then replaced with a positive displacement gear pump. Future tests from this point on resulted in no difficulties with the feed or injector system.

The primary conclusions of these tests were that proper feed injection could be maintained through a combination of: (1) sufficient feed line steam tracing, (2) ample purging of the injector tip prior to switch over to black liquor, and (3) the use of a simple gear pump.

On June 10, 1988, tests were conducted over a black liquor feed period of seven hours. The tests were performed at a relatively low bed temperature of $1030^{\circ} \mathrm{F}$, similar to the temperature conditions of the initial feasibility test operated in 1987. A total of 144 pounds of black liquor was fed during the test period. Gas composition measurements were made at regular intervals and the system was shutdown at the end of the test period as planned.

On June 15, 1988, tests were conducted at an increased temperature level of $1120^{\circ} \mathrm{F}$. A total of 78 pounds of black liquor was fed for a period of approximately 6 hours. Regular gas samples were analyzed and the system was shutdown as planned.

On June 22,1988 , the reactor temperature was further elevated to $1160^{\circ} \mathrm{F}$. Prior to this test, a bed solids sampling valve was installed on the reactor. The sample valve allowed instantaneous sampling of the fluid bed solids for the purpose of establishing the temporal carbon content of the bed during the test run. This provided valuable information regarding specific gasification rates. The test was conducted for 5 hours and a total of 61 pounds of black liquor was fed to the gasifier. Eleven solid samples were withdrawn from the bed during the test period. These samples were analyzed at Weyerhaeuser's 
1aboratory facility. In addition, numerous analyses were made of the product gas, and the test was shutdown as planned.

On June 28, 1988, the reactor temperature was increased to 1200 to $1250^{\circ} \mathrm{F}$. Black liquor was not introduced during the heat-up period in order to accelerate the rate in which the bed achieved the desired operating temperature. However, before black liquor was introduced, proper bed fluidization performance was lost, and the gasifier was shutdown. This was identified by rapidly increasing tube wall temperatures and increased bed pressure drop. Post-test inspection of the gasifier revealed that the bed had agglomerated, particularly near the base of the reactor. Furthermore, the carbon on the bed solids had been completely gasified, leaving almost no residual surface carbon. Scanning electron micrographs (SEM), provided by Weyerhaeuser, clearly identified the participation of surface chlorides in the agglomeration process. It is now believed that such agglomeration can be avoided at these temperatures if a surface coating of carbon is maintained on the bed solids. This can be accomplished through an operating protocol that requires black liquor injection when bed temperatures rise above $1200^{\circ} \mathrm{F}$. A more detailed discussion of this phenomena is found in a later section.

On July 6, 1988, a long-term test run of over 40 hours was achieved. The tests were conducted over a two-day period covering four separate shifts. Approximately 347 pounds of black liquor were fed into the gasifier. The gasifier was operated at two separate temperature plateaus, one at $1090^{\circ} \mathrm{F}$ and one in the range of 1120 to $1140^{\circ} \mathrm{F}$. During the test period, 16 separate solid samples were withdrawn from the bed. In addition, 15 cyclone solids samples of the solids entrained from the fluid bed and collected in the cyclone were taken. Selected samples were analyzed for elemental composition at Weyerhaeuser's laboratory.

These tests provided a more meaningful evaluation of the longer term stability of the fluidized bed. The quantity of inorganic material fed to the reactor was sufficient to completely replace the initial bed charge material. In this sense, any anomalous behavior which might occur with respect to particle size evolution, defluidization tendencies, or other problems should have been evident. However, no such phenomena were found to occur over the test period.

The results of these tests provided a sufficient data base with which to prepare preliminary estimates of performance in a larger scale integrated system. Preliminary evaluation of a one ton $/ \mathrm{hr}$ plant is made in a later section.

\subsubsection{Gasification Product Yieldos}

Product gas compositions were analyzed using a seven-column Carle gas chromatograph. The gas chromatograph is specifically designed for analyzing refinery gases such as those represented in the gasifier product stream. The gas samples are drawn from the exit of the gasifier cyclone and passed through a condenser, knock-out pot, and vacuum pump for delivery to the gas chromatograph. The gas includes quantities of nitrogen which are used to purge the reactor ports, e.g., pressure taps, injection nozzles, etc. In addition, some air in leakage in the vacuum line contributes to nitrogen in the sample gas. 
These quantities are normalized out in presenting the dry gas product compositions. Selected gas compositions which are representative of each test run at steady-state conditions are given in Table 6-3.

TABLE 6-3:

REPRESENTATIVE DRY GAS YIELDS FOR

BLACK LIOUOR GASIFICATION TEST RUNS

\begin{tabular}{|c|c|c|c|c|c|}
\hline $\begin{array}{l}\text { TEMPERATURE, } \bullet F \\
\text { GAS COMPOSITION, Vol.\% }\end{array}$ & $\frac{6 / 10 / 88}{1030}$ & $\frac{6 / 15 / 88}{1120}$ & $\frac{6 / 22 / 88}{1160}$ & $\frac{7 / 6 / 88}{1090}$ & $\frac{7 / 7 / 88}{1140}$ \\
\hline $\mathrm{CH}_{4}$ & 5.12 & 2.37 & 1.40 & 3.31 & 2.25 \\
\hline $\mathrm{H}_{2}$ & 63.97 & 64.85 & 65.72 & 64.17 & 64.76 \\
\hline $\mathrm{CO}_{2}$ & 24.56 & 29.18 & 29.69 & 29.32 & 29.16 \\
\hline $\mathrm{CO}$ & 4.70 & 3.13 & 2.95 & 2.74 & 3.45 \\
\hline$C 2^{\prime} 5$ & 0.69 & 0.33 & 0.19 & 0.34 & 0.29 \\
\hline$C 3^{\prime} 5$ & 0.28 & 0.14 & 0.05 & 0.12 & 0.09 \\
\hline Dry Gas HHV, scf & 292 & 253 & 241 & 258 & 250 \\
\hline
\end{tabular}

The bed temperature and feed history for these tests are shown in Figures 6-15 through 6-18. Note that some of these graphs plot the temperature measured by several different thermocouples placed at various vertical locations within the bed. It can be seen that under normal operating conditions, the bed temperature is very uniform throughout.

As seen in the table, the product gases range in methane concentration from approximately 5 to 1.5 percent depending on temperature. The higher temperatures favor lower methane levels, as consistent with equilibrium predictions, The hydrogen content remains relatively constant at 64 to 66 percent, as does the carbon dioxide content which is typically found to be in the range of 29 percent. The carbon monoxide content varies from approximately 5 to 2.5 percent. Higher hydrocarbons are generally found only in relatively small concentrations and diminish with temperature.

It should be recognized that the ratio between carbon dioxide and carbon monoxide is significantly affected by the steam partial pressure within the gasifier, due to the water gas shift reaction. High steam partial pressures favor the production of carbon dioxide relative to carbon monoxide. The test 


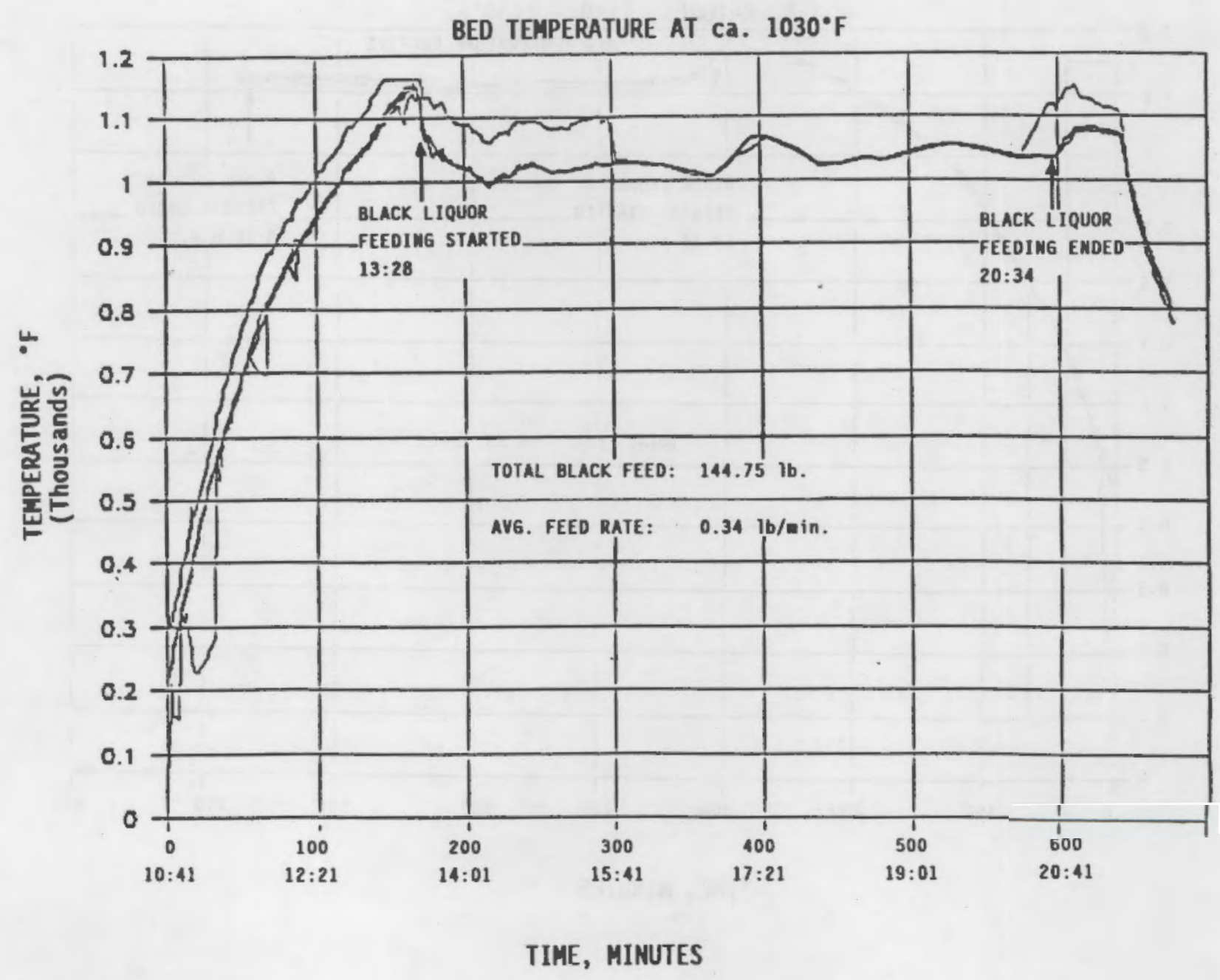

FIGURE 6-15: BLACK GASIFICATION TEST, 6/10/88 (Bed Temperature at CD. $1030^{\circ} \mathrm{F}$ ) 


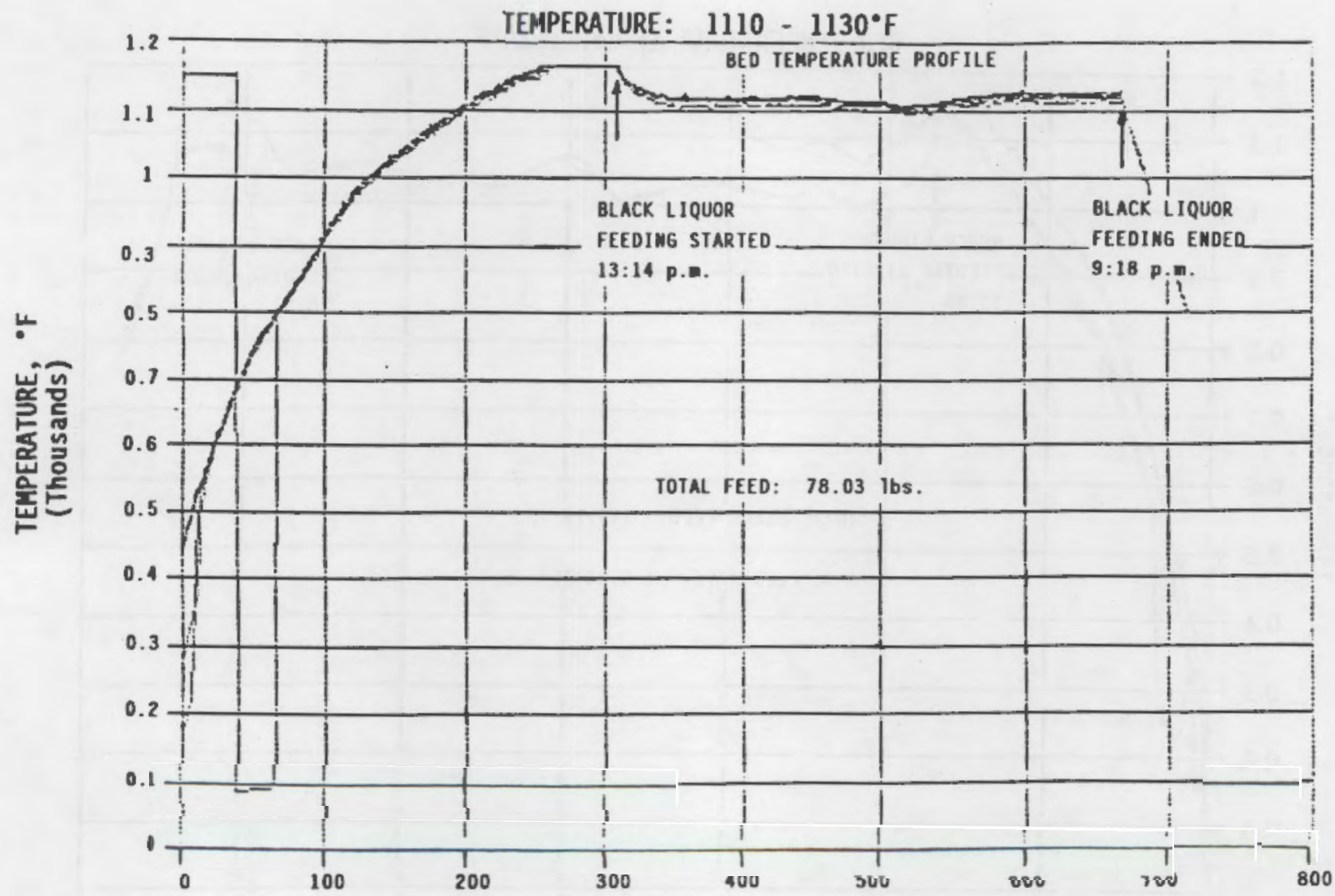

TIME, MINUTES

FIGURE 6-16: BLACK GASIFICATION TEST, 6/15/88

(Temperature, 1110 - 11300F) 


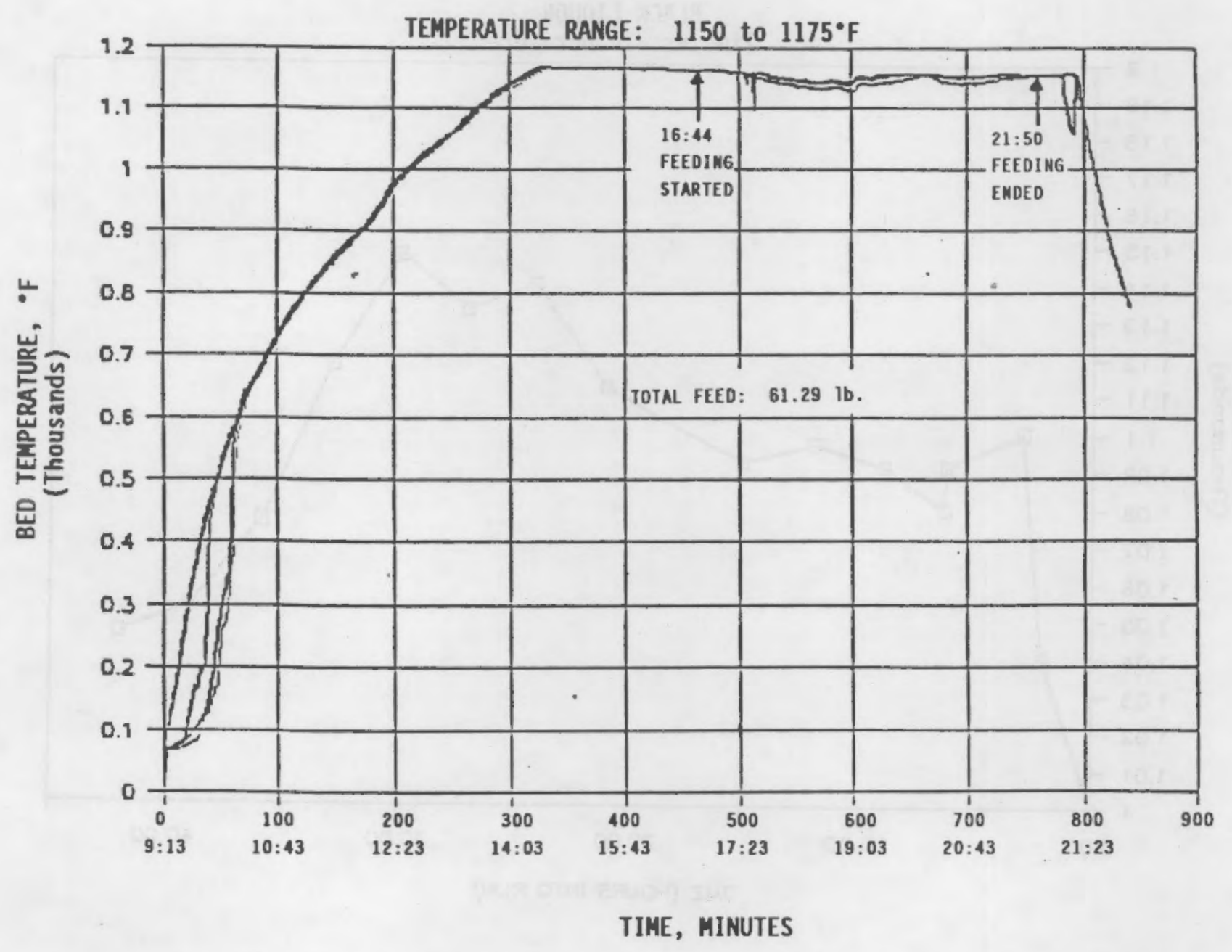

FIGURE 6-17: BLACK GASIFICATION TEST, 6/22/88

(Temperature, 1150 - 11750 F) 


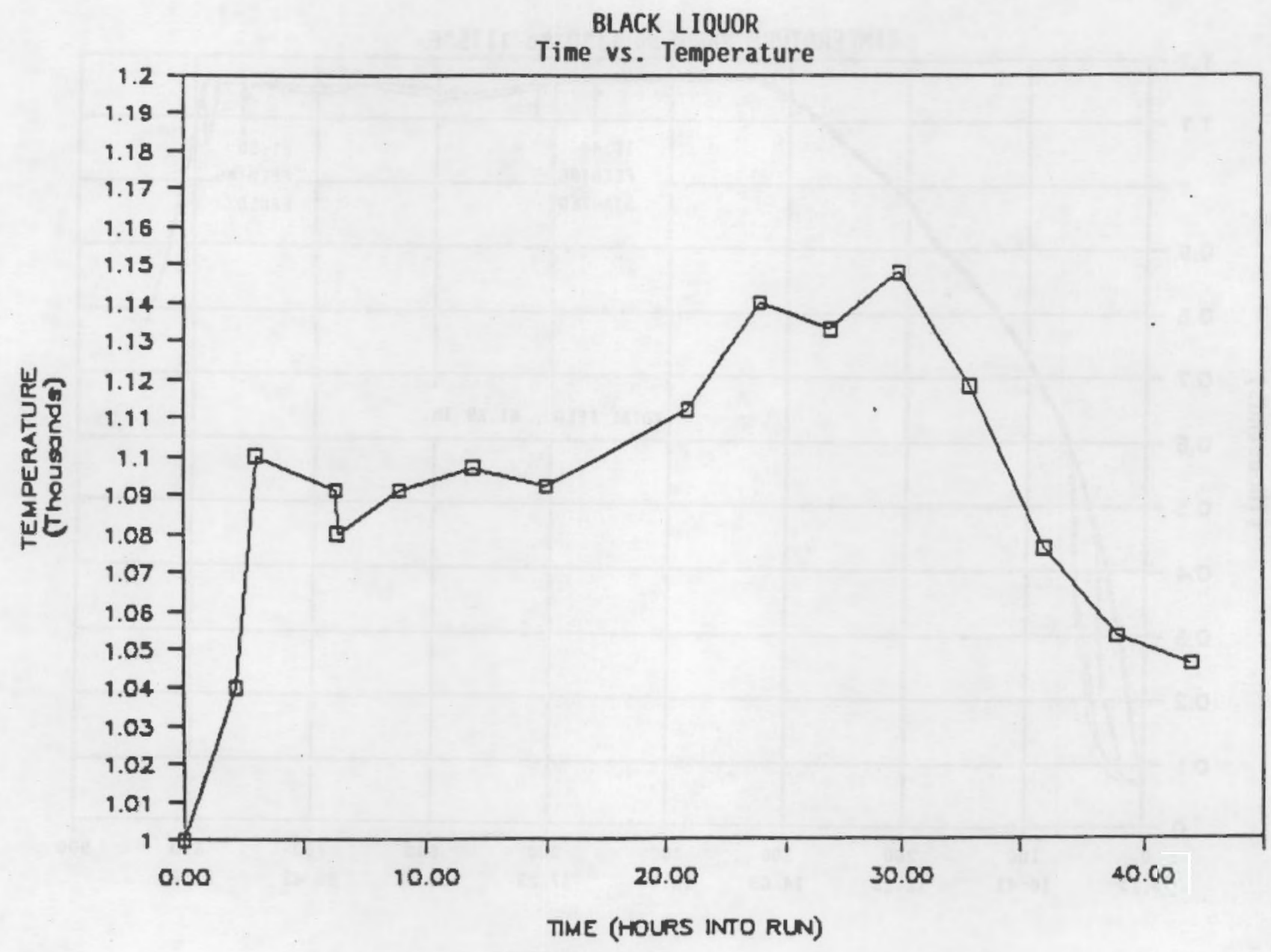

FIGURE 6-18: REACTOR TEMPERATURE VS. TIME FOR LONG DURATION TEST RUN 
conditions in the bench-scale reactor were operated with steam partial pressures in the range of 80 percent. These are significantly higher than those anticipated in the commercial configuration employing recycle of product gas for fluidization. Therefore, in the commercial configuration, the relative ratio of carbon dioxide to carbon monoxide will diminish. Based on the results of the experimental data, the gas concentrations appear to be predicted by the water-gas shift equilibrium to a good approximation. This can be used to extrapolate gas compositions at different conditions, such as those for the commercial configuration with product gas recycle.

The heating value of the product gas varied from about $240 \mathrm{Btu} / \mathrm{scf}$ to $300 \mathrm{Btu} / \mathrm{scf}$ and decreased with increasing temperature. Figure 6-19 shows a plot of the product gas heating value as a function of gasifier temperature. The higher heating values exhibited in the lower temperature test runs is due to the increasing methane and higher hydrocarbon contents of these gases. As temperature increases, the extent to which these hydrocarbons are gasified with steam increases. This generates increasing quantities of hydrogen, carbon monoxide and carbon dioxide, which reduces the gas heating value.

Note that in the earlier feasibility test, higher heating values in the range of $400 \mathrm{Btu} / \mathrm{scf}$ were attained at operating temperatures in the range of $1030^{\circ} \mathrm{F}$. These heating values appear to be more representative of pyrolysis conditions with a minimum level of char gasification.

\subsubsection{Product SOLIds Amalysis}

In order to better define the operating behavior of the gasifier, to detect the distributions of elements in the various solid product streams, and to assist in preparing material balances, numerous solid samples were collected during selected gasifier test runs. These solid samples were then analyzed for pertinent species including organic carbon, total sulfur, sulfide, sulfate, and sodium. The bulk of these solids were analyzed at Weyerhaeuser's Laboratory facilities in Tacoma, Washington.

Solid samples were collected in several different locations. Both instantaneous and post-run samples were collected for some tests. Sample point locations included the fluid bed, the cyclone dipleg, and the cyclone catch-drum. Instantaneous bed samples were withdrawn during gasifier operation using a screw-type sample drain valve. Instantaneous solid samples were also taken from the cyclone dipleg using a dual lock valve and "Tee" arrangement.

At the completion of the test run, the fluidized bed was completely drained and weighed. The fines collected in the cyclone catch-drum were also discharged and weighed. Solids at the conclusion of the test runs were employed to calculate over-all material balances when possible. Table 6-4 summarizes the elemental analysis of bed solids withdrawn at ten separate times during the test run on June 22, 1988. Figure 6-20 shows the percent carbon on the bed solids versus time. Note that the bed was operating at a temperature of $1160^{\circ} \mathrm{F}$. 


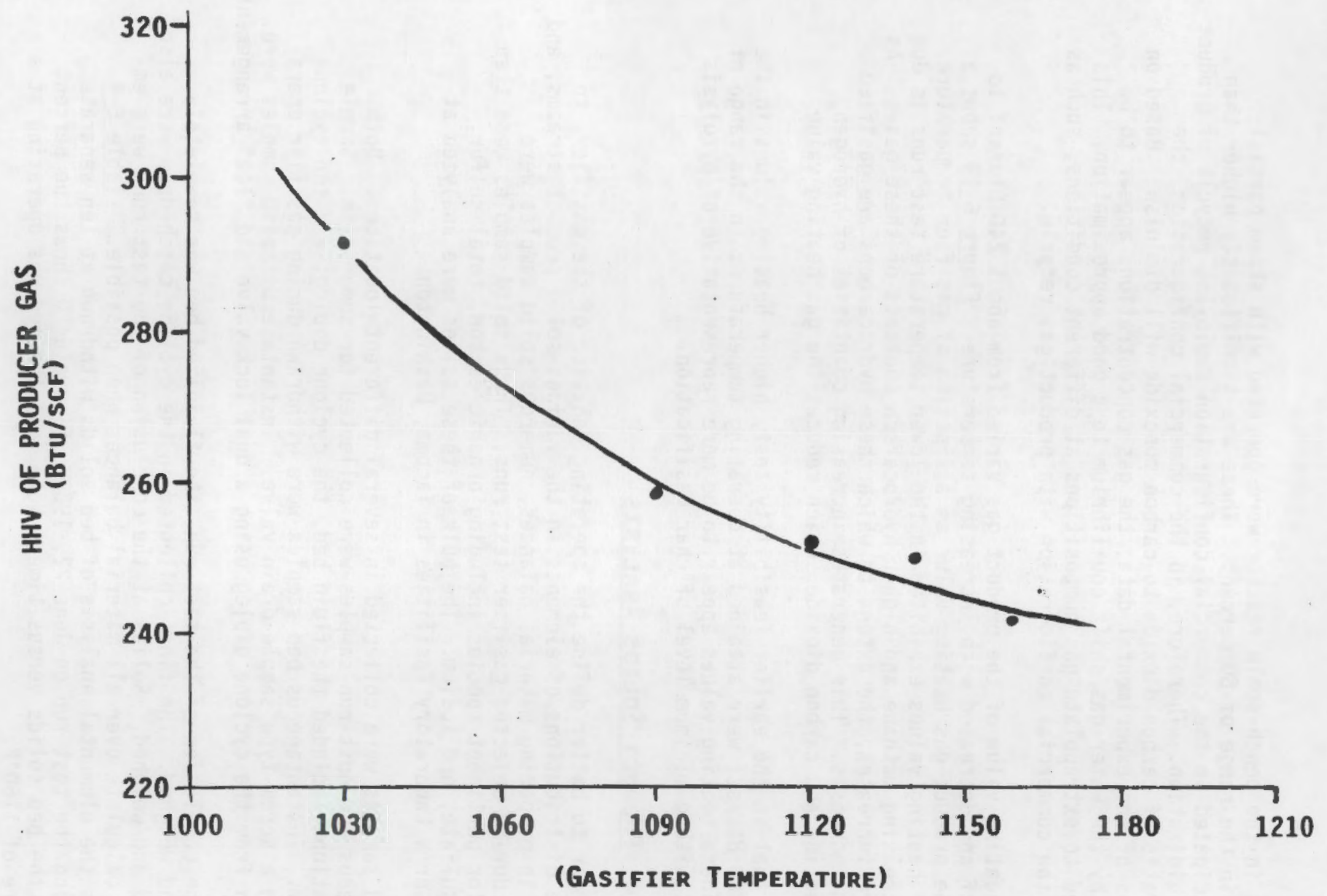

FIGURE 6-19: PRODUCT GAS HEATING VALUE AS A FUNCTION OF GASIFIER TEMPERATURE 
TABLE 6-4:

BED SOLID SAMPLES FOR TEST RUN (6/22/88)

(x)

\begin{tabular}{llccccc} 
SAMPLE & TYPE & TIME & $\begin{array}{c}\text { ELEMENTAL } \\
\text { CARBON }\end{array}$ & $\begin{array}{c}\text { TOTAL } \\
\text { SULFUR }\end{array}$ & $\begin{array}{c}(\mathbf{( m g} / \mathbf{k g}) \\
\text { SULFIDE }\end{array}$ & $\begin{array}{c}(\boldsymbol{\chi}) \\
\text { SULFATES }\end{array}$ \\
\hline BLB 6/22-1 & Bed & 1345 & 7.8 & 0.32 & 10 & 0.26 \\
BLB 6/22-2 & Bed & 1534 & 4.9 & 0.19 & 10 & N/A \\
BLB 6/22-3 & Bed & 1621 & 2.7 & 0.15 & 10 & N/A \\
BLB 6/22-4 & Bed & 1745 & 3.1 & 0.15 & 13 & N/A \\
BLB 6/22-5 & Bed & 1845 & 2.6 & 0.22 & 25 & N/A \\
BLB 6/22-6 & Bed & 1945 & 2.6 & 0.15 & 66 & N/A \\
BLB 6/22-7 & Bed & 2045 & 2.3 & 0.20 & 103 & 0.12 \\
BLB 6/22-8 & Bed & 2145 & 2.7 & 0.23 & 16 & N/A \\
BLB 6/22-9 & Bed & 2210 & 1.7 & 0.18 & 10 & N/A \\
BLB 6/22-10 & Bed & 2225 & 1.1 & 0.15 & 37 & 0.12
\end{tabular}

The initial carbon content of the bed was approximately $7.8 \mathrm{wt} . \%$. This initial bed carbon level was established during prior test runs conducted at lower temperatures. As shown in the figure, the carbon content steadily diminished during the first two or three hours while the bed was being fluidized with steam, without black liquor being fed. The reduction in bed carbon fives a clear indication that the char deposited in the bed solids is being gasified by reaction with steam.

After introduction of the black liquor feedstock, the bed eventually establishes an equilibrium carbon level which at this temperature and feed rate is approximately $2.6 \mathrm{wt} . \%$. When the feed was removed, the carbon level diminished further to $1.1 \mathrm{wt} . \%$. An estimation of the gasification rate from this data will be made in later sections.

Figure 6-21 shows the bed total sulfur and sulfate content during the course of the run. Notice that despite the fact that both sulfur and sulfate is being introduced into the bed via the black liquor, the bed sulfur/sulfate levels are diminishing or remaining approximately constant. Also note from Table 6-4 that the sulfide content of the bed is negligible. These results provide quantitative evidence for both sulfate reduction, and sulfur removal via reduced gas species in the product gas. A more quantitative discussion of the sulfur distributions are provided in a later subsection.

For the long-duration test run conducted on July $6-8,1988$, instantaneous samples were withdrawn from both the bed and the cyclone dipleg. A summary of the bed samples is given in Table 6-5 and a summary of the cyclone samples is given in Table 6-6. Figure 6-22 shows the carbon level plotted as a function of run time. Figure 6-23 shows the sulfur and sulfate levels plotted versus run time. 


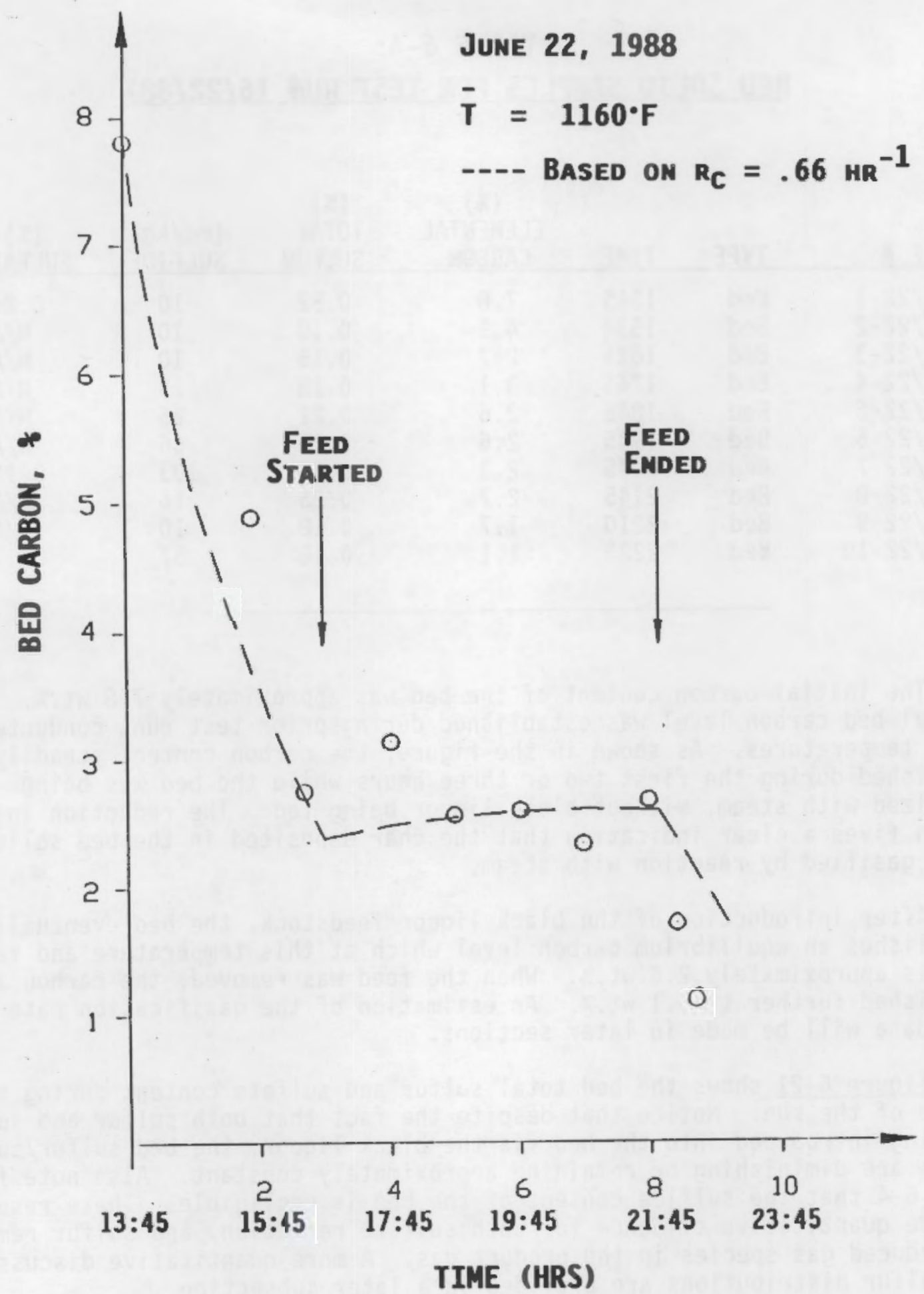

FIGURE 6-20: BED SOLIDS CARBON CONTENT VS. OPERATING TIME 


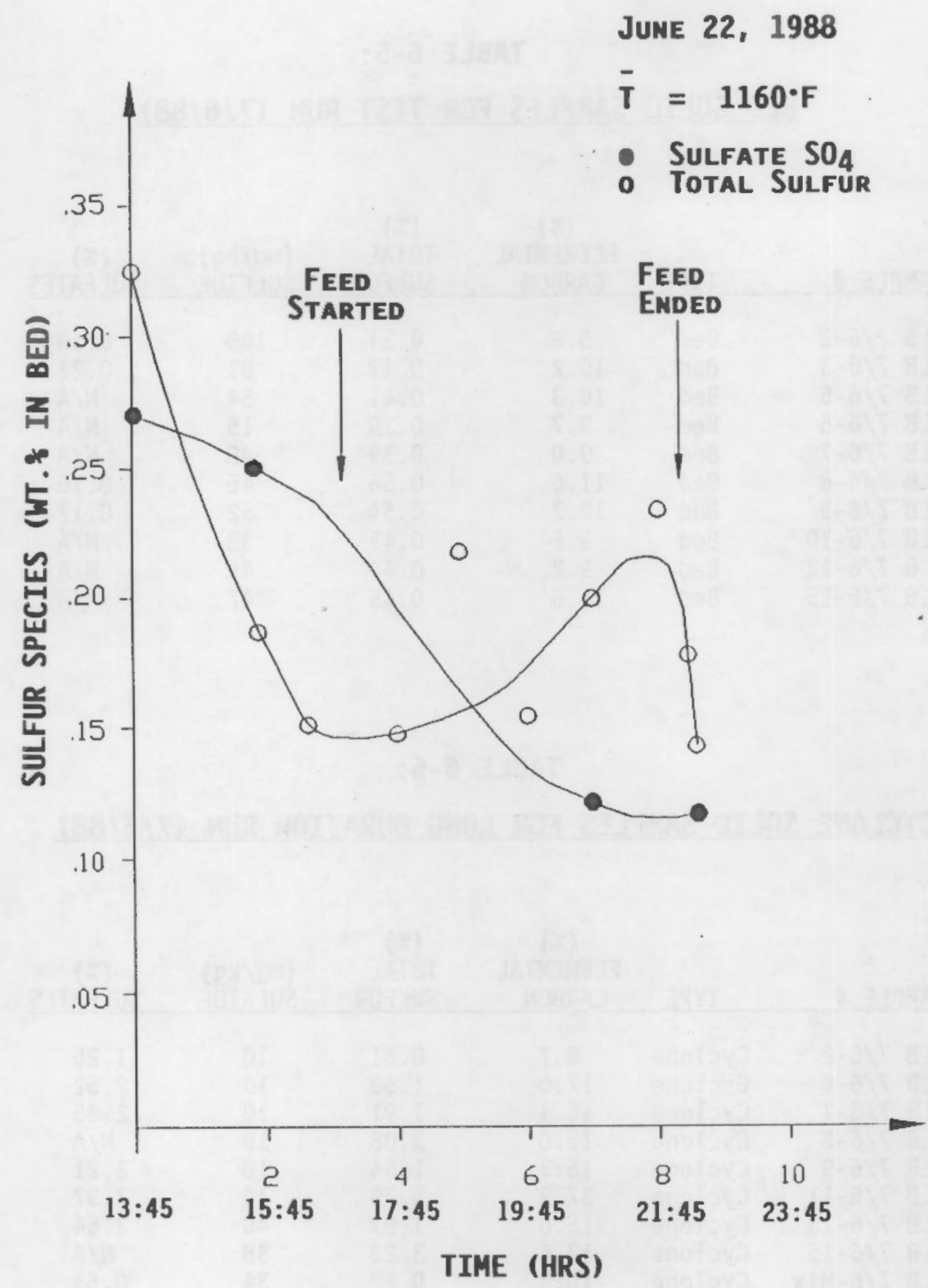

FIGURE 6-21: SULFUR SPECIES IN BED SOLIDS VS. OPERATING TIME 
TABLE 6-5:

BED SOLID SAMPLES FOR TEST RUN $(7 / 6 / 88)$

\begin{tabular}{|c|c|c|c|c|c|}
\hline SAMPLE & TYPE & $\begin{array}{l}\text { (\%) } \\
\text { ELEMENTAL } \\
\text { CARBON }\end{array}$ & $\begin{array}{l}(\%) \\
\text { TOTAL } \\
\text { SULFUR }\end{array}$ & $\begin{array}{l}(\mathrm{mg} / \mathrm{kg}) \\
\text { SULFIDE }\end{array}$ & $\begin{array}{c}(\%) \\
\text { SULFATES }\end{array}$ \\
\hline $\begin{array}{l}\text { BLB } 7 / 6-2 \\
\text { BLB } 7 / 6-3 \\
\text { BLB } 7 / 6-5 \\
\text { BLB } 7 / 6-6 \\
\text { BLB } 7 / 6-7 \\
\text { BLB } 7 / 6-8 \\
\text { BLB } 7 / 6-9 \\
\text { BLB } 7 / 6-10 \\
\text { BLB } 7 / 6-12 \\
\text { BLB } 7 / 6-15\end{array}$ & $\begin{array}{l}\text { Bed } \\
\text { Bed } \\
\text { Bed } \\
\text { Bed } \\
\text { Bed } \\
\text { Bed } \\
\text { Bed } \\
\text { Bed } \\
\text { Bed } \\
\text { Bed }\end{array}$ & $\begin{array}{r}5.8 \\
10.2 \\
10.3 \\
9.7 \\
9.0 \\
11.6 \\
10.7 \\
9.6 \\
9.2 \\
11.6\end{array}$ & $\begin{array}{l}0.34 \\
0.43 \\
0.41 \\
0.39 \\
0.39 \\
0.56 \\
0.54 \\
0.43 \\
0.40 \\
0.45\end{array}$ & $\begin{array}{r}109 \\
83 \\
54 \\
15 \\
48 \\
46 \\
52 \\
38 \\
46 \\
47\end{array}$ & $\begin{array}{l}0.19 \\
0.21 \\
\text { N/A } \\
\text { N/A } \\
\text { N/A } \\
0.16 \\
0.17 \\
\text { N/A } \\
\text { N/A } \\
\text { N/A }\end{array}$ \\
\hline
\end{tabular}

TABLE 6-6:

CYCLONE SOLID SAMPLES FOR LONG DURATION RUN (7/6/88)

\begin{tabular}{|c|c|c|c|c|c|}
\hline SAMPLE & TYPE & $\begin{array}{c}(\boldsymbol{(}) \\
\text { ELEMENTAL } \\
\text { CARBON }\end{array}$ & $\begin{array}{l}(\boldsymbol{\alpha}) \\
\text { TOTAL } \\
\text { SULFUR }\end{array}$ & $\begin{array}{l}(\mathrm{mg} / \mathrm{kg}) \\
\text { SULFIDE }\end{array}$ & $\begin{array}{c}(\boldsymbol{q}) \\
\text { SULFATES }\end{array}$ \\
\hline $\begin{array}{l}\text { BLB } 7 / 6-2 \\
\text { BLB } 7 / 6-6 \\
\text { BLB } 7 / 6-7 \\
\text { BLB } 7 / 6-8 \\
\text { BLB } 7 / 6-9 \\
\text { BLB } 7 / 6-11 \\
\text { BL8 } 7 / 6-13 \\
\text { BLB } 7 / 6-15 \\
\text { BLB } 7 / 6-M i x\end{array}$ & $\begin{array}{l}\text { Cyclone } \\
\text { Cyclone } \\
\text { Cyclone } \\
\text { Cyclone } \\
\text { Cyclone } \\
\text { Cyclone } \\
\text { Cyclone } \\
\text { Cyclone } \\
\text { Cyclone }\end{array}$ & $\begin{array}{l}6.7 \\
17.0 \\
16.4 \\
15.6 \\
15.3 \\
37.2 \\
15.0 \\
12.4 \\
10.8\end{array}$ & $\begin{array}{l}0.81 \\
1.58 \\
1.91 \\
3.08 \\
1.64 \\
5.79 \\
1.93 \\
3.28 \\
0.67\end{array}$ & $\begin{array}{l}10 \\
10 \\
10 \\
10 \\
10 \\
10 \\
40 \\
38 \\
34\end{array}$ & $\begin{array}{l}1.26 \\
2.52 \\
2.85 \\
\text { N/A } \\
2.21 \\
7.37 \\
2.64 \\
\text { N/A } \\
0.53\end{array}$ \\
\hline
\end{tabular}




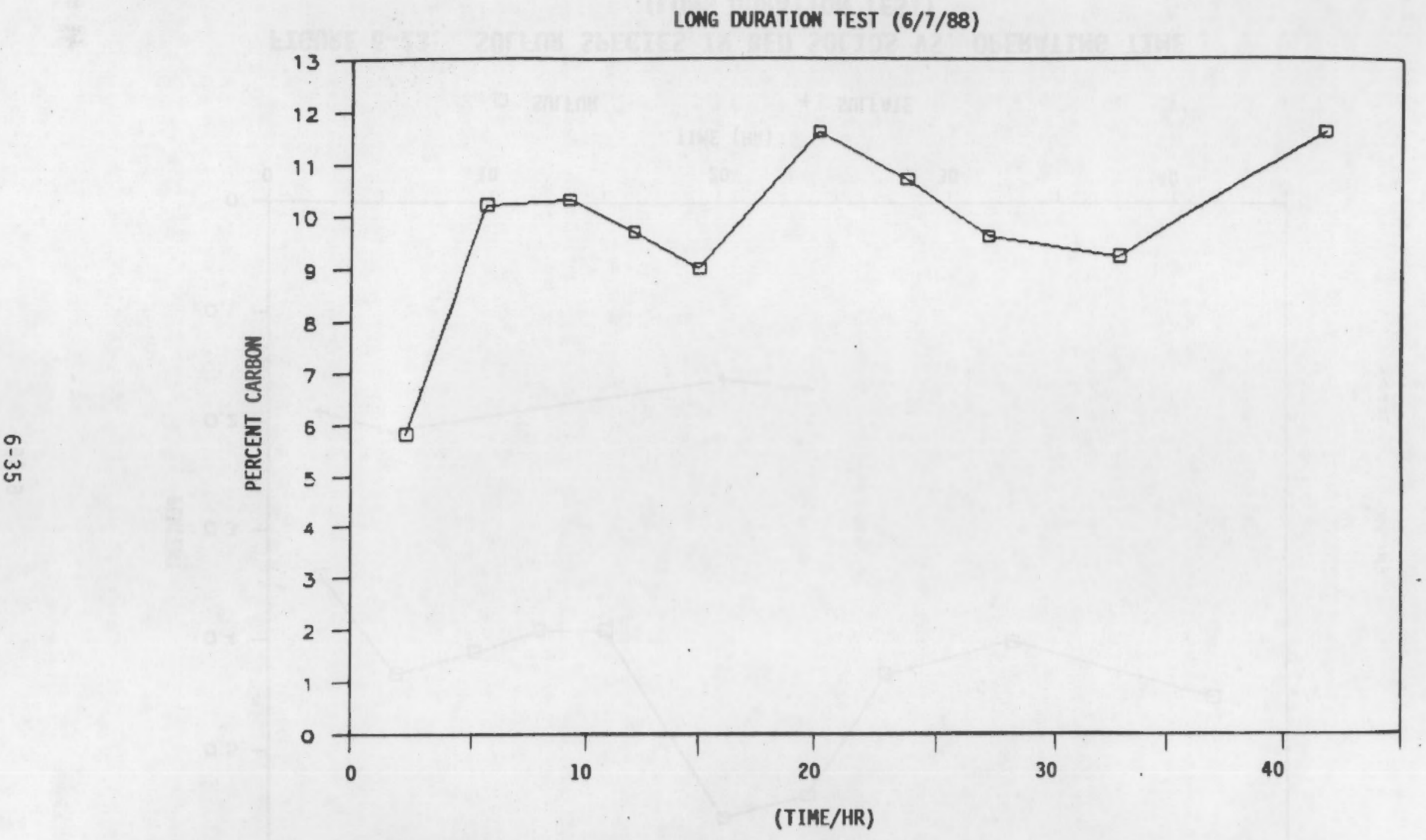

FIGURE 6-22: CARBON CONTENT OF BED SOLIDS VS. OPERATING TIME 
LONG DURATION TEST $(6 / 7 / 88)$

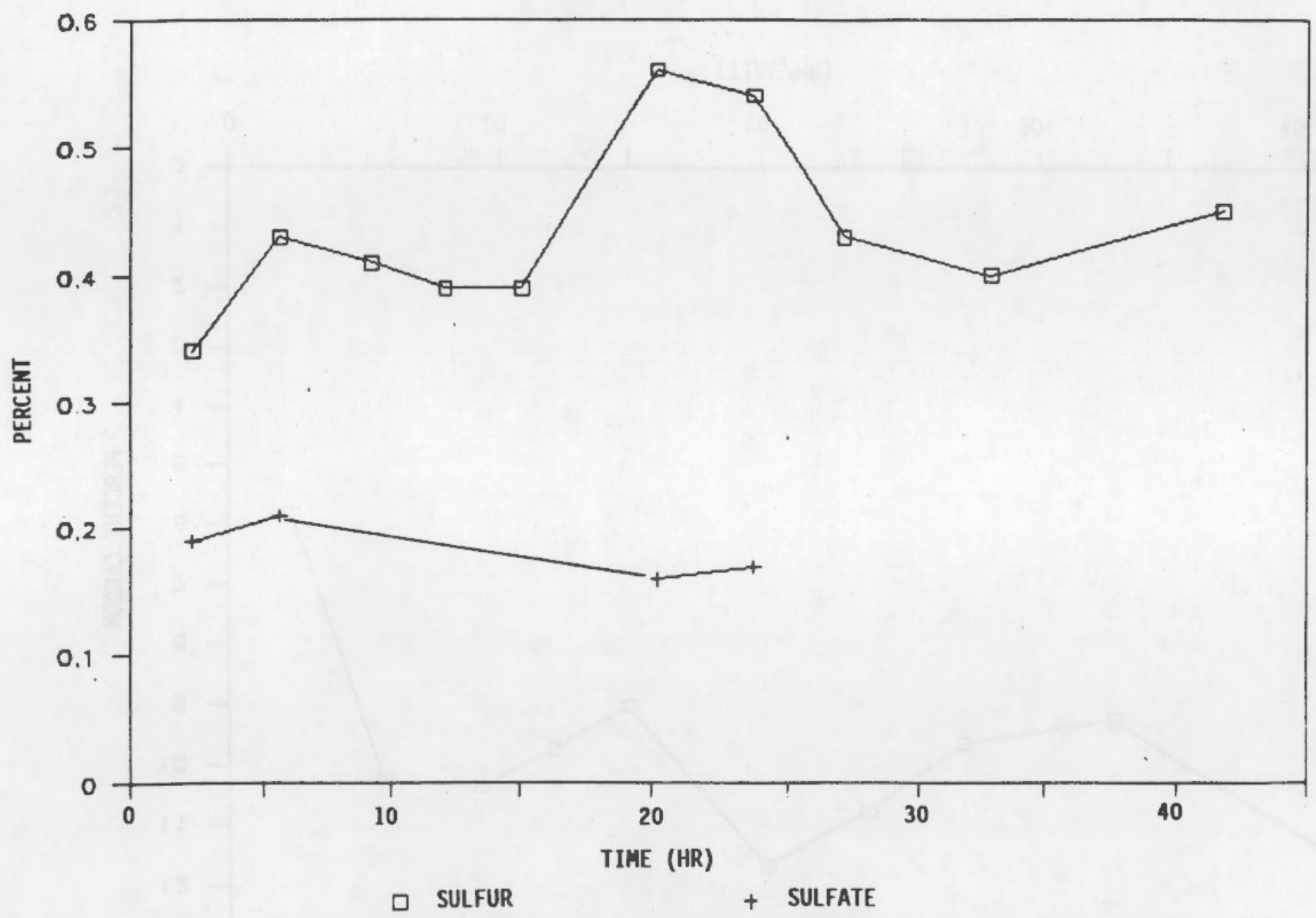

FIGURE 6-23: SULFUR SPECIES IN BED SOLIDS VS. OPERATING TIME (LONG DURATION TEST) 
Note that the steady-state bed carbon level (9-11 wt.\%) for the long duration test run which was conducted in the temperature range of $1090^{\circ} \mathrm{F}$ to $1140^{\circ} \mathrm{F}$ is higher than the bed carbon level for the run conducted at the higher temperature of $1160^{\circ} \mathrm{F}$. This is quantitatively consistent with expectation. Also note that the bed sulfur and sulfate levels are relatively constant throughout the run, once again supporting the removal of sulfur in the gas phase.

As seen in Table 6-6, the instantaneous cyclone fines exhibit significantly higher levels of carbon, total sulfur, and sulfate. However, as will be discussed shortly, the quantity of this carry-over material appears to be relatively small.

Two theories can be postulated to explain the enrichment of these elements in the cyclone product. First, when black liquor is sprayed onto the hot bed solids, it forms an annular shell or coating. Due to the direct contact with the solids, the black liquor heats up at an extremely rapid rate, pyrolyzing a significant portion of the organic material and leaving a friable char layer. Part of this char layer is steam-gasified, but a portion may be attrited into the gas phase due to particle-to-particle collisions. Under this scenario, the cyclone material would be enriched in carbon, sulfur and sulfate, since its residence time within the fluid bed is insufficient to promote complete reaction which would otherwise form gaseous species from the elements (e.g., $\mathrm{CO}, \mathrm{CO}_{2}, \mathrm{H}_{2} \mathrm{~S}$ ). Note that a degree of control over the attrition severity can be had by varying the fluidization velocity.

A second theory may also explain this behavior. When the black liquor is sprayed onto the bed, most of the material is deposited onto the surface of the bed solids. However, a portion of the spray may be entrained in rising fluid bed bubbles. As the material rises, it pyrolyzes to form a non-sticky char which will no longer adhere to the bed solids. This material, if small enough in size, will be entrained from the bed and enter the cyclone. Once again, due to the shortened residence times within the bed, the entrained material will be enriched in sulfur and carbon elements. If this hypothesis is correct, then modification of the black liquor spray nozzle may exert some control over this process.

Note that the last cyclone sample in Table 6-6 represents a mix of all material collected in the cyclone catch-drum. It is evident that the mix sample is generally lower in carbon, total sulfur, and sulfate from the instantaneous samples. This is due to the fact that the bulk of the cyclone material is composed of fresh fines which are lost during the initial heat-up period, and thus do not contain high levels of the black liquor components.

Using the final bed sample analysis and the cyclone mix sample, in addition to the measured total weight for each, an elemental balance can be prepared as shown in Table 6-7. Note that the mass of sulfur, sulfide, and sulfate in the solid products is significantly less than that which is accounted for by the total sulfur input mass. This indicates that a large portion of the sulfur is removed in the gas phase. A more detailed discussion of this aspect is found in later sections. 
TABLE 6-7:

ELEMENTAL BALANCE FOR LONG DURATION TEST RUN

$(7 / 6 / 88)$

\begin{tabular}{|c|c|c|c|c|c|}
\hline - & CARBON & $\begin{array}{l}\text { TOTAL } \\
\text { SULFUR }\end{array}$ & SULFIDE & SULFATE & $\begin{array}{c}\text { TOTAL } \\
\text { INORGANIC }\end{array}$ \\
\hline \multicolumn{6}{|l|}{ INPUT (1bs) } \\
\hline $\begin{array}{l}\text { Black Liquor Feed } \\
\text { Initial Bed Material }\end{array}$ & $\begin{array}{l}87.64 \\
\text { Negl. }\end{array}$ & $\begin{array}{l}9.18 \\
0.25 \\
\end{array}$ & $\begin{array}{l}3.02 \\
\text { Negl. }\end{array}$ & $\begin{array}{l}2.56 \\
0.20 \\
\end{array}$ & $\begin{array}{l}102.3 \\
165.0 \\
\end{array}$ \\
\hline TOTAL INPUT & 87.64 & 9.43 & 3.02 & 2.76 & 267.3 \\
\hline \multicolumn{6}{|l|}{ OUTPUT (1bs) } \\
\hline $\begin{array}{l}\text { Final Bed Material } \\
\text { Cyclone Bottoms }\end{array}$ & $\begin{array}{r}28.92 \\
9.94 \\
\end{array}$ & $\begin{array}{l}1.09 \\
0.62 \\
\end{array}$ & $\begin{array}{l}\text { Negl. } \\
\text { Negl. }\end{array}$ & $\begin{array}{l}0.41 \\
0.49 \\
\end{array}$ & $\begin{array}{r}214.0 \\
82.0 \\
\end{array}$ \\
\hline TOTAL OUTPUT & 38.86 & 1.71 & Negl. & 0.90 & 296.0 \\
\hline
\end{tabular}

Also, as seen in Table 6-7, the cyclone fines which are elutriated from the bed only account for a small fraction of the feed carbon. In any case, this carbon is easily recovered upon dissolution of the solids. This carbon may be reinjected into the bed or it may be utilized elsewhere in the mill, such as for fuel in the calciner. Note that if the carbon is reinjected into the gasifier, it may be beneficial to premix it with fresh black liquor feedstock. This is done to promote sticking of the residue to the bed solids and to reduce premature elutriation from the bed.

It is possible that some additional elutriated material was not captured in the cyclone. In order to estimate the fraction of the material which may have been lost, an independent cyclone efficiency test was conducted. Here, material was dispersed into a pipe connecting to the cyclone. Soda ash containing fines representative of the bed was employed for these tests. Material was collected in the cyclone catch-drum and in a bag filter at the cyclone exit. The cyclone inlet velocities were similar to those of the gasification tests.

The test results indicated a collection efficiency of over 95 percent. In support of this, a condensate sample from the test run was analyzed for sodium and found to contain $706 \mathrm{ppm}$. Assuming that the sodium carbonate particulate at the exit of the cyclone was uniformly sampled, and based on the measured steam flow rate to the reactor, the cyclone efficiency was indirectly calculated to be 98 percent. 
Thus, the total loss of solids from the cyclone is only in the order of 2 to 5 percent. This level can be considered to be negligible for material balance purposes.

\subsubsection{Gasification RATES}

A primary objective of the experimental program was to derive specific gasification rates that could be employed as a data base for future design efforts.

The specific gasification rate $(\mathrm{rg})$ is defined here as the mass of carbon gasified $(\mathrm{Mg})$ per hour per mass of carbon inventory contained within the fluidized bed $\left(M_{b} X_{b}\right)$ and is given by:

$$
r_{g}=1 /\left(M_{b} \times b\right) \quad d M_{g} / d t
$$

where $M_{b}$ is the total mass of bed solids, and $X_{b}$ is its organic carbon content.

At steady-state, the carbon inventory within the bed achieves a constant value, and thus the mass rate of carbon contained in the feed material (minus carbon losses in the cyclone carry-over material and draw-off solids) must equal the gross gasification rate $\left(\mathrm{dM}_{\mathrm{g}} / \mathrm{dt}\right)$. This is expressed as follows:

$$
\mathrm{dM}_{g} / \mathrm{dt}=M_{f} X_{f}-M_{c} X_{c}-M_{d} X_{d}
$$

where $M_{f}, M_{c}$, and $M_{d}$ are the mass of feed, cyclone carry-over, and draw-off solids, and $X_{f}, X_{c}$, and $X_{d}$ are the respective carbon contents of each fraction.

Based on this gross material balance approach, the specific rate of gasification is given as:

$$
r_{g}=\left(M_{f} X_{f}-M_{c} x_{c}-M_{d} X_{d}\right) /\left(M_{b} X_{b}\right)
$$

where $X_{b}$ is experimentally determined by measuring the carbon content of the bed at each steady-state condition.

Note that the apparent specific gasification rate as defined above includes contributions from both steam-char gasification reactions and pyrolysis of the black liquor feedstock. Since the pyrolysis reaction rates are rapid compared to the steam-char gasification rates, the measured apparent specific gasification rates are anticipated to be somewhat higher than for those measured using black liquor char only. Li and Van Heiningan (1986) reported gasification rates of black liquor char by $\mathrm{CO}_{2}$. The steam gasification rates are expected to be slightly higher than the $\mathrm{CO}_{2}$ gasification rates. 
Based on this approach, specific gasification rates were calculated for several runs. The results are shown in Table 6-8. The measured gasification rates are compared to those predicted by extrapolation of $\mathrm{Li}$ and von

Heiningen's data to steam conditions and lower temperatures. The measured and predicted rate constants agree reasonably well.

TABLE 6-8:

ESTIMATED GASIFICATION RATES

\begin{tabular}{cccc}
$\begin{array}{c}\text { TEMPERATURE } \\
\cdot \boldsymbol{F}\end{array}$ & $\begin{array}{c}\text { PERCENT } \\
\text { CARBON }\end{array}$ & $\begin{array}{c}\text { EXPERIMENTAL RATE } \\
\mathrm{hr}^{-1}\end{array}$ & $\begin{array}{c}\text { PREDICTED RATE } \\
\mathrm{hr}^{-1}\end{array}$ \\
\hline 1090 & 9.0 & 0.18 &..- \\
1100 &.-- & 0.22 & 0.27 \\
1120 & 7.5 & 0.66 & $-\cdots$ \\
1160 & 2.6 & $-\cdots$ & 0.75
\end{tabular}

Referring back to Figure $6-20$, a line is shown which represents the bed carbon level as predicted using the estimated steady-state gasification rate. Assuming that rapid pyrolysis accounts for 40 percent of the carbon gas yield, the prediction is extended even to the steaming period (e.g., no black 1 iquor feed). The predicted behavior closely correlates to the measured data.

\subsubsection{Particle SIZE EVOLUTION}

One of the key issues investigated during the long duration test concerned the stability of the bed solids particle size distribution. The initial bed charge consisted of a mixture of two separate commercial sodium carbonate products. The two products differed in mean particle size and were proportioned to give the desired fluidization properties. During the course of a run, black liquor is sprayed onto the particle surface. At steady-state, the rate of carbon gasification equals the rate of carbon deposition, and thus, no net accumulation of carbon is expected. However, several other physical processes, such as agglomeration, attrition, and elutriation, may result in an evolution in particle sizes which could change the bed fluidization properties with time. In order to investigate the potential evolution of bed solids particle sizes, solid samples were taken before, during, and after the long duration test run. Figure 6-24 shows the initial and final particle size distributions. The only significant difference in the particle distribution results from the loss of fines (-200 micron) in the final bed solids. This suggests that no significant changes in fluidization properties are anticipated during extended operations. 


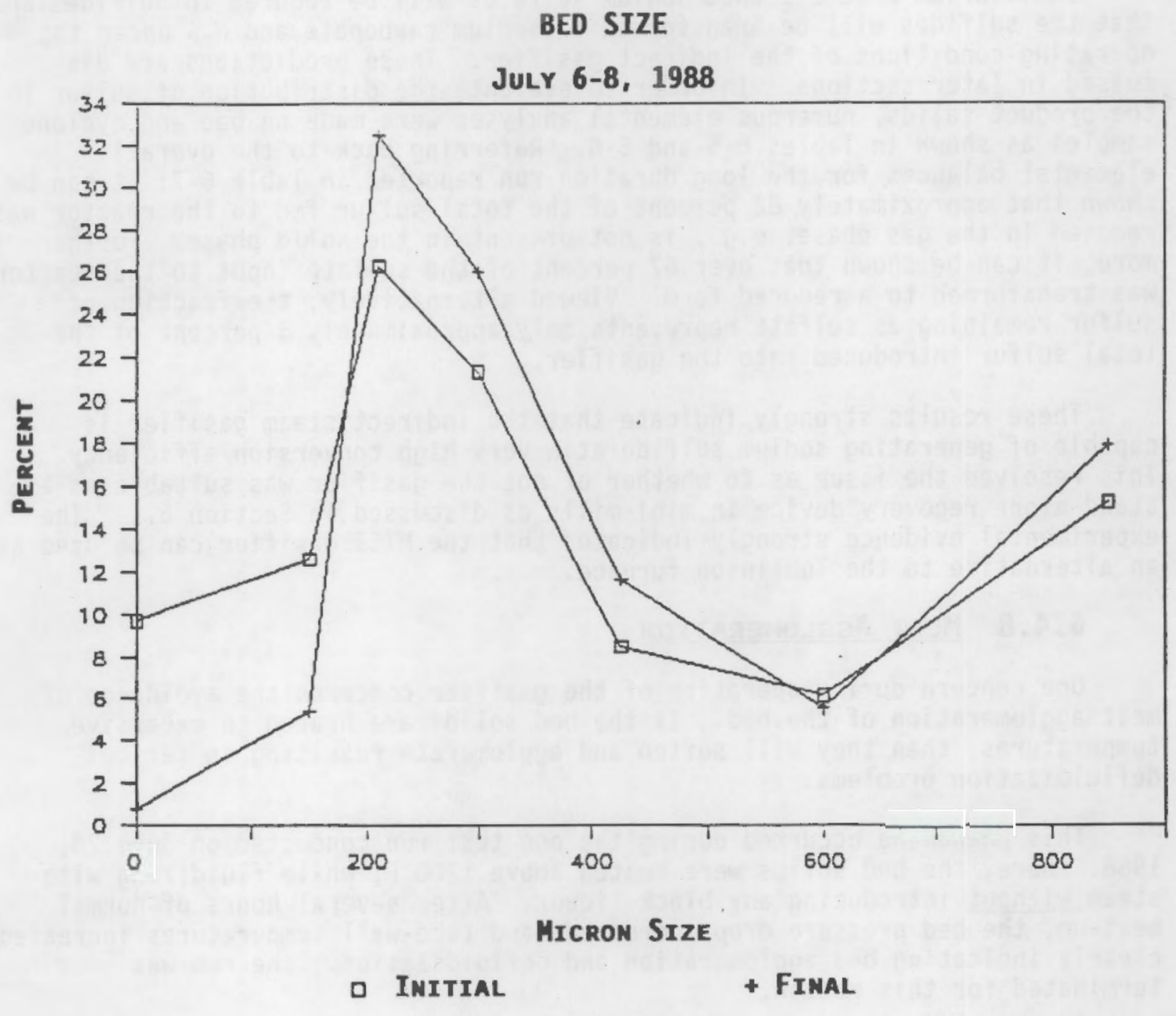

FIGURE 6-24: INITIAL AND FINAL PARTICLE SIZE DISTRIBUTIONS FOR LONG DURATION TEST RUN 


\subsubsection{Sulfur Distribution and Sulfate Reduction}

Unlike most of the alternate black liquor recovery processes which operate in a regime which promotes the direct formation of sodium sulfide, the indirect steam gasifier promotes hydrogen sulfide formation. The hydrogen sulfide is then easily recovered to form sodium sulfide by absorption in aqueous sodium carbonate which is produced during dissolution of the gasifier product salts. This provides a useful means for regenerating green liquor, and it has significant implications for application to sulfite liquors.

Equilibrium predicts that sodium sulfates will be reduced to sulfides and that the sulfides will be transformed to sodium carbonate and $\mathrm{H}_{2} \mathrm{~S}$ under the operating conditions of the indirect gasifier. These predictions are discussed in later sections. In order to evaluate the distribution of sulfur in the product solids, numerous elemental analyses were made on bed and cyclone samples as shown in Tables 6-5 and 6-6. Referring back to the overall elemental balances for the long duration run reported in Table 6-7, it can be shown that approximately 82 percent of the total sulfur fed to the reactor was removed in the gas phase, e.g., is not present in the solid phase. Furthermore, it can be shown that over 67 percent of the sulfate input to the reactor was transformed to a reduced form. Viewed alternatively, the fraction of sulfur remaining as sulfate represents only approximately 3 percent of the total sulfur introduced into the gasifier.

These results strongly indicate that the indirect steam gasifier is capable of generating sodium sulfide at a very high conversion efficiency. This resolved the issue as to whether or not the gasifier was suitable as a stand-alone recovery device in mini-mills as discussed in Section 6.1. The experimental evidence strongly indicates that the MTCI gasifier can be used as an alternative to the Tomlinson furnace.

\subsubsection{Melt Agglomeration}

One concern during operation of the gasifier concerns the avoidance of melt agglomeration of the bed. If the bed solids are heated to excessive temperatures, then they will soften and agglomerate resulting in serious defluidization problems.

This phenomena occurred during the one test run conducted on June 28 , 1988. Here, the bed solids were heated above $1200^{\circ} \mathrm{F}$, while fluidizing with steam without introducing any black 7iquor. After several hours of normal heat-up, the bed pressure drop increased, and tube-wall temperatures increased clearly indicating bed agglomeration and defluidization. The run was terminated for this reason.

Post-run inspection of the reactor revealed that a large mass had agglomerated near the base of the shielded resonance tubes. In addition, material was deposited on the tube surfaces immediately following transition to the bare resonance tubes. These locations are the areas where the highest tube-wall temperatures were anticipated. The bulk of the solid appeared to be only loosely bound and could be crushed by hand into smaller particles. This evidence suggested that the particles had not completely fused, but rather were held by a relatively weak particle-to-particle binder. 
Since the agglomerated mass limited the rate of heat from the tube, the surface temperatures at the lowest portion of the shielded resonance tube rose to a point where molten salt was formed in contact with the tube surface. The corrosive nature of the molten salt severely affected the outer layer of the shield tube.

Post-run analysis revealed that the carbon content of the bed solids had been completely steam gasified prior to agglomeration. Typically, bed solids contained several percent carbon as the normal state during black liquor gasification after the run which resulted in agglomeration. The bed solids were completely stripped of carbon by reduction with steam during the heat-up period. Therefore, the solids did not have a protective surface coating of carbon at the onset of agglomeration. It was believed that the combination of high temperature and blow carbon content of the bed were contributing factors. It was hypothesized that the agglomeration process could have been avoided, even at 1200 to $1250^{\circ} \mathrm{F}$, if residual carbon on the surface of particles had been maintained. This is due to the fact that the surface coating would have prevented particle-to-particle sticking.

In order to further explore the mechanisms of particle agglomeration, a sample of the agglomerated mass was sent to the Weyerhaeuser Laboratories for SEM analysis. It was noted that the agglomerated particles were not fused together, but rather loosely held by some type of binder. The SEM analysis are shown in Figures $6-25$ and $\underline{6-26}$. The photographs provide striking evidence that the particles are held together by a sticky sodium chloride eutectic binder which softens and melts at lower temperatures than the bulk of the solid particles. As seen in Figure 6-25, the interface of the agglomerated particles are enriched in chloride, while the bulk of the particle has very little chloride. This evidence seems to suggest that a non-sticky carbon surface layer will be effective in preventing particle agglomeration. Therefore, operation protocol must require that biack liquor be introduced into the gasifier before temperature of above $1200^{\circ} \mathrm{F}$ is achieved. This will ensure a minimum surface coating.

\subsubsection{SUlfur EOUILIbrium ANalysis}

Sulfur management and recovery is an important issue in the processing of black liquor feedstocks. Since sodium sulfide represents the active species in Kraft pulping, the recovery process must provide means for conserving and/or regenerating sulfur in the reduced sodium form.

In conventional Tomlinson recovery furnaces, oxidized sulfur species, in the form of sodium sulfate, are reduced in a smelt bed by reaction with carbon species. While the high temperature of the smelt bed enhances the kinetic activation of the reduction process, the smelt also contributes a significant mass transfer limitation which diminishes the rate of these reduction reactions.

In the gasification process investigated here, the inorganic solids are maintained in a dry form. The gasifier environment also presents a high reduction potential since no oxygen is introduced into the system. In addition, the gasifier is operated at low temperatures and with considerable 


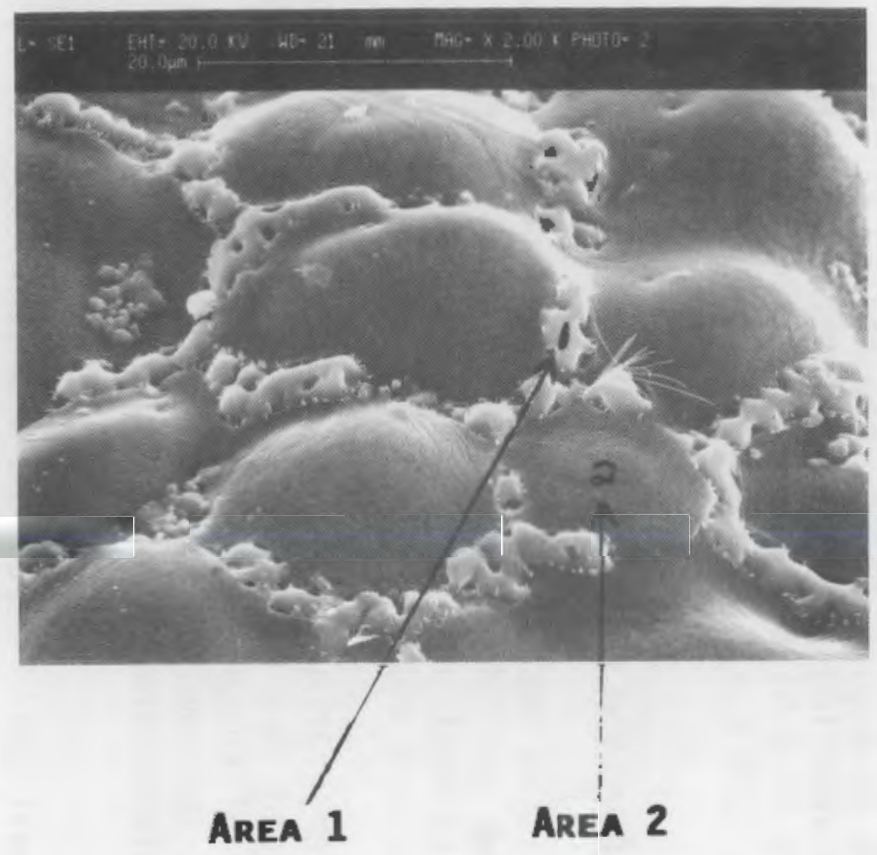

FIGURE 6-25: SEM OF AGGLOMERATED PARTICLE SHONING CHLORIDE-ENRICHED BINDER ZONE
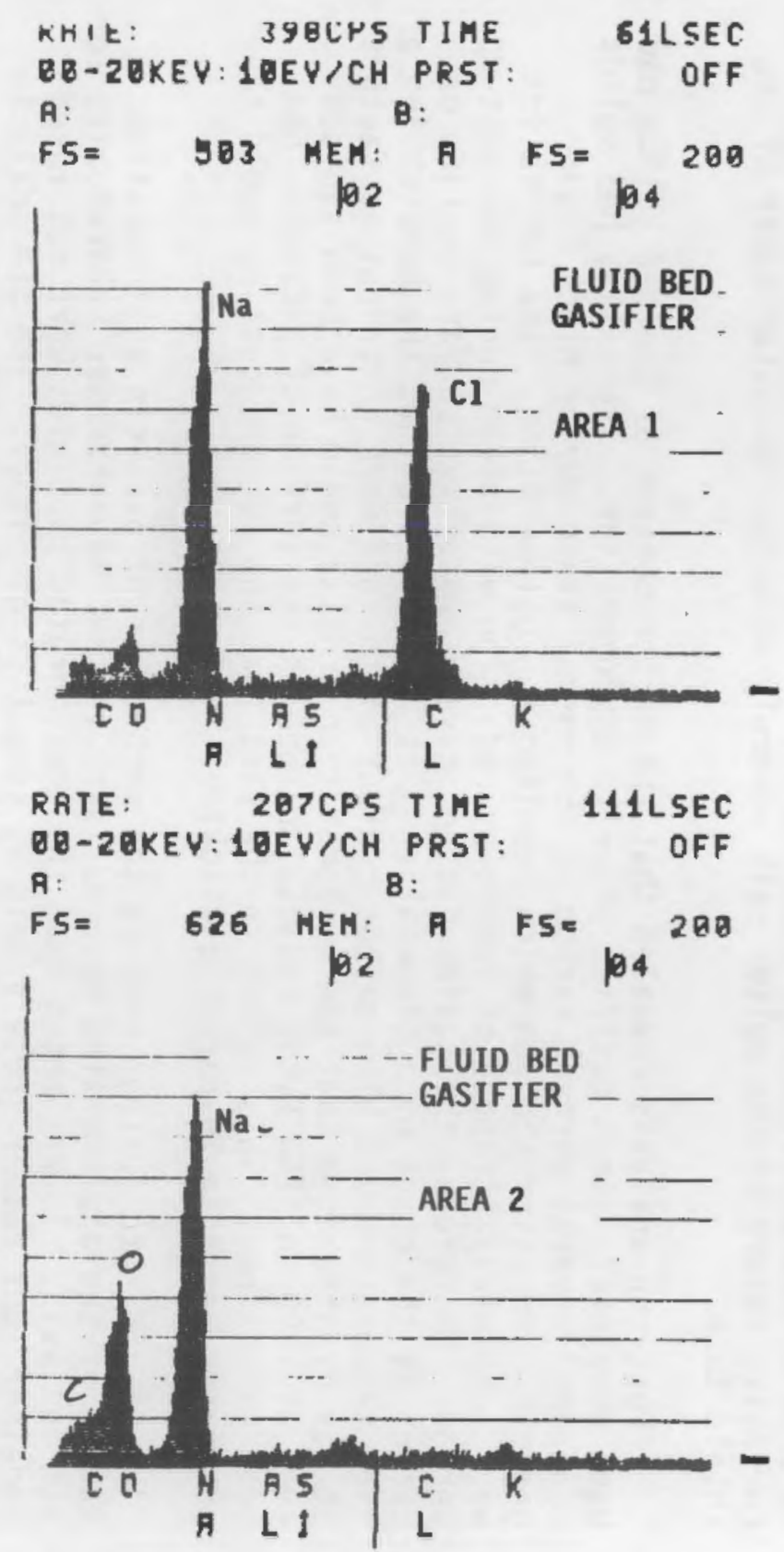


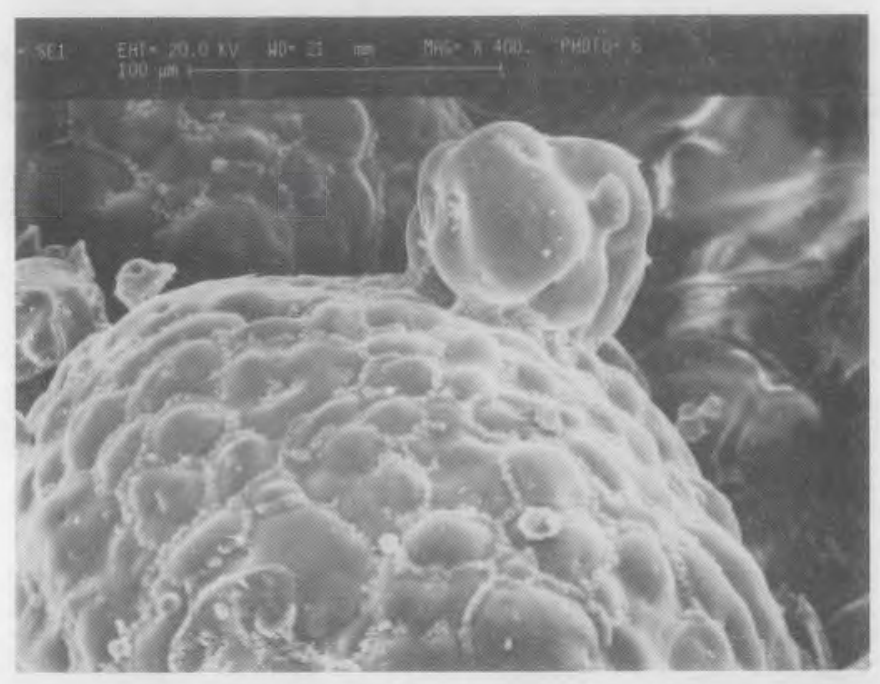

14-JUL-E8 13:10:42 5TANDBY

RATE: $254 C P S$ TIME

QO-2EKEY: 18EV/CH PRST:

$16 B L S E C$

ค :

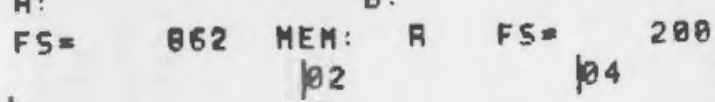
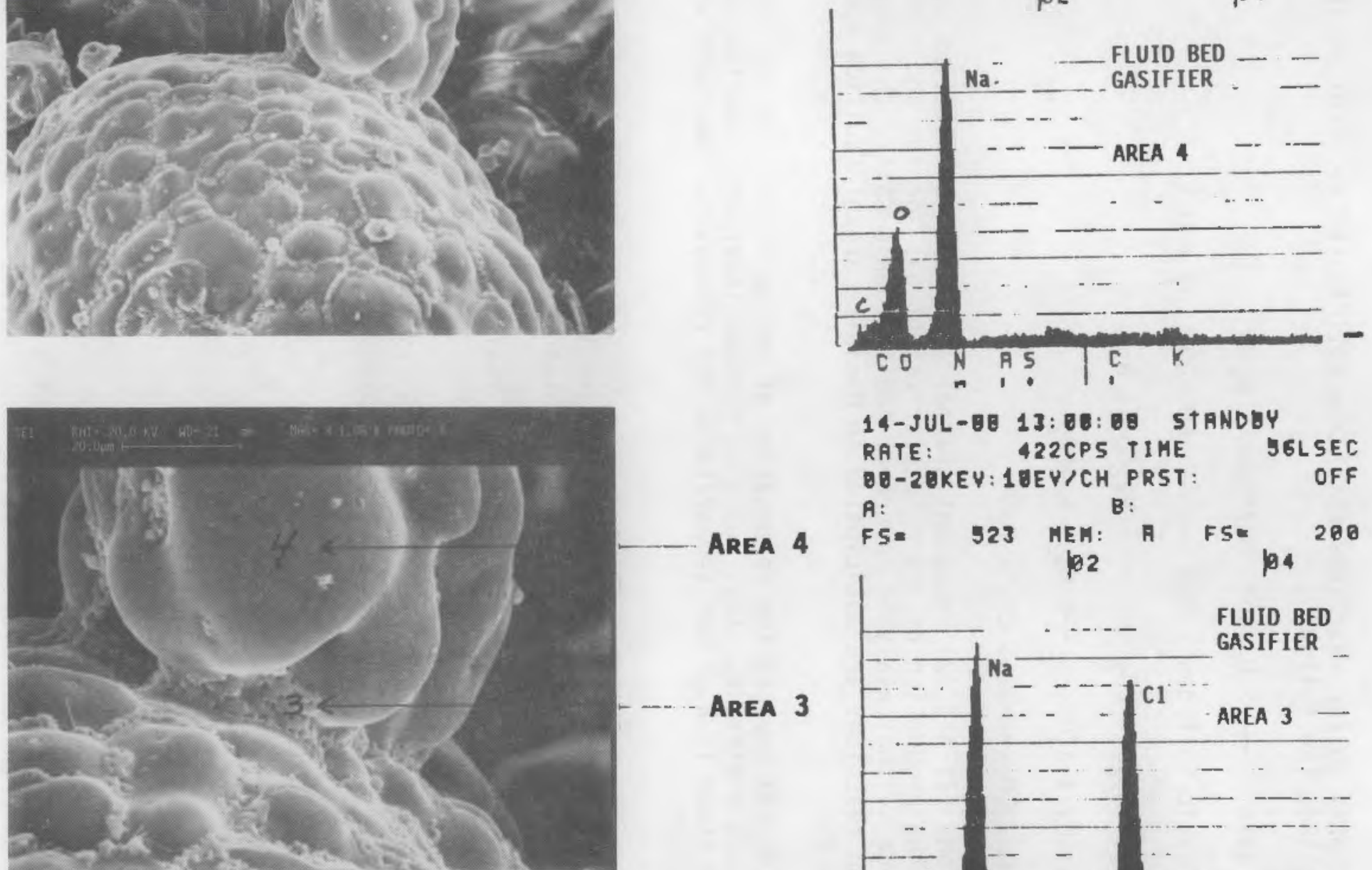

14-3UL-BE 13: $88: 08$ STANDEY

RATE: $422 \mathrm{CPS}$ TIME J6LSEC OD-2OKEY: 10EV/CH PRST: OFF

A: $\quad B$ :

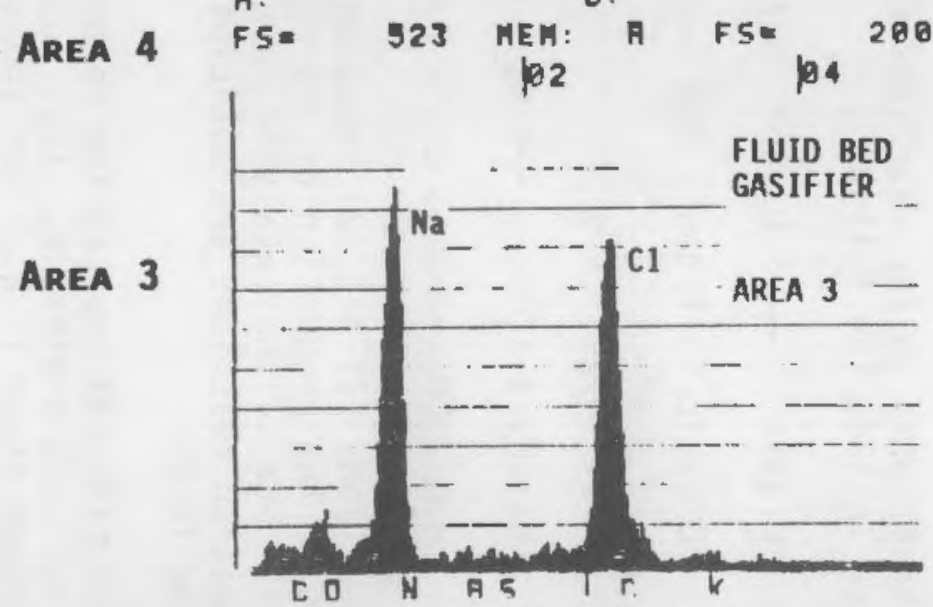

FIGURE 6-26: SEM OF AGGLOMERATED PARTICLE SHOWING CHLORIDE-ENRICHED BINDER ZONE 
quantities of steam vapor compared to the conditions in the Tomlinson furnace. Although the intrinsic kinetic rate of sulfate reduction is anticipated to be less rapid in the gasifier due to the lower operating temperatures, mass transfer limitations are anticipated to be less than for the smelt bed.

The primary sulfur reactions which are anticipated to occur in the gasifier include the following:

1. Lignin $\longrightarrow$ Organic Sulfides $+\mathrm{H}_{2} \mathrm{~S}$

2. Organic Sulfides $+\mathrm{H}_{2} \mathrm{O} \longrightarrow \mathrm{CO}, \mathrm{CO}_{2}, \mathrm{H}_{2}+\mathrm{H}_{2} \mathrm{~S}$

3. $\mathrm{Na}_{2} \mathrm{~S}+\mathrm{H}_{2} \mathrm{O}+\mathrm{CO}_{2} \longleftrightarrow \mathrm{Na}_{2} \mathrm{CO}_{3}+\mathrm{H}_{2} \mathrm{~S}$

4. $\mathrm{Na}_{2} \mathrm{SO}_{4}+4 \mathrm{CO} \longrightarrow \mathrm{Na}_{2} \mathrm{~S}+4 \mathrm{CO}_{2}$

5. $\mathrm{H}_{2} \mathrm{O}+\mathrm{CO} \longrightarrow \mathrm{CO}_{2}+\mathrm{H}_{2}$

Reactions (1) and (2) represent thermal and steam gasification steps leading to the production of low molecular weight gas species and hydrogen sulfide. Due to the catalytic nature of the inorganic salts, the steam gasification reactions are anticipated to diminish organic sulfide species to very low levels.

Reaction (3) depicts the carbonation of sodium sulf: $\because$ in the presence of steam and carbon dioxide. This reaction becomes importani hen the partial pressure of steam is high and temperatures are relatively low, such as found in the gasifier.

Reaction (4) represents the reduction of sodium sulfate to sodium sulfide via the reaction with carbon monoxide. A similar reduction step could be written for hydrogen by combination of reactions (4) and (5).

Reaction (5) represents the water-gas shift equilibrium which primarily effects the relative ratio of carbon monoxide to carbon dioxide.

The equilibrium constants for reactions (3) and (4) primarily dictate the distribution of sulfur species within the product streams. The equilibrium constants can be expressed as follows:

$$
\mathrm{K}_{3}=\left(\mathrm{P}_{\mathrm{H}_{2} \mathrm{~S}} / \mathrm{P}_{\mathrm{CO}_{2}} \mathrm{P}_{\mathrm{H}_{2} \mathrm{O}}\right)
$$

and,

$$
\mathrm{K}_{4}=\mathrm{P}_{\mathrm{CO}_{2}}^{4 / \mathrm{P}} \mathrm{CO}^{4}
$$

When the equilibrium gas composition at a given temperature results in ratios less than the calculated thermodynamic values for $K_{3}$ and $K_{4}$, then the reaction is predicted to move to completion from left to right as written for reactions (3) and (4). 
Table 6-9 shows the equilibrium gas composition at $1200^{\circ} \mathrm{F}$ and 1 atm for three different steam to black liquor solids ratios $(4.0,1.0)$. The higher ratio is indicative of test conditions in the bench-scale reactor, while the lower ratio reflects anticipated conditions for a commercial scale-up gasifier. All calculations were based on the assumptions that reactions (3) and (4) go to completion. This assumption can then be checked by comparing the ratios calculated from the actual gas compositions to that of the thermodynamic equilibrium constants. The K-values and gas ratios are shown in Table 6-10.

The gas ratios yield calculated values for both reactions which are significantly less than the thermodynamic equilibrium values. This means that neither sodium sulfate nor sodium sulfide is stable in the gasifier environment. Thus, equilibrium predicts that the sulfur should be quantitatively released as hydrogen sulfide. The net reaction for sulfate is, therefore,

$$
\mathrm{Na}_{2} \mathrm{SO}_{4}+4 \mathrm{CO}+\mathrm{H}_{2} \mathrm{O} \longrightarrow \mathrm{Na}_{2} \mathrm{CO}_{3}+3 \mathrm{CO}_{2}+\mathrm{H}_{2} \mathrm{~S}
$$

The hydrogen sulfide must then be absorbed in an aqueous phase to regenerate sodium sulfide. This can be accomplished by scrubbing the product gas with the sodium carbonate solution formed from the bed solids dissolution step. Since the sodium carbonate solution so formed is slightly basic, the acidic hydrogen sulfide species will be absorbed as sodium bisulfide. This green liquor may then be returned to the conventional causticizing loop, where lime is added to precipitate carbonate, and form sodium hydroxide and sodium sulfide. The scrubbing process will be discussed in the following sections.

\subsubsection{RECOVERY OF SOdIUM SULFIdE}

Hydrogen sulfide contained in the product gas must be reabsorbed to form sodium sulfide precursors. Fortunately, the sodium carbonate solution generated by dissolution of the sodium carbonate product solids provides an ideal solution for scrubbing the product gas. In fact, sodium carbonate solutions have long been commercially employed for acid gas scrubbing.

A sodium carbonate solution, being alkaline in nature, will absorb both $\mathrm{H}_{2} \mathrm{~S}$ and $\mathrm{CO}_{2}$. Because of the buffering action of the carbonate ion, the solution pH will not change rapidly as the acid gases are absorbed.

Although $\mathrm{CO}_{2}$ is a slightly stronger acid than $\mathrm{H}_{2} \mathrm{~S}, \mathrm{H}_{2} \mathrm{~S}$ is absorbed at a rate many times that of $\mathrm{CO}_{2}$. This is due to the slow rate of reaction between dissolved molecular $\mathrm{CO}_{2}$ and $\mathrm{OH}^{-}$ion. Hydrogen does not require hydration to form an acid, and thus, the absorption in alkaline solutions is more rapid.

The selectivity for $\mathrm{H}_{2} \mathrm{~S}$ absorption relative to $\mathrm{CO}_{2}$ is useful since excess $\mathrm{CO}_{2}$ absorption will place an additional burden on the lime kiln and causticizing loop. This, however, is not anticipated to be a significant penalty. Since the relative selectivity can only be confirmed through actual scrubbing tests, future work will be necessary to define the optimum scrubbing conditions. 
TABLE 6-9:

\section{EQUILIBRIUM GAS COMPOSITION} IN GASIFIER AT $1200^{\circ} \mathrm{F}$

\begin{tabular}{|c|c|c|}
\hline $\begin{array}{l}\text { STEAM/BLACK } \\
\text { LIOUOR RATIO }\end{array}$ & 1.0 & 4.0 \\
\hline Component & Vol.\% & $\underline{Y 01 . x}$ \\
\hline Methane & 0.50 & Negl. \\
\hline Carbon Monoxide & 7.38 & 1.10 \\
\hline Carbon Dioxide & 13.42 & 8.16 \\
\hline Hydrogen & 40.10 & 20.40 \\
\hline Hydrogen Sulfide & 0.97 & 0.42 \\
\hline Water Vapor & 37.63 & 69.90 \\
\hline
\end{tabular}

TABLE 6-10:

COMPARISON OF GAS RATIOS WITH THERMODYNAMIC EOUILIBRIUM CONSTANTS AT $1200^{\circ} \mathrm{F}$

STEAM-TO-

BLS RATIO

$\mathrm{P}_{\mathrm{H}_{2} \mathrm{~S}} /\left(\mathrm{P}_{\mathrm{H}_{2} \mathrm{O}} \mathrm{P}_{\mathrm{CO}_{2}}\right)$

$\mathrm{P}_{\mathrm{CO}_{2}}^{4} / P_{\mathrm{CO}}^{4}$
4.0
0.07
$3 \times 10^{3}$
1.0
0.19
10.9
0.3
0.47
0.57

$K_{3}=7.0$

$K_{4}=5.3 \times 10^{5}$ 


\subsubsection{DISSOLUTION OF INORGANICS}

The inorganic salts contained in the bed solids draw-off and cyclone materials are comprised primarily of sodium carbonate and also include sodium sulfide, sodium sulfate, sodium chloride, and residual carbon in smaller quantities. The residual carbon is generally in the range of $1 \mathrm{wt} . \%$ to $10 \mathrm{wt} . \%$ depending on the gasifier conditions.

These materials are dissolved in water to recover the inorganic salts for recycling to the pulping $\mathrm{plant}$. In addition, the carbon value of these solids must be recovered. This process could be accomplished in an agitating dissolving tank followed by a disk filter for carbon recovery. The residual carbon may then be reinjected into the gasifier or used as fuel in the plant calciner.

Since the carbon contained on the inorganic solids is formed by spraying black liquor on to the surface of the fluidized bed particles, there is a tendency for carbon to be deposited in a relatively thin shell surrounding the particle. If the carbon shell was non-porous, and highly impervious to water penetration, then dissolution of the internal salts could be difficult. This might limit the ability to efficiently recover salts and carbon separately as desired.

In order to test the dissolution efficiency of the bed solids, a sample was collected and mixed with water in a beaker. The sample contained almost 14 percent carbon and thus represents a conservative test of the dissolving efficiency since most bed solids contain a significantly lower carbon level. The sample was dried and weighed. On the basis of inorganic weight loss, the recovery efficiency was 99.9 percent.

In order to cross-check this efficiency, and to ensure that carbon was not lost in the filtering process thus yielding erroneously high dissolving efficiencies, the dried material was ashed. Based on weight loss in the ashing furnace, the dissolving efficiency was calculated as 97.7 percent. In this method of analysis, carbon loss during the washing step would result in lower than actual efficiency numbers.

Thus, the dissolving efficiency is conservatively estimated as 97.7 percent and liberally estimated as 99.9 percent. Given these values, it is evident that water may easily penetrate the porous carbon shell in order to effectively dissolve contained salts. This suggests that problems relating to carbon and salt recovery are not anticipated for this process.

\subsubsection{Pulsatimg Heat Transfer}

A primary feature of the indirect steam gasifier employed in this work involves the use of the resonance tubes of a pulse combustor as the in-bed heat transfer surface within a fluidized bed. The resonance tubes offer an ideal method for transferring large quantities of heat to a fluidized bed. The resonance tubes allow the attainment of higher heat transfer coefficients and more uniform heat fluxes compared to conventional convective fire tubes. These benefits are derived from the oscillating velocity fields set up within the resonance tubes by virtue of the pulsating combustor. 
Modifications of convective heat transfer coefficients in pulsating flow can be explained in terms of the nonlinear relation between heat transfer and stream velocity. The velocity of gas under oscillating flow conditions is given by:

$$
V=V_{m}(1+B(\cos (w t))
$$

where $B=w A / V_{m}$, the dimensionless pulsation velocity, $V_{m}$ is the steady-flow velocity component, and $w$. is the oscillation frequency, and $A$ is the pulsation amplitude.

Using the quasi-steady state theory (Hanby, 1969), the heat transfer coefficient at any instant can be calculated from the instantaneous velocity through the following relation for turbulent flow:

$$
h D / k=a\left(c_{p} \mu / k\right)^{0.4}(V D / v)^{0.8}
$$

Thus, by integrating over a pulsation cycle, the ratio of the mean pulsating heat transfer coefficient to that under steady flow conditions is given by:

$$
h_{i} / h_{s}=1 /(2 \pi) \int_{0}^{2 \pi}(|1+B \cos (w t)|)^{0.8} d(w t)
$$

This relation is shown to yield approximately linearly increasing enhancement ratios for values of $B$ greater than 1.0 .

In order to evaluate the heat transfer enhancement for the resonance tubes contained within the fluidized bed reactor used in this work, the reactor tubes were outfitted with a series of flue gas and tube wall thermocouples. Heat fluxes were calculated based on known firing rates and measured thermocouple data. The measured heat transfer coefficients under pulsating flow were then compared to steady flow heat transfer coefficients predicted by the standard correlations.

Several heat transfer tests were conducted during the reactor shakedown period. These included heat transfer from the resonance tubes to three different media: air, water, and a steam fluidized bed. The results of these tests are shown in Figure 6-27. The predicted steady-flow (non-pulsating) heat transfer coefficients are shown in the lower line. Measured heat transfer coefficients are also plotted for each test as a function of the firing rate per tube. The upper pulsating line depicts the predicted heat transfer coefficients using the quasi-steady-state theory previously described. It is evident that the quasi-steady-state theory correlates well with the actual data. 


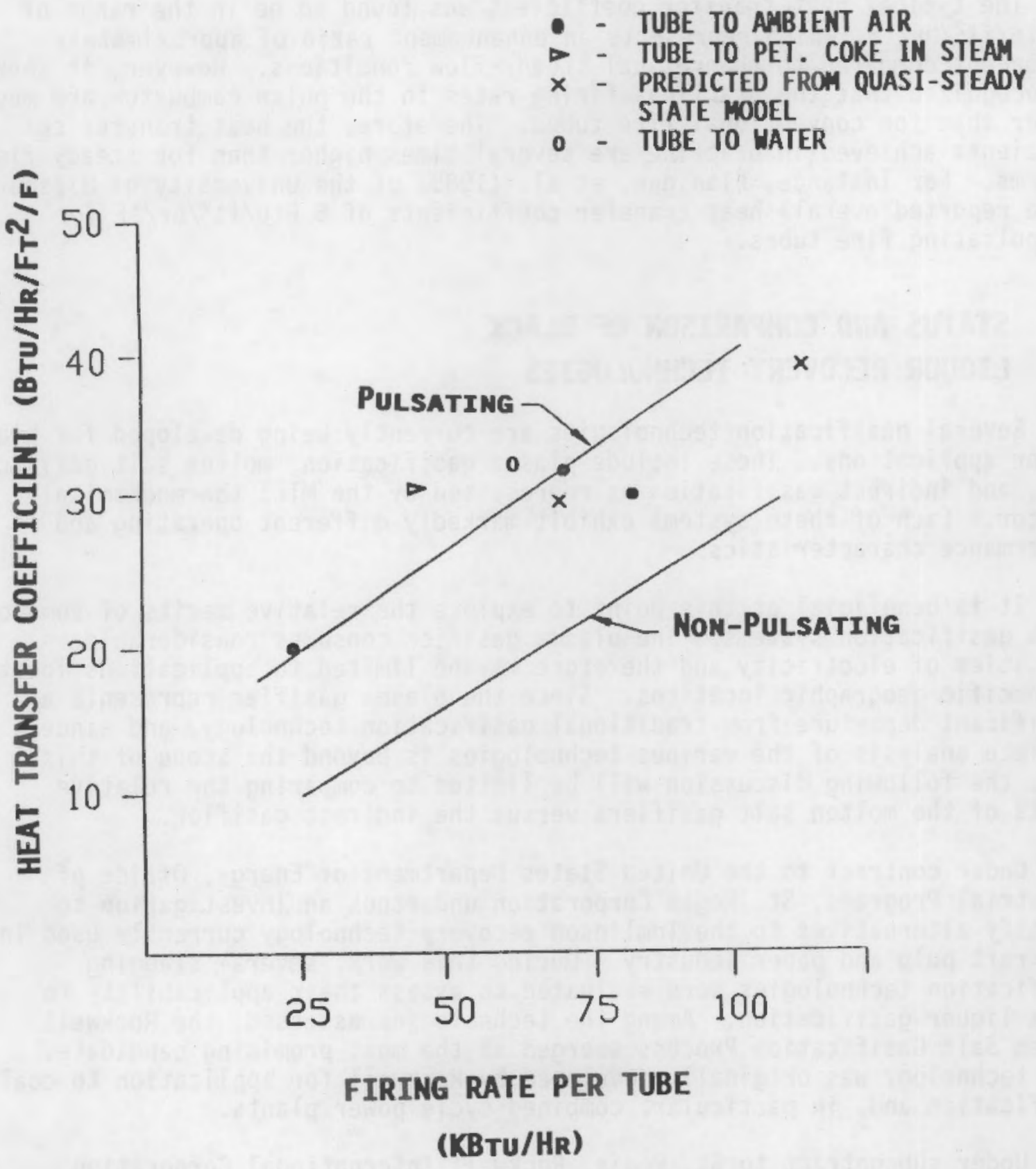

FIGURE 6-27: THEORETICAL HEAT TRANSFER COEFFICIENTS UNDER NON-PULSATING CONDITIONS COMPARED TO MEASURED DATA IN PULSATING FIRE TUBES 
The typical heat transfer coefficient was found to be in the range of $30 \mathrm{Btu} / \mathrm{ft}^{2} / \mathrm{hr} /{ }^{\circ} \mathrm{F}$, which represents an enhancement ratio of approximately

50 percent compared to theoretical steady-flow conditions. However, it should be recognized that the practical firing rates in the pulse combustor are much higher than for conventional fire tubes. Therefore, the heat transfer coefficients achieved in practice are several times higher than for steady-flow systems. For instance, Flanigan, et al. (1985) of the University of MissouriRolla reported overall heat transfer coefficients of $8 \mathrm{Btu} / \mathrm{ft}^{2} / \mathrm{hr} /{ }^{\circ} \mathrm{F}$ for non-pulsating fire tubes.

\subsection{STATUS AND COMPARISON OF BLACK LIQUOR RECOVERY TECHNOLOGIES}

Several gasification technologies are currently being developed for black liquor applications. These include plasma gasification, molten salt gasification, and indirect gasification as represented by the MTCI thermochemical reactor. Each of these systems exhibit markedly different operating and performance characteristics.

It is beneficial at this point to explore the relative merits of some of these gasification systems. The plasma gasifier consumes considerable quantities of electricity and therefore may be limited to applications located in specific geographic locations. Since the plasma gasifier represents a significant departure from traditional gasification technology, and since a complete analysis of the various technologies is beyond the scope of this work, the following discussion will be limited to comparing the relative merits of the molten salt gasifiers versus the indirect gasifier.

Under contract to the United States Department of Energy, Office of Industrial Programs, St. Regis Corporation undertook an investigation to identify alternatives to the Tomlinson recovery technology currently used in the Kraft pulp and paper industry. During this work, several slagging gasification technologies were evaluated to assess their applicability to black liquor gasification. Among the technologies assessed, the Rockwell Molten Salt Gasification Process emerged as the most promising candidate. This technology was originally developed by Rockwell for application to coal gasification and, in particular, combined cycle power plants.

Under. subcontract to St. Regis, Rockwell International Corporation conducted a bench-scale test program to verify the feasibility of black liquor gasification in their small-scale molten salt gasifier. Based on this work, a Phase I feasibility study was issued in June 1983. That study indicated that the molten salt gasifier technology could offer a potential cost-effective alternative to the Tomlinson recovery furnace. After St. Regis merged with Champion International Corporation, DOE awarded Champion a Phase II contract to conduct additional bench-scale and pilot-scale tests. The bench-scale test results yielded product gases with heating values in the range of $120 \mathrm{Btu} / \mathrm{scf}$, and a high level of reduction of sulfate to sulfide. Due to high heat losses in the pilot-scale tests, large amounts of air were required to sustain autothermal conditions. For this reason, product gas heating values were typically quite low ( $30 \mathrm{Btu} / \mathrm{scf}$ ), as was the extent of sulfur reduction. 
Upon completion of Phase II efforts, Champion recommended that development of the molten salt gasifier technology be continued through a two-step demonstration program. The first step would involve operation of a new pilot-scale plant which would overcome the limitations of the prior pilotscale effort, and which would provide essential design data for a large-scale demonstration plant.

In comparison, the MTCI technology is based on the principle of indirect steam-gasification which separates gasification products from combustion products. Black liquor is injected into a fluidized bed containing sodium salts, and the gasifier is operated in a lower temperature regime (1100 $1200^{\circ} \mathrm{F}$ ), which avoids melt formation. Heat is supplied to the reactor by means of the resonance tubes of a pulse combustor. By transferring heat indirectly, product gases with heating values of approximately $300 \mathrm{Btu} / \mathrm{scf}$ can be generated. Although the gasification technology does not solely depend on the use of pulse combustion, the high heat transfer rates attainable in the pulse resonance tubes significantly improve system economics to the point where it becomes a cost-effective and performance-effective alternative to the conventional technology.

The molten salt gasification process operates in the temperature regime of 1700 to $1900^{\circ} \mathrm{F}$. In comparison, the MTCI gasification process operates in a significantly lower temperature regime of 1100 to $1200^{\circ} \mathrm{F}$. The lower temperature of operation for the MTCI process is anticipated to reduce system heat losses, improve system thermal efficiency, and reduce the cost of reactor materials of construction.

As the name implies, the molten salt gasifier operates with a melt pool located at the bottom of the reactor. Since the melt pool is highly corrosive, special materials must be used to minimize chemical attack by the melt. In contrast, the MTCI process operates with dry salts only. This is anticipated to significantly reduce maintenance requirements and material costs.

During start-up, an external burner is required to heat-up and melt the molten salt pool. In the MTCI gasifier, an additional start-up burner is unnecessary since the pulse combustor is an integral part of the unit.

The molten salt gasifier must provide means for withdrawing and quenching draw-off salts. Corrosion and plugging of the discharge spout is considered to be a serious reliability issue. Water-cooled smelt spouts are available, but smelt-water mixing due to corrosive failure presents a hazard.

Refractory-lined smelt spouts have been employed only to a limited extent. Gas burners may be required to heat the spouts to ensure proper smelt flow.

The smelt discharge system also requires steam shatter jets for breaking up the smelt stream. This increases steam use and reduces plant thermal efficiency. Furthermore, failure of steam shatter nozzles can result in hazardous smelt-water explosions such as those which plague the conventional Tomlinson recovery technology. 
In contrast, the MTCI technology completely avoids any need to handle smelt streams. The product salts are discharged from the fluid-bed in a solid state. Solids discharge systems for fluid bed applications are available with proven and safe performance experience. This is anticipated to offer significant capital savings compared to molten salt gasifier systems.

Perhaps the most significant difference between the two technologies involves the method of heat supply. The molten salt gasifier is air-blown. The organic material is partially combusted to provide the necessary autothermal heat for gasification. In addition, the air-stream introduces significant levels of nitrogen diluent.

In contrast, the MTCI gasifier is heated indirectly by combusting product gas in a pulse combustor which is physically isolated from the gasifier. The gasification reaction thus results from reactions between steam $/ \mathrm{CO}_{2}$ and the organic carbon. This results in a product gas with two to three times the energy density compared to molten gasifiers. This, of course, also translates to significantly smaller down-stream processing equipment for the MTCI reactor due to the lower volumetric flows for a given feed capacity.

Black liquor feeding for the molten gasifier is critical to the successful operation of the unit. The spray nozzles must deliver a narrow range of droplet sizes in a narrow cylindrical pattern. This is required so that the droplets dry as they fall through the drying zone, but are not entrained in the rising gas stream. Thus, plugging or degraded performance of the spray nozzle significantly affects gasifier performance. In contrast, black liquor is sprayed directly into the fluid bed of the indirect gasifier. Although a reasonable spray quality is desirable, the spray pattern does not appear to affect gasifier performance.

The molten gasification process requires air sparging into the melt pool. Delivery of air to the feed nozzles consumes considerable parasitic power. Plugging of air nozzles may therefore also be a reliability issue. Proper distribution of air within the bed is critical to ensure proper heat release and gasification. Improper air distribution can also lead to poor sulfate reduction. In general, due to the simultaneous and inter-related processes of gasification and heat release, process control is anticipated to be more difficult than for indirectly heat systems. In the indirect gasifier, the oxidizing components are isolated from the reaction zone, completely independent control of the system heat input is allowed, thus providing improved flexibility of operation.

\section{A. Sulfur Balance}

The sulfur balance is one of several key issues that drives the overall economics of the recovery process. Due to the high cost of chemical-make-up (salt cake), excessive sulfur losses cannot be tolerated within the recovery cycle. In the conventional $\mathrm{Kraft}$ recovery boiler, sulfur is released as $\mathrm{SO}_{2}$ in the furnace section. The bulk of this $\mathrm{SO}_{2}$ recombines with sodium fume and is recovered by the particulate collection equipment. The recovered sulfur salts are recycled to the process; however, $\mathrm{SO}_{2}$ losses can still be significant requiring chemical make-up. 
In the molten salt gasifier, sulfur is intended to be recovered as molten $\mathrm{Na}_{2} \mathrm{~S}$ which can be drained from the bed. It was thought that the molten salt solution could be simply dissolved in water to form green liquor of the desired sulfidity. Unfortunately, experimental results clearly showed that large amounts of $\mathrm{H}_{2} \mathrm{~S}$ are evolved into the wet gas during air gasification. In fact, sulfur losses in bench-scale tests often exceeded 20 percent by weight of the feedstock sulfur. Furthermore, thermodynamics predicts increasing sulfur losses when gasifier pressure is increased (Kelleher, 1983). It is evident that this level of sulfur loss is unacceptable for an economic recovery process.

Therefore, if the molten gasifier is to be viable, gas phase scrubbing of the released $\mathrm{H}_{2} \mathrm{~S}$ is required. Also, since this released sulfur must be returned to the green liquor solution, the use of green liquor itself as the scrubbing media appears to be the only available option. Unfortunately, the green liquor so formed in the molten salt process is of relatively high sulfidity, and thus is thermodynamically incapable of removing $\mathrm{H}_{2} \mathrm{~S}$ at low concentrations from the gas phase. Based on these considerations, there does not exist an immediately apparent means for reducing sulfur losses in the molten salt process.

In the MTCI process, the gasifier conditions are expressly devised to promote the release of $\mathrm{H}_{2} \mathrm{~S}$ into the gas phase. Only pure sodium carbonate is thermodynamically stable under the operating conditions of the indirect gasifier. Thus, upon dissolving the recovered sodium carbonate salts in water, an alkaline solution of low sulfidity is generated. By using this solution in a counter-current absorber, $\mathrm{H}_{2} \mathrm{~S}$ can be effectively recovered from the gas phase. This is due to the fact that the equilibrium partial pressure of $\mathrm{H}_{2} \mathrm{~S}$ over sodium carbonate containing low sulfidity is low. Therefore, an effective means for recovering sulfur from the MTCI process does exist and can be, in fact, incorporated as an integral part of the process.

In black liquor gasification tests performed in the MTCI reactor, experimental results indicated that $B 2$ percent of the total sulfur input was gasified as $\mathrm{H}_{2} \mathrm{~S}$. This portion of gas phase sulfur will be completely (within practical limits) recovered in the absorption scrubber. The remainder of the sulfur is retained in solid form and is thus completely recovered upon dissolution in water. Note also that only negligible levels of sulfide could be detected in the solid phase indicating nearly 100 percent sulfide stripping efficinecy. Thus, the alkaline solution formed by dissolution of the solid will be of low sulfidity and thus quite effective for scrubbing $\mathrm{H}_{2} \mathrm{~S}$ from the gas phase. To summarize, the total quantity of sulfur recovered from the gas and solid phase should approach 100 percent. It should also be mentioned that since the MTCI product gas contains no combustion diluents $\left(\mathrm{N}_{2}\right.$ and $\left.\mathrm{CO}_{2}\right)$, the scrubbed gas volume is significantly less $(50 \%)$ than for the air-blown gasifier. Since scrubber costs are related primarily to gas volume, a significant economic advantage exists for the MTCI process.

\section{B. Development Costs and Commercial Flexibility}

A key issue in the successful commercialization of the recovery technology concerns its relative cost and risk of development, as well as its ultimate flexibility in meeting a wide range of end-user needs. 
If the molten salt gasifier is to be economic, it must be operated under pressure, and thus, it must be integrated with a combined cycle gas turbine. A gas turbine is required since pressurized air must be delivered to the airblown molten salt gasifier. Since this consumes large amounts of parasitic power, energy must be recovered by expanding the combusted fuel gas through a turbine generator. Therefore, since the demonstration unit must include not only the gasifier component, but the turbomachinery island as well, development costs are quite high.

In contrast, the MTCI process can be operated under pressure without any turbomachinery. This is due to the fact that only steam must be supplied to the gasifier. Since steam can be generated at any reasonable pressure level, a pressurized fuel gas stream can be achieved quite simply. Thus, fuel gas could be delivered to a gas turbine if so desired. However, the demonstration unit does not demand such coupling.

In addition to high costs, the need for turbomachinery increases the risk and complexity of the demonstration project. The possibility of contaminating the turbine blades by entrained particulates is a serious concern. Furthermore, the complexity of operation is an additional burden on the development project. In contrast, the MTCI demonstration project need only focus on the key element of the technology, that is, the gasifier recovery system itself.

Also, due to the need for coupling the molten gasifier with commercially available turbomachinery, the demonstration project must be of necessity scaled to a reasonably large size. In contrast, meaningful demonstration of the MTCI gasifier can be conducted at a smaller, more cost-effective scale.

Finally, the MTCI gasifier need not be tied to any particular configuration, but rather, allows the commercial end-user complete flexibility to dictate the desired format of the recovery process which best suits their operating requirements.

\section{Operability}

Simplicity of operation and insensitivity of the process to various control parameters is essential for the successful recovery technology. In the molten gasifier, narrow control of several parameters is critical to achieving good performance. These include:

\footnotetext{
- Feedstock moisture content

- Heat loss

- Spray droplet size

- Air distribution
}

Control of feedstock moisture content and heat loss is critical to the molten salt process. High moisture content and/or high heat loss will result in higher air rates to maintain the proper heat balance. This results in a diminished reduction efficiency and a significant deterioration of gas quality. In contrast, in the MTCI process, the quality of the product gas and the reduction efficiency do not in any way depend on moisture content or heat losses. 
The spray droplet pattern is a critical operating variable in the molten salt gasifier. Coarse droplets will lead to inefficient drying, requiring higher air rates and resulting in reduced thermal efficiency. However, if the droplet size is too sma11, excessive carryover will result. In the MTCI process, the black liquor is sprayed directly onto the agitated solids of a fluid bed. For this reason, droplet size is not as critical compared to the suspension-type spray system.

Finally, the control of air flow rates and injection locations are critical to the operation of the molten gasifier. Excessive air rates will cause high gasifier temperatures and reduced fuel heating value. Furthermore, improper distribution of air will result in poor reduction efficiency. In contrast, the method and rate of steam introduction into the MTCI gasifier is not a critical parameter. A wide range of steam to black liquor ratios can be employed without significantly disturbing the process. Furthermore, the adjustment of fuel to the combustion system is straightforward and highly decoupled from the gasification process.

Table 6-11 provides a comparative summary of the black liquor technologies as represented by the conventional, the molten salt, and the MTCI indirect gasification processes.

\subsection{COMMERCIAL CONFIGURATION}

Near-term commercial applications for the indirect gasifier are anticipated to focus on incremental capacity additions. The gasifier system, because of its modular capability, can be constructed in modular units with capacities in the range of 2 to 10 tons per hour. The units can be shop fabricated to allow reasonable economies at the smaller scale. The units can also be skid-mounted, truck or rail transportable, and require a minimum level of field installation.

A preliminary process flow diagram for the commercial configuration is shown in Figure 6-28. The gasifier is represented by reactor R-1. Here, black liquor is introduced into the fluidized bed along with steam and a portion of recycled product gas. Heat is supplied by the in-bed fire tubes which connect directly to the pulse combustor. The product gas exits the gasifier and enters cyclone $V-3$ where entrained fine particulates are separated from the gas stream. A portion of the product gas is recycled to the fluidized bed through ejector $X-1$. The motive fluid for the ejector is steam, which is internally generated within the process battery 1 imits. The balance of the gas, referred to as net product gas, is cooled in a kettle-type steam generator $(E-4)$. This steam generator supplies steam to the ejector $(x-1)$ and the balance is exported for power generation or process use.

The cooled process gas then enters a scrubbing column. The recirculating scrubbing liquid consists of alkaline sodium carbonate which is formed in the dissolving tank $(V-4)$. The process gas is scrubbed of hydrogen sulfide to form green liquor. The green liquor is then sent to the mill causticizing 10op. 


\section{TABLE 6-11: COMPARISON OF BLACK LIOUOR RECOVERY TECHNOLOGIES}

\begin{tabular}{|c|c|c|c|}
\hline & CONVENTIONAL & MOLTEN SALT & MTCI INDIRECT \\
\hline Process & Combustion & $\begin{array}{l}\text { Air-blown } \\
\text { gasification }\end{array}$ & $\begin{array}{l}\text { Indirect steam } \\
\text { gasification }\end{array}$ \\
\hline Modularity & Low & Medium & High \\
\hline Energy Output & Steam & Steam/electricity & Steam/electricity \\
\hline Safety Hazards & $\begin{array}{l}\text { Smelt water } \\
\text { explosions }\end{array}$ & Smelt handling & None \\
\hline Smelt Production & Yes & Yes & No \\
\hline Fuel Gas HHV & $N / A$ & $\begin{array}{l}\text { Low (100- } 150 \\
\text { Btu/scf) }\end{array}$ & $\begin{array}{l}\text { Medium }(300-400 \\
\text { Btu/scf) }\end{array}$ \\
\hline $\begin{array}{l}\text { Slagging/Fouling } \\
\text { Problems and Soot } \\
\text { Blower Steam Use }\end{array}$ & High & Low/None & None \\
\hline Sulfur Balance & High $\mathrm{SO}_{2}$ loss & $\begin{array}{l}\text { Problems with } \\
\text { recovery of } \mathrm{H}_{2} \mathrm{~S}\end{array}$ & $\begin{array}{l}\text { High sulfur recov- } \\
\text { ery efficiency }\end{array}$ \\
\hline $\begin{array}{l}\text { Materials in } \\
\text { Reducing Zone }\end{array}$ & $\begin{array}{l}\text { Expensive high- } \\
\text { temperature, } \\
\text { corrosion- } \\
\text { resistant } \\
\text { refractory }\end{array}$ & $\begin{array}{l}\text { Expensive high- } \\
\text { temperature, } \\
\text { corrosion- } \\
\text { resistant } \\
\text { refractory }\end{array}$ & $\begin{array}{l}\text { Inexpensive } \\
\text { refractory }\end{array}$ \\
\hline $\begin{array}{l}\text { Boiler } \\
\text { Construction }\end{array}$ & Complex & $\begin{array}{l}\text { Combined cycle } \\
\text { with waste heat } \\
\text { boiler required }\end{array}$ & Simple gas-fired \\
\hline $\begin{array}{l}\text { Pressurized } \\
\text { Operation }\end{array}$ & Not available & $\begin{array}{l}\text { Available but } \\
\text { expensive turbo- } \\
\text { machinery required }\end{array}$ & $\begin{array}{l}\text { Available without } \\
\text { expensive turbo- } \\
\text { machinery }\end{array}$ \\
\hline $\begin{array}{l}\text { Thermal } \\
\text { Efficiency }\end{array}$ & $\begin{array}{l}65 \% \text { for modern } \\
\text { plant not } \\
\text { including soot- } \\
\text { blowing steam } \\
\text { loss }\end{array}$ & $N / A$ & $\begin{array}{l}67 \% \text { steam on } 1 y \text {; } \\
79-80 \% \text { steam plus } \\
\text { gas }\end{array}$ \\
\hline
\end{tabular}




\section{TABLE 6-11: COMPARISON OF BLACK LIQUOR RECOVERY TECHNOLOGIES (CONT'D)}

\begin{tabular}{|c|c|c|c|}
\hline & CONVENTIONAL & MOLTEN SALT & MTCI INDIRECT \\
\hline Operability & $\begin{array}{l}\text { Critical control } \\
\text { of primary, } \\
\text { secondary, and } \\
\text { tertiary air for } \\
\text { proper reduction } \\
\text { efficiency, com- } \\
\text { bustion efficiency } \\
\text { and control of } \\
\text { deposits and } \\
\text { emissions }\end{array}$ & $\begin{array}{l}\text { Critical control of } \\
\text { air to achieve good } \\
\text { reduction performance } \\
\text { and heat balance }\end{array}$ & $\begin{array}{l}\text { No air required - } \\
\text { control of steam is } \\
\text { not critical to } \\
\text { process }\end{array}$ \\
\hline $\begin{array}{l}\text { Black Liquor } \\
\text { Droplet Size } \\
\text { Distribution }\end{array}$ & Critical & $\begin{array}{l}\text { Critical control of } \\
\text { droplets size essen- } \\
\text { tial to good reduc- } \\
\text { tion efficiency, } \\
\text { minimal entrainment, } \\
\text { and thermal balance }\end{array}$ & $\begin{array}{l}\text { Insensitive to } \\
\text { droplet size }\end{array}$ \\
\hline $\begin{array}{l}\text { Black Liquor } \\
\text { Solids Content }\end{array}$ & $\begin{array}{l}\text { Control of } \\
\text { moisture con- } \\
\text { tent essential } \\
\text { for thermal } \\
\text { efficiency }\end{array}$ & $\begin{array}{l}\text { High moisture con- } \\
\text { tent degrades gas } \\
\text { quality }\end{array}$ & $\begin{array}{l}\text { Gas quality insensi- } \\
\text { tive to moisture } \\
\text { content }\end{array}$ \\
\hline $\begin{array}{l}\text { Heat Loss from } \\
\text { Smal1 Unit }\end{array}$ & N/A & $\begin{array}{l}\text { Results in lowered } \\
\text { fuel gas energy con- } \\
\text { tent and reduction } \\
\text { efficiency }\end{array}$ & $\begin{array}{l}\text { Heat loss does not } \\
\text { affect gas quality } \\
\text { or reduction } \\
\text { efficiency }\end{array}$ \\
\hline Development Costs & $N / A$ & $\begin{array}{l}\text { High - Expensive } \\
\text { field demonstration } \\
\text { configuration }\end{array}$ & $\begin{array}{l}\text { Low - Simple field } \\
\text { demonstration } \\
\text { configuration }\end{array}$ \\
\hline Scalability & $N / A$ & Low & $\begin{array}{l}\text { High - Modular heat } \\
\text { exchange approach } \\
\text { allows ease of } \\
\text { scaling }\end{array}$ \\
\hline Risks & N/A & $\begin{array}{l}\text { High - System } \\
\text { demonstration } \\
\text { requires risky } \\
\text { integration with } \\
\text { gas turbine }\end{array}$ & Low \\
\hline
\end{tabular}




\begin{tabular}{|c|c|c|c|c|c|c|c|c|}
\hline$E-1$ & $R-1$ & $v-1$ & $v-2$ & $x-1$ & $E-1$ & $v-3$ & $E-3$ & $V-4$ \\
\hline $\begin{array}{l}\text { HASTE } \\
\text { HEAT } \\
\text { STEAM }\end{array}$ & GASIFIER & CYCLONE & $\begin{array}{l}\text { DISSOLUTION } \\
\text { TANK }\end{array}$ & $\begin{array}{l}\text { RECYCLE } \\
\text { EJECTOR }\end{array}$ & $\begin{array}{l}\text { PROCESS GAS } \\
\text { STEAM BOILER }\end{array}$ & SCRUBBER & CONDENSER & $\begin{array}{c}\text { CONDENSER } \\
\text { KNOCK-OUT } \\
\text { VESSEL }\end{array}$ \\
\hline
\end{tabular}

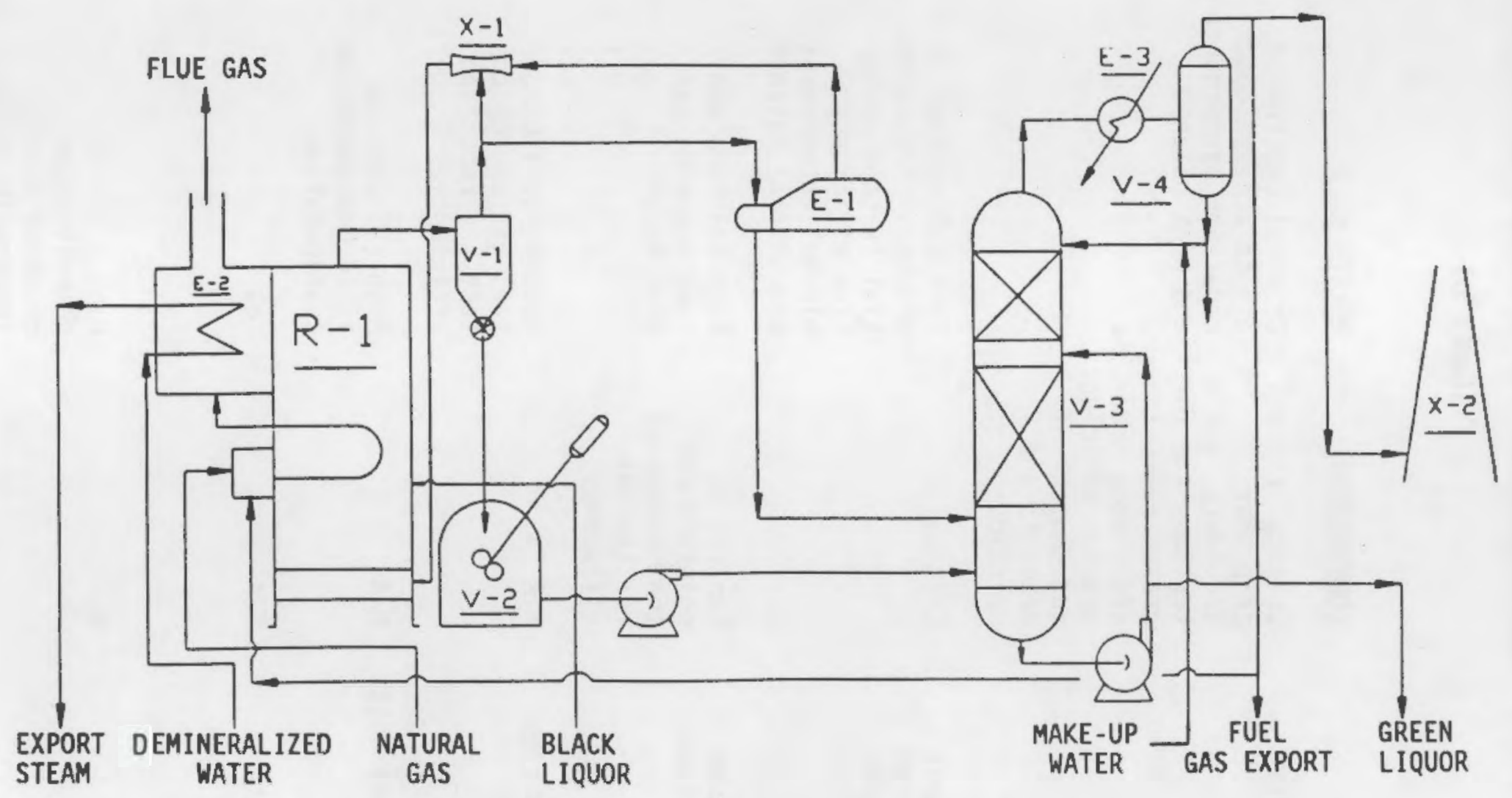

FIGURE 6-28: BLACK LIQUOR GASIFIER FOR COMMERCIAL CONFIGURATION 
A cleaned, desulfurized product gas is generated from the scrubber. This gas may be utilized as a fuel source for a boiler, gas turbine, or other unit. The flue gases from the pulse combustor which exit R-1 are sent to a water or fire-tube boiler for heat recovery. The net product gas may be combusted here to allow a single means for steam generation.

Although the bench-scale gasifiers have generally employed vertically mounted resonance tubes due to geometric constraints at the smaller scale, the commercial gasifier configuration is envisioned to employ horizontally mounted resonance tubes. This configuration will simplify manifolding of fluidizing steam, and will allow easy maintenance of the combustors.

The commercial configuration consists of a rectangular fluidized bed with sidewall-mounted pulse combustors. The pulse combustors will be located at several vertical elevations. A typical combustor would consist of two coupled pulse combustors for noise reduction. The dual module would have a nominal firing capacity of about $2.5 \mathrm{MMBtu} / \mathrm{hr}$. Three modules would be required for a one ton per hour unit such as shown in Figure 6-29.

A material balance (Table 6-12) was prepared for a one ton per hour (BLS) capacity unit based on the process flow diagram. The gas compositions were estimated based on experimental results and equilibrium adjustments accounting for the lower steam partial pressures anticipated in the commercial case. Based on preliminary experimental data, 80 percent of the total sulfur is assumed to be stripped to hydrogen sulfide in the product gas, and 70 percent of the sulfate content in the black liquor feed is assumed to be reduced. The hydrogen sulfide is also assumed to be quantitatively absorbed in the scrubber. The carbon rejected with the product solids is taken to be 5 percent. This carbon is assumed to be recovered for reinjection into the gasifier or to be used as calciner fuel.

A mass and energy balance summary for the commercial system is shown in Table 6-13. The balance is based on the production of fuel gas that can be combusted in an auxiliary boiler and refers to Figure 6-28.

As seen, the fuel gas export accounts for $7.473 \mathrm{MMBt} / \mathrm{hr}$, or about 72 percent of the net energy output. Export steam production accounts for $2.424 \mathrm{MMBtu} / \mathrm{hr}$ or 23 percent of the energy output. Recoverable carbon accounts for the balance of the energy output.

Based on the total energy output relative to the black liquor feed input, the net system thermal efficiency is estimated as 78.7 percent. If only steam export is desired, it may be accomplished by combusting the export fuel in the flue gas waste heat recovery section. If a high efficiency boiler is employed, the net thermal efficiency for the steam export only case (no fuel export) is estimated to be approximately 67 percent. Despite the small size of the system, the efficiency exceeds, or is competitive with, the efficiencies achievable in large-scale Tomlinson recovery boilers. 


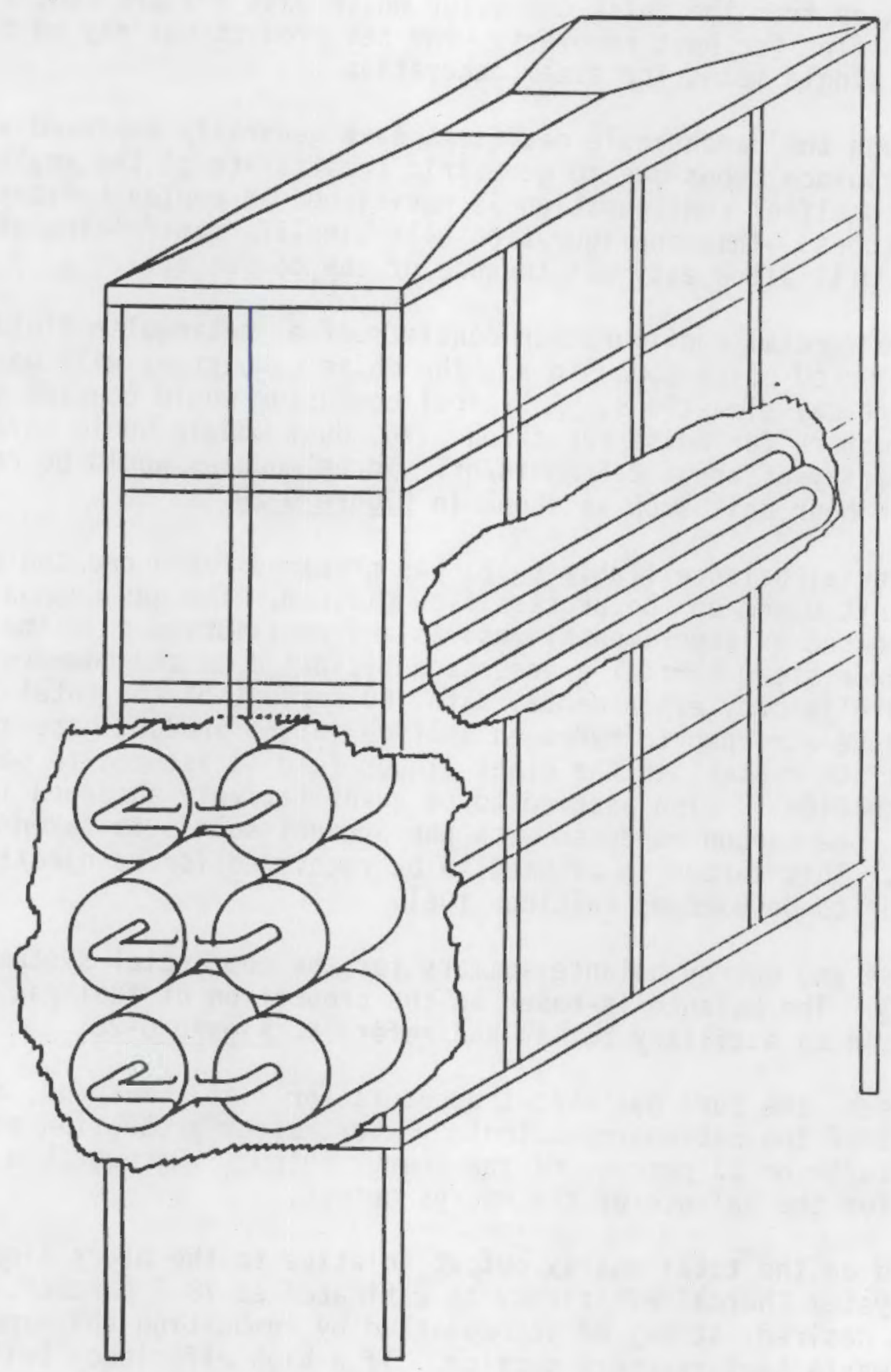

FIGURE 6-29: CONCEPTUAL COMMERCIAL MTCI GASIFIER 


\section{TABLE 6-12: MATERIAL BALANCE FOR 1 TON/H BLACK LIQUOR}

SOLIDS GASIFICATION PLANT

\begin{tabular}{|c|c|c|c|c|c|c|c|c|}
\hline \multicolumn{2}{|l|}{ STREAM NO. } & 1 & 2 & 3 & 4 & 5 & 6 & 7 \\
\hline \multicolumn{2}{|c|}{ STREAM NAME } & $\begin{array}{l}\text { BLACK } \\
\text { LIQUOR } \\
\text { FEED } \\
\end{array}$ & $\begin{array}{c}\text { STEAN } \\
\text { RECYCLE } \\
\text { MIXTURE }\end{array}$ & $\begin{array}{l}\text { PRODUCT } \\
\text { GAS FROH } \\
\text { R-1 } \\
\end{array}$ & $\begin{array}{l}\text { SOL IDS } \\
\text { DRAM- } \\
\text { OFF } \\
\end{array}$ & $\begin{array}{c}\text { HET } \\
\text { PRODUCT } \\
\text { GAS } \\
\end{array}$ & $\begin{array}{l}\text { PRODUCT } \\
\text { GAS TO } \\
\text { C-1 } \\
\end{array}$ & $\begin{array}{l}\text { FUEL GAS } \\
\text { TO PULSE } \\
\text { COMBUSTOR }\end{array}$ \\
\hline COMPONENT & n & $1 b / h$ & $1 b / h$ & $\mathbf{t b} / \mathrm{h}$ & lb/h & $\mathrm{lb} / \mathrm{h}$ & $\mathrm{Jb} / \mathrm{h}$ & $1 b / h$ \\
\hline $\mathrm{O}_{2}$ & 32.00 & - & - & - & - & - & - & - \\
\hline $\mathrm{N}_{2}$ & 28.01 & - & - & - & - & - & - & - \\
\hline $\mathrm{CO}$ & 28.01 & - & 739.10 & 1478.20 & - & 739.10 & 739.10 & 380.60 \\
\hline $\mathrm{CO}_{2}$ & 44.01 & - & 1032.50 & 2065.00 & - & 1032.50 & 1032.50 & 531.70 \\
\hline $\mathrm{CH}_{4}$ & 16.04 & - & 42.70 & 85.00 & - & 42.70 & 42.70 & 22.00 \\
\hline $\mathrm{C}_{2} \mathrm{H}_{6}$ & 30.07 & - & 10.70 & 21.40 & - & 10.70 & 10.70 & 5.50 \\
\hline $\mathrm{C}_{3} \mathrm{H}_{6}$ & 44.09 & - & 7.80 & 15.60 & - & 7.80 & 7.80 & 4.00 \\
\hline $\mathrm{H}_{2}$ & 2.02 & - & 169.60 & 339.20 & - & 169.60 & 169.60 & 87.30 \\
\hline $\mathrm{H}_{2} \mathrm{~S}$ & 34.09 & - & 73.10 & 146.20 & - & 73.10 & 73.10 & - \\
\hline $\mathrm{H}_{2} \mathrm{O}$ & 18.02 & 985.00 & 1211.80 & 1223.60 & - & 611.80 & 611.80 & 180.10 \\
\hline $\mathrm{C}$ & 12.01 & - & - & - & 34.00 & - & - & - \\
\hline $\mathrm{Na}_{2} \mathrm{SO}_{3}$ & 106.00 & - & - & - & 799.10 & - & - & - \\
\hline $\mathrm{Ha}_{2} \mathrm{~S}$ & 78.04 & - & - & - & 37.50 & - & - & - \\
\hline $\mathrm{Na}_{2} \mathrm{SO}_{4}$ & 142.00 & - & - & - & 9.70 & - & - & - \\
\hline $\mathrm{HaCl}$ & 58.45 & - & - & - & 16.50 & - & + & - \\
\hline BLS & - & 2000.00 & - & - & - & - & - & \\
\hline TOTAL MASS & $(\mathrm{lb} / \mathrm{hr})$ & 2985.00 & 3288.00 & 5375.00 & 897.00 & 2688.00 & 2688.00 & 1211.00 \\
\hline PRESSURE & sig) & 30.00 & 10.00 & 7.00 & - & 7.00 & 3.0 & 1.00 \\
\hline TEMPERATUR & $\left({ }^{\circ} \mathrm{F}\right)$ & 180.00 & 1075.00 & 1200.00 & 1200.00 & 1200.00 & 180.00 & 120.00 \\
\hline
\end{tabular}


TABLE 6-12: MATERIAL BALANCE FOR 1 TON/H BLACK LIQUOR SOLIDS GASIFICATION PLANT

(CONT'D)

\begin{tabular}{|c|c|c|c|c|c|c|c|c|}
\hline \multicolumn{2}{|c|}{$\begin{array}{l}\text { STREAM NO. } \\
\text { STREAM NAME }\end{array}$} & $\begin{array}{c}\text { COMBUSTION } \\
\text { AIR }\end{array}$ & $\begin{array}{c}9 \\
\text { FLUE } \\
\text { FROM } \\
\text { PULSE } \\
\text { COMBUSTOR } \\
\end{array}$ & $\begin{array}{l}10 \\
\text { FLUE } \\
\text { FRON E-2 } \\
\text { STEAM } \\
\text { GENERATOR }\end{array}$ & $\begin{array}{l}11 \\
\text { FLUE } \\
\text { FROM } \\
\text { E-3 } \\
\end{array}$ & $\begin{array}{r}12 \\
\text { FEED } \\
\text { UATER } \\
\text { IO E-5 } \\
\end{array}$ & $\begin{array}{c}13 \\
\text { BOILER } \\
\text { FEEO HATER } \\
\text { FROM E-4 }\end{array}$ & $\begin{array}{l}14 \\
\text { STEAN } \\
\text { FRON } \\
\text { E-4 } \\
\end{array}$ \\
\hline \multicolumn{2}{|c|}{ COMPONENT } & lb/h & lb/h & $\mathrm{lb} / \mathrm{h}$ & $1 b / h$ & $1 b / h$ & $1 b / h$ & $\mathrm{Ib} / \mathrm{h}$ \\
\hline $\mathrm{O}_{2}$ & 32.00 & 1343.00 & 310.00 & 310.00 & 310.00 & - & - & - \\
\hline $\mathrm{N}_{2}$ & 28.01 & 4422.20 & 4422.20 & 4422.20 & 4422.20 & . & - & - \\
\hline $\mathrm{CO}$ & 28.01 & - & - & - & - & - & - & - \\
\hline $\mathrm{CO}_{2}$ & 44.01 & $\cdot$ & 1218.20 & 1218.20 & 1218.20 & - & - & - \\
\hline $\mathrm{CH}_{4}$ & 16.04 & - & - & - & - & - & - & - \\
\hline $\mathrm{C}^{2} \mathrm{H}_{6}$ & 30.07 & - & - & - & - & - & - & - \\
\hline $\mathrm{C} 3 \mathrm{H}_{6}$ & 44.09 & - & $\cdot$ & - & - & - & - & - \\
\hline $\mathrm{H}_{2}$ & 2.02 & - & - & - & - & - & - & - \\
\hline $\mathrm{H}_{2} \mathrm{~S}$ & 34.09 & - & - & - & - & - & - & - \\
\hline $\mathrm{H}_{2} \mathrm{O}$ & 18.02 & - & 1026.10 & 1026.10 & 1026.10 & 1222.00 & 1222.00 & 1198.00 \\
\hline$c$ & 12.01 & - & - & - & - & - & - & - \\
\hline $\mathrm{Na}_{2} \mathrm{SO}_{3}$ & 106.00 & - & - & - & - & - & - & - \\
\hline $\mathrm{Na}_{2} \mathrm{~S}$ & 78.04 & - & - & - & - & - & - & - \\
\hline $\mathrm{Na}_{2} \mathrm{SO}_{4}$ & 142.00 & - & - & - & - & - & - & - \\
\hline $\mathrm{NaCl}$ & 58.45 & . & $\cdot$ & - & - & - & - & - \\
\hline BLS & - & - & $\cdot$ & - & - & - & - & - \\
\hline TOTAL & $(1 \mathrm{~b} / \mathrm{h})$ & 5765.00 & 6976.00 & 6976.00 & 6976.00 & 1222.00 & 1222.00 & 1198.00 \\
\hline PRESSUF & psig) & 1.00 & - & - & - & 620.00 & 610.00 & 600.00 \\
\hline TEMPER & $E\left({ }^{\circ} F\right)$ & 77.00 & 1300.00 & 680.00 & 300.00 & 77.00 & 470.00 & 490.00 \\
\hline
\end{tabular}


TABLE 6-12: MATERIAL BALANCE FOR 1 TON/H BLACK LIQUOR SOLIDS GASIFICATION PLANT

\section{(CONT'D)}

\begin{tabular}{|c|c|c|c|c|c|c|c|c|}
\hline STREAM NO & & 15 & 16 & 17 & 18 & 19 & 20 & 21 \\
\hline STREAM NA & & $\begin{array}{l}\text { PROCESS } \\
\text { STEAM TO } \\
X-1 \\
\end{array}$ & $\begin{array}{l}\text { EXPORT } \\
\text { STEAN } \\
\text { FROH E-4 }\end{array}$ & $\begin{array}{c}\text { FEED } \\
\text { MATER } \\
\text { TO E-3 } \\
\end{array}$ & $\begin{array}{l}\text { BOILER } \\
\text { FEED WATER } \\
\text { TO E-2 } \\
\end{array}$ & $\begin{array}{c}\text { EXPORT } \\
\text { STEAM } \\
\text { FROM E-2 }\end{array}$ & $\begin{array}{l}\text { NET } \\
\text { EXPORT } \\
\text { STEAM }\end{array}$ & $\begin{array}{c}\text { EXPORT } \\
\text { FUEL } \\
\text { GA5 } \\
\end{array}$ \\
\hline COMPONENT & & $1 \mathrm{~b} / \mathrm{h}$ & $l b / h$ & $1 b / h$ & $1 b / h$ & $1 b / h$ & $1 \mathrm{~b} / \mathrm{h}$ & $1 b / h$ \\
\hline $0_{2}$ & 32.00 & - & - & - & - & - & - & - \\
\hline $\mathrm{N}_{2}$ & 28.01 & - & - & - & . & - & - & - \\
\hline $\mathrm{CO}$ & 28.01 & - & - & - & - & - & - & 358.50 \\
\hline $\mathrm{CO}_{2}$ & 44.01 & - & - & - & - & - & - & 500.80 \\
\hline $\mathrm{CH}_{4}$ & 16.04 & - & - & - & - & - & - & 20.70 \\
\hline $\mathrm{C}_{2} \mathrm{H}_{6}$ & 30.07 & - & - & - & - & - & - & 5.20 \\
\hline $\mathrm{C}_{3} \mathrm{H}_{6}$ & 44.09 & - & - & - & - & - & - & 3.80 \\
\hline $\mathrm{H}_{2}$ & 2.02 & - & - & - & - & - & - & 82.30 \\
\hline $\mathrm{H}_{2} \mathrm{~S}$ & 34.09 & - & - & - & - & - & - & - \\
\hline $\mathrm{H}_{2} \mathrm{O}$ & 18.02 & 600.00 & $333.00^{(1)}$ & 1793.00 & 1793.00 & 1757.00 & 2090.00 & 169.50 \\
\hline C & 12.01 & - & - & - & - & - & - & - \\
\hline $\mathrm{Na}_{2} \mathrm{SO}_{3}$ & 106.00 & - & - & - & * & . & - & - \\
\hline $\mathrm{Na}_{2} \mathrm{~S}$ & 78.04 & - & - & - & - & - & - & - \\
\hline $\mathrm{Na}_{2} \mathrm{SO}_{4}$ & 142.00 & - & - & - & - & - & - & - \\
\hline $\mathrm{NaCl}$ & 58.45 & - & - & - & - & - & - & - \\
\hline BLS & - & - & - & - & - & - & - & - \\
\hline TOTAL MAS & $(1 \mathrm{~b} / \mathrm{hr})$ & 600.00 & 333.00 & 1793.00 & 1793.00 & 1757.00 & 2090.00 & 1140.80 \\
\hline PRESSURE & sig) & 600.00 & 600.00 & 620.00 & 610.00 & 600.00 & 600.00 & 1.00 \\
\hline TEMPERATU & $\left({ }^{\circ} \mathrm{F}\right)$ & 490.00 & 490.00 & 77.00 & 470.00 & 490.00 & 490.00 & 120.00 \\
\hline
\end{tabular}

(1) Allows for steam to black liquor; heater not shown in PFD 
TABLE 6-13:

MASS AND ENERGY BALANCE SUMMARY

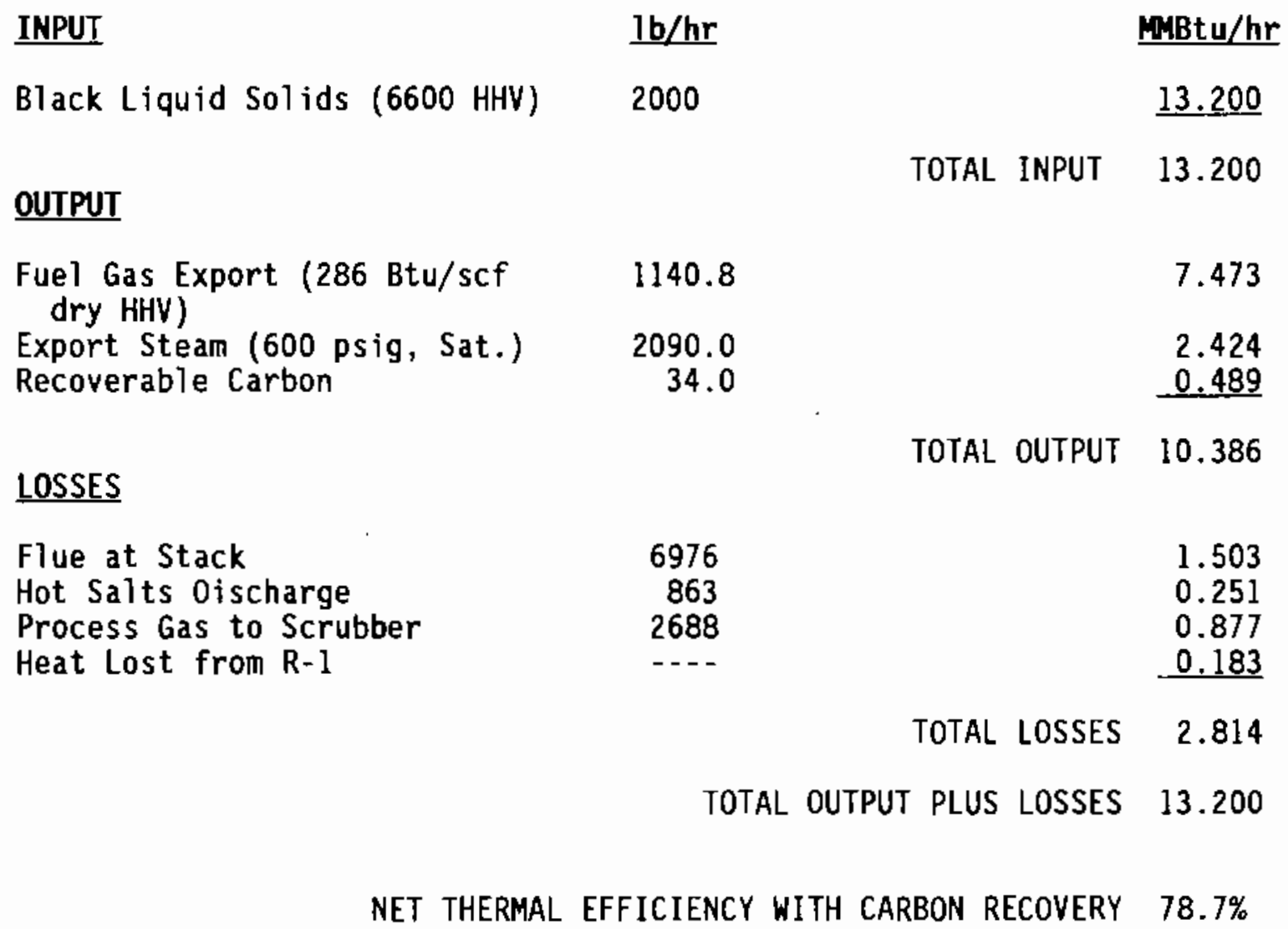

\subsection{RESEARCH AND DEVELOPHENT NEEDS}

An extensive data base has been accumulated covering the performance of the black liquor gasifier as a result of the current program. Test runs yielded significant information regarding product distributions, gasification rates, and operational boundaries.

While the gasifier performance met or exceeded expectations during the recent test program, several key areas need further investigation. In particular, a more detailed characterization of the product sulfur species is needed. Preliminary evidence, based on solids analysis, indicate that most of the sulfur is released in the gas phase as hydrogen sulfide. However, several other sulfur containing gas species may exist in lesser quantities, such as carbonyl sulfide and mercaptans. 
In the prior tests, the existing gas chromatograph was incapable of speciating minor sulfur-containing gas constituents. If a more detailed sulfur distribution is to be made, then additional gas chromatographic capability is required. Although these sulfur species are anticipated to exist in only trace quantities, it is important to confirm this since dissolution of such components in the recycled liquor could be undesirable.

In the commercial configuration, the product gas will be scrubbed by an alkaline sodium carbonate solution to remove hydrogen sulfide. Integrated operations will include dissolution of the product solids, and product gas scrubbing. From a systems viewpoint, confirmation would be important for systems integration into an existing mill environment. This could be performed using a slip-stream from the bench-scale gasifier. It is also important to estimate the particulate removal efficiency in the scrubber, since entrained salts could pose problems due to slagging and fouling in the pulse combustor and resonance tubes.

In the commercial configuration, a portion of the product gas is burned in the pulse combustor. The product gas is a medium-Btu fuel containing a high concentration of hydrogen. In the prior tests, only natural gas fuels were used in the pulse combustor. Therefore, pulse combustion tests should be performed using a simulated gas mixture to verify proper functioning of the combustor.

Finally, product gas will be recycled to assist fluidizing the bed in the commercial configuration. This will reduce the steam partial pressure within the reactor which may effect gasification rates, sulfur yields, and product gas distributions, particularly the carbon monoxide to carbon dioxide ratio. While integrated recycling of the product gas is impractical in the benchscale reactor, tests should be conducted to evaluate the effect of steam to carbon ratio using a diluent. 


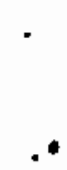

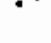

-

. 


\section{SECTION 7.0 \\ CONCLUSIONS AND RECOMMENDATIONS}

The successful testing of the MTCI "Process Design Verification System" for a wide spectrum of biomass and black 1 iquor feedstocks has achieved and exceeded all program objectives. It has further demonstrated the maturity of the biomass gasification process to the level required for the first commercialization stage; the field test of a unit in an integrated industrial environment and its subsequent entry into service producing revenue or its equivalent, avoiding costs associated with the disposal of waste materials, either by open burning or landfilling.

For the black liquor recovery system it has fully demonstrated that it is a near-term alternative for the current processes resolving the safety, performance, and cost issues now associated with them. In this case, however, one additional stage of process development is required prior to the field test of an integrated unit into an on-site process. That stage is concerned only with the more complex portion of the black liquor process in which the recovered chemicals are reprocessed for use in the pulping stage. Perhaps the most important technical advantage demonstrated was the processing of black liquor without corrosive smelt production. Product solids are removed in dry form, completely avoiding the potential for smelt-water explosions that now exist in conventional processes.

The work accomplished has verified experimentally and analytically that the system overcomes many of the technical, economic, and environmental issues associated with the direct firing of biomass for cogeneration and black liquor for energy and process chemical recovery. For example, waste with a significant amount of moisture content may have to be dried prior to combustion in order to enhance its heating value and combustion characteristics. However, drying is a capital-intensive process and is generally characterized by significant odor and environmental emission problems. In contrast, the MTCI gasifier can utilize material of 50 percent moisture and drying can be avoided. Fibrous material may become light and fluffy after drying and combustion is likely to cause serious entrainment losses within the furnace. The waste material may also contain sodium salts and plastic material. Hightemperature combustion processes release sodium vapors and chlorine compounds which could pose a significant environmental hazard. In contrast, the lower temperature MTCI gasification process does not release sodium or other trace metal vapors. If chlorine compounds are present they will primarily be absorbed by the calcium sorbents contained in the bed to form non-hazardous calcium chloride. Since no oxygen is added to the system and chlorine, if present, would be captured within the bed, dioxin formation, if any, is minimized.

The MTCI gasifier introduces no combustion contaminants $\left(\mathrm{N}_{2}, \mathrm{CO}_{2}\right)$ into the product gas stream. Therefore, a higher quality product gas was generated which had thermal properties similar to that of natural gas. Specific gasification rates were measured and found to be consistent with predictions extrapolated from literature data sources. The producer gas heating vaTue 
varjed from 240 to $300 \mathrm{Btu} / \mathrm{scf}$ and contained $63 / 65$ vo1.\% hydrogen. The energy density of the producer gas was shown to be several times that achievable for autothermal systems. This high-quality gas can be used in combined cycles or simple boiler cycle applications without the derating penalty associated with the low-Btu gases produced from autothermal gasifiers. This provides increased flexibility and allows the direct replacement of premium fuels in gas turbine combustors or duct burners.

In addition, as consistent with equilibrium predictions, the gasifier operating on black liquor exhibited a high efficiency for sulfate reduction. Based on overall material balances, residual sulfate from the gasifier accounted for only 3 percent of the total feed sulfur. The buik of the sulfur contained in the black liquor feed was directly converted to $\mathrm{H}_{2} \mathrm{~S}$. In a commercial configuration, this $\mathrm{H}_{2} \mathrm{~S}$ can be scrubbed with an aqueous sodium carbonate solution formed from the product salts to regenerate green liquor. Since the gasifier directly releases sulfur or $\mathrm{H}_{2} \mathrm{~S}$, it may al so have a significant application in sulfite liquor recovery systems.

These results strongly indicate that the indirect steam gasifier is capable of generating sodium sulfide at a very high conversion efficiency. This resolved the issue as to whether or not the gasifier was suitable as a stand-alone recovery device in mini-mills as discussed previously and demonstrates that the HTCI gasifier can be used as an alternative to the Toml inson furnace.

The pulse combustor integration with the gasifier proved to be highiy successful and was demonstrated to be an extremeiy compact and efficient means for supplying heat to the fluidized bed. Also, due to the system's overall simplicity, the compact nature of the pulse combustor, and the high heat transfer rates attainable within the pulsating combustor resonance tubes, a significant economic advantage was identified for the MTCI system as compared to alternative indirect gasification routes.

A commercial configuration for a 2 to 10 ton/hr gasification system was also developed. Heat and material balances indicated that the system's net thermal efficiency (export fuel and steam) is over 78 percent.

The multi-series of biomass feedstock and long-term process characterization tests using a 67 percent solids-containing black liquor feedstock covering the temperature range of $1030^{\circ} \mathrm{F}$ to $1160^{\circ} \mathrm{F}$ verified that gasifier performance met or exceeded expectations during the test program which included a 40 -hour long duration test run.

It is evident that the development progress for the indirect gasifier has been quite rapid. The success of the development effort can be attributed to the inherent simplicity of the process. For this reason, it is believed that the indirect gasifier can be successfully commercialized under an accelerated demonstration program. 
It is also apparent that ETAP criterion for the evaluation of a potential technology have also been fulfilled. These are summarized here to indicate that the program achieved the objectives of California's energy policy:

\section{The Mitigation of Envirommental Issues}

- The technology has been demonstrated to be an inherently low "emissions polluter" that can mitigate environmental impacts of solid waste disposal, land, air, and water usage due to its effective capability to process waste, recover energy and because of its modularity, collaterly reduce traffic, noise, dust, and waste material problems from the collection and transport of biomass materials.

\section{The Reduction in Capital and Operatimg Costs AND EMHANCED MOdULARITY and Adaptation}

- The technology reduces capital and operating costs by the efficient recovery of "waste" energy, enhancing availability and reliability, decreasing outages and landfill site acreage because of its essentially "stand-alone" process characteristics. The modularity of the system provides small business opportunities in biomass processing as well as for small increments of capacity enhancements in the pulp and paper industry.

\section{The Avotdance of Economic and Emgineerimg Risk}

- The technology reduces economic and engineering $r$ isk because it is based on a wel1-developed technology base and is an "application of technology" process. There are no basic scientific or engineering issues involved. The technology base accumulated by MTCI has provided an extensive bank of test data for a wide spectrum of biomass materials including sludge containing plastic materials and other difficult-to-process agricultural wastes.

\section{The Potentral for Early Availability}

- The project has demonstrated the ability of the technology to resolve near-term issues in biomass energy recovery and production and provide early field testing and the economic and technical information required for early commercialization and development of a biomass energy industry. This provides an early acceleration and broadening of the "window of opportunity" for biomass utilization.

\section{The Contribution to Diversity of Energy Supply}

- The project has demonstrated that the technology can contribute to the diversity of energy supply by expanding the option to develop low-cost distribution systems for local primary energy needs utilizing locally generated waste feedstocks. 
At present, no technical barriers have been found which would prevent this technology from achieving successful commercialization by the early 1990 s. The system benefits from 1) the lower temperature of operation, 2) avoidance of smelt handling, 3) no expensive electrical costs, 4) high thermal efficiency, 5) low overall production costs, and 6) capability to process a wide variety of energy-containing feedstock. 


\section{REFERENCES}

U.S. Department of Energy, "Biomass Energy Technology Research Program Summary - FY 83," prepared for the Department of Energy by the Technical Information Branch of Solar Energy Research Institute, September 1983, pp. 1-14.

Antal, M.J., Biomass Energy Enhancement - A Report to the President's Council on Environmental Quality, Princeton University, Princeton, New Jersey, July 1978.

Babu, S.P., M. Onischak, and W.G. Bair, "Thermal Gasification of Biomass The IGT Renugas Process," 16th World Gas Conference, Munich, F.R.G., June 24 - 27, 1985.

Reed, T.8., B. Levie, and M.A. Grabowski, "Fundamentals, Development, and Scale-up of the Air-0xygen Stratified Down-draft Gasifier," prepared by SERI for PNL, DOE Contract No. DE-AC06-76RL01830, June 1988.

Feldmann, H.F., M.A. Paisley, H.R. Appelbaum, D.R. Taylor, "Conversion of Forest Residues to Methane-Rich Gas in a High-Throughput Gasifier," prepared by Battelle Columbus Division for PNL, DOE Contract No. DE-AC06-76RL.01830, May 1988.

Flanigan, V.J., et al., "Steam Gasification of Wood in a Fluidized Bed Using Indirect Heating with Fire Tubes," University of Missouri, Rolla, Missouri, Proceedings of the 15 th Biomass Thermochemical Conversion Contractor's Meeting, Atlanta, Georgia, March 16-17, 1983, pp. 14-30. 


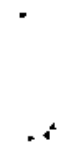

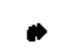

.

- 


\section{OISTRIBUTION}

No. of

Copies

OFFSITE

12 DOE/Office of Scientific and Technical Information

T. N. Adams

5960 Beverly Avenue, N.E.

Tacoma, WA 98422

A. 0. Armstrong

Georgia Pacific Corporation

133 Peachtree Street

P.0. Box 105605

Atlanta, GA 30303

W. Ayres

Pyrotech, Inc.

8016 Stateline

Suite 101

Leawood, KS 66208

S. Babu

Institute of Gas Technology

IIT Center

3424 South State Street

Chicago, IL 60616

L. Back

Fluid Dynamics and Reactive Process

Jet Propulsion Laboratory

4800 0ak Grove Drive

Pasadena, CA 91109

P. Badger

Southeastern Regional Biomass Energy Program

Tennessee Valley Authority

435 Chemical Building

Muscle Shoals, AL 35660

N. Banns

Onsite* Ofsite, Inc.

2500 East Foothill BTvd.

Suite 201

Pasadena, CA 91107
No. of

Copies

R. G. Barker

Union Camp Corporation

P.0. Box 3301

Princeton, NJ 08543

J. A. Barsin

Babcock \& Wilcox, Inc.

20 South Van Buren Avenue

P.0. Box 351

Barberton, OH 44203-0351

R. L. Best

Stone Container Corporation

2150 Parklake Orive, Suite 400

Atlanta, GA 30345

K. Birkinshaw

California Energy Commission

1516 - 9th Street, MS-43

Sacramento, CA 95814

C. C. Bolts

Combustion Engineering, Inc.

900 Long Ridge Road

P.0. Box 9308

Stamford, CT 06904

D. Bousfield

Department of Chemical

Engineering

Jenness Ha 11, Rm. 317B

The University of Maine

Orono, ME 04469

T. T. Bramlette

Combustion Research Division

Sandia National Laboratory

Livermore, CA 94550

C. Brown

Pulp Mill Processes, R\&O

WTC-2H22

Weyerhaeuser Paper Co.

Tacoma, WA 98477 
No. of

Copies

C. A. Brown

Weyerhaeuser Paper Company

Energy \& Recovery Technology

Dept., R \& D

WTC $2 \mathrm{H} 22$

Tacoma, WA 98477

J. F. Cassidy

Research \& 0evelopment

Boise Cascade Corporation

P.0. Box 1414

Portland, OR 97207

L. A. Chaddick

Westraco Corporation

P.0. Box 5207

North Charleston, SC 29406

E. Chism

Gaylord Container Corporation

California Mill

1779 Wilbur Ave.

P.0. Box 10

Antioch, CA 94509

D. T. Clay

James River Corporation

Neenah Technical Center

1915 Marathon Avenue

P.0. Box 899

Neenah, WI 54957-0899

M. J. Coleman

Tappi Journa 1

Technology Park/Atlanta

P.0. Box 105113

At lanta, GA 30348-5113

T. C. Coleman

Chas. T. Main, Inc., Engineers

Prudential Center

Boston, MA 02199

R. Costello

Biofuels and Municipal Waste

Technology Division

U.S. Department of Energy

Forrestal Building (CE-341)

1000 Independence Avenue

Washington, D.C. 20585
No. of

Copies

J. Craig

P.0. Box 70

Tahoka, TX 79373

R. A. Oamon

Technical Services Group

James River Corporation

349 N.W. Seventh Avenue

Camas, WA 98607

K. Davey

Intelligent Dynamic Systems, Inc.

2445 0ld Covington Highway

Conyers, GA 30207

H. Davis

Gulf Machinery Co.

Safety Harbor, FL 34695

J. M. Davis

Conservation \& Renewable Energy

U.S. Department of Energy

1000 Independence Ave., S.W.

washington, DC 20585

G. W. Diadone

Stone \& Webster Engineering Corporation

500 Southborough Drive

South Portland, ME 04106

J. J. Dominguez

Georgia Pacific Corporation

133 Peachtree St.

P.0. Box 105605

Atlanta, GA 30303

5 K. Durai-Swamy

Manufacturing and Technology

Conversion International

Incorporated

13080 Park Street

Santa Fe Springs, CA 90670

J. Empie

Chemical Sciences Division

The Institute of Paper Science

\& Technology

575 14th St. N.W.

Atlanta, GA 30318 
No. of

Copies

T. E. Farrington

Kimberly-Clark Corporation 2100 Winchester Road

Neenah, WI 54956

H. F. Feldmann

Battelle-Columbus Division

$505 \mathrm{King}$ Avenue

Columbus, $\mathrm{OH} 43201$

E. Fitzsimmons

Chas. T. Main, Inc., Engineers

Prudential Center

Boston, MA 02199

V. J. Flanigan

Univ. of Missouri-Rolla

223 Engineering Research Lab.

Rolla, MO 65401

G. Fleischman

Bureau of Energy

Idaho Department of Water

Resources

1301 N. Orchard St.

Boise, ID 83706

P. Fox

Pacific Northwest and Alaska Regional Biomass Energy Prog.

Bonneville Power

Administration

905 11th Avenue, NE

Portland, OR 97208

T. Freshwater

Federal Paper Board Co., Inc.

Riegelwood Operations

Riegelwood, NC 28456

A. L. Fricke

Chemical Engineering Department

Chemical Eng. Bldg., Rm. 429

The University of Florida

Gainesville, FL 32611

S. Friedrich

Biofuels and Municipal Waste Technology Division

U.S. Department of Energy

Forrestal Building (CE-341)

1000 Independence Avenue

washington, D.C. 20585
No. of

Copies

F. Gallagher

Corporate Technical Services

Garden State Paper Company, Inc.

950 River Drive

Garfield, NJ 07026

J. P. Gorog

Pulp Mill Process R\&D

Weyerhaeuser Paper Company

WTC $2 \mathrm{H} 22$

Tacoma, WA 98477

M. S. Graboski

Syngas Systems Inc.

4601 Indiana St., Bldg. 13

Golden, CD 80403

T. M. Grace

T. M. Grace Company, Inc.

2517 S. Harmon Street

P.0. Box 833

Appleton, WI 54912-0833

T. J. Grant

Materials and Technology

The American Paper Institute. Inc.

260 Madison Avenue

New York, NY 10016

J. T. Hamrick

Aerospace Research Corporation

5454 Jae Valley Rd, , S.E.

Roanoke, VA 14014

D. R. Hardesty

Combustion Research Division

Sandia National Laboratory

Livermore, CA 94550

J. E. Harrison

Technology and Engineering

Stone Container Corporation

2150 Parklake Drive

At]anta, GA 30345

R. E. Harrison

Attn: $\mathrm{CH} \mathrm{3E27}$

Weyerhaeuser Paper Company

Tacoma, WA 98477 
No. of

Copies

T. Heazel

S. D. Warren Company

Subsidiary of Scott Paper

Research Laboratory

P.0. Box 5000

Westbrook, ME 04092

N. L. Heberer

3719 Pebble Beach Drive

Augusta, GA 30907

J. S. Helah

Georgia Institute of Technology

778 Atlantic Drive

School of Chemical Engineering

Atlanta, GA 30332-0100

V. A. Higgins

Combustion Engineering

1200 Ashwood Parkway, N.E.

Suite 510

Atlanta, GA 30338

H. I. Hintz

Corporate Research Center

Hestvaco

299 Park Avenue

New York, NY 10171

W. D. Hunter

Energy Technology Department

WTC-2G22

Heyerhaeuser Paper Company

Tacoma, WA 98477

J. Karoly

HPD, Incorporated

305 East Shuman Boulevard

Naperville, IL 60540

A. Kassebi

Mead Corporation

8th \& Hickory Streets

Chillicothe, OH 45601

E. G. Kelleher

Champion International Corp.

1 Champion Plaza

Stamford, CT 06921
No. of

Copies

J. K. Kennedy

Primary Operations

Nekoosa Packaging Corporation

P.0. Box 697

1695 Indianwood Circle

Toledo, OH 43694-0697

J. D. Kerstetter

Washington State Energy office

State of Washington

809 Legion Way S.E. ER-11

0lympia, WA 98504-1211

T. King

72092 Apiary Road

Rainier, OR 97048

C. M. Kinoshita

Manager of Biomass Programs

Hawaji Natural Energy Institute

University of Hawai at Monoa

2540 Dole Street

Honolulu, HI 96822

M. Jones

Malcolm Jones Assocjates

25401 Cabot Road, Suite 107

Laguna Hills, CA 92653

T. Kisla

Stone Container Corporation

2150 Parklake Drive

Atlanta, GA 30345

D. L. Klass

Institute of Gas Technology

IIT Center

3424 South State Street

Chicago, IL 60616

A. Koleff

Energy \& Environmental

Technology

Stone Container Corporation

Suite 400, Fourth Floor

2150 Parklake Drive

Atlanta, GA 30345 
No. of

Copies

D. J. Kraske

Dept. of Chemical Engineering

Jenness Hal1, Room 115

The University of Maine

Orono, ME 04469

F. Kuzel

Council of Great Lakes Governors

310 South Michigan Ave., SW

Chicago, IL 60604

J. V. LeBlanc

PuTp and Power Group

Savannah Mill Technical

P.0. Box 570

Savannah, GA 31402

V. B. Lesokhin

International Paper Company

Long Meadow Road

Tuxedo, NY 10987

R. R. Loose

Office of Renewable Energy Technologies

U.S. Department of Energy

Forrestal Building (CE-34)

1000 Independence Avenue

Washington, DC 20585

\section{A. Macek}

Chemical Process Metrology Div.

Center for Chemical Engineering

National Institute for

Standards \& Technology

Bldg., 221, Rm. B312

Gaithersburg, MO 20899

E. W. Malcolm

Chemical Sciences Division

The Institute of Paper Science

\& Technology

575 14th Street, N.W.

Atlanta, GA 30318

M. N. Mansour

Manufacturing \& Technology

Conversion International, Inc.

P.0. Box 21

Columbia, MD 21044
No. of

Copies

G. E. Maples

Champion International Corp.

P.0. Box 87

Cantonment, FL 32533

P. D. Mathusa

New York State Energy Research

and Development Authority

2 Rockefeller Plaza

Albany, NY 12223

S. W. McKibbins

Champion International Corp.

West Nyack Road

West Nyack, NY 10994

F. McManus

American Paper Machinery Association

5313 38th Street, N.W.

Washington, DC 20015

J. Metz

Energy Policy \& Technology

American Paper Institute, Inc.

260 Madison Avenue

New York, NY 10016

T. R. Miles

Consulting Oesign Engineers

5475 S.W. Arrowwood Lane

Portland, OR 97225

J. Monacelli

Industrial Performance Eng.

Babcock \& Wilcox. Inc.

20 South Van Buren Avenue

P.0. Box 351

Barberton, $\mathrm{OH}$ 44203-0351

W. G. Nichols

Bowater Carolina Company

Bowater, Incorporated

P.0. Box 7

Catawba, SC 29704

A. Nissen

Westraco Corporation

6 A 0 ickel Road

Scarsdale, NY 10583 
No. of

Copies

J. R. Obst

U.S. Department of Agriculture

Forest Products Laboratory

One Gifford Pinchot Drive

Madison, WI 53705-2398

R. A. O'Connell

CONEG Policy Research Center, Inc.

400 N. Capital Street, NW

Washington, DC 20001

R. A. 01 son

P. H. Glatfelter Company

Spring Grove, PA 17362-0500

M. Onischak

Institute of Gas Technology

IIT Center

3424 South State Street

Chicago, IL 60616

S. Oshen

HPO, Incorporated

305 E. Shuman Blvd.

Naperville, IL 60540

E. Ouderkirk

Lincoln Pulp \& Paper Company

Katahdin Avenue

Lincoln, ME 04457

M. Paisley

Battelle-Columbus Division

505 King Avenue

Columbus, $\mathrm{OH} 43201$

A. Plumley

Combust ion Engineering, Inc.

1000 Prospect Hill Road

P.0. Box 500

Windsor, CT 06095-0500

G. W. Poehlein

Georgia Institute of Technology

Atlanta, GA 30332-0265

D. R. Raymond

Equipment \& Process Technology

Division

WTC 1B-24

Heyerhaeuser Paper Company

Tacoma, WA 98477
No. of

Copies

W. B. Robbins

S. D. Warren Company

Subsidiary of Scott Paper

Research Laboratory

P.0. Box 5000

Westbrook, ME 04092

J. K. Rogers

James River Corporation

Neenah Technical Center

1915 Marathon Avenue

P.0. Box 899

Neenah, WI 54956-0899

R. W. Rousseau

School of Chemical Engineering

Georgia Institute of Technology

Atlanta, GA 30332-0100

R. Q. Ruffer

Air Products and Chemicals, Inc.

7201 Hamilton Boulevard

Allentown, PA 18195-1501

P. H. Salmon-Cox

Office of Industrial Programs

U.S. Department of Energy

Forrestal Building (CE-142)

1000 Independence Avenue

Washington, D.C. 20585

J. T. Sanderson

Corporate Technology

Combustion Engineering, Inc.

900 Long Ridge Road

P.0. Box 9308

Stamford, CT 06904

H. G. Senerjian

Chemical Process Metrology Division

Center for Chemical Engineering

B1dg. 221, Rm. B312

U.S. Department of Commerce

Nat. Inst. of Standards \& Tech.

Gaithersburg, MD 20899

D. E. Severeid

Energy and Resources R \& D

Heyerhaeuser Paper Company

WTC 2 G 22

Tacoma, WA 98477 
No. of

Copies

C. Sherban

Technical Service Engineering

Mead Paper Company

P.0. Box 1964

Kingsport, TN 37662

P. E. Shick

3628 Cavalear Drive

Toledo, OH 43606

G. Simons

California Energy Commission

1516 - 9th Street, MS-43

Sacramento, CA 95814

R. J. Slinn

Pulp, Materials \& Tech Group

American Paper Institute, Inc.

260 Madison Avenue

New York, NY 10016

G. C. Snith

Mead Corporation

Central Research Laboratory

8th \& Hickory Streets

Chillisothe, $\mathrm{OH} \quad 45601$

25 S. Sobczynski

Division of Improved Energy

Productivity

U.S. Department of Energy

Forrestal Building CE-142

1000 Independence Avenue

Washington, DC 20585

C. H. Sprague

Pulp \& Paper Technology

Mead Corporation

8th \& Hickory Streets

Chillicothe, OH 45601

D. Stancil

Center for Economic Research

Research Triangle Institute

P.0. Box 12194

Research Triangle Park, NC 27709

M. S. Steltenkamp

Chemical Pulping Technology

Champion International Corp.

Kraft Center

Cantonment, FL 32533
No. of

Copies

D. J. Stevens

Solar Fuels Division

Solar Energy Research Institute

1617 Cole Blvd.

Golden, C0 80401

A. J. Streb

U.S. Department of Energy

1000 Independence Ave, S.W.

CE-10

Washington, DC 20585

R. C. Streisel

Westvaco Corporation

P.0. Box 5207

North Charleston, SC 29406

D. R. Swanson

Western Regional Biomass Energy Program

Western Area Power

Administration

1627 Cole Blvd., Bidg. A-147

Golden, CO 80401

B. Szafranski

St. Joe Forest Products Co.

P.0. Box 190

Port St. Joe, FL 32456

C. E. Taylor

Louisiana-Pacific Corporation

P.0. Box 158

Samoa, CA 95564

R. Thorman

International Paper Company

P.0. Box 797

Tuxedo Park, NY 10987

J. R. Thrift

Forest Products

Georgia Power Company

P.0. Box 4545

Atlanta, GA 30302

C. T. Tolar

Georgia Pacific Corporation

133 Peachtree Street

Atlanta, GA 30303 
No. of

Copies

G. Vachtsevanos

School of Electrical

Engineering

Georgia Institute of Technology

Atlanta, GA 30332-0100

C. J. Wallace

Solar Energy Research

Institute

5109 Leesburg Pike, Suite 414

Falls Church, VA 22041

D. K. Walter

Biofuels and Municipal Waste

Technology Division

U.S. Department of Energy

Forrestal Building (CE-341)

1000 Independence Avenue

Washington, D.C. 20585

E. I. Wan

Science Applications

International Corporation

1710 Goodridge Drive

McLean, VA 22102

D. W. Warren

Manufacturing \& Technology

Conversion Internationa]

13080 Park Street

Santa Fe Springs, CA 90670

B. Welch

Gulf Machinery Co.

P.0. Box 4987

Clearwater, FL 34618

L. A. Wilhelmsen

Longview Fiber Company

P.0. Box 639

Longview, WA 98632

E. Wood

Energetics, Inc.

9210 Route 108

Columbia, MD 21045

R. E. Yeske

The Institute of Paper Science

8 Technology

575 14th St., N.H.

At lanta, GA 30318
No. of

Copies

B. T. Zinn

School of Aerospace Engineering

Georgia Institute of Technology

Atlanta, GA 30332-0150

FOREIGH

D. Barham

Department of Chemistry

University of Toronto

200 College Street

Toronto, Ontario

CANADA M5S IA4

T. Bisaro

Louisiana Pacific Paper Co.

$520 \mathrm{~W}$. 6th Ave.

Suite 200

Vancouver, B.C.

CANADA V5Z $4 J 5$

A. V. Bridgwater

The University of Aston in Birmingham

Dept. of Chemical Engineering

Gosta Green

Birmingham

ENGLAND B4 7ET

W. J. Frederick, Jr. ABO Akademi/liekki

Leminkaistenkatu 14-18 B

Turku SF-20520

FINLAND

M. Hupe

Liekii

Combustion Research Program

ABO Akademi

Turku SF-20500

FINLAND

0 . Wennberg

Chemical Recovery Systems

Gotaverken Energy

Box 8734

S-402 75

Goteborg,

SWEDEN 
No. of

Copies

R. D. Winship

CE Canada Power Systems

Combustion Engrg, Canada, Inc.

99 Bank Street

Ottawa, Ontario

CANADA K1P 6C5

\section{ONSITE}

DOE Richland

Operations office

E. C. Norman

25 Pacific Northwest

Laboratory

M. D. Brown

D. C. Elljott

M. A. Gerber

G. F. Schiefelbein (15)

L. J. Sealock

Publishing Coordination

Technical Report Files (5)
No. of

Copies 
, 